\title{
Uso de aspectos para apoiar a evolução não funcional de frameworks: aplicação ao framework GREN
}

\author{
Maria Tânia Francelino da Silva
}

Orientador: Prof. Dr. Paulo Cesar Masiero

Dissertação apresentada ao Instituto de Ciências Matemáticas e de Computação - ICMC-USP, como parte dos requisitos para obtenção do título de Mestre em Ciências de Computação e Matemática Computacional.

USP - São Carlos Junho/2004 
A Comissão Julgadora:

Prof. Dr. Paulo Cesar Masiero

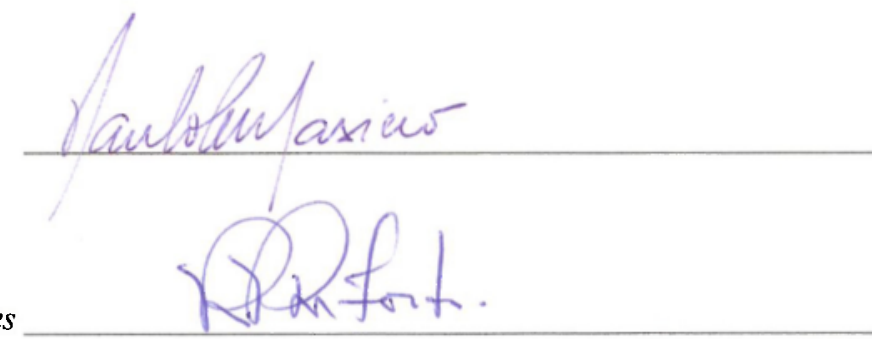

Prof. Dr. Antonio Francisco do Prado

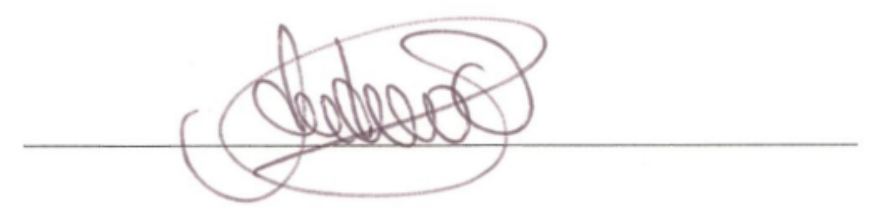




\section{Agradecimentos}

Agradeço primeiramente a DEUS, pelo dom da vida!

Aos meus familiares, em especial aos meus pais, Cíccro c Solcdade, pelo incentivo constante, confiança c credibilidade que em mim depositam e a minha irmã e amiga Jú, por sua amizade e carinho.

Ao meu orientador. Prof. Dr. Paulo Cesar Masicro, pclo cxtremo profissionalismo na orientaçăo deste trabalho, pela confiança em me aceitar como aluna e pelos ensinamentos passados ao longo deste trabalho.

À minha colega do grupo de pesquisa Prof". Dr". Rosana Teresinha V. Braga, pelas sugestões oferecidas, participação ativa durante o desenvolvimento deste trabalho e disponibilidade para testar a nova versão do GREN c GREN-Wizard.

Ao Prof. Dr. Marcelo Augusto Santos Turine e Prof. Marcelo Siqueira Ferreira, do departamento de Estatística e Computação da Universidade Federal de Mato Grosso do Sul, pelas cartas de recomendação, incentivo c confiança cm mim depositada.

Aos meus amigos, desde a graduação, Douglas, Renato e Vinícius, pela amizade, apoio c incentivo. Aos demais amigos da graduação que torcem por mim, em especial à minha amiga Cintia.

Ao meu amigo Rosiel Vital pelo incentivo para que eu atingisse meus objetivos.

À minha amiga Dani c família, por, apesar da distância ainda serem meus amigos.

A todos os colegas e amigos que conquistei no ICMC, $\mathrm{cm}$ especial à minha amiga Patricia (Paty), pelo companheirismo e amizade, e ao pessoal do Labes: Adenilso (AdenilsoN), André (maluquinho), André Rocha, Andrea, Antonielly, Auri, Bira, Camila, Débora, Elisa, Ellen, Erika, Fabiano, Prof. José Carlos, Lisandra, Luciana, Maria Istela (Maris), Marco, Mateus, Otávio, Reginaldo, Prof ${ }^{\circledR}$. Renata, Prof ${ }^{\prime \prime}$. Rosana, Prof'. Rosely, Sandro (KLB), Simone, Tatiana, Thaise, Valter, e Willie, pelos bons momentos de convivência e descontração. Agradeço especialmente à Maris pelo apoio no uso da linguagem Smalltalk.

Aos professores e funcionários do ICMC, pela disposiçãa e atenção.

A todos aqueles que, de certa forma, me apoiaram neste trabalho.

À FAPESP pelo apoio financeiro. 


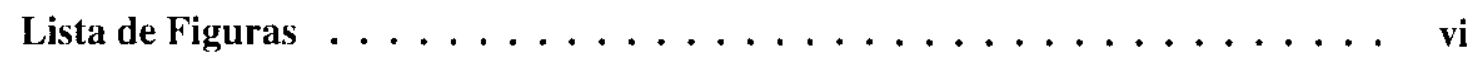

I jista de Tabelas $\ldots \ldots \ldots \ldots \ldots \ldots \ldots \ldots \ldots \ldots \ldots$ viii

$\operatorname{Resumo\ldots \ldots \ldots \ldots \ldots \ldots \ldots \ldots \ldots \ldots \ldots \ldots \ldots \ldots \ldots }$

Abstract ..........................

1 Introdução 1

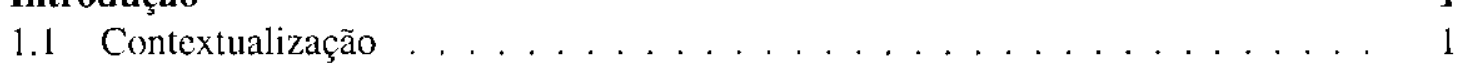

1.2 Motivação . . . . . . . . . . . . . . . . . . . . . . . . 2

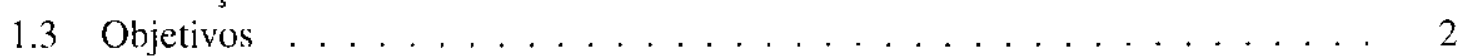

1.4 Organização do Trabalho . . . . . . . . . . . . . . . . 3

2 Frameworks 4

2.1 Considerações Iniciais . . . . . . . . . . . . . . . . . . . . . 4

2.2 Frameworks de Software Orientados a Objetos . . . . . . . . . . . . . . 4

2.3 Evolução de Frameworks . . . . . . . . . . . . . . . . . . . . . 8

2.4 O Framework para Gestão de Recurso de Negócios . . . . . . . . . . . . . . . 11

2.4 .1 O Processo de Desenvolvimento . . . . . . . . . . . . . 11

2.4 .2 O Framework GREN . . . . . . . . . . . . . . 13

2.5 Frameworks Orientados a Aspectos . . . . . . . . . . . . . . 16

2.6 Considerações Finais . . . . . . . . . . . . . . . . . . . 18

3 Programação Orientada a Aspectos $\quad 19$

3.1 Considerações Iniciais . . . . . . . . . . . . . . . . . . . . . . . . . . 19

3.2 Conceitos Básicos de Programação Orientada a Aspectos . . . . . . . . . . . . . 19

3.3 Linguagens de Suporte à Programação Orientada a Aspectos . . . . . . . . . . 21

3.3.1 Linguagens de Propósito Geral . . . . . . . . . . . . . . . . . 21

3.3.1.1 AspectJ ................... 22

3.3 .1 .2 Hyper/J . . . . . . . . . . . . . . . . . . . . . 24

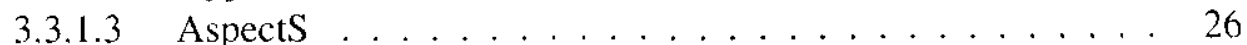

3.3 .1 .4 Apostle . . . . . . . . . . . . . . . 30

3.3 .2 Linguagens de Propósito Específico . . . . . . . . . . . . . . . . . . . . . . . . . . . . . 32

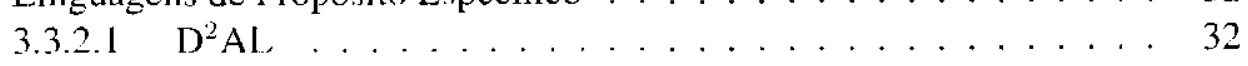


3.3.2.2 TyRuBa ..................... 33

3.4 Outras Abordagens Relacionada à POA . . . . . . . . . . . . . . . . . . . . 34

3.5 Projeto de Software Orientado a Aspectos . . . . . . . . . . . . . . . . 36

3.6 Considerações Finais . . . . . . . . . . . . . . . . . . . 46

4 Evolução do GREN: Implementação de um Subsistema de Segurança usando POA 47

4.1 Considerações Iniciais . . . . . . . . . . . . . . . . . . . . . . . . . . . . . 47

4.2 Análise dos requisitos de segurança . . . . . . . . . . . . . . . . . 48

4.3 Projeto, implementação e testes do Subsistema de Segurança . . . . . . . . . 50

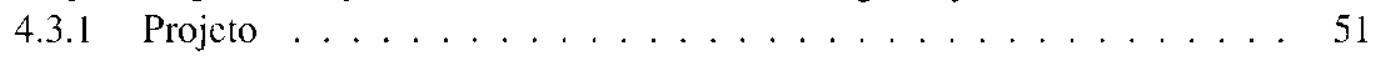

4.3.2 Implementação do SS para o frumework GREN . . . . . . . . . . 56

4.3 .3 Testes do Subsistema de Segurança . . . . . . . . . . . . . . . . 62

4.4 Atualização da documentação do framework GREN . . . . . . . . . . . . . . 63

4.4.1 Considerações sobre o processo de instanciação caixa-branca para a

nova versão do GREN . . . . . . . . . . . . . . . . . . . . 63

4.5 Teste da nova versão do framework GREN . . . . . . . . . . . . . . . . . . . 65

4.6 Evolução do GREN-Wizard . . . . . . . . . . . . . . . . . . . . . 65

4.7 Gerenciamento de Controle de Versão . . . . . . . . . . . . . . . . . . . 67

4.8 Considerações Finais . . . . . . . . . . . . . . . . . . . . . . . . . . . . . 68

5 Exemplo - Instanciação da nova versão do GREN

5.1 Considerações Iniciais . . . . . . . . . . . . . . . . . . . . . . . . . . . . . . 69

5.2 Instanciação do GREN de forma caixa-branca. . . . . . . . . . . . . . . . . . . 69

5.2 .1 Análise do Sistema . . . . . . . . . . . . . . . . . . . . 69

5.2 .2 Mapeamento do modelo de análise para o GREN . . . . . . . . . . 70

5.2.3 Implementação do sistema para Clínica Veterinária . . . . . . . . . 71

5.2.3.1 Criação da base de dados para o sistema de Clínica Veterinária 73

5.2.3.2 Configuração do estado inicial do sistema . . . . . . . . . . 74

5.2.4 Teste do sistema para Clínica Veterinária . . . . . . . . . . . . . . . . 74

5.3 Instanciação do GREN usando a ferramenta GREN-Wizard . . . . . . . . . . . 78

5.3.1 Análise do Sistema . . . . . . . . . . . . . . . . . . . 78

5.3.2 Uso do GREN-Wizard para a geração das classes da aplicação . . . . . 78

5.3.3 Implementação de funcionalidades não cobertas pelo framework . . . . 80

5.3 .4 Testes do sistema resultante . . . . . . . . . . . . . . . 81

5.4 Considerações finais . . . . . . . . . . . . . . . . . . . 81

6 Conclusões $\quad 82$

6.1 Considerações Iniciais . . . . . . . . . . . . . . . . . . . . . . 82

6.2 Avaliação . . . . . . . . . . . . . . . . . . . . . . . . . . . . . . . . . . . . . 82

6.3 Contribuições . . . . . . . . . . . . . . . . . . 84

6.4 Sugestões de Trabalhos Futuros . . . . . . . . . . . . . . . 84

Referência Bibliogrática . . . . . . . . . . . . . . . . 86

A Subsistema de Segurança proposto para o framework GREN (SS). 92

A.l Visão Geral do Sistema . . . . . . . . . . . . . . . . . . . . . . . . . . . . . . . . . . . . . . . .

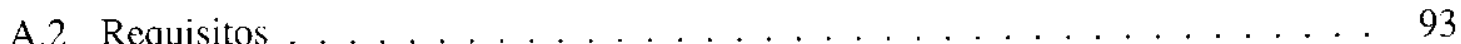

B Casos de uso elaborados para o SS proposto para o framework GREN 95 
C Documento de Requisitos do Sistema para Clínica Veterinária 102

C.1 VISÃO GERAL DO SISTEMA . . . . . . . . . . . . . 102

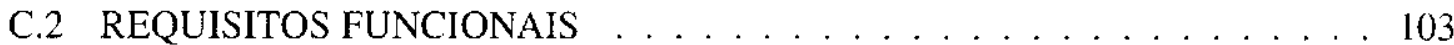

C.2.1 Lançamentos diversos . . . . . . . . . . . . . . . . 103

C.2.2 Impressão de diversos tipos de relatórios e consultas . . . . . . . . . 104

C.3 REQUISITOS NÃO HUNCIONAIS . . . . . . . . . . . . . . . . . 104

C.3.1 Confiabilidade . . . . . . . . . . . . . . . . . . 104

C.3.2 Eficiência . . . . . . . . . . . . . . . . 105

C.3.3 Portabilidade . . . . . . . . . . . . . . . . . 105

C.3.4 Glossário . . . . . . . . . . . . . . . . . . . 105

D Alterações resultantes da evolução GREN-Wizard 106

E Documentação adicional do SS 108

E.1 Instalação do Subsistema de Segurança e do pacote de classes AspectS . . . . 108

E.2 Considerações sobre a instanciação . . . . . . . . . . . . . . . . . . . . . . 109

E.2.1 Classes concretas . . . . . . . . . . . . . . . . . . . . . . 109

E.2.2 Mćtodos sobrepostos . . . . . . . . . . . . . . . . . . . . . 109

E.2.3 Janela Principal/Menus . . . . . . . . . . . . . . . . . 110

E.2.4 Persistência . . . . . . . . . . . . . . . . . . 110

E.2.5 Configuração do estado inicial da aplicação . . . . . . . . . . . 112

F Hierarquia de Classes das novas versões do GREN e da GREN-wizard $\quad 114$

F.1 Hierarquia de Classes do GREN . . . . . . . . . . . . . . . . . . . . 114

F.2 Hicrarquia de Classes da Ferramenta GREN-Wizard . . . . . . . . . . . 119 


\section{Lista de Figuras}

2.1 Processo para evolução de frameworks (Cagnin et al., 2004). . . . . . . . . . . . 9

2.2 Processo Geral (Braga, 2002b) . . . . . . . . . . . . . . . . . . . . 12

2.3 Linguagens de padrões para gestão de recursos de negócios (Braga, 2002b). . . 14

2.4 Arquitctura do GREN (Braga, 2002b) . . . . . . . . . . . . . . . . 15

2.5 Exemplo de algumas classes da hierarquia de classes do GREN (Braga, 2002b). 16

3.1 Contraste entre geração tradicional (a) e POA (b) de código executável. . . . . 21

3.2 Exemplo de implementação de aspecto em AspectJ. . . . . . . . . . . . . . . . . 24

3.3 Dois exemplos de classes. . . . . . . . . . . . . . . . . . . . . . . . . . . . . . . . .

3.4 Exemplo de arquivos de entrada para o Hyper/J. . . . . . . . . . . . . . 26

3.5 Diagrama de classes AspectS. . . . . . . . . . . . . . . . . . . . 27

3.6 Representação das classe Integer c AsFactorialTraceAspect. . . . . . . 29

3.7 Definição em linguagem Smalltalk da classe AsfactorialTraceAspect . . 29

3.8 Código do método advicefactorial Inout . . . . . . . . . . . 30

3.9 Resultado do rastreamento do método factorial () . . . . . . . . . . . . 30

3.10 Sugestão Around em Apostle. . . . . . . . . . . . . . . . . . . . . . . . . . . . 31

3.11 Diagrama de classes do sistema de email. . . . . . . . . . . . . . . . . 33

3.12 Expressão em $\mathrm{D}^{2} \mathrm{AL}$ (colaboração entre os objetos EMai1 e ConteudotMai1). 33

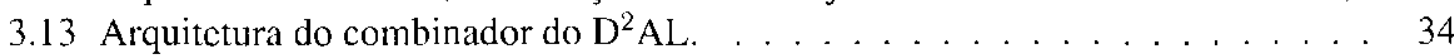

3.14 Ilustração do entrelaçamento de código para o aspecto de sincronização. . . . . 35

3.15 Código em linguagem TyRuBa. . . . . . . . . . . . . . . . 35

3.16 Faceta estrutural do modelo de Aspectos de Chavez \& Lucena (2001). . . . . . 37

3.17 Notação para projeto de software orientado a aspectos (Pawlak et al,, 2002). . . 38

3.18 Notação de aspecto em AODM (Stein et al., 2002) . . . . . . . . . . . . . . 41

3.19 Representação gráfica dos estereótipos «aspect» e «pointcut» (Camargo \& Masiero, 2004b) . . . . . . . . . . . . . . . . . . . . . 42

3.20 Representação gráfica do estereótipo «crosscutting» (Camargo \& Masicro, 2004b) . . . . . . . . . . . . . . . . . . . 42

3.21 Representação gráfica para as sugestões (Camargo \& Masiero, 2004b) . . . . . 43

3.22 Representação gráfica do estereótipo «introduction» (Camargo \& Masicro, 2004b) . . . . . . . . . . . . . . . . . . . . . . . . . . . . . . . . . .

3.23 Representação gráfica de outros estereótipos . . . . . . . . . . . . . . . . . 44

4.1 Padrão RBAC (Fernandez \& Pan, 2001) . . . . . . . . . . . . . . . 49

4.2 Modelo de classes do Subsistema de Segurança para o framework GREN. . . . 50 
4.3 Exemplo de marcações realizadas no caso de uso 'Entrar no sistema'. . . . . . . 51

4.4 Visão esquemática do projeto da nova versão do framework GREN. . . . . . . 52

4.5 Diagrama de classes do SS para oframework GREN . . . . . . . . . . . . . 54

4.6 Classes aspecto do SS para framework GREN. . . . . . . . . . . . . . . . . 55

4.7 Classes de negócio do SS para framework GREN. . . . . . . . . . . . . . . . 56

4.8 Interface gráfica do SS para gerenciamento de papéis da aplicação. . . . . . . . . 57

4.9 Interface gráfica do SS para gerenciamento de permissões. . . . . . . . . . . . . 58

4.10 Código da sugestão adviceUserAuthentication $1 \ldots \ldots$. . . . . . . . 59

4.11 Código da sugestão adviceUserAuthentication $2 \ldots \ldots \ldots$. . . . . . 59

4.12 Código da sugestão adviceLoginRegister . . . . . . . . . . . . . . . 60

4.13 Código da sugestão advi ceLogoutRegister . . . . . . . . . . . . . . . . . 60

4.14 Código da sugestão adviceoperationControl . . . . . . . . . . . . . 62

4.15 Interlace GREN-Wizard (Criação de uma nova aplicação) . . . . . . . . . . . . 66

4.16 Interace GREN-Wizard (Configuração do estado inicial da aplicação) . . . . . 67

4.17 Planejamento de controle de configuração do GREN. . . . . . . . . . . . . . 68

5.1 Modelo de análise do sistema para Clínica Veterinária . . . . . . . . . . . . 70

5.2 Parte da hierarquia de classes do GREN . . . . . . . . . . . . . . . . . 73

5.3 Menus e jancla principal do sistema para Clínica Veterinária. . . . . . . . . . . 74

5.4 Janela para autenticação de usuários. . . . . . . . . . . . . . . . . . . . . . . . . . . . . . . . . . . . .

5.5 Janela para manutenção de papéis da aplicação . . . . . . . . . . . . . . . . . . . . . . . . . . . . . . . . . . . .

5.6 Janela para atribuição de direitos aos papéis da aplicação. . . . . . . . . . . . . . 76

5.7 Janela para manutenção de usuários da aplicação. . . . . . . . . . . . . . . . 76

5.8 Exemplo do relatório de registro de acessos em um período. . . . . . . . . . . 77

5.9 Exemplo da interceptação do aspecto que realiza o controle de acesso. . . . . . 77

5.10 Janelas para a criação de uma nova aplicação. . . . . . . . . . . . . . . . . 79

5.11 Exemplo da aplicação de um padrão. . . . . . . . . . . . . . . . . . . . . . . 79

5.12 Janela para seleção dos relatórios da aplicação. . . . . . . . . . . . . . . 80

5.13 Configuração do estado inicial do sistema para Clínica Veterinária. . . . . . . . . 80

E.1 Interface para configuração do estado inicial da aplicação instanciada . . . . . 113 
3.1 Exemplos de tipos de pontos de junção e respectiva descrição (Gradecki \& Lesiccki, 2003). . . . . . . . . . . . . . . . . . . . 22

3.2 Exemplo de ponto de corte. . . . . . . . . . . . . . . . . . . 23

3.3 Estercótipos para definição de alguns tipos de métodos de aspectos (Pawlak et al., 2002) . . . . . . . . . . . . . . . . . . 38

3.4 Elementos notacionais para pontos de junção (Pawlak et al., 2002). . . . . . . . 39

3.5 Palavras chaves permitidas com os pontos ! e ? (Pawlak et al., 2002). . . . . . . 39

3.6 Estercótipos para AOSD (Camargo \& Masicro, 2004b). . . . . . . . . . . . . 41

3.7 Estereótipos básicos de projeto de frameworks orientados a aspectos (Camargo \& Masicro, 2004a) . . . . . . . . . . . . . . . . 45

4.1 Classes GUI do sistema de segurança e respectivas superclasses. . . . . . . . . 58

5.1 Padrões e variantes aplicados na fase de análise. . . . . . . . . . . . . . 71

5.2 Mapeamento APP para Clínica Veterinária. . . . . . . . . . . . . . . 72

5.3 Mapeamento GUI para Clínica Veterinária. . . . . . . . . . . . . . . . 72

B.l Caso de uso Entrar no Sistema. . . . . . . . . . . . . . . . . . . . . . . . 96

B.2 Caso de uso Sair do Sistema . . . . . . . . . . . . . . . . . . . . . . . 97

B.3 Caso de uso Manutenção de Usuários (Criar novo) . . . . . . . . . . . . . . 97

B.4 Caso de uso Manutenção de Usuários (Remover) . . . . . . . . . . . . . . . . . . . . 97

B.5 Caso de uso Manutenção de Usuários (Alterar) . . . . . . . . . . . . . . . . 98

B.6 Caso de uso Manutenção de Papéis (Criar novo) . . . . . . . . . . . . . . . . . . . . . . . . . . . . . . . .

B.7 Caso de uso Manutenção de Papéis (Remover) . . . . . . . . . . . . . . . . . . 99

B.8 Caso de uso Manutenção de Papéis (Alterar) . . . . . . . . . . . . . . . . . . 99

B.9 Caso de uso Manutenção de Direitos (Atribuir direitos a um papel) . . . . . . . 100

B.10 Caso de uso Manutenção de Direitos (Remover direitos de um papcl) . . . . . . 100

B.11 Caso de uso Alterar Senha . . . . . . . . . . . . . . . . . . . . 100

B.12 Caso de uso Desbloquear Usuário . . . . . . . . . . . . . . . . . . 101

D.1 Classes alteradas do framework GREN. . . . . . . . . . . . . . . . 106

D.2 Tabelas pertencente à base de dados do GREN-wizard alteradas. . . . . . . . . . 106

D.3 Classes alteradas do GREN-Wizard. . . . . . . . . . . . . . . 107

E.1 Classes aspecto do SS X Classes aspecto da aplicação específica a serem criadas. 109 
E.2 Classes de interface do SS X Classes de interface da aplicação específica a serem criadas. . . . . . . . . . . . . . . . . . . . . . . . . . 109

E.3 Classes aspecto do SS X métodos a serem sobrepostos. . . . . . . . . . . . 110

E.4 Classes de interface do SS X métodos a serem sobrepostos. . . . . . . . . . . 110 
Esta dissertação apresenta a evolução do framework orientado a objetos GREN, realizada usando a abordagem de Programação Orientada a Aspectos. Nessa evolução foram considerados apenas requisitos nãofuncionais que não haviam sido implementados nas versões originais do GREN, mais especificamente os requisitos de scgurança (autenticação, registro de acesso e controle de acesso). A implementação desses requisitos deu origem a um Subsistema de Segurança orientado a aspectos, que permite a autenticação, registro de acesso e controle de acesso de usuários sobre as aplicaçõos instanciadas a partir do GREN. Também é apresentada a evolução da ferramenta para instanciação automática do GREN, o GREN-Wizard, para torná-la compatível com a nova versão do GREN. Para a evolução do GREN foi seguido um processo de evolução de frameworks proposto na literatura que sofreu influência deste trabalho em seu refinamento. Uma avaliação sucinta dos resultados obtidos é também apresentada. 
Abstract

This dissertation presents an evolution of an object-oriented framework called GREN that was done using an Aspect Oriented Approach. In this evolution, only non functional requirements were considered, more specifically the general requirements of security (authentication, access log and access control). An aspect-oriented Security Subsystem was origineted from the implementation of these requirements. The Security Subsystem allows authentication, log and access control of system's users for the applications instantiated using GREN. The evolution of the GREN-Wizard, a tool to automatically instantiate GREN applications, is also presented, making it compatible with the new version of GREN. A process proposed in the literature for frameworks evolution was followed in this evolution of GREN. This use has contributed to the refinement of that process. A brief evaluation of the results obtained is also presented. 


\section{Introdução}

\subsection{Contextualização}

A reutilização de software é um antigo objeto de estudo da Engenharia de Software. As linguagens e técnicas de programação evoluíram nesse sentido, com o objetivo de apoiar a separação de interesses (concerns) cm módulos bem definidos que podem ser vistos como componentes reusáveis $\mathrm{cm}$ novos sistemas.

Na década de setenta apareceu a programação orientada a objetos como um paradigma poderoso para o reuso por meio de herança; entretanto, o reuso era alcançado apenas em pequena escala c não resolvia o problcma de reutilizar componentes grandes que cuidassem de partes relevantes de um sistema. Nesse contexto deu-se início aos estudos de métodos e técnicas de análise de domínio para maximizar o reuso no processo de desenvolvimento de software por meio da identificação e organização do conhecimento a respeito de uma classe de problemas. Com esse mesmo objetivo surgiram os frameworks de software orientados a objetos, os quais permitem o reuso de grandes estruturas em um domínio particular. O reuso ocorre por meio da personalização dessas estruturas para atender aos requisitos de aplicações específicas do domínio. Framework é definido como um esqueleto de classes, objetos e relacionamentos agrupados para construir aplicações específicas. Eles são utilizados tanto em processos bascados no conceito de linhas de produtos de software (Weiss \& Lai, 1999) como isoladamente, nos mais diversos domínios e níveis: frameworks de aplicação, frameworks de middleware, frameworks de infra-estrutura etc.

Uma limitação encontrada na tecnologia de objetos é a dificuldade na localização de interesses que envolvem restrições globais e comportamentos dispersos. Procurando resolver essáa 
limitação, surgiu nos últimos anos a programação orientada a aspectos (POA), como uma alternativa importante para o projeto de software, permitindo separar os aspectos puramente funcionais de outros que se espalham ao longo dos componentes modulares proporcionado, assim, a criação de módulos mais "limpos" (Kiczales et al., 2001b).

Recentemente, a junção das tecnologias de frameworks e POA deu origem aos frameworks orientados a aspectos. A combinação dessas duas tecnologias constitui uma abordagem bastante promissora para aumentar a reusabilidade dos frameworks e facilitar sua evolução. De um lado a programação orientada a aspectos torna possível a scparação e implcmentação de interesses, o que é importante para melhorar a manutenibilidade no desenvolvimento de software. Os frameworks, por outro lado, possibilitam o reuso e a personalização de uma implementação particular cm aplicações diferentes.

\subsection{Motivação}

Seguindo cssa linha de pesquisa de frameworks e reuso, o Grupo de Pesquisa em Engenharia de Software do ICMC vem trabalhando há alguns anos no desenvolvimento de um framework OO, denominado GREN, para o domínio dos recursos de gestão de negócios e num processo de desenvolvimento de framework em que a base é uma linguagem de padrões que especifica o domínio (Braga et al., 1999; Braga, 2002b; Braga \& Masicro, 2002c,b). Como a junção das tecnologias de frameworks e POA é bastante promissora e vem sendo estudada como uma alternativa adicional para aumentar a reusabilidade dos frameworks e facilitar sua evolução, torna-se importante pesquisar quais as vantagens de se utilizar a POA não apenas para a confecção de um novo framework, como é encontrado na literatura, mas para a evolução de um framework OO já existente como, por exemplo, o GREN. Essa expcriência pode mostrar se é válido o uso de POA na manutenção e evolução de programas já existentes e quais tipos de manutenção poderiam ser ou não beneficiadas com essa técnica.

\subsection{Objetivos}

Esta dissertação tem como objetivo realizar uma evolução orientada a aspectos do framework GREN, na qual são considerados requisitos não funcionais. Essa cvolução é baseada em um processo de evolução de frameworks proposto na literatura e prioriza a implementação de requisitos não funcionais de segurança que não foram implementados nas versões anteriores do GREN. Portanto, consiste de uma evolução aperfeiçoativa (ou perfectiva), pois novas funcionalidades são adicionadas ao GREN. Pretende-se também avaliar o uso de orientação a aspectos para manutenção de frameworks. 


\subsection{Organização do Trabalho}

Este trabalho está organizado em seis capítulos e scis apêndices. No Capítulo 2, é apresentada uma revisão bibliográfica sobre os conceitos gerais de frameworks de software orientados a objetos, evolução de frameworks e algumas pesquisas existentes na literatura relacionadas à junção da tecnologia de frameworks com a tecnologia de POA. Uma descrição detalhada sobre o framework GREN, que foi a base para a realização deste trabalho é também apresentada.

No Capítulo 3, são fornecidos os conceitos básicos sobre POA necessários para o entendimento e desenvolvimento deste trabalho. São apresentadas também algumas linguagens de programação que apóiam a POA, outras abordagens relacionadas a POA e algumas propostas presentes na literatura para apoiar o projeto de software orientado a aspectos.

No Capítulo 4 é apresentada, em detalhes, a evolução realizada no framework GREN, na qual foi implementado o Subsistema de Segurança seguindo a abordagem POA. A apresentação dessa evolução é realizada de acordo com o seu desenvolvimento, seguindo cada um dos passos do processo de evolução de frameworks proposto por Cagnin et al. (2004). Nesse Capítulo também é apresentada a evolução da ferramenta para instanciação automática do GREN, a GREN-Wizard, para torná-la compatível com a nova vcrsão do GREN criada.

No Capítulo 5, são apresentadas duas instanciações da nova versão do GREN, para um sistema de Clínica Veterinária: uma de forma caixa-branca e outra por mcio da fcrramenta GREN-Wizard. Essas instanciações têm por objetivo ilustrar quais tarefas adicionais devem ser realizadas, nos casos de instanciações da nova versão do GREN incluírem o Subsistema de Segurança.

No Capítulo 6, apresentam-se as conclusões desta dissertação, com um resumo e uma avaliação sobre o trabalho realizado, as contribuições ao estado da arte e sugestōes de trabalhos futuros.

No Apêndice A são apresentados os requisitos do Subsistema de Segurança e no Apêndice $B$ são mostrados os casos de uso elaborados a partir desses requisitos. No Apêndice $C$ ć apresentado o documento de requisitos do sistema para Clínica Veterinária. No Apêndice D são apresentadas as alterações realizadas decorrentes da evolução da ferramenta GREN-Wizard. No Apêndice E apresenta-se documentação adicional do Subsistema de Segurança, que enfoca os passos para a instalação do pacote de classes AspectS e do Subsistema de Segurança e, também. considerações sobre a instanciação do GREN incluindo o Subsistema de Segurança. Por fim, no Apêndice F mostra-se a hierarquia de classes das novas versões do GREN $\mathrm{e}$ da ferramenta GREN-Wizard. 


\section{Frameworks}

\subsection{Considerações Iniciais}

Considerando-se os objetivos deste trabalho, que é o uso da recente tecnologia de aspectos para apoiar a evolução de framéworks, apresenta-se, neste capítulo, uma revisão bibliográfica sobre frameworks orientados a objetos, e considerações sobre a junção da tecnologia de frameworks com a tecnologia de programação orientada a aspectos. Para tal, este capítulo cstá organizado como segue. Na sç̧ão 2.2 são abordados conceitos gerais sobre frameworks. A seção 2.3 trata do assunto de evolução de frameworks c descreve um processo de evolução de frameworks proposto na literatura, o qual recebeu contribuições com o desenvolvimento deste trabalho. Na seção 2.4 é apresentado o framework GREN, que foi a base para a realização deste trabalho de mestrado, abordando o seu processo de desenvolvimento e as suas principais características. Na seção 2.5 é apresentado o assunto de frameworks orientados a aspectos, citando alguns exemplos propostos atualmente na literatura. Por fim, na seção 2.6 são apresentadas as considerações finais deste capítulo.

\subsection{Frameworks de Software Orientados a Objetos}

Frameworks ${ }^{1}$ são soluçôes de software que têm o objetivo de apoiar o desenvolvimento de aplicações em domínios específicos. O objetivo principal é a reutilização tanto de código

'Para simplificação, o termo "framework" será usado nesta dissertação com o mesmo significado de "framen'ork oricntado a objctos" 
quanto de esforços despendidos em todas as fases do ciclo de vida, num esforço de aumentar a velocidade do desenvolvimento e a qualidade das aplicações desenvolvidas. Um framework ć uma aplicação semidefinida e reusável que pode ser especializada para criar uma aplicação específica (Fayad et al., 1999). A arquitetura de tempo de execução de um framework é caracterizada pela inversão de controle, ou seja, os métodos definidos pelo usuário para especializar o framework são invocados dentro do próprio framework, ao invés de serem chamados a partir do código do usuário.

A arquitetura dos frameworks possui pontos fixos (frozen spots) e pontos variáveis (hot spots) (Pree, 1995). As várias aplicações dentro de um mesmo domínio são diferenciadas por um ou mais pontos variáveis. Os pontos variáveis são pontos do framework projetados para serem genéricos e poderem ser adaptados de alguma forma às necessidades de cada aplicação especííca, por exemplo, por meio do preenchimento de parâmetros ou da criação de subclasses. Pontos fixos ou partes fixas são usadas sem nenhuma modificação em todas as instanciações dos frameworks.

Considerando a forma de reuso, os frameworks podem ser classificados como framework caixa-branca, caixa-preta ou caixa-cinza. As funcionalidades de um framework caixa-branca são reusadas e estendidas por meio de herança, ou seja, o usuário deve criar subclasses das classes abstratas contidas no framework para construir aplicações específicas. Dessa forma, o usuário precisa conhecer detalhes das estruturas internas do framework para utilizá-lo. O framework caixa-preta permite estender suas funcionalidades por composição ou definição de interfaces para os componentes. Assim, o usuário deve entender apenas a interface para usar estc tipo de framework. Finalmente, o framework caixa-cinza é uma combinação do caixa-branca $c$ do caixa-preta, ou scja, o reuso é feito por herança e pela definição de interfaccs. Em outras palavras, frameworks caixa-cinza são projetados para suprir as desvantagens apresentadas pelos frameworks caixa branca e preta. Ele deve possuir flexibilidade e extensibilidade suficiente, c a habilidade de ocultar de seus usuários informações desnecessárias (Fayad et al., 1999). Portanto, os frameworks caixa branca são mais fáceis de projetar, pois não há necessidade de prever todas as alternativas de implementação possíveis. Já os frameworks caixa-preta são mais difíceis de projetar por haver necessidade de fazer essa previsão. Por outro lado, o framework caixa-preta é mais fácil de usar, pois basta escolher a implementação desejada, enquanto no caixa-branca é necessário completar a implementação.

De acordo com Fayad \& Schmidt (1997) Fayad et al. (1999) os frameworks podem ser classificados, segundo seu escopo, em três grupos:

- Frameworks de infra-estrutura do sistema: simplificam o desenvolvimento da infraestrutura de sistemas portáveis e eficientes como, por exemplo, sistemas operacionais, sistemas de comunicação, interfaces com o usuário e ferramentas de processamento de linguagem. São geralmente usados internamente em uma organização de software e não são vendidos a clientes diretamente. 
- Frameworks de integração middleware: são geralmente usados para integrar aplicações e componentes distribuídos. Eles são projetados para melhorar a habilidade de desenvolvedores em modularizar, reutilizar e estender a infra-estrutura de software para funcionar cm um ambiente distribuído.

- Frameworks de aplicação cmpresarial: estão voltados para domínios de aplicação mais amplos e são a base para atividades de negócios das cmpresas como, por exemplo, sistemas de telecomunicações, aviação, manufatura e engenharia financeira. Eles são mais caros de desenvolver e comprar, e apóiam diretamente o desenvolvimento de aplicações e produtos.

Os principais benefícios fornecidos pelos frameworks aos desenvolvedores, segundo Fayad \& Schmidt (1997) e Fayad et al. (1999), são: modularidade, reusabilidade, extensibilidade c inversāo de controle.

A modularidade proporcionada pelos frameworks melhora a qualidade do software por localizar o impacto das alterações de projeto e implementação, reduzindo o esforço necessário para entender e manter softwares existentes.

Os frameworks aumentam a reusabilidade por fornecer implementações genéricas de soluções que podem ser reutilizadas para definir novas aplicações. Esse fato produz uma melhora substancial na produtividade dos programadores, assim como aumenta a qualidade, desempenho e confiabilidade do software.

Um framework aumenta a extensibilidade por possuir métodos adaptáveis que podem ter suas interfaces estendidas para atender aos requisitos de diferentes aplicações. A extensibilidade é indispensável para assegurar a personalização adequada de características e serviços de novas aplicações.

Frameworks também são importantes rccursos para o enfoque de linha de produto. Uma linha de produto de software envolve um conjunto de aplicações similares de um domínio que podem ser desenvolvidas a partir de uma arquitctura genérica comum, a arquitetura da linha de produto $e$ um conjunto de componentes que povoam a arquitetura. O objetivo dessa abordagem é identificar os aspectos comuns e as diferenças entre os artefatos de software ao longo do processo de desenvolvimento da linha de produto, de modo a explicitar os pontos de decisão em que a adaptação dos componentes para a geração de produtos específicos pode ser realizada. Portanto, para sc conceber uma linha de produto é necessário partir de conceitos que levem à generalização de aplicações c que permitam instanciações para aplicações específicas. Os frameworks fornecem esse tipo de recurso por ser uma arquitetura de softwarc semidefinida que consiste de um conjunto de unidades individuais e de interconexöes entre elas, de tal forma que cria uma infra-cstrutura de apoio pré-fabricada para o desenvolvimento de aplicações de um ou mais domínios (Gimenes \& Travassos, 2002).

A litcratura apresenta algumas abordagens e estratégias para a implementação de linha de produto de software como, por exemplo, a iniciativa PLP (Product Line Practice) do SEI/CMU 
(PLP apud (Gimenes \& Travassos, 2002)) $)^{2}$ a abordagem Synthesis elaborada pelo Software Productivity Consortium (SPC, 1993 apud (Gimenes \& Travassos, 2002)) ${ }^{3}$, a abordagem FAST (Weiss \& Lai, 1999), a abordagcm PULSE (Product line Software Engeneering) (Bayer et al., 1999 apud (Gimenes \& Travassos, 2002) $)^{4}$ e a abordagem de Bosch (Bosch, apud (Gimenes \& Travassos, 2002) $)^{5}$. Algumas dessas abordagens apresentam uma solução abrangente para questões relativas à representação de aspectos referentes à engenharia de domínio e aplicação, bem como aos conceitos inerentes à evolução, gerenciamento, análise de custo / benefício. tomada de decisão orientada ao mercado e avaliação de riscos. Outras fornecem métodos concentrados em alguns dos aspectos inerentes à tecnologia de linha de produto, tais como a definição da família de produtos, construção da infra-estrutura básica e até mesmo a implantação de componentes reutilizáveis (Gimenes \& Travassos, 2002).

A maioria dos frameworks existentes oferece suporte a domínios técnicos (tais como interfaces com o usuário ou distribuição), como por exemplo os frameworks MacApp, específicos para aplicações Macintosh, o InterViews e o Smalltalk Model-View-Controller. O Model-ViewController foi o primeiro framework amplamente utilizado. Ele é usado pelo Smalltalk como interface com o usuário, tendo mostrado a adequação da orientação a objetos para implementação de interfaces gráficas com o usuário (Fayad et al., 1999).

Os frameworks OO têm representado um importante papel no desenvolvimento de software atual (Fayad et al., 1999). Dentre esses frameworks podemos citar: os framewoks de integração middleware ACE (Schmidt, 1998), desenvolvido em linguagem C++ e que implementa padrões de concorrência e distribuição para softwares de comunicação, o JavaSoft's RMI e implementações do OMG CORBA; os frameworks de aplicação ET++ (Weinand et al., 1988) e o Microsoft Foundation Classes (MFC) desenvolvidos ambos em linguagem C++ e o IBM SanFranciso. O framework SanFrancisco foi desenvolvido por uma equipe da IBM utilizando linguagem Java, para auxiliar seus parceiros de negócios na construção de aplicações para uso próprio ou para distribuição para seus clientes (Monday, 2000 apud (Braga, 2002b) ${ }^{6}$. Ele pode ser alugado por empresas para a criação de aplicações que, depois de encerrado o período de desenvolvimento, passam a utilizar o sistema gerado sem outros encargos (Yassin \& Fayad, 2000 apud (BRAGA et al., 2002)) ${ }^{7}$.

\footnotetext{
2PLP. Homepage: A Framework for Software Product Line Practice Version 4.1. Disponível cm:ht tp:// www. sei.cmu.edu/plp/ framework. html

${ }^{3}$ SPC - Software Productivity Consortium, Reuse-Driven Software Processes Guidebook, SPC-92019-CMC version 02.00.03 November 1993.

${ }^{4}$ BAYER, J; FLEGE, O.; KNALBER, P.; LAQUA, R.; SCHMID, K. WIDEN, T.; DEBALD, J. PuLSE: A Methodology to Develop Software Product Lines. Simposium on Software Reusability (SSR99), May 1999.

${ }^{5} \mathrm{BOSCH}$, J. Designing \& Use of Software Architectures: Adopting and Evolving a Product-Line Approach. Great Britain: Ed. Addison -Wesley, 2000). 354p

${ }^{6}$ MONDAY, P.; CAREY, J.; DANGLER, M. SanFrancisco component framework: An introduction. Addison Wesley, 2000.

${ }^{7}$ YASSIN, A.; FAYAD,M. E. Application frameworks: A survev, cap. 29 In: M. E. Fayad and R. E. Johnson. Domain-Specific Application Frameworks: Frameworks Experience by Industry, John Wiley \& Sons, p.615 - 632 , 2000.
} 


\subsection{Evolução de Frameworks}

Uma vez implementados, os frameworks são usados para reduzir esforços na criação dc aplicações, e continuam a cvoluir a medida que aplicações são instanciadas, em razão da introdução de novos requisitos, funcionalidades ou até mesmo por correçõcs da implementação já existente. A evolução dos frameworks apresenta algumas conscquiências para as aplicações que foram anteriormente instanciadas, isto é, quando um framework evolui, as aplicações instanciadas a partir desse framework também devem evoluir e é necessário decidir se a implementação da evolução deve ser implementada diretamente nas aplicações já instanciadas ou se deve ser generalizada implementando-a no próprio framework (van Gurp \& Bosch, 2001).

Roberts \& Johnson (1998) propõem uma linguagem de padrões que descreve os passos de desenvolvimento e evolução de um framework. De forma resumida, os passos comuns na evolução são: primeiro o desenvolvimento de um framework caixa-branca e, em segundo, a sua transição para um framework caixa-preta. A transição de caixa-branca para caixa-preta é marcada por uma série de evoluções como a criação de uma biblioteca de componentes, a qual é constituída pelos objetos mais utilizados nas instanciações do framework, criação de partes variáveis do framework, criação de objetos "plugáveis", isto é, classes adaptáveis que possam ser parametrizadas, por exemplo, pelo envio de mensagens. O terceiro passo é a criação de uma ferramenta visual para automatizar o processo de instanciação e, como último passo, o desenvolvimento de uma ferramenta da linguagem que possa inspecionar e depurar o processo de instanciação automática. Entretanto, alguns frameworks podem parar de evoluir por não serem mais usados ou simplesmente pelo motivo de que é melhor para ele continuar sendo um framework caixa-branca e, assim, alguns desses passos podem não ser executados.

Mattsson \& Bosch (1998) apresentam uma classificação dos tipos de evolução a que um framework pode ser submetido de acordo com os tipos de manutenção a serem realizadas. Essa classificação é composta por quatro categorias: i) reorganização interna - é um tipo de evolução em resposta ao surgimento de novos requisitos, sendo que o framework é reorganizado internamente sem afetar as funcionalidades visíveis externamente e tem por objetivo melhorar al qualidade dos requisitos (algumas vezes requisitos não-funcionais como flexibilidade, reusabilidade ou desempenho) do framework; ii) mudança de funcionalidade - motivada, por exemplo, pela necessidade de adaptar a interação do framework com uma nova tecnologia de hardware ou software; iii) extensão de funcionalidades - é motivada pela introdução de novas funcionalidades ou de novos conceitos não atendidos pela versão corrente do framework; iv) redução de funcionalidade - pode ser motivada por instanciações do framework nas quais uma funcionalidade deve ser removida ou desabilitada e ocorre em situações muito especiais de junção de dois frameworks de um mesmo domínio, em que uma das funcionalidades existente nos dois precisa ser eliminada.

Em um estudo recente, Cagnin et al. (2004) propõem um processo abrangente para evolução de Frameworks de Aplicação composto pelos oito passos mostrados na Figura 2.1. A claboração 
desse processo foi motivada por dois estudos de caso de reengenharia utilizando o processo de reengenharia ágil PARFAIT (Cagnin et al., 2003), que usa o framework GREN, descrito na seção 2.4.2, como basc para a reengenharia de sistemas legados, nos quais notou-sc que muitos dos sistemas legados possuíam funcionalidades não implementadas no GREN.

O processo proposto por (Cagnin et al., 2004) enfatiza principalmente a manutenção perfectiva, por essa ser a que mais difere do processo de evolução de outros tipos de software. Entretanto, o processo também pode ser usado em outros tipos de manutenção. Para a implementação dos tipos de manutenção corretiva, adaptativa e preventiva (Pressman, 2001) aplicam-se diretamente os passos 5 a 8 , após ser realizada uma análise técnica, econômica, de mercado, dentre outras, para checar a viabilidade da manutenção desejada. Quanto ao responsávcl pela cxecução dos passos do processo, verifica-se que, os passos $2,3 \mathrm{e} 4$ do processo são executados pelo engenheiro da aplicação, os passos 1, 5, 6, 7 e 8 são executados pelo engenheiro de domínio.

Para cada requisito (funcional ou não funcional) não atendido pelo framework:

Passo 1) Analisar se o requisito pode ser considerado como genérico ao domínio do framework.

Caso não seja considerado générico:

Passo 2) Implementar a funcionalidade na aplicação para atender ao requisito (ou conjunto de requisitos)

Passo 3) Testar as funcionalidades implementadas na aplicação.

Passo 4) Armazenar o requisito no histórico.

Caso seja genérico ao domínio do framework deve-se:

Passo 5) Projetar, implementar e testar as funcionalidades no framework para atender ao requisito (ou conjunto de requisitos).

Passo 6) Atualizar a documentação do framework.

Passo 7) Testar a nova versão do framework.

Passo 8) Cuidar do Gerenciamento de Controle de Configuração.

Figura 2.1: Processo para evolução de frameworks (Cagnin et al., 2004).

A seguir são descritos, de forma resumida, cada um dos passos do processo de cvolução proposto por Cagnin et al. (2004):

- Passo 1 - Analisar se o requisito pode ser considerado como genérico ao domínio do framework. Neste passo, o engenheiro de domínio deve decidir se uma certa funcionalidade ou conjuntos de requisitos que especificam total ou parcialmente uma certa funcionalidade, que constitui a causa da manutenção a scr cfetuada, é genérica ao domínio do framework e poderá ser utilizada em outros produtos do domínio, ou se não deve ser implementada por não ser considerada genérica ou por carência de viabilidade econômica. 
Caso a decisão seja implementar o requisito, se ele for considerado genérico ao domínio os passos 5 a 8 do processo de evolução proposto devem ser executados. Caso contrário, se o requisito não for considerado genérico ao domínio, os passos 2 a 4 devem ser executados. Caso a decisão seja por não implementar deve-se registrar a funcionalidade ou conjuntos de requisitos para uma possível mudança de decisão no futuro.

- Passo 2 - Implementar funcionalidades na aplicação para atender o requisito. Neste passo a funcionalidade ou conjunto de requisitos deve ser implementada na aplicação instanciada a partir do framework. Para realizar a implementação deve-se inicialmente fazer um estudo das classes e métodos da aplicação, bem como das superclasses herdadas do framework para que a implementação da nova funcionalidade não danifique o comportamento das classes do framework. Deve-se ainda, dar grande atenção para a flexibilidade de alterações, uma vez que, caso seja decidido estender o domínio do framework posteriormente, o código da nova funcionalidade implementada poderá ser reaproveitado como base para a implementação da generalização dessa funcionalidade no framework.

- Passo 3 - Testar as funcionalidades implementadas na aplicação. Devem ser realizados testes de unidade dos módulos afetados pela implementação realizada no passo 2 para checar a sua correção. Alćm disso, também devem ser realizados testes de integração e de sistema para checar se nenhuma funcionalidade do framework foi danificada pela implementação da nova funcionalidade.

- Passo 4 - Armazenar o requisito no histórico. Após a implementação e testes da nova funcionalidade, neste passo o engenheiro de aplicação deve armazenar no histórico de requisitos a descrição e o tipo (funcional ou não funcional) de cada requisito implementado e armazenar também a solução adotada e o tipo de manutenção realizada.

- Passo 5 - Projetar, implementar e testar as funcionalidades no framework para atender ao requisito (ou conjunto de requisitos). Uma vez que a funcionalidade ou conjunto de requisitos analisados no passo 1 foi considerada genérica ao domínio do framework, aqui, no passo 5, o engenheiro de domínio deve fazer um estudo da arquitetura e da hierarquia de classes do framework para decidir como, na fase de projeto, o requisito poderá ser atendido pelo framework. Para isso, o diagrama de classes do projeto do framework é modificado observando-se quais classes, relacionamentos, métodos e atributos de classes devem ser adicionados e/ou modificados para atender à implementação da nova funcionalidade. Funcionalidades já implementadas cm aplicações geradas poderão servir como base para esse estudo e se possível poderão ser generalizadas para incorporar a nova funcionalidade ao framework. Quanto a funcionalidades típicas do domínio, mas que ainda não foram implementadas, deve-se aplicar um processo de análise de domínio semelhante ao processo usado para gerar o framework (Braga \& Masiero, 2002b; Braga, 2002b; Roberts \& Johnson, 1998). O engenheiro de domínio deve, então, codificar a nova 
funcionalidade ou conjunto de requisitos do framework a partir do novo projeto criado e em seguida testar, por meio de algum critério de teste. Além disso, testes de integração devem ser realizados para verificar se as funcionalidades implementadas atendem a todos os requisitos precstabelccidos e se nenhuma funcionalidade do framework foi danificada pela implementação da nova funcionalidade.

- Passo 6 - Atualizar a documentação do framework. Neste passo toda a documentação do framework, que refletem as alterações realizadas pela implementação da nova funcionalidade, deve ser atualizada, como por exemplo, diagrama de classes, hierarquia de classes, manual de uso do framework cookbook e guia do usuário da ferramenta de apoio a instanciação, se existir.

- Passo 7 - Testar a nova versão do framework. Neste passo devem ser realizados testes mais rigorosos de sistema para checar se as funcionalidades implementadas satisfazem os requisitos pretendidos e se nenhuma funcionalidade do framework foi prejudicada com a implementação da nova funcionalidade. Todas as partes do framework que refletem as alterações realizadas devem ser testadas por meio de diversas instanciações incluindo a nova funcionalidade implementada seguindo o processo descrito no cookbook atualizado.

- Passo 8 - Cuidar do Gerenciamento de Controle de Configuração. Neste passo deve-se decidir em quais versões do framework a implementação da nova funcionalidade deve ser incorporada, se as aplicações já instanciadas devem ser modificadas para incorporar a nova funcionalidade implementada no framework e a partir de qual momento a manutenção realizada será incorporada à versão operacional do framework.

\subsection{O Framework para Gestão de Recurso de Negócios}

O Framework para Gestão de REcursos de Negócios (GREN) foi desenvolvido no JCMCUSP no contexto da tese de doutorado de Braga (2002b), na qual foi proposto um processo de desenvolvimento de frameworks com base em linguagens de padrõcs.

\subsubsection{O Processo de Desenvolvimento}

O processo proposto por Braga \& Masiero (2002b), ilustrado na Figura 2.2, usando a notação SADT (Ross, 1977), é composto de quatro passos: o primeiro utiliza sistemas específicos e experiência prática em um dado domínio para construir uma linguagem de padrões,utilizada como entrada para todos os demais passos. Essa linguagem consiste basicamente de padrões de análise, ou seja. padrões a serem aplicados durantc a fase de análise de sistemas. Além disso, essa linguagem de padrões pode ser utilizada de forma independente para auxiliar desenvolvcdores, a modelarem sistemas no domínio por cla coberto 


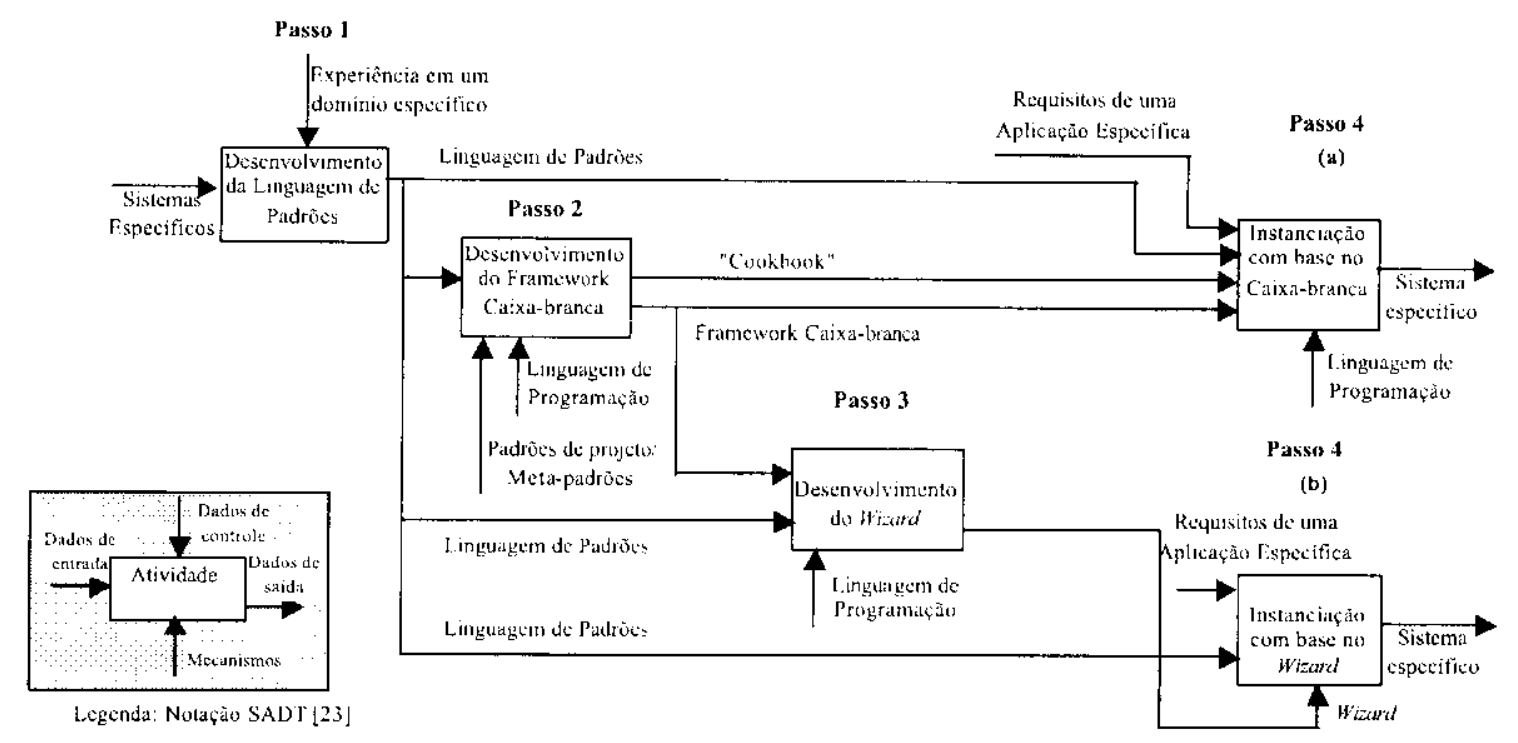

Figura 2.2: Processo Geral (Braga, 2002b)

No segundo passo, um framework caixa-branca é construído para apoiar a implementação de aplicações específicas modeladas pela linguagem de padrões. Tal framework possui classes concretas e abstratas implementadas em uma linguagem de programação específica, que correspondem, embora não necessariamente de forma direta, às classes de cada um dos padrões de análise da linguagem de padrões. É um framework caixa-branca porque, para derivar aplicações a partir dele, é necessário criar subclasses que herdem de suas classes abstratas. Recursos como Padrões de projeto (Gamma et al., 1995) e meta-padrões (Pree, 1995) são utilizados para prover a flexibilidade desejada no framework. Além disso, outro resultado desse passo é um manual de uso do framework, que inclui o mapeamento da linguagem de padrões para as classes do framework, de forma que, sabendo-se quais foram os padrões aplicados para modelar um sistema específico, pode-se identificar quais as classes do framework que devem ser especializadas e quais métodos devem ser sobrepostos durante a instanciação.

No terceiro passo é construída uma ferramenta (wizard) para automatizar a instanciação do framework caixa-branca a aplicações específicas. A interface gráfica de tal ferramenta ć totalmente baseada na linguagem de padrões, de forma que sua utilização torna-se intuitiva para desenvolvedores que conhecem a linguagem de padrões. Tendo o desenvolvedor fornecido à ferramenta todas as informações sobre os padrões aplicados para modelar seu sistema alvo, a ferramenta baseia-se no mapeamento da linguagem de padrões para as classes do framework, a fim de gerar o código das novas classes. O resultado é um sistema executável acompanhado do código-fonte, que pode ser modificado manualmente pelo engenheiro de software para atender requisitos não cobertos pela linguagem de padrões.

O quarto c último passo da abordagem é a instanciação do framework caixa-branca a aplicações específicas. Duas alternativas de instanciação são possíveis: com base no caixa-branca c 
com base no wizard. Na primeira alternativa utiliza-se diretamente oframework caixa-branca e seu cookbook, criando manualmente as novas classes da aplicação e seus respectivos métodos. $\mathrm{Na}$ segunda alternativa o wizard é utilizado para obtenção das novas classes e métodos. Em ambas as alternativas a linguagem de padrões é utilizada inicialmente para modelar o sistema, de acordo com seus requisitos específicos.

Deve-se ressaltar que o processo é iterativo, podendo haver, durante quaisquer de suas atividades, o retorno de informações que podem ser úteis para o refinamento de atividades já realizadas. Por exemplo, durante o desenvolvimento do framework caixa-branca podem ser identificadas funcionalidades não tratadas pela linguagem de padrões. Essa informação pode ser utilizada para complementar a linguagem de padrões, por meio do acréscimo de novos participantes, novas variantes, ou até mesmo novos padrões, ou pode ser documentada adequadamente para inclusão em futuras versões da linguagem de padrões e do framework. Outro exemplo que reforça o aspecto iterativo do processo é o passo de instanciação do framework, tanto pelo framework caixa-branca quanto pelo wizard. A instanciação é o momento no qual uma nova aplicação deve ser desenvolvida por meio da adaptação dos pontos flexíveis do framework. É nesse momento também que são identificadas a maioria das funcionalidades não cobertas, mas desejáveis de serem incorporadas ao framework e à linguagem de padrões.

\subsubsection{O Framework GREN}

O GREN é um framework orientado a objetos que foi desenvolvido com base na linguagem de padrões GRN (Braga et al., 1999), usando o processo apresentado na Seção 2.4.1. Ele permite criar aplicações no domínio de sistemas de gestão de recursos de negócios e foi implementado com a linguagem Smalltalk, mais especificamente o ambiente Visual Works NonCommercial 5i.4 (CINCOM, 2004).

A linguagem de padrões para Gestão de Recursos de Negócios (GRN), Figura 2.3, é formada por quinze padrōes de análise, alguns dos quais são aplicaçōes ou extensões de padrões propostos na literatura. Ela foi projetada para auxiliar os engenheiros de software a desenvolver aplicações que lidam com gestão de recursos, oferecendo-lhes material substancial para o desenvolvimento de novos sistemas, juntamente com soluções alternativas, quando necessário (Braga, 2002b).

A arquitetura do framework GREN é apresentada na Figura 2.4. Atualmente ele é composto de oitenta c duas classes de negócio, setenta e cinco classes referentes à interface gráfica e três classes para apoiar a persistência dos dados, fazendo conversão de objetos em Smalltalk para registros relacionais em um SGBD. A camada de persistência trata da conexão com a base de dados, gerenciamento dos identificadores dos objetos e negócios dos objetos. A camada de negócios comunica-se com a camada de persistência sempre que precisa armazenar um objeto permanentemente. Na camada de ncgócios existem diversas classes derivadas diretamente dos padrões que compõem a linguagem de padrões GRN. A camada de interface gráfica com o 


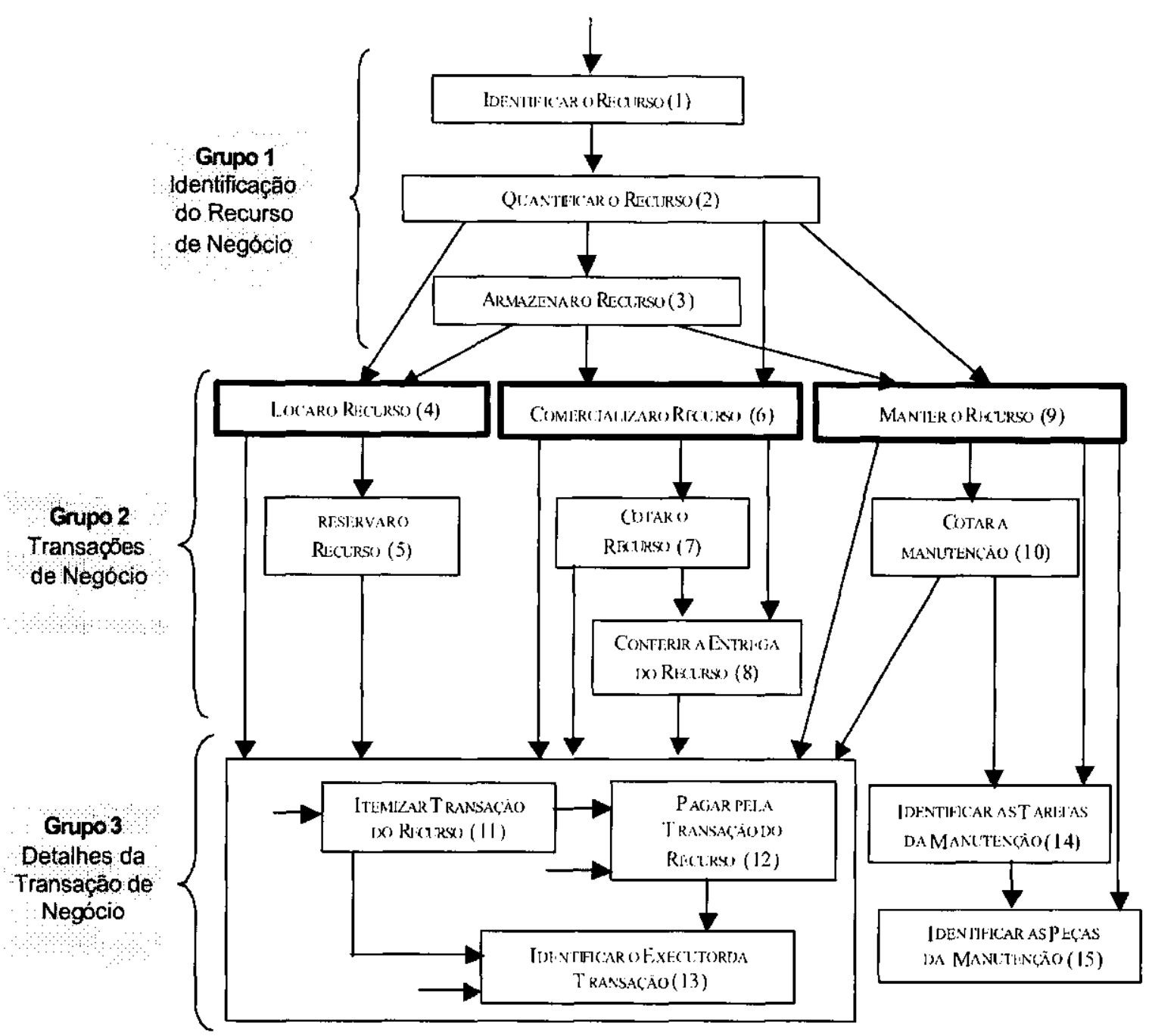

Figura 2.3: Linguagens de padrões para gestão de recursos de negócios (Braga, 2002b).

usuário contém as classes responsáveis pela entrada e saída de dados, e comunical-se com a camada de negócios para obtenção de objetos a screm mostrados na interface com o usuário e para devolver informações a serem processadas pelos métodos da camada de negócio. A camada GREN-Wizard contém as classes que implementam o instanciador do GREN, essa camada comunica-se com as camadas mais abaixo para a criação de classes de negócio e de GUI, e também faz uso da camada de persistência. As aplicações cspecíficas criadas por meio do GREN localizam-se nas camadas mais altas $c$ podem ser geradas manualmente usando a camada de interface gráfica com o usuário ou a partir do instanciador do GREN (GRLN-Wizard) (Braga, 2002b).

Definida a arquitctura do GREN, foi então projetada a sua hierarquia de classes. Inicialmente foi construído um modelo de classes geral englobando as classes de todos os padrões da GRN e posteriormente esse modclo foi refinado por mecanismos de especialização e generali- 


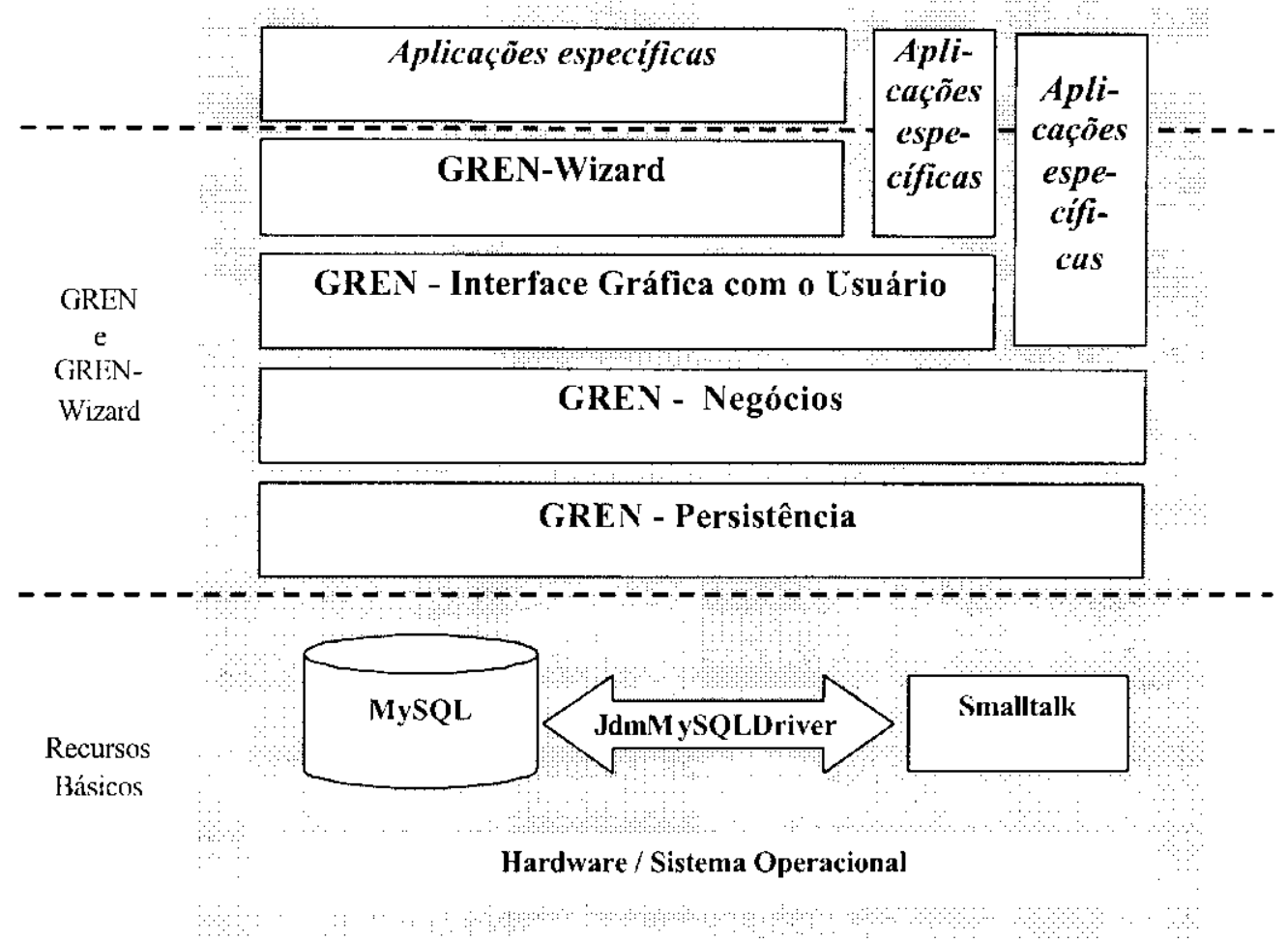

Figura 2.4: Arquitetura do GREN (Braga, 2002b).

zaçăo. A Figura 2.5 mostra alguns exemplos de classes pertencentes à hicrarquia de classes do GREN.

Várias aplicações foram desenvolvidas usando o framework GREN (Braga, 2002b), por exemplo:

- Sistema para Hotel, consistindo basicamente no gerenciamento das estadias de hóspedes do hotel, controlando desde a rescrva de acomodações até o acompanhamento do período de estadia, considerando os diversos tipos de consumo efetuados pelos hóspedes, tais como frigobar, restaurante, lavanderia c telefonemas.

- Sistema para Locadora de Carros, consistindo no gerenciamento dos aluguéis de carros, bem como do controle de ítens que podem ser adicionados ao aluguel, tais como combuslível, seguros (danos materiais e pessoais), taxa de retorno, cadeiras de bebê, motoristas, entrega do carro, etc. Emissão de diversos tipos de relatórios e consultas, para um melhor gerenciamento dos aluguéis. 


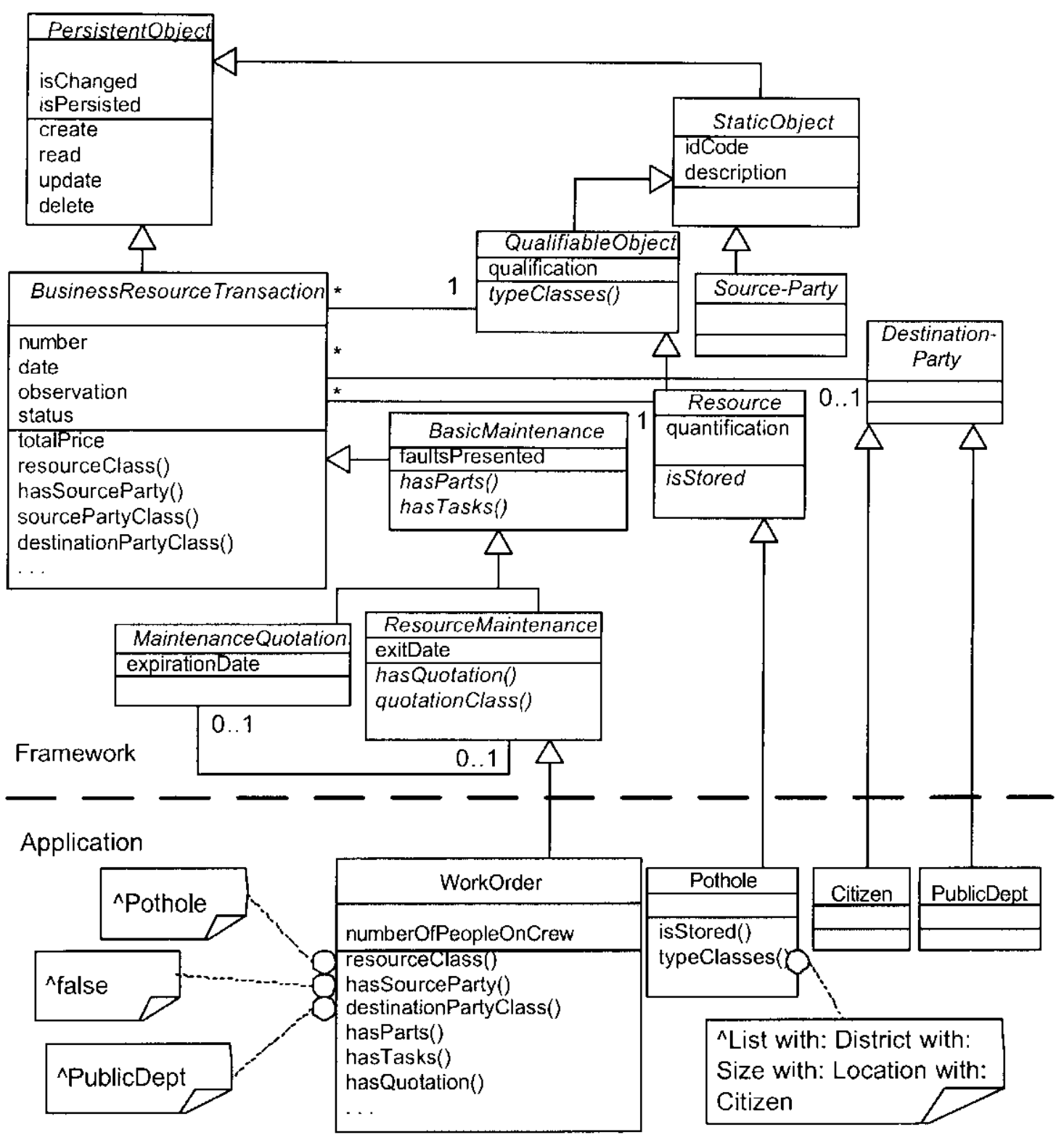

Figura 2.5: Exemplo de algumas classes da hierarquia de classes do GREN (Braga, 2002b).

\subsection{Frameworks Orientados a Aspectos}

Os frameworks orientados a aspectos sugiram recentemente como resultado da combinação das tecnologias de frameworks e programação orientada a aspectos. Eles constituem uma abordagem bastante promissora para aumentar a reusabilidade dos frameworks e facilitar sua evolução. Os frameworks orientados a aspectos têm sido foco de pesquisa de alguns autores tais como Constantinides et al. (2000), Netinant et al. (2000), Elrad et al. (2001a), Garcia et al. (2002), Pace \& Campo (2001), Rasshid \& Chitchyan (2003) e Camargo (2003). 
Em um trabalho de doutorado $\mathrm{cm}$ andamento no ICMC-USP, Camargo (2003) diferencia os frameworks orientados a aspectos em duas classes: i) frameworks de aplicação orientados a aspectos (FAOAs) c ii) frameworks puramente orientados a aspectos (FOAs). A difcrença básica é que os FAOAs são utilizados para instanciar aplicações, enquanto os FOAs, por si só, não instanciam nenhuma aplicação, pois eles são apenas a implcmentação genérica de um determinado requisito não funcional (persistência, controle de segurança, sincronização etc.). Dessa forma, para instanciar uma aplicação, os FOAs devem ser utilizados em conjunto com outros frameworks ou aplicações, que não possuam a implementação do requisito não funcional implementado pelo FOAs.

Camargo \& Masiero (2003) propõem um framework dc persistência orientado a aspectos (FOAs), cuja implementação foi baseada em um estudo anterior de Camargo et al. (2003), em que foi proposto um projeto baseado em aspectos para o padrão de projeto Camada de Persistência (Persistent Layer (Yoder et al., 1998)). Nesse estudo, os autores mostram como o padrão Camada de Persistência pode ser implementado separando-se os aspectos funcionais dos aspectos relativos ao padrão, facilitando, dessa forma, o entendimento do padrão e melhorando sua reusabilidade no que diz respeito a sua implementação. Identificou-se também que o padrão Camada de Persistência é composto por sub-padrões. considerados como sub-interesses dentro do interesse maior de persistência. Assim, foi feito o mapeamento desses sub-interesses para determinados aspectos, isto é, os aspectos foram criados utilizando fragmentos de vários subpadrões ou um sub-padrão completo. Foram realizadas duas implementações, ambas orientadas a aspecto, do framework de persistência orientado a aspectos (Camargo \& Masiero, 2003). A primeira implementação desse framework permite ao engenheiro de aplicações ter consciência sobre os métodos relacionados à persistência dos objetos, ou seja, o engenheiro de aplicação decide qual o melhor momento de estabelecer comunicação com a base de dados inserindo, propriamente, em seu código, durante o processo de instanciação, os métodos para salvar, atualizar ou recuperar objetos da base de dados. Na segunda implementação, o engenheiro de aplicação não necessita ter consciência sobre os alguns métodos de persistência, pois a própria implementação do framework percebe quando um objeto deve ser, por exemplo, persistido na base de dados. Essa última implementação apresentou uma queda na desempenho das aplicações instanciadas, por causa da sobrecarga de processamento necessária para manter na base de dados a mesma imagem dos objetos presente na memória durante a execução da aplicação instanciada. A versão atual do framework de persistência proposto por Camargo \& Masiero (2003) é voltado para aplicações baseadas na Web.

Rasshid \& Chitchyan (2003) também propõem um projeto inicial de framework de persistência baseado $\mathrm{cm}$ aspectos, com o objetivo de introduzir os interesses de persistência em uma aplicação nas fases finais de desenvolvimento. A camada de persistência, que é independente da aplicação, foi generalizada por meio da criação de pontos de junção abstratos que devem ser concretizados por aspectos especializados. O interesse de persistência foi dividido em Conexão, Armazenamento e $\Lambda$ tualização, Remoção, Transações e Acesso a meta-dados. Entretanto, essas 
partes não foram consideradas como sub-interesses c tampouco baseadas em algum padrão de projeto que trata de persistência, como nos trabalhos de Camargo et al. (2003) e de (Camargo \& Masiero, 2003).

Netinant et al. (2000) propōem um framework orientado a aspectos para apoiar o projeto de sistemas operacionais adaptáveis. O framework orientado a aspectos proposto por esse autor caracteriza-se por expressar a fase de projeto em um nível de abstração mais alto c ć bascado num projeto de sistema com três dimensões: componentes, aspectos e camadas. Os componentes compreendem as funcionalidades básicas dos módulos do sistema, os aspectos representam as propriedades ortogonais aos componentes do sistema e as camadas consistem de componentes e aspectos

Com base nas experiência dos autores referenciados nesta seção, pode-se concluir que a arquitetura geral dos frameworks orientados a objeto pode ser estendida por meio de aspectos, criando módulos (componentes e aspectos) independentes que facilitam o reuso e a manutenção.

\subsection{Considerações Finais}

Neste capítulo foram apresentados conceitos e também trabalhos já desenvolvidos, referentes à tecnologia de frameworks, que forneceram a base para o desenvolvimento deste trabalho de mestrado.

Comparando a revisão elaborada sobre o framework orientado a objetos GREN, base central para o desenvolvimento deste trabalho, e a recente tecnologia de frameworks orientados a aspectos, pode-se constatar que no projeto e desenvolvimento do GREN não houve nenhuma preocupação com relação a identificação e separação de interesses não funcionais ortogonais às suas funcionalidades. Foi neste sentido que se inseriu a proposta e o desenvolvimento deste trabalho, um estudo dos benefícios e implicações da junção das tecnologias de frameworks e programação orientada a aspectos. Para um maior entendimento sobre a tecnologia de programação orientada a aspectos, no próximo capítulo é apresentada uma abordagem sobrc essa tecnologia, incluindo os seus conceitos básicos e uma introdução sucinta à linguagens de programação e propostas de projeto que tem por objetivo apoiar essa nova tecnologia. 


\section{Programação Orientada a Aspectos}

\subsection{Considerações Iniciais}

Este capítulo é dedicado à programação orientada a aspectos (POA), a algumas linguagens de suporte à POA e a alguns modelos de projetos usados para representar sistemas orientados a aspectos na fase inicial de desenvolvimento. Dessa forma, este capítulo tem por objetivo apresentar um embasamento teórico para a compreensão deste trabalho de mestrado. Para tal, na seção 3.2 são definidos conceitos básicos sobre a programação orientada a aspectos. Na seção 3.3 são apresentadas algumas linguagens de suporte a POA, classificando-as cm duas abordagens. Assim, nas seções 3.3.1 e 3.3.2 são apresentados alguns excmplos de linguagens de propósito geral (Hyper/J, AspectJ, AspectS, Apostle) e de propósito específico (D²AL e TyRuBa), ilustrando suas principais características. Na seção 3.4 são apresentadas outras abordagens ligadas à POA. Na seção 3.5 são apresentadas algumas propostas de modelos para apoiar o projeto de software orientado a aspectos e, por fim, na seção 3.6 sāo apresentadas as considerações finais deste capítulo.

\subsection{Conceitos Básicos de Programação Orientada a As- pectos}

Scgundo Kiczales et al. (1997), os mecanismos de abstração das linguagens mais comumente utilizadas (sub-rotinas, procedimentos, funções, objetos, classes, APIs) podem ser enquadrados em um modelo de procedimentos generalizados, obtidos pela decomposição funcional 
do sistema. Entretanto, há propriedades que não se enquadram em componentes ${ }^{1}$ da decomposição funcional, tais como: tratamento de exceções, restrições de tempo real, distribuição e controle de concorrência e de acesso. Elas normalmente estão espalhadas por diversos componentes do sistema, afetando o descmpenho ou a semântica da aplicação. Embora elas possam ser visualizadas e analisadas relativamente em separado, sua implementação em linguagens orientadas a objetos ou estruturadas torna-se confusa; além disso, seu código encontra-se espalhado pelo código da aplicação, dificultando a separação entre a funcionalidade básica do sistema e essas propriedades. Esse fato, denominado entrclaçamento de código, é responsável por boa parte da complexidade encontrada nos sistemas atuais. Ele aumenta a dependência entre os componentes funcionais, desviando-os de sua finalidade principal, tornando-os menos reusáveis e mais propensos a erros.

A programação orientada a aspectos é uma abordagem que permite a separação dessas propriedades ortogonais ${ }^{2}$ dos componentes funcionais de uma forma natural e concisa, utilizando mecanismos de abstração e de composição para a produção de código executável (Kiczales et al., 1997). A separação dessas propriedades ortogonais em unidades modulares torna mais simples a evolução, compreensão, adaptação e reuso do sistema (Elrad et al., 2001b). Para alcançar esse objetivo, a abordagem de POA introduz novos construtores de linguagens por intermédio da definição de alguns conceitos básicos. De acordo com Elrad et al. (2001a), os conceitos básicos considerados na abordagem de POA são:

Pontos de junção (join points): representam os pontos no código do programa onde o programa de aspecto deve ser inserido durante o processo de weaving (processo de composição do programa que representa as funcionalidades básicas do sistema com o programa de aspecto);

Pontos de Corte (pointcuts): identifica um conjunto de pontos de junção. Os pontos de corte fornecem estruturas para descrição e manipulação de partes do programa;

Sugestões (advices): forma de especificar o comportamento de um ponto de corte. Em outras palavras, especifica a forma como o programa de aspecto afetará o comportamento do programa componente;

Introduções (introductions): construção para inserir unidades (métodos, atributos) no programa;

Unidades encapsuladas (aspects): constituem a implementação do aspectos, os quais combinam as especificações dos pontos de corte e o comportamento a eles anexados.

A forma de implementação desses conceitos varia de acordo com as linguagens de programação destinadas a dar apoio à POA.

${ }^{1} \mathrm{O}$ termo componente será usado nesta dissertação com o significado de "parte funcional de um sistema."

${ }^{2}$ Essas propriedades são também chamadas de "interesses". 


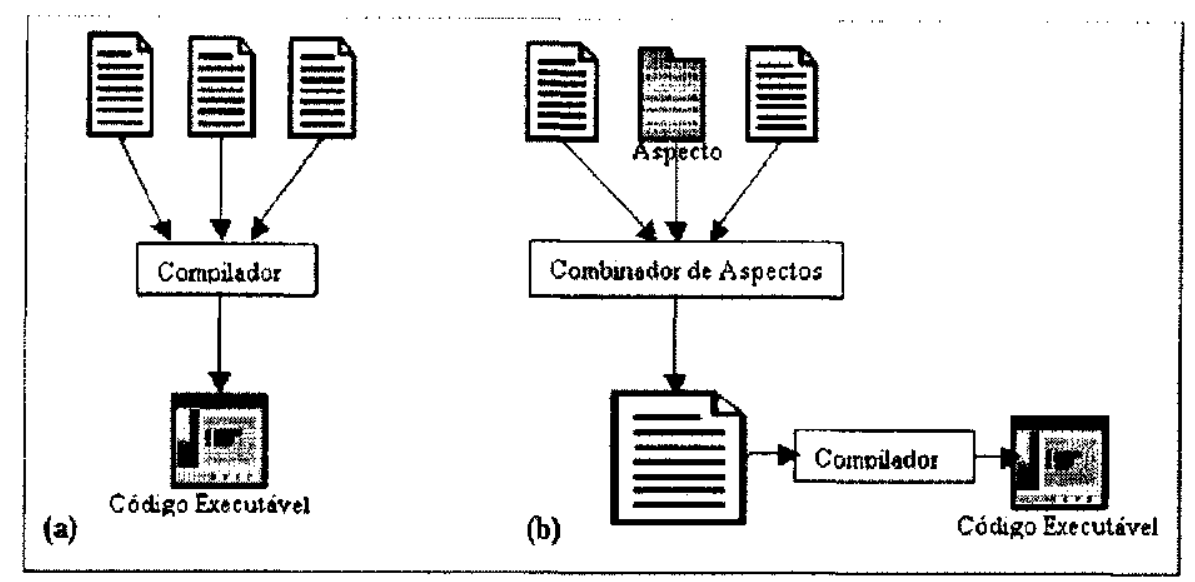

Figura 3.1: Contraste entre geração tradicional (a) e POA (b) de código executável.

Em contraste com as técnicas tradicionais, ilustradas na Figura 3.1(a), na POA, conforme a Figura 3.1(b), cada aspecto é expresso de uma forma separada por meio de construtores lingüísticos específicos. Para obtenção do programa final, os aspectos devem ser combinados com os componentes, por meio do processo chamado de combinação de aspectos (aspect weaver).

\subsection{Linguagens de Suporte à Programação Orientada a Aspectos}

Várias linguagens têm sido criadas para apoiar a programação orientada a aspectos. Essas linguagens se dividem em duas vertentes, de acordo com o seu foco de abrangência: linguagens de propósito geral, que tratam de aspectos de maneira genérica, e as linguagens de propósito específico, que tratam aspectos específicos de um domínio. Embora as linguagens de propósito geral tenham a vantagem de abranger um domínio maior de problemas, elas são mais complexas e de mais baixo nível, sendo assim, mais difíceis de usar. Por outro lado, as linguagens específicas de domínio, embora se limitem a atender somente um domínio bem definido, proporcionam, por mcio de notações e abstrações, um poder significativo para a solução de problemas próprios desse domínio.

\subsubsection{Linguagens de Propósito Geral}

Linguagens de propósito geral visam a definir abstrações e mecanismos de composição que ofereçam suporte à programação orientada a aspectos de maneira genérica, ou seja, os aspectos tratados não são específicos de um domínio. A seguir são apresentadas as descrições de algumas dessas linguagens tais como AspectJ (Gradecki \& Lesiccki, 2003; Kiselev, 2003; Kiczales et 
al., 2001b,a), Hyper/J (Lay et al., 2000), Apostle (Alwis, 2002) c AspectS (ASPECTS, 2004; Hirschfeld, 2002).

\subsubsection{AspectJ}

AspectJ é uma extensão de Java de propósito geral que tem por objetivo dar suporte à Programação Orientada a Aspectos. Foi desenvolvida pela Xerox Palo Alto Research Center, e permite uma fácil instalação de interesses que interceptam as classes do sistema (Gradecki \& Lesiecki, 2003; Kiselev, 2003). AspectJ define um conjunto de construtores da linguagem tais como: pontos de junção (join points), pontos de corte (pointcuts), sugestões (advices), introduções (introductions) e aspectos (aspects). Pontos de corte $\mathrm{e}$ sugestões afetam dinamicamente o fluxo do programa, enquanto uma introdução afeta estaticamente a hierarquia de classes do programa.

Os pontos de junção são pontos bem definidos na execução do programa. AspectJ tem vários tipos de pontos de junção, tais como: chamadas a construtores e a métodos, execução de construtores e métodos, acesso a campos, tratamento de exceçôes e iniciação de classes c objetos (Gradecki \& Lesiecki, 2003: Kiselev, 2003). Alguns exemplos de pontos de junção e sua respectiva descrição são apresentados na Tabela 3.1 .

Tabela 3.1: Exemplos de tipos de pontos de junção c respectiva descrição (Gradecki \&

\begin{tabular}{|c|c|}
\hline Pontos de Junção & Descrição \\
\hline call\{void point. $\overline{s e t} x($ int $)\}$ & $\begin{array}{l}\text { Ponto de junção de chamada de método. Neste } \\
\text { exemplo, esse ponto de junção identifica todas } \\
\text { as chamadas ao método setx definido na classe } \\
\text { Point. }\end{array}$ \\
\hline initialization (Boxset.now(String)\} & $\begin{array}{l}\text { Ponto de junção de chamada de construtor. Neste } \\
\text { cxemplo, este ponto de junção identifica as cha- } \\
\text { madas do construtor do objeto Boxset. }\end{array}$ \\
\hline $\begin{array}{l}\text { execution(public void } \\
\text { setTitle(String)\} }\end{array}$ & $\begin{array}{l}\text { Ponto de junção de execução de método. Este } \\
\text { tipo de ponto de junção é definido quando um } \\
\text { método é chamado a partir de um outro objeto e o } \\
\text { controle de exccução é transferido para o método } \\
\text { chamado. }\end{array}$ \\
\hline set \{public string DVD.location\} & $\begin{array}{l}\text { Ponto de corte de atribuição de campo. E defi- } \\
\text { nido quando um atributo de um objeto é escrito. } \\
\text { Neste exemplo, esse ponto de junção será dis- } \\
\text { parado qundo o atributo locat ion definido na } \\
\text { classe DVD for alterado. }\end{array}$ \\
\hline
\end{tabular}

Um ponto de corte em AspectJ é um construtor que identifica um conjunto de pontos de junção, além de alguns valores no contexto da execução desses pontos por meio de critérios bem definidos. Estes critérios podem ser nomes de funções específicas, ou nomes de funções generalizados pelo sinal de asterisco $\left({ }^{*}\right)$. Um ponto de corte pode ser composto por operadores 
lógicos ('\&\&', ' ll'e '?') e, além disso, ć possível atribuir-lhe um nome para identificar pontos de junção de diferentes classes (Kiczales et al., 2001a). Um exemplo de ponto de corte é mostrado na Tabela 3.2

Tabela 3.2: Exemplo de ponto de corte.

\begin{tabular}{|c|c|}
\hline Ponto de Corte & Descrição \\
\hline $\begin{array}{l}\text { pointcut mover(): } \\
\text { call(void UmaFigura.sctXY(int, int)) || } \\
\text { call(void Ponto.setX(int)) || } \\
\text { call(void Ponto.sety(int)) || } \\
\text { call(void Linha.setPl(Ponto)) || } \\
\text { call(void Linha.setp2(ponto)); }\end{array}$ & $\begin{array}{l}\text { Ponto de corte denominado mover. } \\
\text { Esse ponto de corte intercepta as } \\
\text { classes UnaFigura, Ponto e Linha } \\
\text { por meio dos pontos de junção } \\
\text { nele definidos. }\end{array}$ \\
\hline
\end{tabular}

Sugestões definem a implementação do interesse que intercepta as classes do sistcma (Kiselev, 2003), ou seja, definem o código a ser executado quando um ponto de junção é alcançado na execução do programa. AspectJ implementa três tipos de sugestões (before, after e around) cujo código é processado antes, depois ou durante a execução de um ponto de junção. Para ilustrar, considerando o ponto de corte definido na Tabela 3.2, a sugestão after a seguir imprime a mensagem "moveu" após qualquer clemento da figura ter sido movido.

after() : mover () (System.out.println("moveu");\}

Uma introdução em AspectJ permite alterar classes e o relacionamento de herança entre classes externamente à definição da classe original. Por exemplo, um aspecto pode ser usado para adicionar métodos, construtores e atributos em uma classes ou para declarar que uma classe estende uma nova superclasse. Portanto, uma introdução afeta e modifica a hicrarquia de tipos estáticos do programa (Gradecki \& Lesiecki, 2003).

Um Aspecto é uma unidade modular definida em termos de pontos de corte, sugestões e introduções. Somente os aspectos podem incluir sugestões. Os aspectos funcionam lado a lado com as demais classes de uma aplicação (Gradecki \& Lesiecki, 2003), sendo que as classes refletem a lógica do negócio e os aspectos implementam os interesses que afetam e modificam uma ou mais dessas classes. Em Aspectl, um aspecto difere de classe por não poder ser instanciado diretamente e, além disso, classes não podem estender aspectos (Kiselev, 2003). A Figura 3.2(c) ilustra um exemplo de aspecto para resolver o problema de atualização do visualizador. As figuras 3.2(a) e 3.2(b) mostram que a implementação do mecanismo de atualização do visualizador afeta vários métodos de classes diferentes, representadas pelas linhas de código em negrito, fazendo com que este interesse torne-se espalhado e entrelaçado com o código funcional. A Figura 3.2(c) apresenta a solução para o problema, criando um aspecto que possui um ponto de corte denominado mover () . Esse ponto de corte agrupa dois pontos de junção, destacados com elipses tracejadas: o primeiro identifica as chamadas a todos os métodos, que iniciam com a palavra set, da classe Linha e o segundo faz o mesmo para a classe Ponto. Quando 
há uma chamada a algum método set* , a sugestão after() exccuta o método a tualiza() da classe Visualizador após o término da execução dos métodos chamados. A declaração returning garante que a sugestão só será executada se os pontos de junção, relativos ao ponto de corte mover, retornarem com sucesso de seus processamentos. As linhas de código em negrito, figuras 3.2(a) e 3.2(b), devem ser retiradas quando esse aspecto for implementado.

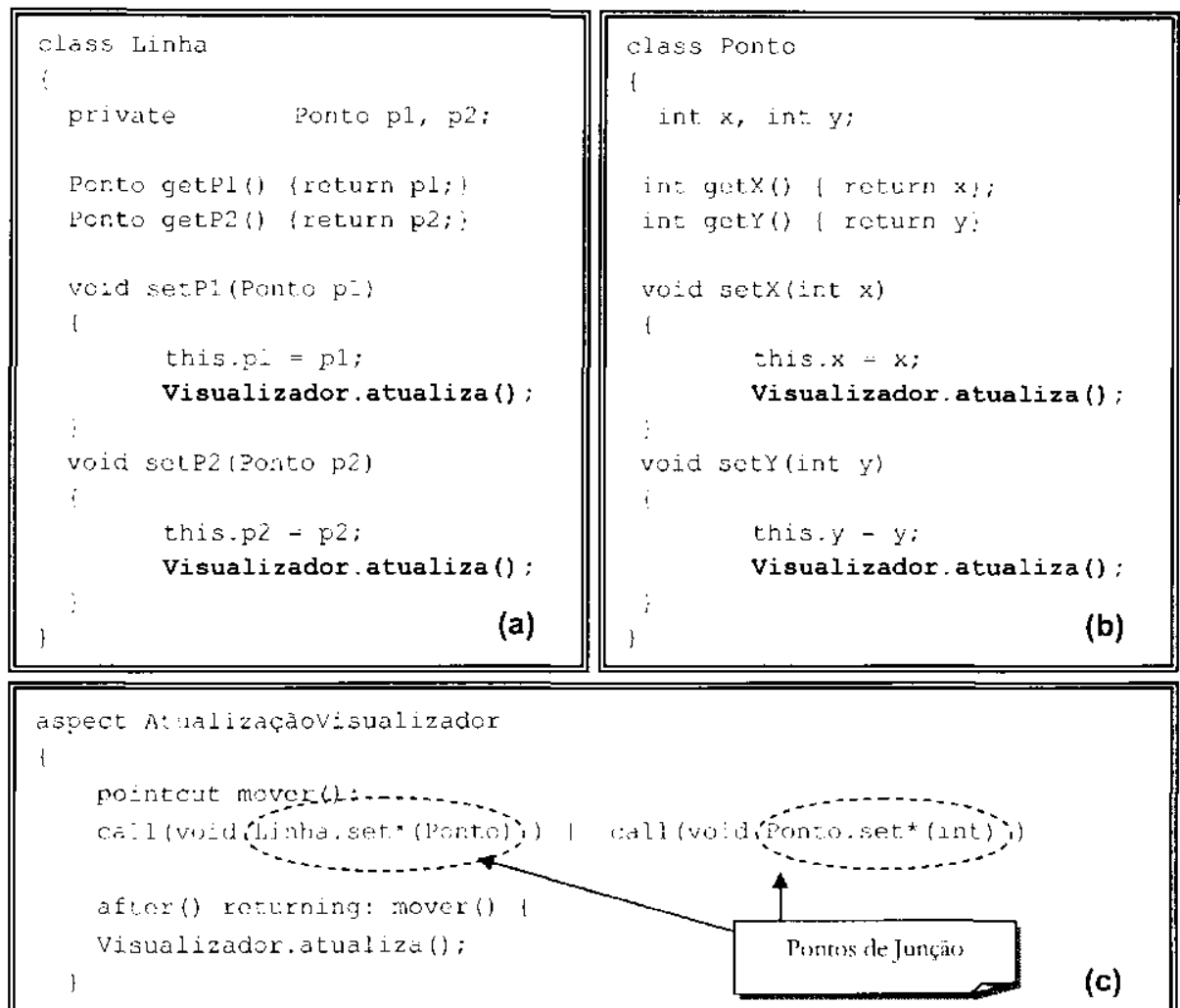

Figura 3.2: Exemplo de implementação de aspecto em AspectJ.

O processo de composição de aspectos é implementado como um pré-processador que reccbe como entrada o(s) programa(s) de componentes e o(s) programa(s) de aspectos e gera arquivos Java que podem ser compilados normalmente.

\subsubsection{Hyper/J}

Hyper/J é uma ferramenta desenvolvida pela IBM T.J. Watson Research Center como uma extensão de Java para apoiar a scparaçăo multidimensional e integração de interesses em Java. Em outras palavras, ela permite a decomposição de programa Java em múltiplas dimensões de interesses simultaneamente e, depois, permite combinar cssas dimensões de interesses em um sistema coerente por meio de regras de composição (Lay et al., 2000).

Na utilização do Hyper/J, o usuário fornece três entradas: arquivo do hiperespaço, que descreve os arquivos das classes Java a serem manipulados pelo Hyper/J; um arquivo de ma- 
peamento dos interesses, que descreve quais classes devem ser mapeadas para cada dimensão de interesse; e, um arquivo do hipermódulo, o qual especifica quais dimensões devem ser intercaladas e como essa integração deve proceder. Por exemplo, considerando as duas classes apresentadas na Figura 3.3 abaixo, a classe A, conforme Figura 3.3(a), tem um método chamado print, que imprimc a cadeia de caracteres "Alô" como saída; a classe B, mostrada na Figura 3.3(b), também possui um método print, que imprime "Mundo".

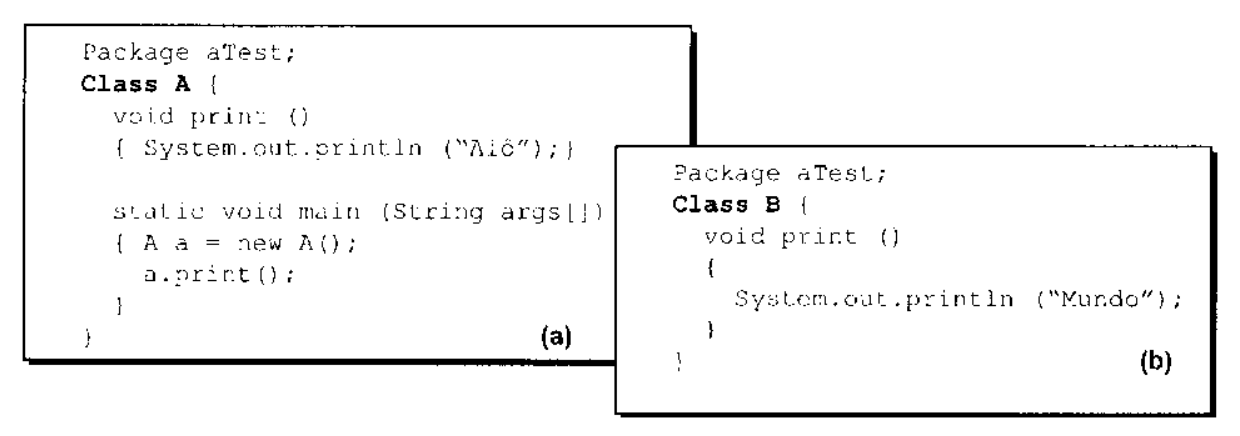

Figura 3.3: Dois exemplos de classes.

Visando a criar um sistema para imprimir a saída "Alô Mundo", pode-se usar o Hyper/J da seguinte forma: descrevendo a classe A como pertencente ao interesse Núcleo e a classe B ao interesse Novo; posteriormente, combinando esses dois métodos para obter o comportamento desejado.

Na Figura 3.4 são mostrados os três arquivos de entrada que são necessários para o Hyper/J realizar a decomposição c a composição desejada. O arquivo hiperespaço, Figura 3.4(a), declara que as classes a serem manipuladas pertencem ao pacote aTest. $O$ arquivo de mapeamento de interesses, Figura 3.4(b), especifica o mapeamento das classes em diferentes interesses. Finalmente, o arquivo de hipermódulo, mostrado na Figura 3.4(c), especifica que o sistema composto inclui as funcionalidades de ambos os interesses, Núcleo c Novo, c que elas serão combinadas por meio da regra de composição mergeByName (Lay et al., 2000)

Hyper/J oferece suporte para a edição e construção de regras de composição, as quais descrevem o inter-relacionamento e as interações entre interesses c como construir novos interesses a partir dos já existentes. As regras de composição podem ser habilitadas e desabilitadas individualmente. Outra característica é que regras inválidas são automaticamente desabilitadas. Os principais benefícios do uso de Hyper/J são: separação e modularização de interesses de maneira flexível; composição não invasora com adaptação de componentes e características de fácil instalação; possibilita a criação de extensões e configurações de componentes existentes sem modificação do código fonte; e desenvolvimento descentralizado de classes (Hyper/J, 2004). 


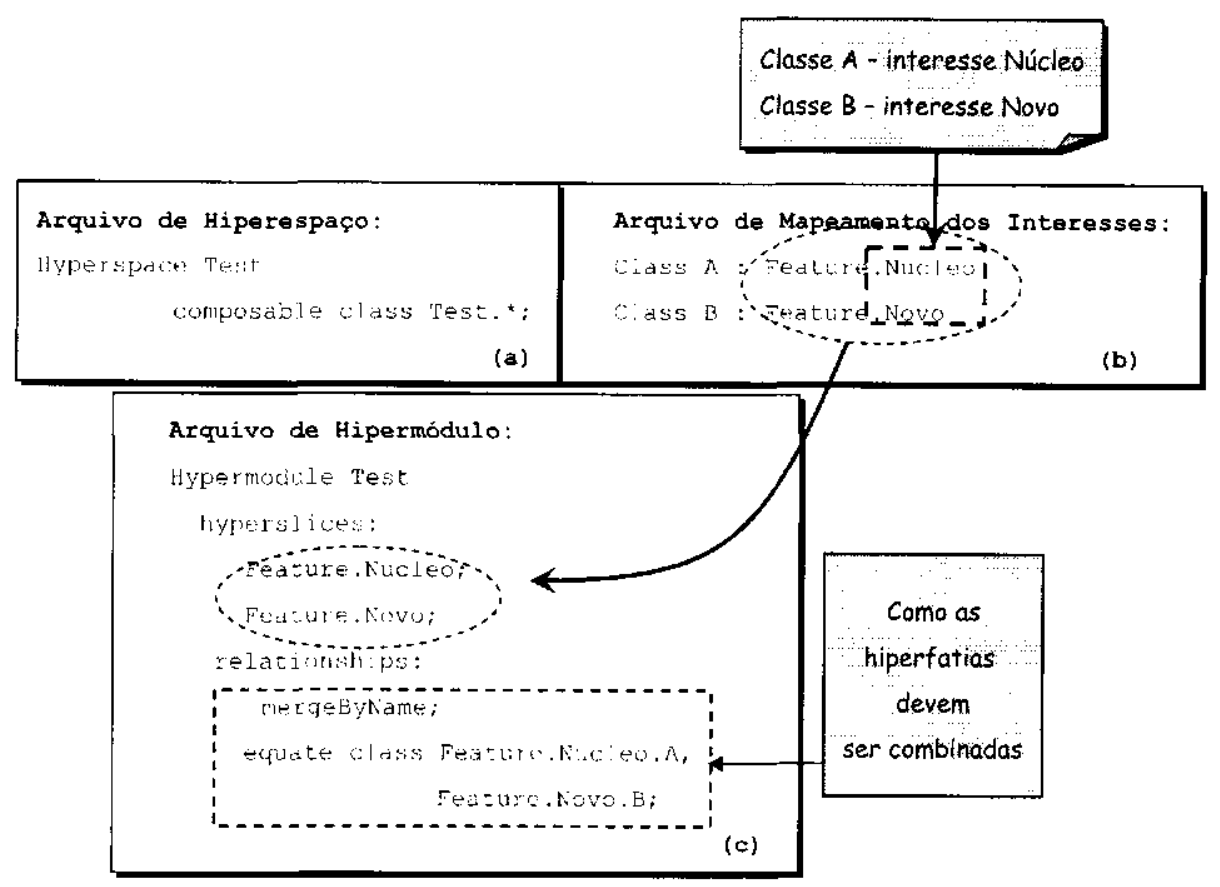

Figura 3.4: Exemplo de arquivos de entrada para o Hyper/J.

\subsubsection{AspectS}

AspectS é uma forma de programação orientada a aspectos de propósito geral implementada no ambiente Squeak (Hirschfeld, 2002; ASPECTS, 2004). Squeak é uma implementação de Smaltalk-80 abcrta e altamente portável, cuja máquina virtual é inteiramente escrita $\mathrm{em}$ Smalltalk, favorecendo sua depuração, análise e alterações (Squeak, 2004).

Segundo Hirschfeld (2002), AspectS estende o ambiente Squeak/Smalltalk para permitir o desenvolvimento de sistemas orientados a aspectos experimentais. AspectS baseia-se principalmente nos resultados de dois projetos. O primeiro deles é o AspectJ (Gradecki \& Lesiecki, 2003) e o segundo consiste do mecanismos de empacotamento de métodos (methodWrappers) (Brant, 2004), que é um mecanismo que permite introduzir um novo comportamento à ser executado antes, depois ou em lugar de um método compilado do Smalltalk. AspectS considera a programação em meta-nível e trata o fenômeno de entrelaçamento de código por meio de módulos relacionados a aspectos. Na sua implementação atual, AspectS não modifica a sintaxc nem a máquina virtual Smalltalk.

Embora tenha sido inicialmente criado para o ambiente Squeak, AspectS também é portável para o ambiente VisualWorks. Por essa razão foi usado na implementação deste trabalho. Na Figura 3.5 é apresentado o diagrama de classes contendo todas as classes, relativas à implementação de AspectS, que tornam possível a implementação de aspectos na linguagem Smalltalk usando o ambiente de programação VisualWorks. 


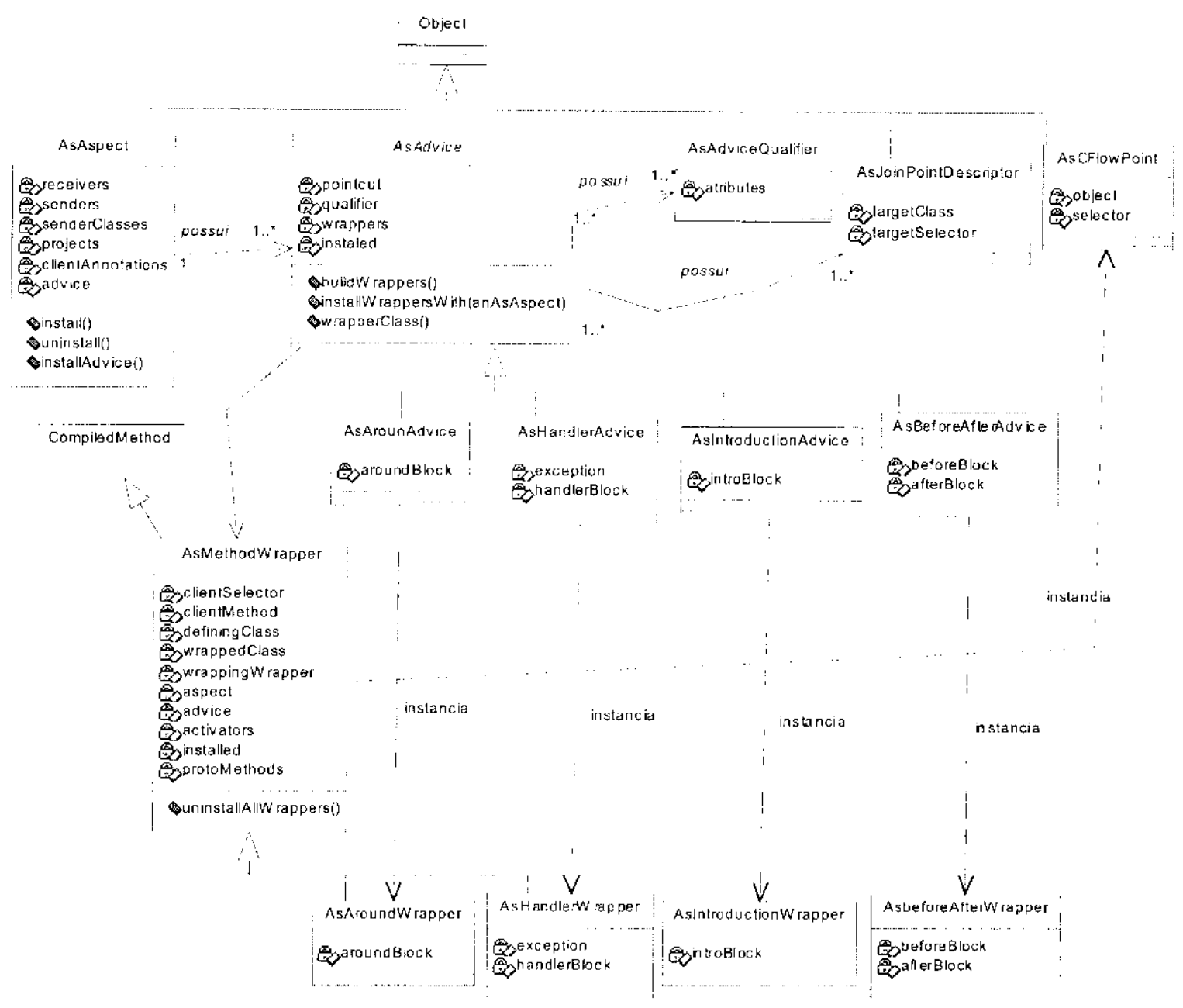

Figura 3.5: Diagrama de classes AspectS.

Em AspectS os aspectos são implementados como classes regulares especializadas a partir da classe AsAspect ${ }^{3}$ e, dessa forma, suas instâncias agem como objetos regulares. Diferentemente de AspectJ, em AspectS os aspectos podem ser instanciados diretamente. Isso é realizado enviando uma mensagem de instalação por intermédio do método install, a uma instância do aspecto. O efeito de um aspecto no sistema é revertido enviando uma mensagem de desinstalação por intermédio do método uninsstalı, à mesma instância do aspecto responsável pela transformação do sistema.

A implementação de sugestões é tratada pela classe AsAdvice. AspectS dá suporte à implementação de quatro tipos de sugestões por intermédio das classes que especializam a classe

\footnotetext{
"Todas os nomes de classes em AspectS possuem o prefixo "As" para melhor identificação das classes deste pacote entre as demais classes no ambiente de programação. Isso se deve ao fato da primeira implementação de AspectS ter sido desenvolvida no ambiente Squeak, cuja implementação atual possui apenas um espaço de nome (do inglês namespace) global. No ambiente VisualWorks essa caracterização não seria necessária, pois é possível criar um espaço de nome para cada projeto ou conjunto de classes que implementam um propósito em comum. Entretanto, o pacote de classes de AspectS foi utilizado na implementação deste trabalho de mestrado sem alterações de quaisquer características da versão que foi disponibilizada para o ambiente VisualWorks.
} 
AsAdvice. A classe AsBeforeAfterAdvice possibilita a implementação de uma sugestão cujo código, relativo ao interesse tratado. cxecuta antes ou após a invocação de um método. A classe AsHandlerAdvice possibilita a implementação de sugestões para o tratamento de cxceçŏes. A classe AsAroundAdvice pcrmitc implementar uma sugestão cujo código exccuta durante a invocação de um método, tomando para si o controle da exccução deste método e, por fim, a classe AsIntroductionAdvi ce permite implementar uma sugestão para adicionar um novo comportamento a uma determinada classe. As sugestões devem ser implementadas como métodos das classes aspecto, que devem ser especializadas a partir da classe aspecto AsAspect e, é no corpo destes métodos, que uma das classes que possibilitam a implementação de tipos diferentes de sugestões devem ser instanciadas. As classes AsBeforeAfterAdvice, AsHandlerAdvice, AsAroundAdvice e AsIntroductionAdvice usam blocos ${ }^{4}$ para representar os fragmentos de código que implementam o interesse tratado pelo aspecto.

AspestS também implementa o conceito de ponto de corte. A descrição de pontos de corte é permitida pcla implementação da classe AsAdvice que possui um atributo chamado pointcut, o qual armazena um conjunto de pontos de junção. Esse conjunto de pontos de junção é, na verdade, um vetor de objetos do tipo AsJoinPointDescriptor. Assim, os pontos de junção são descritos por meio de instanciações da classe AsJoinPointDescriptor. Os pontos de junção podem ser enumerados estaticamente ou capturados dinamicamente por meio de consultas ao sistema por causa da natureza reflexiva do ambiente Smalltalk.

A classe AsAdviceQualifier permite a descrição de atributos dinâmicos do ponto de corte relacionado a uma sugestão. Estes atributos dinâmicos expressam características dinâmicas dos pontos de junção enumerados pelo ponto de corte, indicando, mais especificamente, quando um ponto de junção será afetado.

O processo de integração de um aspecto e suas sugestōes com um sistema (weaving) ocorre toda vez que um aspecto é instalado $\mathfrak{e}$ o processo reverso (unweaving) ocorre quando o aspecto é desinstalado. Esses processos são considerados complctamente dinâmicos, pois ocorrem em tempo de execução. O código resultante é baseado no empacotamento de métodos (method wrapping) - que permite introduzir o código a ser exccutado antes, depois ou em lugar do método existente - e em meta-programação. As classes representadas na Figura 3.5 que possuem o sufixo Wrapper são responsável por implementar o empacotamento do código de um aspecto com as classes da aplicação que são interceptadas por esse aspecto. Há uma implementação de empacotamento de métodos para cada um dos tipos de sugestão implementados por AspectS. Dessa forma, as classes AsBeforeAfterWrapper, AsHandlerWrapper, As IntroductionWrapper e AsAroundWrapper cuidam, respectivamente, do empacotamento de métodos relativo às sugestões implementadas pelas classes AsBeforeAfterAdvice, AsHandlerAdvice, AsIntroductionAdvice e AsAroundAdvice.

\footnotetext{
"Blocos representam blocos de códigos delimitados por colchetes "[ ]" que podem ser manipulados pela linguagem Smallialk.
} 


\subsection{LINGUAGENS DE SUPORTE À PROGRAMAÇ̃O ORIENTADA A ASPECTOS 29}

Para ilustrar a aplicação de AspectS considere o seguinte exemplo do cálculo do fatorial de um inteiro. Conforme a Figura 3.6. a classe Integer possui um método denominado factorial(), que deve receber um inteiro como parâmetro e retornar o scu fatorial. A classe aspecto AsFactorialTraceAspect possui um método denominado advicefactorialinout () que ć a implementação de uma sugestão para rastrear a execução recursiva do método factorial().

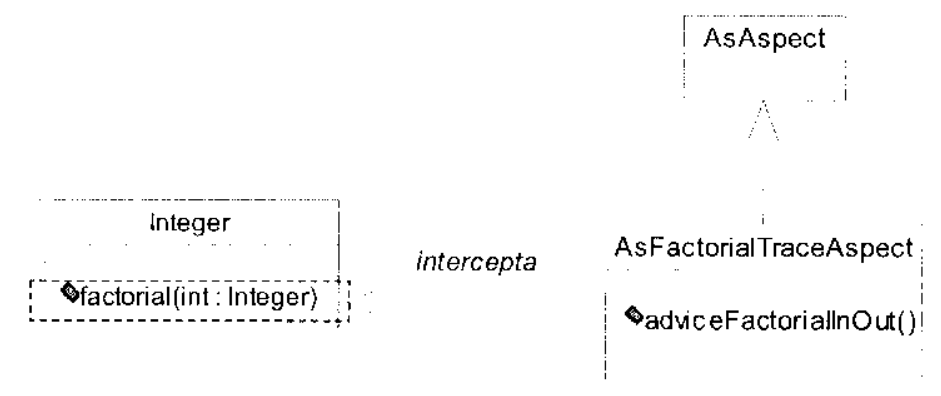

Figura 3.6: Representação das classe Integer e AsFactorialTraceAspect.

A definição da classe AsFactorialTraceAspect é mostrada na Figura 3.7. A linha de código dois (2) indica que essa classe especializa a classe AsAspect.

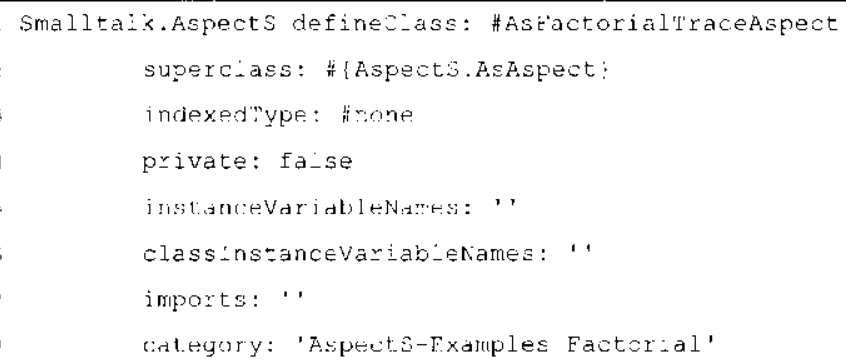

Figura 3.7: Definição em linguagem Smalltalk da classe AsFactorial TraceAspect

A implementação do método advi ceFactorial Inout é apresentada na Figura 3.8. Esse método cria uma sugestão do tipo AsBeforeAfterAdvice. A linha de código quatro indica a definição de um atributo receiverClassSpecific que é um qualificador dos pontos de junção. Este atributo, cspecificamente, indica que todos os receptores da mensagem factorial: que são instância da classe Integer serão afetados por este aspecto. As linhas de código cinco e seis mostram a definição de um ponto de corte desta classe de aspecto e a captura dos pontos de junção, representados por uma coleção de todas as chamadas ao método factorial: definido na classe Integer. As linhas sete a dez mostram a implementação do bloco de código que será executado antes da execução do método factorial: e as linhas de código onze a quatorze mostram a implementação do bloco de código que será cxecutado após a execução do método factorial:. Dessa forma, a sugestão implementada por este método não altera 
o comportamento da classe Integer, ela apenas rastreia a execução do método factorial : imprimindo o parâmetro de entrada por intermédio das linhas de código oito a dez, e o resultado do fatorial desse parâmetro por intermédio das linhas de código doze a quatorze. O resultado impresso por cssa sugestão é mostrado na Figura 3.9.

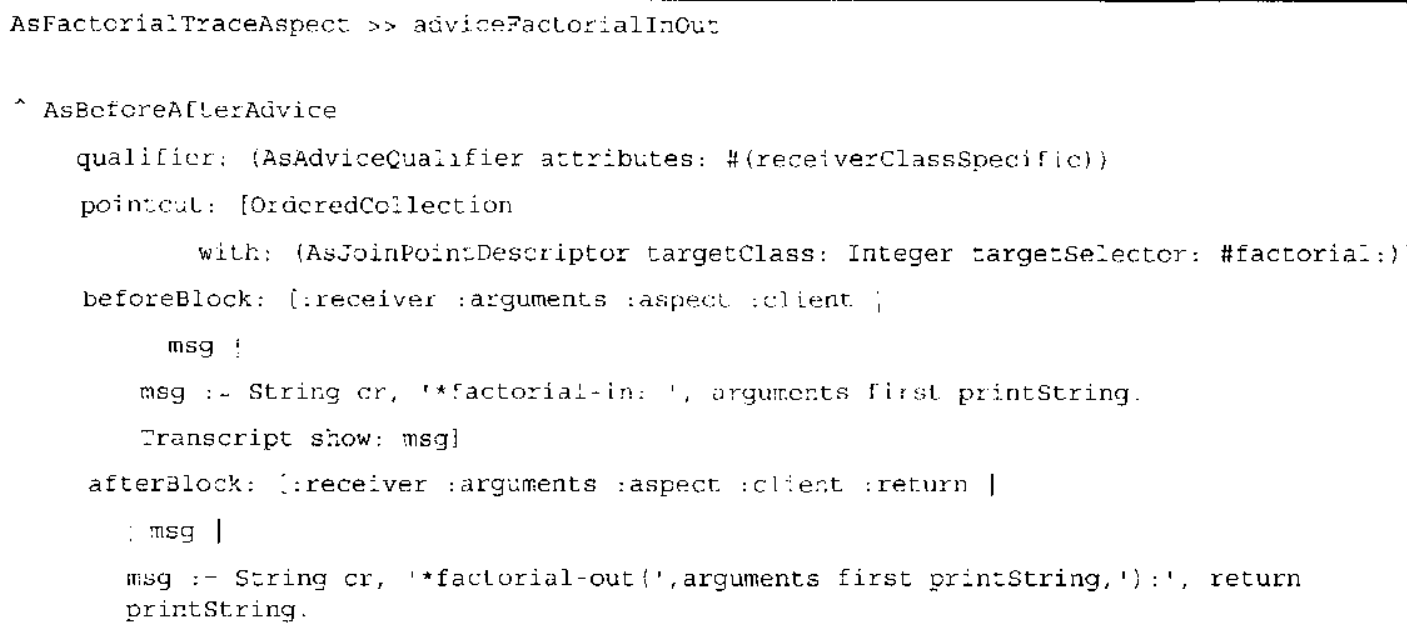

Figura 3.8: Código do método adviceFactorialInout

\begin{tabular}{||l||}
\hline factorial2-in: 5 \\
factorial2-in: 4 \\
factorial2-in: 3 \\
factorial2-in: 2 \\
factorial2-in: 1 \\
factorial2-in: 0 \\
factorial2-out $\{0\}: 1$ \\
factorial2-out $\{1\}: 1$ \\
factorial2-out $(2): 2$ \\
factorial2-out $\{3): \quad 6$ \\
factorial2-out $(4): 24$ \\
factorial2-out $(5): 120$ \\
\hline
\end{tabular}

Figura 3.9: Resultado do rastrcamento do método factorial()

\subsubsection{Apostle}

Apostle é uma extensão orientada a aspectos para a linguagem Smalltalk, atualmente disponível para o ambiente Visual Age, da IBM, para Smalltalk 4.5. Apostle possui duas facetas: um estilo declarativo, apropriado para o uso com o ambiente de navegação, e um protocolo de meta-objetos, adequado para a construção de programas dinâmicos (Alwis, 2002).

Dentre as especificações declarativas da linguagem, ressaltam-se: pontos de corte, sugestões c aspectos. Os pontos de corte são criados e avaliados no cscopo de uma classe ou aspecto e 
identificam um conjunto de pontos de junção. Eles são expressos em uma linguagem compacta, semelhante a consultas lógicas, e são formados pela composição de um pequeno conjunto de pontos primitivos de corte em consultas mais complexas, usando um conjunto de operadores padrões: intersecção ('\&'), união ('|') e complemento ('!').

Os pontos primitivos de corte fornecidos por Apostle são os seguintes: kindOf(type-signature), que identifica os pontos de junção cm que o tipo do objeto em execução é igual ao tipo especificado pela type-signature; receptions(selector), que identifica os pontos de junção de chamada de método (recepção de mensagem) indicado por selector; executions(selector), que identifica os pontos de junção nos quais o selector é exccutado; (flow(pointcut-expression), que identifica pontos de junção na execução do programa como resultado da execução ter passado por um ponto de junção identificado pela pointcut-expression; e nil, que é um ponto de corte autoexclusivo equivalente a pontos de corte nomeados e não conhecidos.

As sugestões são definidas sobre um aspecto e funcionam da mesma forma que em AspectJ, inclusive implementando os mesmos tipos. No tipo around, a execução do ponto ć continuada por meio do uso das palavras-chaves PROCEED ou PROCEEDUSING. A palavra-chave PROCEEDUSING é uma variante de PROCEED e tem a capacidade de alterar o contexto passado ao ponto de junção, conforme mostra a Figura 3.10.

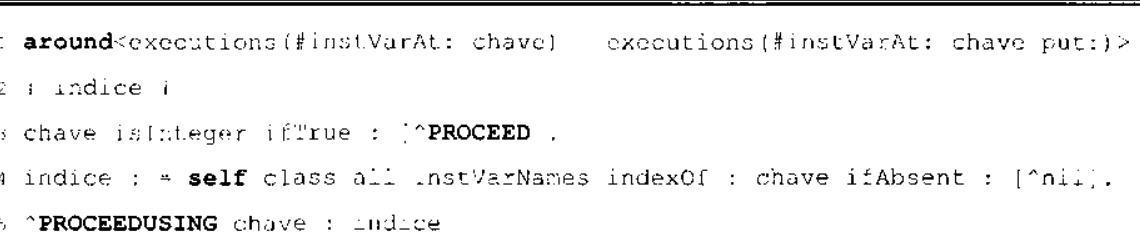

Figura 3.10: Sugestão Around em Apostle.

As variáveis de instância de um objeto podem ser capturadas pelo método \#instvarAt:; mas esse método captura o índice e não o nome da variável. O índice de uma variável pode mudar quando a forma do objeto é modificada, por exemplo, quando variáveis de instância são adicionadas ou removidas. Porćm, o nome de uma variável de instância é facilmente capturado e mapeado para o índice apropriado. De acordo com a Figura 3.10, \#instvarAt: e \#instvarAt: put: capturam o índice c o nome da variável respectivamente. A sugestão usa a captura de nome para seletivamente expor partes do contexto de execução no ponto de junção para a sugestão. A terceira linha de código testa se o argumento chave é um inteiro. Se o resultado for verdade é dada continuidade ao ponto de execução por meio do comando de retorno ^RROCEED. Caso contrário, o retorno será realizado na quinta linha de código por meio do comando de retorno ^PROCEEDUSING. Entretanto, nessa linha de código o valor do argumento \# chave é alterado para o valor da variável \#indice que é obtido na quarta linha de código.

Em Apostle, os aspectos são similares a classes. Entretanto, ao contrário de classes, instâncias de aspectos não podem ser criadas explicitamente, mas sim somente quando uma condição 
específica do aspecto é satisfeita. Apostle deline três tipos de aspectos: singleton, quando existe uma única instância desse aspecto no sistema, que perdura durante a existência do sistema; perobject, que são instanciados sobre qualquer transição de execução de qualquer objeto cujo tipo casa com o tipo especificado pela configuração do ponto de corte, essa instância do aspecto persiste durante o tempo de vida do objeto; e o aspecto per-cflow, os quais são similares aos aspectos per-objects, mas existem durante toda a duração do contexto (por exemplo, durante a execução de um método).

De acordo com Alwis (2002), a estratégia usada na implementação de Apostle foi códigofonte a código-fonte, na qual as sugestões c o código-fonte são unidos para produzir um código em Smalltalk puro, chamado de modelo alvo. O processo de juntar sugestões e código-fonte é realizado de forma incremental e denominado composição incremental. Na composição incremental qualquer alteração no programa é avaliada para detcrminar o seu impacto, resultando, se necessário, em correções de partes do modelo alvo.

\subsubsection{Linguagens de Propósito Específico}

As linguagens de propósito específico baseadas $\mathrm{cm}$ aspectos, ao contrário das linguagens de propósito geral, visam a tratar aspectos específicos de um domínio e só podem ser usadas em problemas do domínio. A seguir são apresentadas brevemente a descrição de $\mathrm{D}^{2} \mathrm{AL}$, uma linguagem de aspecto específica de domínio, que tcm o objetivo de minimizar o número de interações remotas por meio do controle da distribuição e replicação dos objetos, e da linguagem TyRuBa, usada para implementar o aspecto de sincronização.

\subsubsection{1 $\quad D^{2} \mathrm{AL}$}

$\mathrm{D}^{2} \mathrm{AL}$ (Design-Based Distribution Aspect Language) é uma linguagem de domínio específica proposta por Becker (1998). Fla foi desenvolvida para a especificação de distribuição através de uma linguagem de aspectos, permitindo ao desenvolvedor separar o que diz respeito à distribuição do que faz parte da funcionalidade básica do sistema. O foco principal de $\mathrm{D}^{2} \mathrm{AL}$ é minimizar o número de interações remotas por meio do controle da distribuição $c$ replicação dos objetos em interação. A diferença fundamental entre $D^{2} \mathrm{AL}$ c outras linguagens de aspectos é que as construções da linguagem referem-se ao projeto e não à implementação das funcionalidades do sistema.

O conceito de projeto usado como base para a especificação dos requisitos de distribuição foi o de colaboração entre os objctos. Para ilustrar como a colaboração é especificada c usada em $D^{2} \mathrm{AL}$, considere-se o diagrama de classes para um sistema simples de e-mail, ilustrado pela Figura 3.11 .

Como mostrado na Figura 3.11, neste exemplo de projeto, o objeto Emai 1 foi separado do objeto ConteudoEmail, facilitando o envio de diferentes tipos de conteúdo usando apenas 


\begin{tabular}{|c|c|c|c|c|}
\hline ContaEmail & \multirow{3}{*}{ destinatảio } & EMail & conteüdo & \multirow[t]{3}{*}{ ConteúdoEmail } \\
\hline & & assunto: & & \\
\hline & & $\begin{array}{l}\text { enviar() } \\
\ldots\end{array}$ & & \\
\hline
\end{tabular}

Figura 3.11: Diagrama de classes do sistema de email.

subclasses específicas de ConteudoEmail. Enquanto essa separação é compreensível sob o ponto de vista do projeto, faz pouco sentido tratar um Email e seu conteúdo como entidades de distribuição separadas. Em $D^{2} \mathrm{AL}$, a expressão a seguir pode ser usada para obter a colaboração dos objetos EMail e ConteudoEmail.

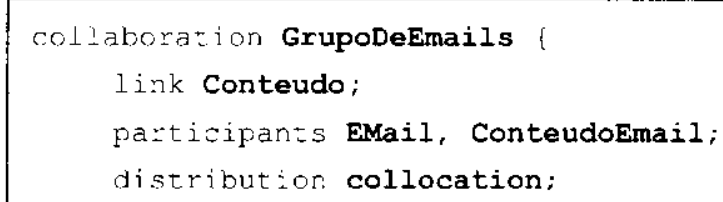

Figura 3.12: Expressão em $D^{2} \mathrm{AL}$ (colaboração entre os objetos EMail e ConteudoEMail).

A expressão apresentada na Figura 3.12 declara que os participantes da colaboração estão relacionados pela associação Contcudo, e que os objetos têm os tipos EMai l e ConteudoEMail, respectivamente. Por fim, os objetos devem ser instalados no mesmo processador (Becker, 1998).

$O$ processo de combinação de aspectos em $D^{2} A L$ funciona como um pré-processador que transforma o código Java de distribuição e a especificação $D^{2} \mathrm{AL}$ em código Java. Um problema enfrentado nesse processo é o fato de alguns elementos de projeto (por exemplo, associações e estados abstratos) não terem um mapeamento direto para a implementação. Dessa forma, além do código Java c das especificações $\mathrm{D}^{2} \mathrm{AL}$, o combinador necessita de uma representação do projeto e de um mapeamento que cspecifique como esses elementos de projeto devem ser implementados. A Figura 3.13 representa a arquitetura do combinador implementado por $\mathrm{D}^{2} \mathrm{AL}$ (Becker, 1998).

\subsubsection{TyRuBa}

TyRuBa (Tyruba, 2004), acrônimo de Type Rule Base, é uma linguagem de meta programação lógica que gera código Java a partir de descrições lógicas da estrutura do programa. Ela foi implementada como um sistema experimental, parte do trabalho de doutorado de Volder (1998), para explorar o assunto de meta-programação lógica orientada a tipos para a geração de código (Volder, 1998; Volder \& D'Hondt, 1999). 


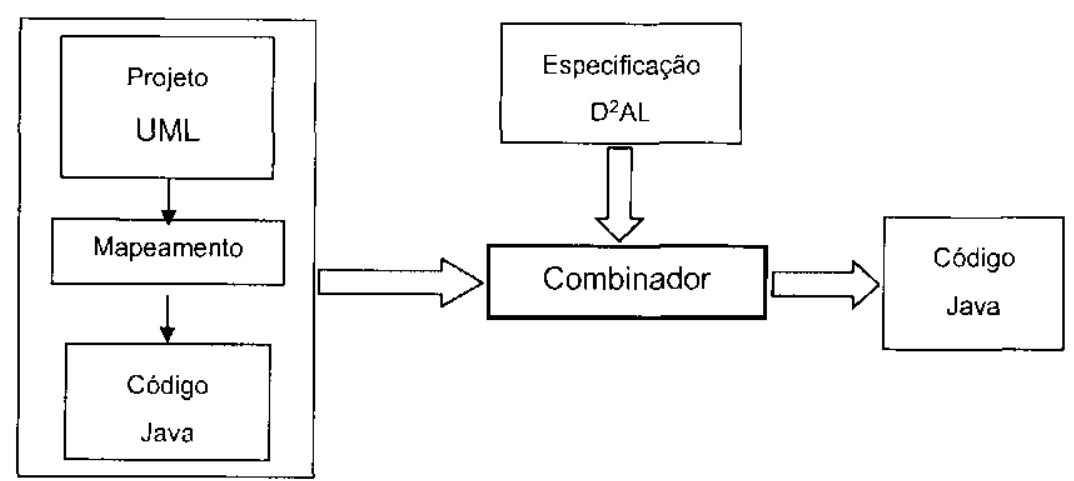

Figura 3.13: Arquitetura do combinador do $\mathrm{D}^{2} \mathrm{AL}$.

As linguagens de tipos e as linguagens de aspectos têm muito em comum, elas são formalismos declarativos de propósito especial para expressar anotações de programas. A declaração de aspectos em TyRuBa constitui-se meramente de cláusulas num programa lógico que podem ser acessadas e definidas dirctamente por regras lógicas, o que é chamado de meta-programação lógica orientada a aspectos.

Para ilustrar o potencial da técnica de meta-programação lógica orientada a aspectos, a linguagem TyRuBa foi usada para implementar o interesse não funcional de sincronização. Na Figura 3.14 é apresentada a implementação de um tipo abstrato de dados pilha por meio da classe stack, ilustrando o problema de entrelaçamento do código referente ao interesse não funcional de sincronização, numa implementação na linguagem Java. A Figura 3.14(a) ilustra uma versão do código sem a implementação do código de sincronização e a Figura 3.14(b) ilustra a implementação do código de sincronização, cm negrito, para o método peek.

Na Figura 3.15 é apresentado o código, em linguagem TyRuBa, correspondente ao tratamento do problema de entrelaçamento do código de sincronização mostrado na Figura 3.14.

A cláusula xxxExclusive declara quais métodos podem ser executados concorrentemente. Assim, a cláusula selfExclusivelist (?c, ?metodos) indica que nenhum dos métodos da lista ?métodos, pertencentes à classe ?c, pode executar concorrentemente com elc próprio. A cláusula mutuallyExclusiveList (?c, ?metodos) indica que nenhum dos métodos da lista ?métodos, pertencentes à classe ?c, pode executar concorrentemente com qualquer outro método da mesma lista. A cláusula requires (?c, ?m, ?condição) significa que o método ?m da classe ?c não será executado a menos que a condição ?condição seja verdadeira.

\subsection{Outras Abordagens Relacionada à POA}

Além das linguagens apresentadas na seção 3.3 , outros trabalhos relacionados a POA têm sido propostos na literatura, tais como: 
class stack

stat $-\mathrm{C}$ final int $\mathrm{M} X \mathrm{X}=10$;

int pos $=\mathrm{C}$;

object I) contents=new coject [MAXI:

public voici print () 1

sysuetrout, print (" ["):

for (int i. 0; i<ros; $i+4$ )

syst.em,out print (contents[i]+" ");

I

System.cut.print.("]";

public object peek o

return contentslpos];

public object pop ()

return contentel-pos!;

pualic void push lobject e)

contents 1 pos $++1=0$;

public noolear emsty ()

return pos $=0 ; 1$

public boolear fuld ()

return poss -- MAX ;

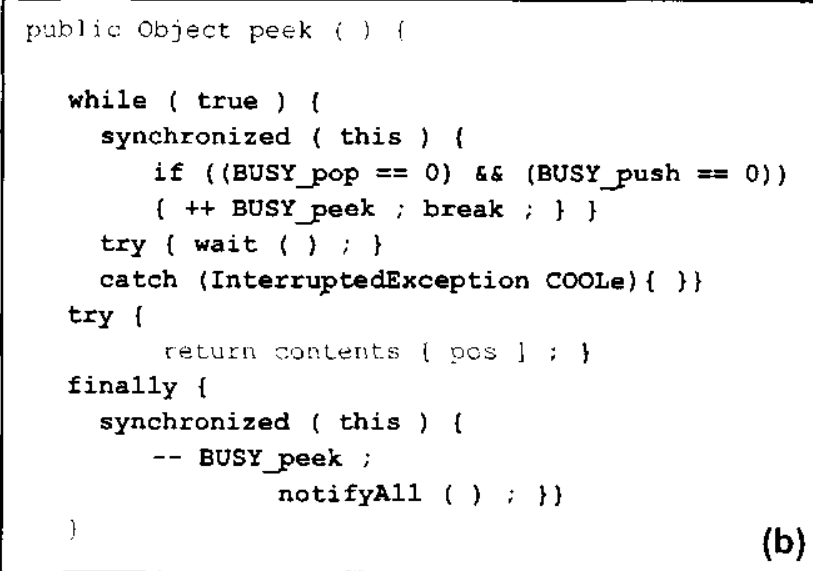

(a)

Figura 3.14: Ilustração do entrelaçamento de código para o aspecto de sincronização.

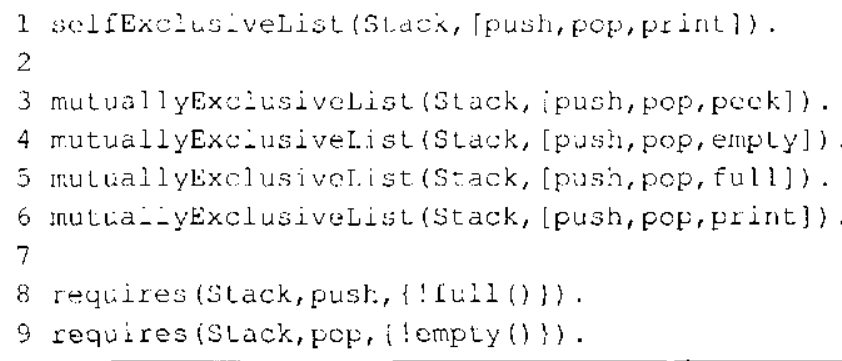

Figura 3.15: Código em linguagem TyRuBa.

- D é mais um exemplo de linguagens de aspectos de propósito específico que fornece abstrações para a implementação do aspecto de sincronização e transferência remota de dados em sistemas distribuídos (Lopes, 1997). Para isso, ela se apóia em duas outras linguagens para a descrição destes aspectos: COOL e RIDL, as quais podem ser integradas a linguagens orientadas a objeto com poucas ou nenhuma alteração na linguagem escolhida;

- AspectC++, que é uma extensão orientada a aspectos para a linguagem $\mathrm{C}++$ (AOSD, 2004); 
- Aspect.pm que é uma biblioteca Perl para programação orientada a aspectos (AOSD, 2004);

As especificações destas e de várias outras linguagens e ferramentas para apoiar a programação orientada a aspectos encontram-se disponíveis em AOSD (2004). Existem, além da programação orientada a aspectos, diversas abordagens que se concentram em encapsular propriedades que são ortogonais às unidades funcionais do sistcma, tais como filtros de composição e programação orientada a assunto.

Filtros de composição é uma técnica de programação orientada a aspectos em que diferentes aspectos são expressos em filtros, de maneira declarativa, juntamente com especificações para a transformação de mensagens. Esta abordagem permite ao desenvolvedor expressar aspectos de uma forma geral por meio do uso de filtros c possibilita sua composição sem a necessidade da construção de geradores específicos. Os filtros de composição podem ser anexados a objetos de diferentes linguagens orientadas a objeto (Filters, 2004; Aksit \& Tekinerdogan, 1998; Elrad ct al., 2001a).

A programação orientada a assunto tem o enfoque baseado em dois pontos principais: i) facilitar a identificação e descrição de conceitos ortogonais (crosscutting concerns) em sistemas de software; ii) facilitar a identificação e integração dos pontos de combinação de um sistema. Os pontos de combinação são as localizações em um sistema que são afetadas por mais de um conceito ao mesmo tempo. O processo de integração descreve como um conceito ortogonal afeta o código em um ou mais pontos de combinação (Harrison \& Ossher, 1993).

\subsection{Projeto de Software Orientado a Aspectos}

Poucos métodos têm sido propostos para expressar aspectos na fase de projeto. Segundo Suzuki \& Yamamoto (1999), o apoio ao projeto orientado a aspectos organiza o processo de desenvolvimento de software orientado a aspectos e proporciona benefícios como, por exemplo, permitir a identificação de aspectos num nível superior de abstração nos primeiros estágios do processo de desenvolvimento e favorccer a aprendizagem e a documentação do modelo de aspectos de uma maneira mais intuitiva. Além disso, a documentação e o conhecimento adquirido facilitam o reuso de aspectos.

Os termos aspecto, interceptação, pontos de junção e composição representam, em conjunto, a essência do paradigma de programação orientada a aspectos. Sendo assim, devem ser considerados como conceitos fundamentais, que também devem ser examinados em outras fases do processo de desenvolvimento de software. Entretanto, as abordagens orientadas a aspectos existentes enfatizam o uso de linguagens e ferramentas específicas para concretizar esses conceitos no nível de implementação. No nível de projeto, a definição de um modelo de aspectos de nível mais alto e que seja independente de linguagem, bem como a definição de técnicas de modelagem baseadas em aspectos, são áreas ainda pouco exploradas. 
Considcrando esse contexto, Chavez \& Lucena (2001) propõem a definição de um modelo de projeto para o desenvolvimento de software orientado a aspectos que incorpora as principais características da POA e que é independente de linguagem de programação. Esse modelo de projeto é definido como uma extensão do modelo de objetos e tem por objetivo diminuir a distância entre projeto e a implementação em situações em que linguagens orientadas a aspectos são utilizadas (Chavez \& Lucena, 2001). O modelo é representado usando UML e compreende três facetas:

- Faceta estrutural - ć focada na modelagem da estrutura dos aspectos e das classes do sistema; na maneira como eles estão relacionados, a qual proporciona a interceptação e no mecanismo de composição convencional. A faceta estrutural do modelo é representada pela Figura 3.16. A parte compreendida pelo quadrado pontilhado representa a estrutura do aspecto. Um aspecto é representado por meio de um losango e possui um conjunto de interfaces que interceptam várias classes em um sistema. A Figura 3.16, possui uma tabela que descreve cada elemento do modelo de aspecto apresentado.

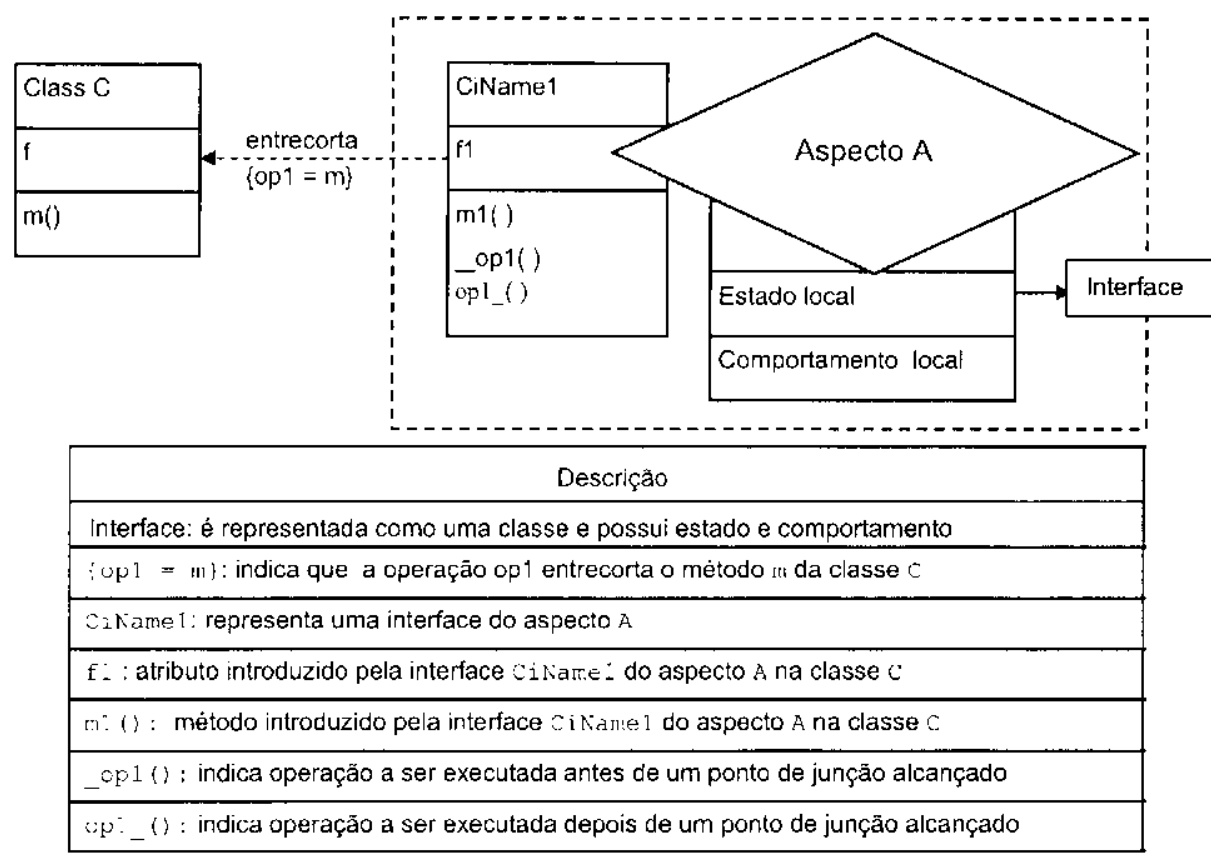

Figura 3.16: Faceta estrutural do modelo de Aspectos de Chavez \& Lucena (2001).

- Faceta dinâmica - é voltada para modelagem das interações entre as instâncias dos aspectos e as instâncias de componentes que eles interceptam.

- Faceta de composição - é direcionada para a modelagem da combinação de aspectos e componentes e tem por objetivo facilitar a compreensão dos efeitos dessa combinação. 
Pawlak ct al. (2002) também propuseram uma notação para o projeto de software orientado a aspectos que é uma extensão do padrão $\mathrm{UML}^{5}$ e teve como base a linguagem AspectJ e trabalhos desenvolvidos por estes autores relacionados a componentes de aspectos. A notação proposta por estes autores define três conceitos adicionais à UML. O primeiro é o conceito de grupos (groups) que permite classificar entidades heterogêneas c distribuídas. O segundo é o conceito de classes de aspecto (aspect-classes) que representa o interesse em questão. As classes de aspecto são apresentadas como classes normais (contendo atributos e métodos) exceto pelo fato de possuírem métodos especiais denominados de métodos do aspecto (aspect-methods) $\mathrm{c}$ que tem por objetivo representar o conceito de sugestões da POA. Esta notação fornece ainda ao projetista alguns estereótipos, apresentados na Tabcla 3.3, que possibilitam a definição de alguns tipos de métodos de aspecto.

Tabela 3.3: Estereótipos para definição de alguns tipos de métodos de aspectos (Pawlak et al.,

\begin{tabular}{|l|l|}
\hline Estereótipo & Descrição \\
\hline \hline «before»m(args) & O método $\mathrm{m}$ () é executado antes de um dado ponto do programa. \\
\hline «after»m(args) & O método $\mathrm{m}$ () é executado após um dado ponto do programa. \\
\hline «around»m(args) & $\begin{array}{l}\text { Uma parte do método } \mathrm{m} \text { ( ) é executada antes e outra parte após um dado ponto } \\
\text { no programa. }\end{array}$ \\
\hline «replace»m(args) & O método $\mathrm{m}$ () modifica um dado ponto da implementação do programa. \\
\hline «role»m(args) & $\begin{array}{l}\text { O método } \mathrm{m} \text { () pode ser invocado por objetos da classe que é afetada pela classe } \\
\text { de aspecto a qual } \mathrm{m} \text { () pertence, além disso, a implementação de } \mathrm{m} \text { () acessa os } \\
\text { atributos da classe afetada e também os atributos da classe de aspecto. }\end{array}$ \\
\hline
\end{tabular}

O terceiro e ultimo conceito, introduzido pela notação de Pawlak et al. (2002), é o de relações do ponto de corte (pointcut relations) que expressa uma associação entre uma classe de aspecto e uma classe base do sistema.

Na Figura 3.17 é ilustrada a notação proposta por Pawlak et al. (2002).

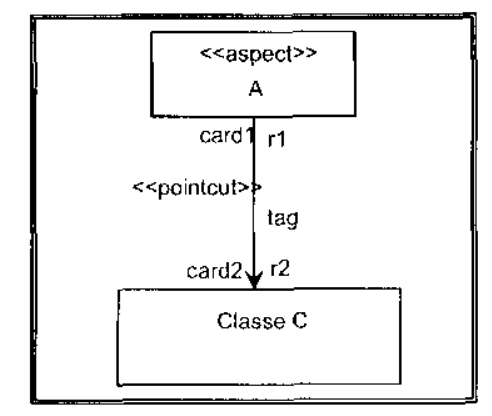

Figura 3.17: Notação para projeto de software orientado a aspectos (Pawlak et al., 2002).

\footnotetext{
${ }^{5}$ A linguagem de modelagem UML (Unified Modelling Language) é a consolidação de outras notações de modelagem: Booch, OMT e OOSE. Ela possui alguns mecanismos de extensão que permitem definir notações específicas de um determinado domínio, ferramenta ou projeto (L:ML, 2004)
} 
Conforme apresentado na Figura 3.17, o estercótipo «aspect» é utilizado para representar um aspecto. O estereótipo «pointcut» denota uma relação unidirecional do aspecto para a classe $C$, indicando que esse aspecto interccpta algum ponto dessa classe. O papel " $r 1$ " é o nome de um método do aspecto definido no aspecto A que afeta algum ponto dos componentes. O papel "r2" é definido como um conjunto de pontos de junção no formato T [expressão], onde $\mathrm{T}$ pertence ao conjunto descrito na Tabela 3.4 e expressão ć uma cxpressão opcional, que especifica o conjunto $\mathrm{T}$ de pontos e contém as palavras chaves definidas na Tabela 3.5 . As cardinalidades "card1" e "card2" indicam o número de instâncias, tanto dos aspectos quanto das classes e o "tag" é uma etiqueta valorada para estender a semântica do relacionamento.

Tabela 3.4: Elementos notacionais para pontos de junção (Pawlak et al., 2002).

\begin{tabular}{|l|l|l|}
\hline Elemento & Exemplo & Descrição \\
\hline \hline$!$ & $!$ (Class.Name.m()) & $\begin{array}{l}\text { Denota a invocação de um método chamando } \mathrm{m}() \mathrm{da} \\
\text { classe ClassName. }\end{array}$ \\
\hline$?$ & $?($ ClassName.m()) & $\begin{array}{l}\text { Denota a execução de um método chamando mo () da classe } \\
\text { ClassName. }\end{array}$ \\
\hline$<\mathrm{N}>$ & $<\mathrm{N}>$ (ClassNane) & $\begin{array}{l}\text { Denota a criação de todas as instâncias da classe } \\
\text { ClassName. }\end{array}$ \\
\hline$<\mathrm{U}>$ & $<\mathrm{U}>$ (ClassName) & $\begin{array}{l}\text { Denota todos os pontos do programa onde uma instância } \\
\text { dal classe ClassName é usada pela primeira vez. }\end{array}$ \\
\hline$<\mathrm{C}>$ & $<\mathrm{C}>$ (ClassName) & $\begin{array}{l}\text { Denota todos os pontos do programa em que alguma ins- } \\
\text { tância da classe ClassName é clonada. }\end{array}$ \\
\hline$<\mathrm{R}>$ & $<\mathrm{R}>$ (ClassName) & $\begin{array}{l}\text { Denota os pontos do programa em que uma instância da } \\
\text { classe ClassName foi remotamente criada. }\end{array}$ \\
\hline$<\mathrm{E}>$ & $<\mathrm{E}>$ (ClassNameException) & $\begin{array}{l}\text { Denota todos os pontos do programa em que a exccução } \\
\text { ClassNameException foi lançada. }\end{array}$ \\
\hline
\end{tabular}

Tabela 3.5: Palavras chaves permitidas com os pontos ! e ? (Pawlak et al., 2002).

\begin{tabular}{|l|l|}
\hline Palavra Chave & Pontos Identificados \\
\hline \hline ALI & Todos os métodos de C \\
\hline CONSTRUCTORS & Todos os Construtores de C \\
\hline SETTERS & todos os métodos "set" de C \\
\hline GETTERS & todos os métodos "get" de C \\
\hline SETTERS(attrname) & O método "set" de um dado atributo \\
\hline GETTERS(attrname) & O método "get" de um dado atributo \\
\hline ACCESSORS & Todos os métodos de C que lê alyumas instâncias \\
\hline ACCESSORS(\{attrnames\}) & $\begin{array}{l}\text { Todos os métodos de C que lêem os atributos contidos na lista } \\
\text { \{attrnames\} }\end{array}$ \\
\hline MODIFIERS & Todos os métodos de C que modificam o estado de instâncias \\
\hline MODIFIERS(\{attrnames\}) & $\begin{array}{l}\text { Todos os métodos de C que modificam os atributos contidos na lista } \\
\text { \{attrnames }\end{array}$ \\
\hline
\end{tabular}

Assim como Pawlak et al. (2002), Stein et al. (2002) também propuseram uma extensão da UML para a modelagem de programas orientados a aspectos implementados em AspectJ. O modelo de projeto proposto por Stein et al. (2002) é denominado AODM (Aspect Oriented 
Design Model) e, além de estender a linguagem de modelagem UML com conceitos clássicos da programação orientada a aspectos, também reproduz o mecanismo de composição (weaving).

No modelo de Stein et al. (2002) os aspectos são representados como classes UML com estereótipo «aspect» e podem participar em rclacionamentos de associação, generalização e dependência. Elas contêm elementos de interceptação que podem alterar a cstrutura de outras classes do modelo. A estrutura é alterada por meio de gabaritos de colaboração (collaboration templates ${ }^{6}$ ), que possuem o estereótipo «introduction» e o comportamento por meio de operações com estercótipo «advice». Os aspectos possuem, ainda, ctiquetas valoradas que especificam como scrá a sua instanciação. O AODM também possui estercótipos que permitem interceptar invocações dentro de uma mesma entidade, tais como: construtores, tratamento de exceções, inicializadores de classes e objetos e acesso a campos. Após a obtenção de um modelo de projeto oricntado a aspectos pode-se transformá-lo em um outro modelo UML normal. Para isso, o AODM implementa um mecanismo de composição que descreve como as colaborações e o comportamento dos relacionamentos de interceptação podem ser combinados. Para relacionamentos de interceptação estruturais, a composição é realizada instanciando os gabaritos de colaboração e isso não pode ser feito utilizando conceitos padrão UML, porém, pode ser representado em um nível mais abstrato usando casos de uso. Por outro lado, a composição de relacionamentos de interceptação comportamentais pode ser feita utilizando conceitos da UML padrão, pois é realizada dividindo e compondo as colaborações.

Na Figura 3.18 é apresentada apenas a representação gráfica de um aspecto com o estereótipo «aspect» denominado Timing. Nota-se que os autores definiram estereótipos tanto para pontos de corte («pointcuts») quanto para sugestões («ađivice»). Além disso, eles também utilizam os "templates de colaboração" que são representados pelas elipses tracejadas na parte inferior do aspecto. Esses templates são utilizados com o estereótipo «introduction».

Ainda se tratando de extensões da UML, Camargo \& Masiero (2004b) propõem um perfil UML para o projeto de sistemas orientados a aspectos que serão implementados em Aspect $J^{7}$, denominado UML-AOP. Este perfil UML utiliza partes de outras notações propostas por outros autores e foi bastante influenciado pela proposta de Pawlak et al. (2002) que foi citada anteriormente nesta mesma seção. Além disso, ele também adiciona novas extensões e elementos notacionais à $\mathrm{UML}$

Os novos estereótipos criados por Camargo \& Masiero (2004b), bem como suas classes basc, podem ser visualizados na Tabela 3.6.

O estercótipo «aspect» é usado para representar o conccito de aspecto. Um aspecto representa uma abstração de um interesse não funcional e pode participar de relacionamentos de associação, dependência e generalização tanto com classes, quanto com outros aspectos. Aspectos abstratos devem ser representados em itálico. O estereótipo «pointcut» é usado para

\footnotetext{
${ }^{6}$ Un template é um elemento do modelo usado para criar outros elementos do modelo através de passagem de parâmetros
}

${ }^{7}$ A proposta de Camargo \& Masiero (2004b) foi adotada durante o desenvolvimento deste trabalho de mestrado. 


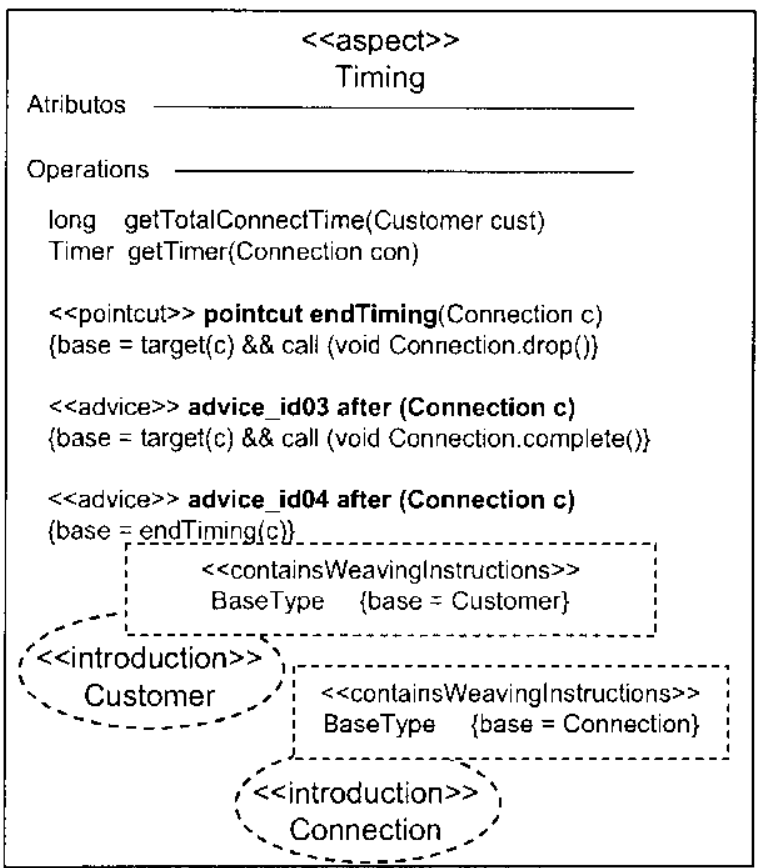

Figura 3.18: Notação de aspecto em AODM (Stein et al., 2002).

Tabela 3.6: Estereótipos para AOSD (Camargo \& Masiero, 2004b).

\begin{tabular}{|l|l|}
\hline Estereótipo & Classe base \\
\hline \hline aspect & Class \\
\hline \hline introduction & Association \\
\hline includes_extends & Association \\
\hline includes_implements & Association \\
\hline crosscutting & Association \\
\hline \hline pointcut & Operation \\
\hline before & Operation \\
\hline after & Operation \\
\hline after_returning & Operation \\
\hline after_throwing & Operation \\
\hline around & Operation \\
\hline
\end{tabular}

representar o conceito de ponto de corte e só pode ser definido para pontos de corte (pointcuts) definidos no aspecto correspondente, sendo opcional quando houver uma sugestão que atua sobre ele. Da mesma forma que o estereótipo «aspect», o estereótipo «pointcut» também deve ser representado em itálico quando for abstrato.

Na Figura 3.19 é ilustrada a representação gráfica dos estereótipos «aspect» e «pointcut» e, além disso, também é ilustrado um relacionamento de generalizaçāo entre dois aspectos.

De acordo com a Figura 3.19, o aspecto AspectoA é abstrato, pois possui um ponto de corte abstrato chamado pt1(). Um ponto de corte é dito abstrato quando não é definido nenhum ponto de junção para ele, a responsabilidade de definir os pontos de junção é delegada aos 


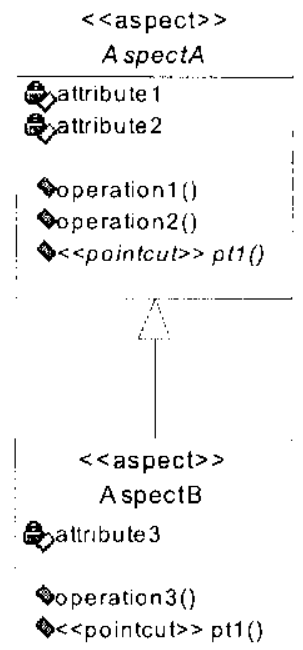

Figura 3.19: Representação gráfica dos estercótipos «aspect» e «pointcut» (Camargo \& Masiero, 2004b)

aspectos concretos que especializam o aspecto abstrato. Neste caso, conforme mostrado na Figura 3.19, o aspecto AspectoB, que é concreto, deve definir algum ponto de junção para o ponto de corte pt1) que ele herdou do aspecto AspectA.

O estereótipo «crosscut ting» é usado para representar um relacionamento de associação que ocorre quando um aspecto intercepta uma funcionalidade dc alguma classe em um determinado ponto de junção. A associação só é permitida entre aspectos e entre aspectos e classes. Além disso, deve ser unidirecional, partindo do aspecto em direção à entidade que ele afeta. A semântica deste estercótipo é completada por duas etiquetas valoradas, \{PCDescriptor\} e \{joinpoint\}. A representação gráfica do estereótipo «crosscutting» e suas etiquetas, \{PCDescriptor\} e \{joinPoint\}, é ilustrada na Figura 3,20.
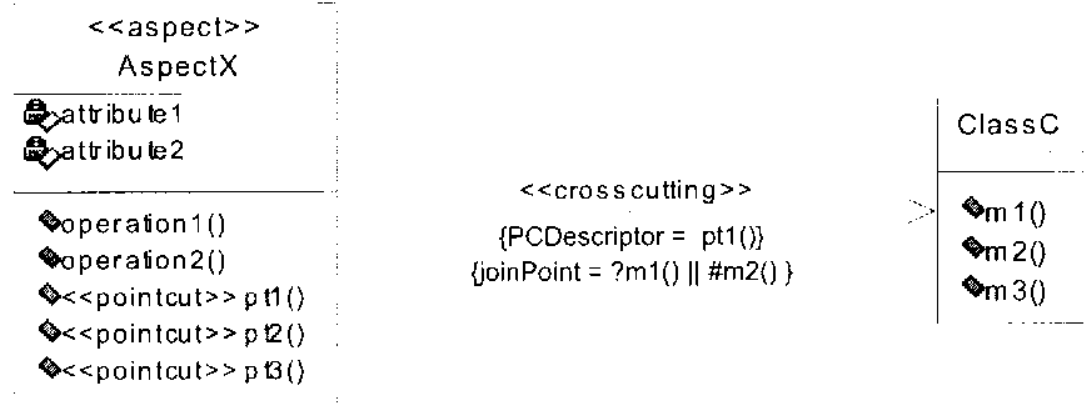

Figura 3.20: Representação) grálica do estercótipo «crosscutting» (Camargo \& Masiero, 2004b) .

Conforme a Figura 3.20, existe um relacionamento de interceptação entre o aspecto AspectX e a classe classC. A etiqueta valorada \{PCDescriptor $=$ pt 1()$\}$ mostra que a interceptação é definida pelo ponto de corte pt1(), definido na classe aspecto AspectX e a etiqueta 
valorada $\{$ joinPoint $=? m 1()||$ \#m2 () $\}$ mostra os pontos onde a classe classC será afetada, que são a execução do método m1 () e a invocação do método m2 (). A sintaxe para elaboração dos pontos de junção tem como base o trabalho de Pawlak ct al. (2002) e faz uso dos elementos notacionais apresentados na Tabela 3.4. Entretanto, a proposta de Camargo \& Masiero (2004b) substitui o sinal de exclamação, usado na notação de Pawlak et al. (2002) para denotar a chamada de métodos, pelo sinal (\#) porque a linguagem Java já faz uso do sinal de exclamação para representar negação.

Os estereótipos «before», «after», «after_returning», «after_throwing»e «around» são usados para representar cada um dos tipos de sugestões implementados por AspectJ. Esses tipos de estereótipos só podem ser usados para operações do tipo «pointcut» e quando o ponto de corte relacionado for anônimo, deve-se representar esta operação com o nome anonymous. A Figura 3.21 mostra um diagrama de classes em que o aspecto AspectX possui três pontos de corte chamados pt1(), pt2() e pt3(). Quando há uma sugestão que atua em um determinado ponto de corte não há necessidade de representar a existência desse ponto de corte por meio do estereótipo «pointcut», pois por meio da representação das sugestões pode-se identificar a existência dos pontos de corte.

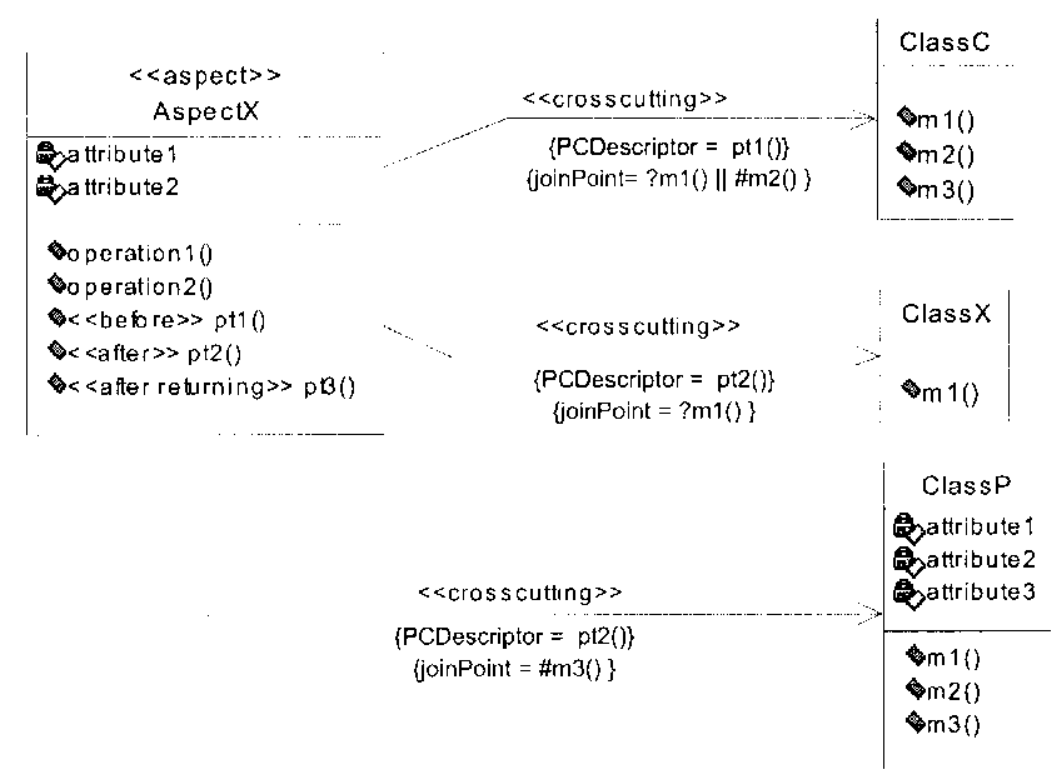

Figura 3.21: Representação gráfica para as sugestões (Camargo \& Masiero, 2004b) .

Conforme é mostrado na Figura 3.21, pode-se notar que um determinado ponto de corte pode afetar mais de uma classe. O ponto de cortc pt2(), por exemplo, afeta tanto a classe ClassX quanto a classe Classp. Dessa forma, a partir do modelo de projeto, o desenvolvedor pode identificar quais pontos de junção compōem um determinado ponto de corte.

O estereótipo «introduction» ć usado para inserir um novo tipo de relacionamento entre aspectos e classes. A Figura 3.22 mostra a representação gráfica destc cstcreótipo. As etiquetas 
\{attribute\} e \{method\} representam, respectivamente, o nome dos atributos e/ou métodos a serem introduzidos na classe apontada no relacionamento de associação. Dessa forma, 0 aspecto Aspectx insere um atributo chamado attribute1 do tipo int, e um método chamado newMethod(string) na classe ClassC.

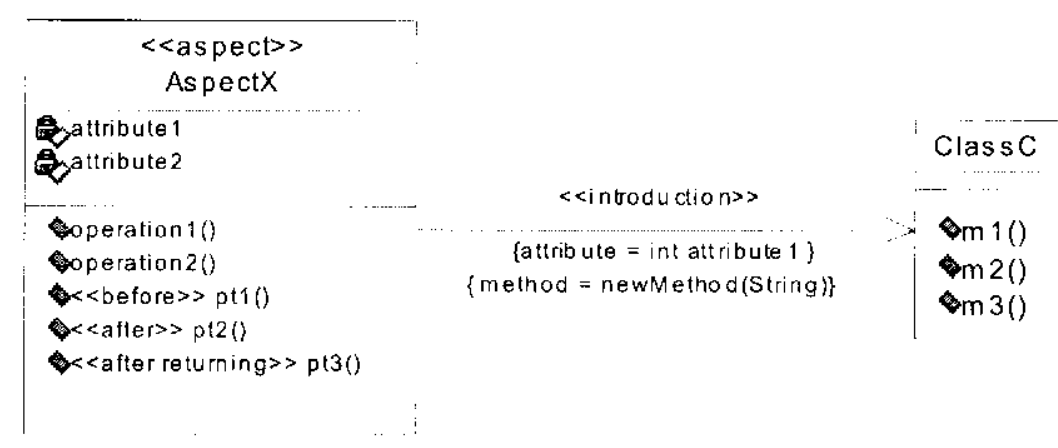

Figura 3.22: Representação gráfica do estereótipo «introduction» (Camargo \& Masicro, $2004 b)$.

Os estereótipos «includes_implements»e «includes_extends»são utilizados para representar relacionamentos entre aspectos ou entre aspectos e classes. Eles expressam que a classe apontada terá um novo relacionamento após o processo de composição. Se o primciro estereótipo for utilizado, o relacionamento implements entre a classe apontada e uma determinada interface será criado. O nome da interface será fornecido pela etiqueta \{interface . Se o segundo estereótipo for utilizado, um relacionamento de herança será criado entre a classe apontada e uma outra. O nome da classe pai será fornecido pela etiqueta (parent). A Figura 3.23 mostra a representação gráfica desses estereótipos.

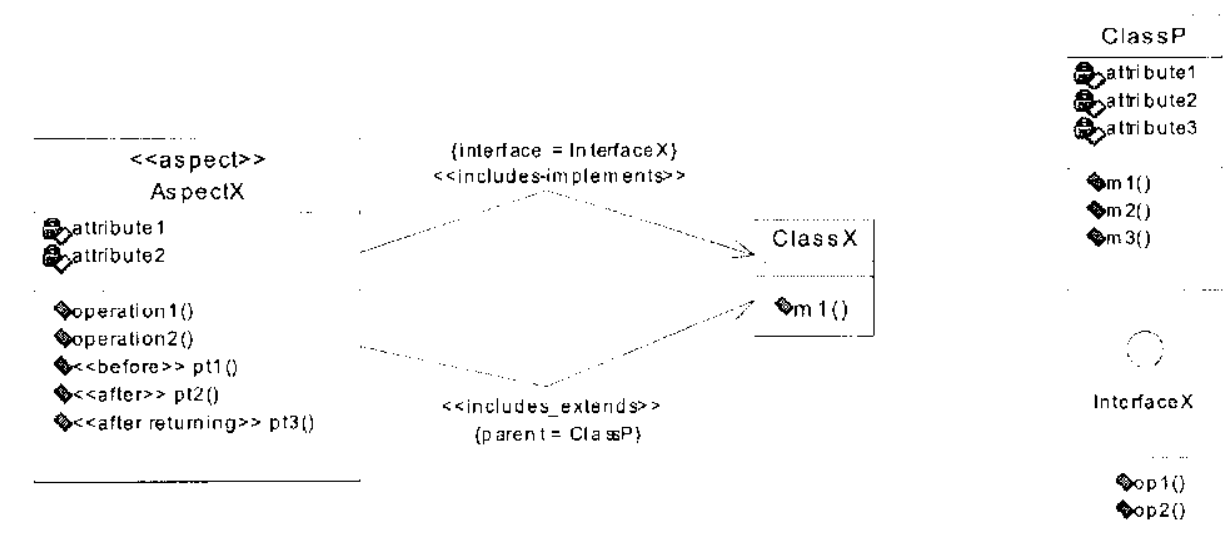

Figura 3.23: Representação gráfica dos estereótipos «includes_implements»e «includes_extends» (Camargo \& Masiero, 2004b).

Conforme a Figura 3.23, as etiquetas $\{$ interface $=$ InterfaceX $\}$ e \{parent $=$ ClassP \} definem, respectivamente, o nome da interface e da classe com as quais a classe 
ClassX deve se relacionar. Assim, após o processo de composição a classe ClassX terá um relacionamento de herança (extends) com a classe Classp e também um relacionamento de implementação (implements) com a interface interfacex.

Ainda sc tratando de projeto orientado a aspectos, (Camargo \& Masiero, 2004a) também propõem um outro perfil denominado UML-AOF, que foi criado para modelagem de framewoks orientados a aspectos $\mathrm{c}$ surgiu da necessidade de modelar mais precisamente a semântica dos conceitos existentes nesse tipo de framework. Esse perfil adota tanto os conccitos/elementos definidos na UML-F (Fontoura et al., 2002), que é um perfil criado para a modelagem de frameworks orientados a objetos, quanto os que foram definidos na UML-AOP, citada nesta mesma seção, e adiciona alguns novos que são específicos de frameworks orientados a aspectos.

Na Tabela 3.7 são apresentados alguns dos estereótipos criados por Camargo, mostrando as restrições e a semântica de cada estereótipo. Esses estcreótipos descrevem as características básicas de projeto de frameworks orientados a aspectos. Eles fornecem uma visão da estrutura do framework, representado quais unidades modulares são do framework e quais são da aplicação. além de informar também quais são os pontos de instanciação ${ }^{8}$ do framework.

Tabela 3.7: Estereótipos básicos de projeto de frameworks orientados a aspectos (Camargo \&

\begin{tabular}{|c|c|c|}
\hline Estereótipo & Restriçōes & Semântica \\
\hline $\begin{array}{l}\text { 《aspect-application》 ou } \\
\text { «aspect-app» }\end{array}$ & $\begin{array}{l}\text { Aplicado apenas at clementos do tipo } \\
\text { Classe. Classes da aplicação abstratas } \\
\text { devem ter seu nome representado em } \\
\text { itálico (essa restrição se aplica a qual- } \\
\text { quer outro elemento). }\end{array}$ & $\begin{array}{l}\text { Denota que o elemento rotulado é um } \\
\text { aspecto e pertence à aplicação. }\end{array}$ \\
\hline $\begin{array}{l}\ll \text { aspect-framework» ou } \\
\ll \text { aspect-f» }\end{array}$ & $\begin{array}{l}\text { Aplicado apenas a elementos do tipo } \\
\text { Classe. }\end{array}$ & $\begin{array}{l}\text { Denota que o elemento rotulado é um } \\
\text { aspecto pertencente ao framework. }\end{array}$ \\
\hline $\begin{array}{l}\text { «class-application》 ou } \\
\text { «class-app》 }\end{array}$ & $\begin{array}{l}\text { Aplicado apenas a elementos do tipo } \\
\text { Classe. }\end{array}$ & $\begin{array}{l}\text { Denota que o elemento rotulado é uma } \\
\text { classc pertencente à aplicação. }\end{array}$ \\
\hline $\begin{array}{l}\text { «class-framework } \gg \text { ou } \\
\text { «class-f》 }\end{array}$ & $\begin{array}{l}\text { Aplicado apenas a clementos do tipo } \\
\text { Classe. }\end{array}$ & $\begin{array}{l}\text { Denota que o elemcnto rotulado ć uma } \\
\text { classe pertencente ao framework. }\end{array}$ \\
\hline «pointcut-hook» & $\begin{array}{l}\text { Aplicado somente a operaçóes de cle- } \\
\text { mentos do tipo aspecto. }\end{array}$ & $\begin{array}{l}\text { Denota um ponto de instanciação do } \\
\text { framework. O elemento rotulado é um } \\
\text { ponto de corte que pode ser redefinido } \\
\text { por um aspecto especializado. }\end{array}$ \\
\hline «template» & $\begin{array}{l}\text { Aplicado somente a apera- } \\
\text { ções/métodos. }\end{array}$ & $\begin{array}{l}\text { Significa que esse método possui uma } \\
\text { parte fixa e várias partes variávcis, quc } \\
\text { são fornecidas por métodos abstratos. } \\
\text { Esses métodos abstratos possucm o } \\
\text { estereótipo «hook». }\end{array}$ \\
\hline$\ll$ hook» & $\begin{array}{l}\text { Aplicado somente a métodos. Os mé- } \\
\text { todos rotulados com esse estereótipo } \\
\text { podem ser ganchos de uma sugestão e } \\
\text { não de um método normal. }\end{array}$ & $\begin{array}{l}\text { Significa que o método é um ponto de } \\
\text { instanciação do framework. }\end{array}$ \\
\hline
\end{tabular}

"Segundo (Camargo \& Masicro, 2004a), "pontos de instanciação" são os pontos do framework que devem ser modificados pelo engenheiro de aplicaçuão durante o processo de instanciação (consiste em sobrcposição/redefinição de métodos, especialização de alguma classe do framework). A modificaçāo de vários pontos de instanciaçāo detcrmina a utilizaçã̃o ou não de uma variabilidade do framework. 
Os estereótipos «hook» e «template $\gg$ apresentados na Tabela 3.7 foram herdados da UML-F e foram mostrados nessa tabela devido à sua importância perante os outros elementos.

\subsection{Considerações Finais}

Neste capítulo foram apresentadas algumas linguagens que apóiam o desenvolvimento de aplicações baseadas $\mathrm{cm}$ aspectos. Dentre as linguagens apresentadas, AspectS foi a linguagem escolhida para a implementação da nova versão orientada a aspectos do framework GREN realizada neste trabalho de mestrado. Essa escolha se deu ao fato dessa linguagem apoiar a programação orientada a aspectos usando a linguagem Smalltalk no ambiente VisualWorks, uma vez que a versão do framework GREN, tomada como base para a realização deste trabalho, também foi implementada em linguagem Smaltallk no ambiente VisualWorks.

Além das abordagens para apoiar a implementação, também foram apresentadas neste capítulo algumas propostas direcionadas a apoiar a fase de projeto de sistemas orientados a aspectos. Dentre os modelos propostos apresentados, as propostas de Camargo \& Masicro (2004b) e (Camargo \& Masiero, 2004a) foram escolhidas para representar o modelo de projeto do sistema orientado a aspecto implementado, pois além de serem propostas bastante completas com relação à cobertura dos conceitos básicos da POA, a autora desta dissertação teve contado direto com a elaboração de ambas. 


\section{Evolução do GREN: Implementação de um Subsistema de Segurança usando}

\subsection{Considerações Iniciais}

Este capítulo trata da extensão do framework GREN em que foi feita a implementação de um subsistema de segurança usando a abordagem de programação orientada a aspectos e apresenta, mais especificamente, a análise, projeto e implementação dessa funcionalidade. Os requisitos não funcionais de segurança que compõem o subsistema implementado são relevantes ao domínio do framework GREN e não estão implcmentados na sua versão atual, sendo reconhecidos na literatura como requisitos que podem ser tratados pela abordagem de programação orientada a aspectos. A implementação desse subsistema consistiu em uma evolução do framework GREN e para realizar essa evolução foi seguido o processo de cvolução de frameworks proposto por Cagnin et al. (2004), resumido na seção 2.3 desta dissertação. É importante ressaltar que a implementação do requisito não funcional de segurança colaborou para o aprimoramento do processo de evolução proposto por Cagnin et al. (2004), uma vez que foram observadas algumas características no processo de evolução de frameworks inicialmente desconsideradas por esse processo, o que resultou em modificações da sua primeira versão.

A organização deste capítulo segue os passos do processo de evolução de frameworks proposto por Cagnin et al. (2004). Na seção 4.2 é descrito o passo de análise para classificar o 
requisito não funcional de segurança como genérico ao domínio do framework GREN. Na seção 4.3 são descritas as etapas de projeto. implcmentação e testes do Subsistema de Segurança. Na seção 4.4 são apresentadas algumas considerações sobre a atualização da documentação do GREN. Na seção 4.5 disserta-se sobre os testes realizados na nova versão do GREN por meio de instanciações de aplicações. Na seção 4.6 é apresentada a evolução realizada na ferramenta para instanciação automática do GREN, o GREN-Wizard. Na seção 4.7 são feitas algumas considerações sobre o gerenciamento de controle de versão do framework GREN. Por fim, na seção 4.8 são apresentadas as consideraçõcs finais deste capítulo.

\subsection{Análise dos requisitos de segurança}

No passo 1 do processo de evolução, o conjunto de requisitos de segurança, que compõem o Subsistema de Segurança (SS), apresentado no Apêndice A foi analisado quanto a sua generalidade. Essa análise mostrou que:

1. Não estava implementado na versão 1.1 do GREN.

2. Durante a implementação original do framework GREN foi considerado para a implementação mas, com prioridade menor, não foi implementado por falta de tempo da autora Braga (2002b).

3. Trata-se de uma aplicação que pode ser implementada em qualquer aplicação do domínio de recursos de negócio, que é um subdomínio dos Sistemas de Informação. Essa afirmação é justificada pelo grande número de sistemas implementados que possuem funcionalidades semelhantes, tais como sistema de gestão de biblioteca, de comércio eletrônico, imobiliárias, de vídeo locadoras, de clínicas médicas ctc.

Assim, caracterizada a generalidade da funcionalidade decidiu-se por sua implementação no framework e foram seguidos os passos 5 a 8 do processo de Cagnin et al. (2004) (Figura 2.1). Ainda a partir da análise realizada no passo 1 , o requisito não funcional de segurança foi subdividido em três interesses: autenticação, registro de acessos e controle de acesso. A autenticação diz respeito à responsabilidade de autenticar um usuário do sistema, o registro de acesso diz respeito à responsabilidade de registrar as operações realizadas pelo usuário no sistema em execução e o controle de acesso diz respeito à responsabilidade de atribuir ou restringir acesso a operações do sistema para um usuário. Esses três interesses identificados são fortes candidatos a serem tratados pela abordagem de programação orientada a aspectos, pois na implementação convencional oricntada a objetos eles se encontrariam espalhados pelas demais classes funcionais da aplicação. De fato, ao executar a operação para entrar no sistema é necessário que o usuário seja autenticado e, quando o usuário tenta executar qualquer operação é necessário que seja checada a sua permissão de acesso a tal operação e também seja realizado, de alguma forma, o registro da operação que o usuário tentou cxecutar. 
O modelo conccitual claborado para o SS foi bascado na linguagem de padrões para modelos de segurança de Fernandez \& Pan (2001), mais especificamente no padrão de análise Controle de Acesso Baseado em Regras (RBAC), apresentado na Figura 4.1. Esse modelo considera regras de composição e separa a administração da segurança por meio de privilégios. $O$ administrador é um usuário especial, que tem o direito de atribuir papéis para grupos $\mathrm{c}$ usuários $\mathrm{e}$ atribuir privilégios aos papéis.

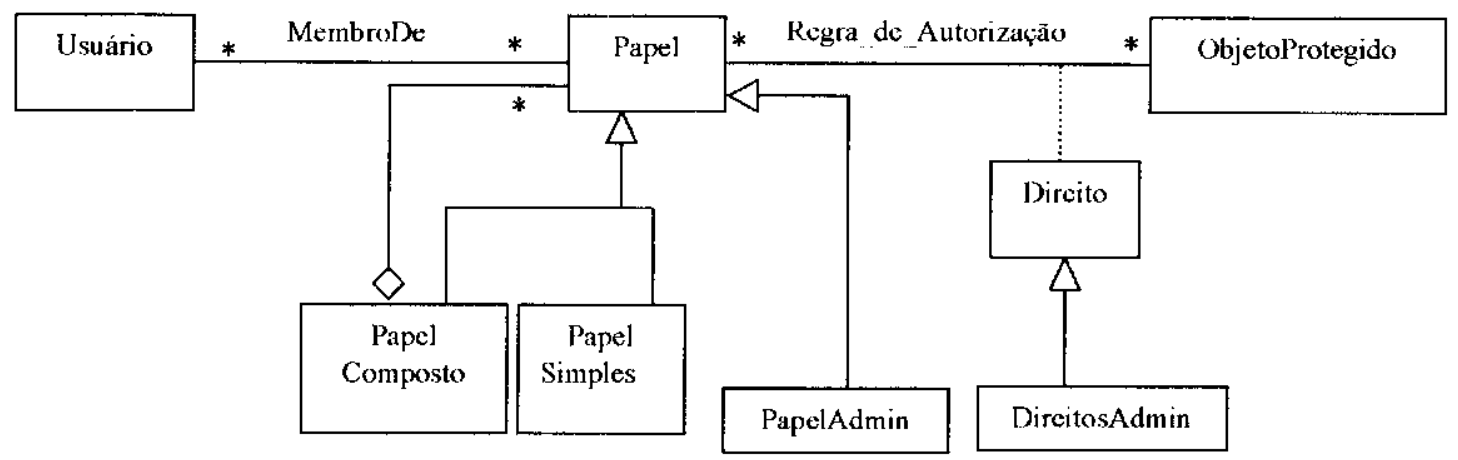

Figura 4.1: Padrão RBAC (Fernandez \& Pan, 2001)

Na Figura 4.2 é apresentado o modelo conceitual do $S^{1}$. Como pode-se observar, não foram considerados os conceitos de sessões e nem de grupos de usuários do padrão de Fernandez \& Pan (2001). O conceito de sessão não foi considerado, pois a implementação atual do GREN permite apenas a instanciação de aplicaçõcs monousuário. O conceito de grupos de usuários não foi considerado para simplificação do modelo e, também, por não ter sido considerado uma característica indispensável para a retidão do SS. Entretanto, ambos os conceitos não considerados poderão ser implementados $\mathrm{cm}$ uma manutenção futura do SS. Uma outra diferença entre o modelo conceitual do SS e o modelo apresentado por Fernandez \& Pan (2001), é a inclusão do conceito de registro de acesso, representado na Figura 4.2 pela classe AccessLog.

$O$ documento de requisitos do SS encontra-se no Apêndice A. Ele apresenta uma visão geral do SS e os seus requisitos. Para obter-se uma visão do uso do SS, foram especificados

${ }^{1}$ As classes mostradas neste modelo c nos demais diagramas apresentados nesta dissertação estão em inglês para manter coerência com as classes da implementação, que estão em inglês, uma vez que todo o GREN está programado nessa língua. 


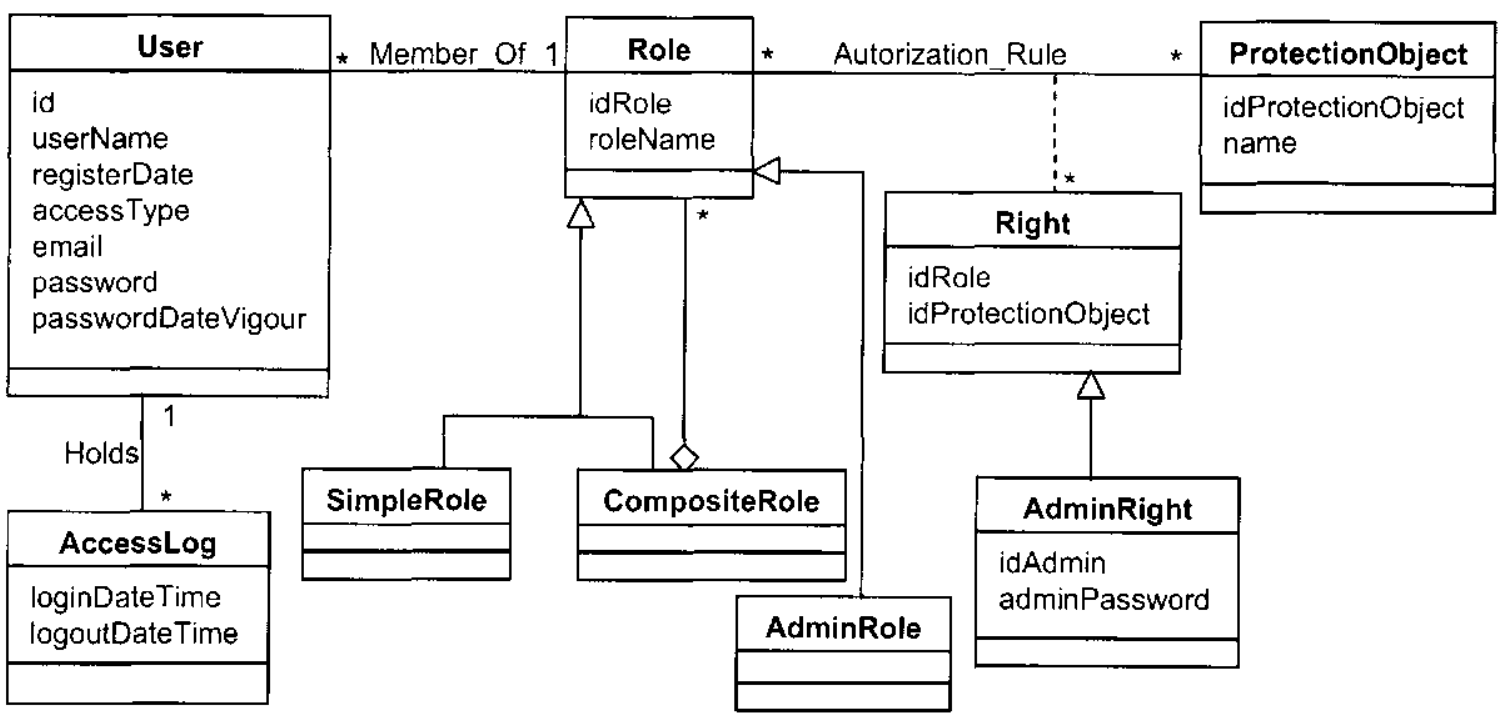

Figura 4.2: Modelo de classes do Subsistema de Segurança para o framework GREN.

os principais casos de uso, que são apresentados no Apêndice B. Durante a elaboração desses casos de uso procurou-se fazer a separação dos requisitos funcionais dos não funcionais, com o propósito de identificar e tornar visível, já na fase de análise, as funcionalidades candidatas a serem implementadas, futuramente, como aspectos. Para isso, foram feitas marcações, nos casos de uso, dos eventos relacionados aos requisitos não funcionais, delimitando-os por colchetes. Após serem marcados, esses eventos foram classificados $\mathrm{cm}$ interesses (autenticação, registro de acesso $\mathrm{C}$ controle de acesso). Para indicar a qual interesse pertence cada um dos eventos marcados, foi atribuída uma letra "maiúscula" a cada interesse (A - autenticação, B registro de acesso e C - controle de acesso), a qual aparece, em sobrescrito, após cada marcação nos casos de uso. Assim, conforme mostra a Figura 4.3, a sequiência de eventos do caso de uso "Entrar no sistema" possui quatro marcações: o evento 2 é marcado mostrando a presença do interesse de autenticação; o evento 5 apresenta três marcações, a primeira e a terceira indicam a presença do interesse de registro de acesso, que deve registrar informações de acesso sobre o usuário que solicitou autenticação no sistema $\mathrm{e}$ a segunda indica a presença do interesse de controle de acesso, que deve disponibilizar para o usuário autenticado somente as transações que lhe são permitidas.

\subsection{Projeto, implementação e testes do Subsistema de Segurança}

No passo 5 do processo de evolução, Figura 2.1, foram desenvolvidas as seguintes atividades: elaboração de um novo projeto para o GREN, incluindo o SS; implementação do SS usando a abordagem POA, por meio do pacote de classes AspectS; e testes para checar a inte- 
4.3. PROJETO, IMPLEMENTAÇÃO E TESTES DO SUBSISTEMA DE SEGURANÇA 51

\begin{tabular}{|c|c|}
\hline \multicolumn{2}{|c|}{ Caso de uso 1: Entrar no Sistema (Login) } \\
\hline Usuário & Sistema \\
\hline 1. Solicita operaçåa Entrar no sistema & 2. Recebe a solicitaçãa e Japresenta a janela de $\log i n]^{A}$. \\
\hline 3. Informa o usuário e senha de acesso ao sistema. & $\begin{array}{l}\text { 4. Checera existência do usuario na tabela de usuários e checa a integridade } \\
\text { da senha. }\end{array}$ \\
\hline Interesse Autenticaç̧a & $\begin{array}{l}5 \text { Se o usuário existe e a senha confere, o sistema checa a data de validade } \\
\text { da senha } \\
5.1 \text { se a senha já estiver expirada o sistema bloqueia o logon do usuário, } \\
\text { informa que a sua senhaexpiratra onome do usuário que } \\
\text { Tentou se conectar ao sistema, a data e hora da tentativa e o status }\end{array}$ \\
\hline Interesse Controle de acesso & 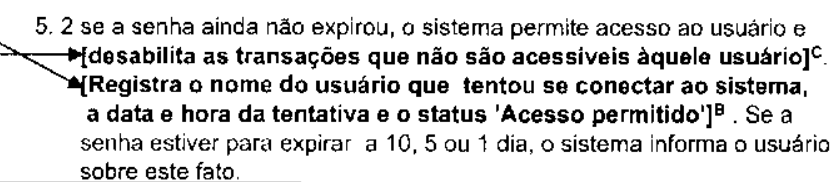 \\
\hline & $\begin{array}{l}\text { 6. Após três tentativas de entrar no sistema com senha incorreta, o sistema } \\
\text { bloqueará o acesso do usuário por um periodo de } 24 \text { horas, após esse peri- } \\
\text { odo o acesso será desbloqueado automaticamente. Após o bloqueio o sis- } \\
\text { tema enviará um aviso ao usuário informando-o sobre o bloqueio e que ele } \\
\text { deve contatar o administrador se quiser desbloquear antes das } 24 \text { horas. }\end{array}$ \\
\hline & $\begin{array}{l}\text { 7. O sistema informarà o usuàrio se ele for bloqueado no sistema por três } \\
\text { vezes consecutivas e pede que entre em contato com o administrador do } \\
\text { sistema para desbloquear o seu acesso. }\end{array}$ \\
\hline
\end{tabular}

Figura 4.3: Exemplo de marcaç̃es realizadas no caso de uso 'Entrar no sistema'.

gridade dessa implementação. O desenvolvimento de cada uma dessas atividades é detalhado nas próximas subseções.

\subsubsection{Projeto}

Para a elaboração do projeto da nova versão do framework GREN incluindo o Subsistema de Segurança foi inicialmente realizado um estudo das classes do GREN, para familiarização com a hierarquia de classes e métodos desse framework. As principais atividades realizadas para o entendimento do GREN foram:

i) Exploração da hierarquia de classes por meio de comandos específicos para isso disponibilizados pelo ambiente VisualWorks, por exemplo, Spawn Hierarchy. Essa tarefa foi facilitada pelo fato das classes do framework GREN se encontrarem agrupadas em namespaces nomeados com o prefixo GREN.

ii) Entendimento parcial da chamada dos métodos das classes do GREN no VisualWorks, também por meio de comandos específicos para isso (Senders - lista os métodos que chamam um determinado método e Implementors - lista as classes que implementam um determinado método).

iii) Instanciações de aplicações usando o GREN. 


\subsection{PROJETO, IMPLEMENTAÇÃO E TESTES DO SUBSISTEMA DE SEGURANÇA 52}

A Figura 4.4 mostra uma visão esquemática do projeto elaborado para a nova versão do framework GREN considerando o SS. O projeto é constituído pelo pacote de classes original do GREN, que compreende as classes de negócio, as classes de persistência e as classes GUI, juntamente com o pacote de classes referente ao SS.

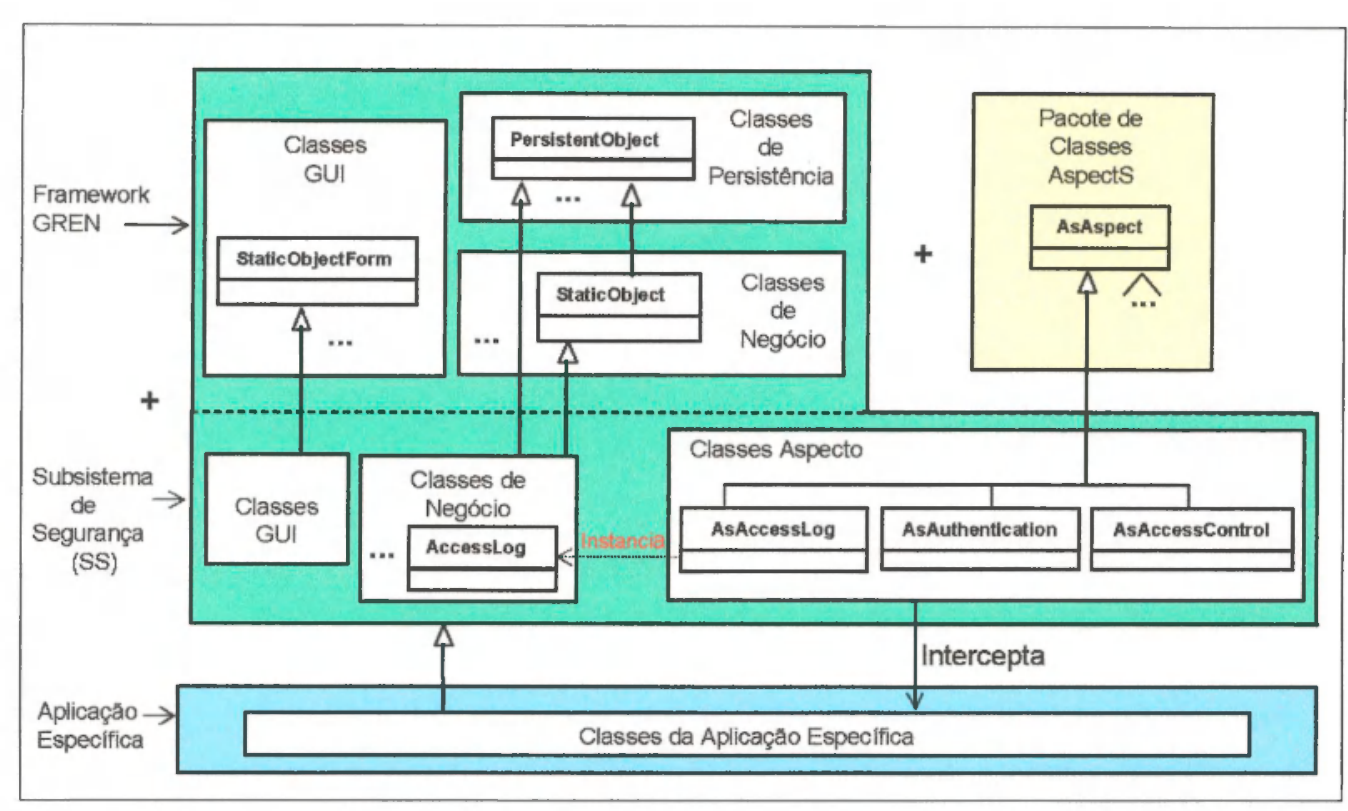

Figura 4.4: Visão esquemática do projeto da nova versão do framework GREN.

O pacote de classes referentes ao SS é composto por suas classes de negócio, pelas classes GUI, que são as classes responsáveis pela interface gráfica com o usuário do SS, e pelas classes que implementam os aspectos. As classes implementadas segundo a abordagem de programação orientada a aspectos foram denominadas "classes aspecto". O projeto também compreende o pacote de classes AspectS, por meio do qual as classes aspectos do SS são criadas. Dessa forma, uma aplicação específica, produto da instanciação da nova versão do GREN, se constituirá de classes especializadas a partir das classes do GREN e também especializadas a partir das classes referentes ao SS. As classes da aplicação específica serão interceptadas, durante a execução, pelas classes aspecto do Subsistema de Segurança

A maior parte das classes de negócio e algumas classes GUI do SS estão diretamente ligadas às classes do GREN por meio de relacionamento de herança. A hierarquia de classes do SS é apresentada no Apêndice $F$ e permite, claramente, a vizualização do relacionamento entre as classes do GREN e as classes do SS. A decisão de projeto de acoplar o Subsistema de Segurança ao GREN deveu-se à reutilização de código permitida pela natureza da arquitetura do GREN.

O diagrama de classes apresentado na Figura 4.5 mostra uma visão geral do projeto do SS. A notação adotada nesse diagrama, e nos demais que se referem ao projeto das classes do SS, segue o perfil UML-AOF (Camargo \& Masiero, 2004a) citado na seção 3.5 do Capítulo 3. Esse perfil fornece elementos notacionais para o projeto de frameworks orientados a aspectos. 


\subsection{PROJETO, IMPLEMENTAÇÃO E TESTES DO SUBSISTEMA DE SEGURANÇA 53}

Entretanto, foi adicionado um estereótipo «Smalltalk. Core» para representar classes base da linguagem Smalltalk.

As classes compreendidas na área com linha pontilhada na Figura 4.5 representam, genericamente, as classes de uma aplicação instanciada. Todas as classes de negócio do SS, com exceção da classe Login e das classes aspecto, estão diretamente ligadas às classes do framework GREN por meio de um relacionamento de herança.

Na Figura 4.6 apresenta-se mais detalhadamente o modelo de projetos das classes aspecto do SS. Como pode-se observar, essas classes possuem um relacionamento de herança com a classe AsAspect, que é a classe aspecto do pacote de classes AspectS citado na Seção 3.3.1.3 do Capítulo 3. Todas elas (AsAccessLog, AsAccessControl e AsAuthentication) são abstratas e, assim, devem ser especializadas durante o processo de instanciação de uma aplicação específica. O método mainApplicationName (), presente nas três classes aspecto, é um método abstrato e deve ser sobreposto para retornar o nome da classe principal ("main") da aplicação instanciada. Trata-se de uma aplicação do padrão de projeto Factory Method (Gamma et al., 1995). Este método é usado para a identificação dos pontos de junção coletados por essas classes aspecto. A classe AsAccesscontrol possui, ainda, um segundo método abstrato que deve ser sobreposto para retornar o nome do método responsável por construir o menu principal da aplicação instanciada. As classes abaixo da linha pontilhada representam genericamente as classes especializadas em uma instanciação. A classe principal da aplicação é representada pela classe ApplicationNameMainWindow. Os pontos de junção são especificados em cada relacionamento de interceptação entre o aspecto especializado e as classes da aplicação.

Como pode-se observar na Figura 4.6, cada um dos sub-interesses identificados, dentro do interesse de segurança, foi projetado como um aspecto do SS. A semântica de cada aspecto é descrita a seguir:

- A classe aspecto AsAuthentication possui uma sugestão do tipo after e outra do tipo before. A sugestão after atua sobre o descritor do ponto de corte denominado adviceUserAuthentication1(). Os pontos de junção identificados por esse descritor do ponte de corte são todas as execuções do método postopenwith( ), definido na classe principal da aplicação. A sugestão before desse aspecto atua sobre o descritor do ponto de corte denominado adviceUserAuthentication2(). Os pontos de junção definidos por esse descritor do ponto de corte são todas as execuções do método login() definido na classe principal da aplicação.

- A classe aspecto AsAccesslog possui duas sugestões do tipo after. A primeira delas atua sobre o descritor do ponto de corte denominado adviceloginRegister (). Os pontos de junção identificados por esse descritor do ponte de corte são todas as execuções do método $\log i n($ ), definido na classe principal da aplicação. A segunda sugestão atua sobre o descritor do ponto de corte denomidado adviceLogoutRegister (). Os pontos 


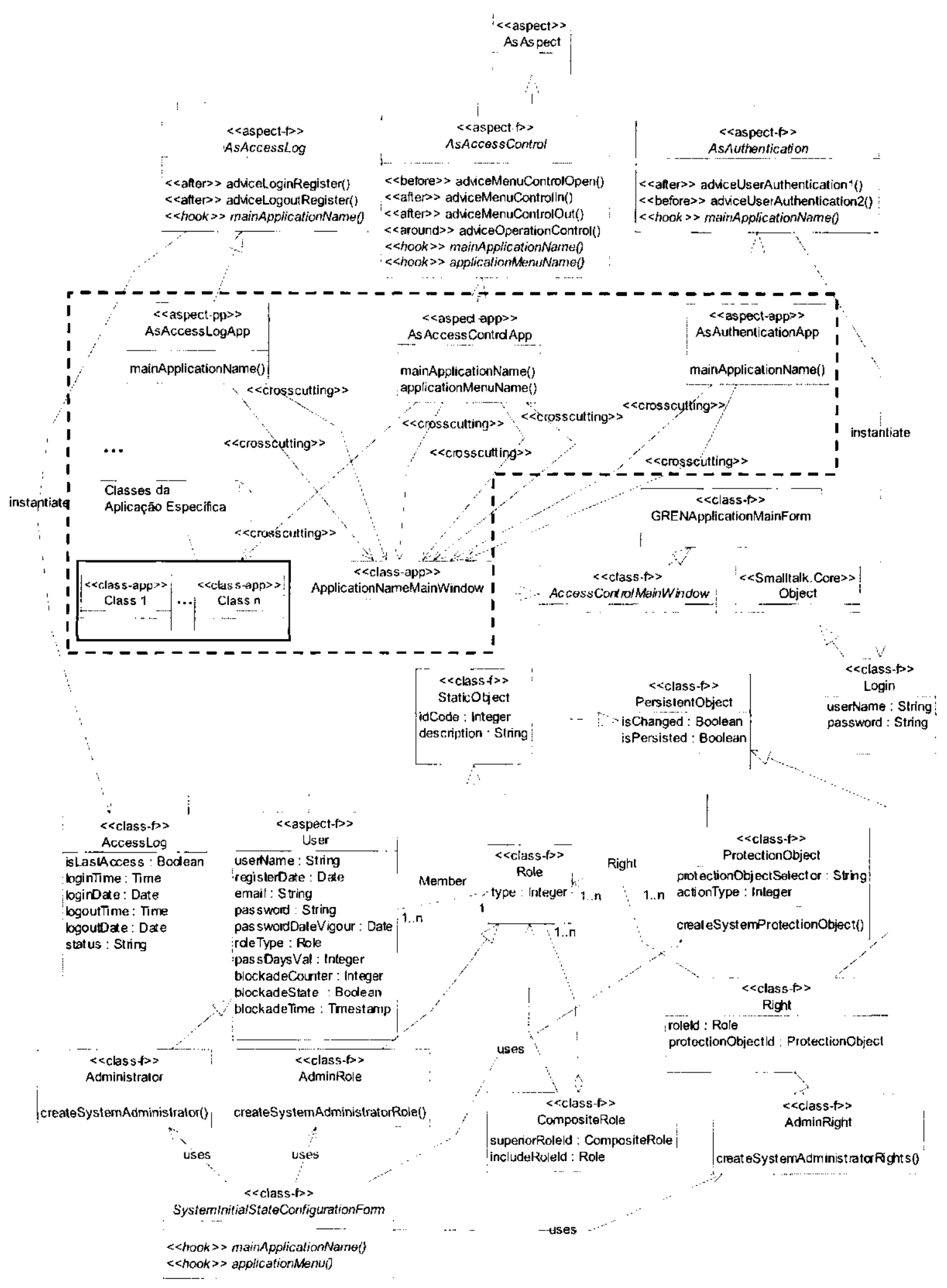

Figura 4.5: Diagrama de classes do SS para o framework GREN 


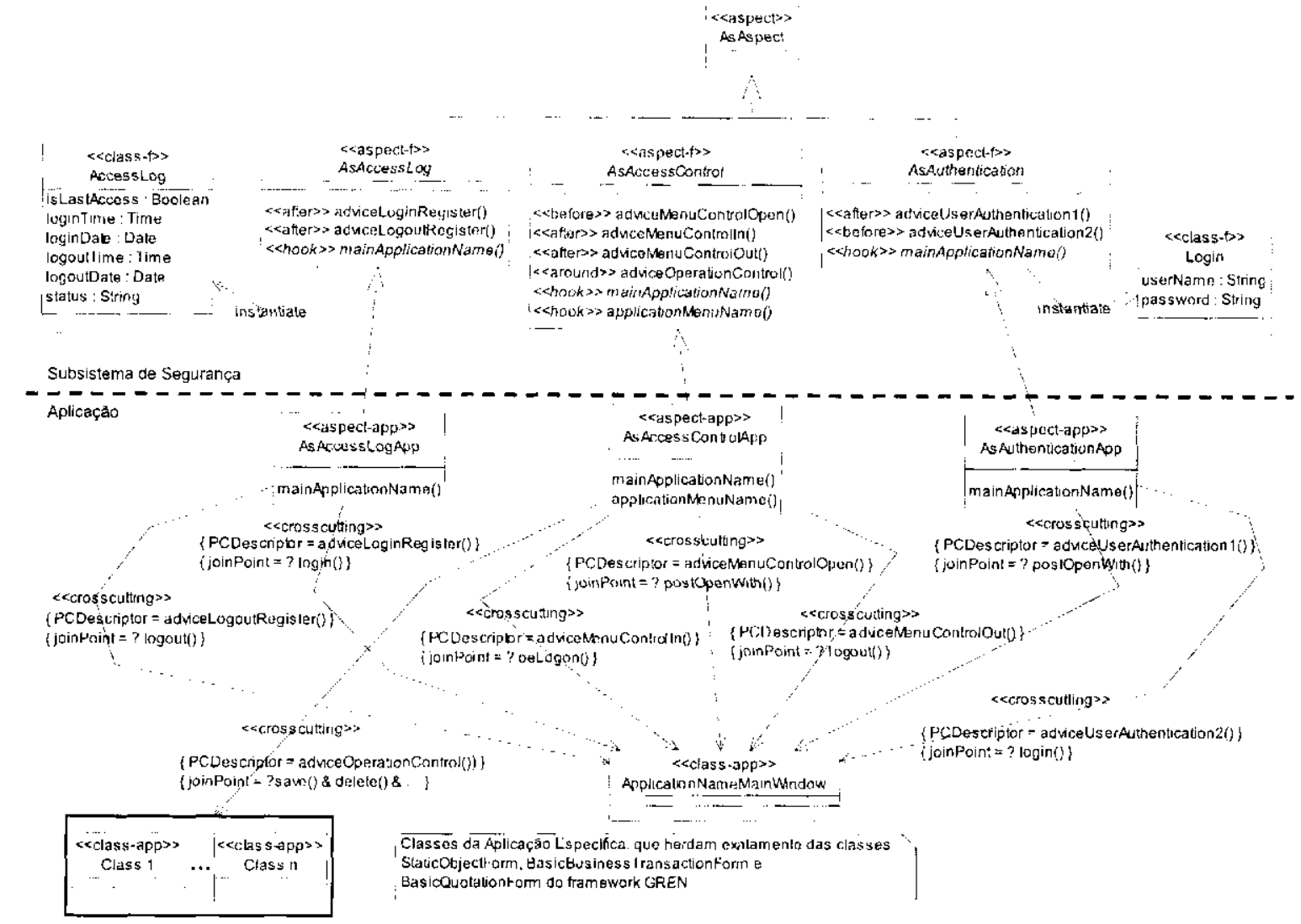

Figura 4.6: Classes aspecto do SS para framework GREN.

de junção definidos por esse segundo descritor do ponto de corte são todas as execuções do método logout () definido na classe principal da aplicação.

- A classe aspecto AsAccesscontrol possui quatro sugestões. A primeira sugestão é do tipo before e atua sobre o descritor do ponto de corte denominado advicemenuControlopen (). Os pontos de junção identificados por esse descritor do ponto de corte são todas as execuções do método postopenwith (), definido na classe principal da aplicação. A segunda sugestão é do tipo after e atua sobre o descritor do ponto de corte denominado advi cemenuControl $\operatorname{In}()$. Os pontos de junção identificados por esse descritor são todas as execuções do método beLogon ( ) definido na classe principal da aplicação. A terceira sugestão desse aspecto também é do tipo after e atua sobre o descritor do ponto de corte denominado advi cemenuControlout (). Os pontos de junção identificados por esse descritor do ponto de corte são todas as execuções do método logout (). A quarta e última sugestão desse aspecto é do tipo around. Ela atua sobre o descritor do ponto de corte denominado advi ceoperationcontrol(). Os pontos de junção identificados por esse descritor do ponto de corte são as execuções de alguns métodos definidos em algumas classes da aplicação específica, que possuem 


\subsection{PROJETO, IMPLEMENTAÇÃO E TESTES DO SUBSISTEMA DE SEGURANÇA 56}

um relacionamento de herança com exatamente uma das classes staticobjectForm, BasicBusinessTransactionForm ou BasicQuotationForm do GREN.

\subsubsection{Implementação do SS para o framework GREN}

O Subsistcma de Segurança é composto por dez classes de ncgócio, sete classes referentes à interface gráfica e três classes implementadas seguindo a abordagem de programação orientada a aspectos. O diagrama de classes apresentado na Figura 4.7 mostra todas as classes de negócio do SS, com excção da classe SystemInitialstateConfigurationForm, que é uma classc de interface gráfica com o usuário e será especificada mais adiante.

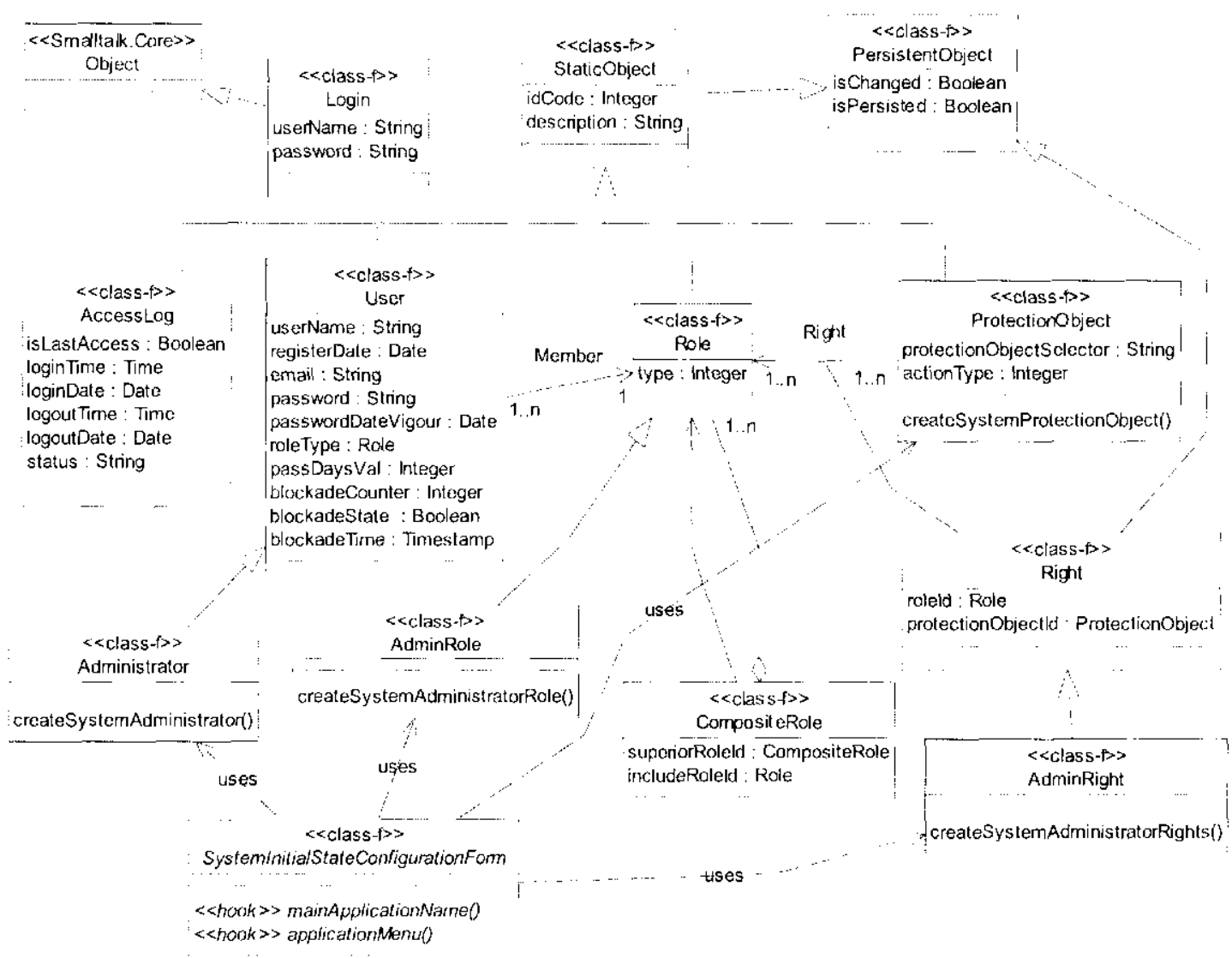

Figura 4.7: Classes de negócio do SS para framework GREN.

O SS faz o controle de usuários de uma aplicação por meio da classe User. O mecanismo de segurança é feito por meio de papéis aos quais são atribuídos dircitos sobre as operações protegidas da aplicação. As operações protegidas da aplicação são representadas pela classe protectionobject. Conforme a implementação realizada, as opcraçõcs protegidas de uma aplicação instanciada são: as opções do menu da aplicação e as operações da aplicação, por exemplo: salvar, cxcluir e visualizar relatórios. Um determinado usuário poderá visualizar determinadas opções do menu ou executar operações da aplicação, dependendo dos direitos 
que foram atribuídos ao papel que possui. A implementação da classe Role, que representa os papéis, utilizou o padrão de projeto Composite proposto por Gamma et al. (1995). Assim, um papel pode ser composto de um outro papel. Na Figura 4.8 é apresentada a interface gráfica do SS que permite ao usuário Administrador gerenciar (cadastrar, excluir, modificar e atribuir subpapéis) os papéis da aplicação, na qual pode-sc observar que o veterinário é um papel composto e possui um subpapcl denominado Auxiliar de Veterinário. Na Figura 4.9 apresenta-se a interface gráfica do SS que permite ao usuário Administrador atribuir direitos aos papéis da aplicação. O campo à esquerda nessa figura representa os papéis da aplicação, o campo superior direito representa os direitos a serem atribuídos a um papel (selccionado no campo à esquerda) e o campo inferior direito mostra os direitos herdados a partir do subpapcl do papel selecionado. Ambas as interfaces gráficas representadas pela Figura 4.8 e pela Figura 4.9 foram extraídas de uma aplicaçäo instanciada para clínica veterinária.

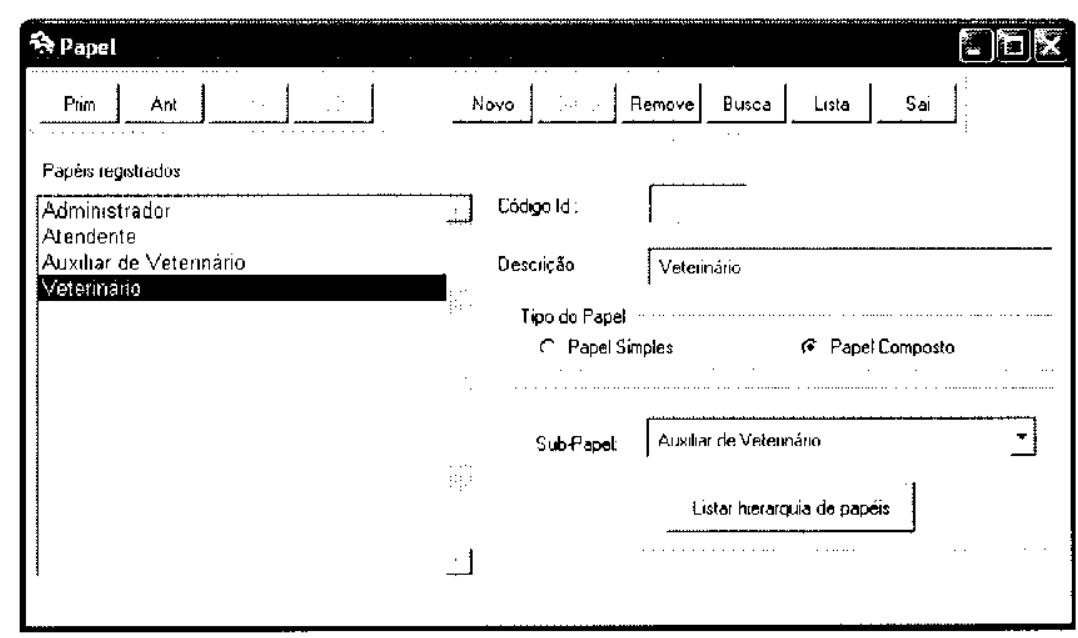

Figura 4.8: Interface gráfica do SS para gerenciamento de papéis da aplicação.

A classe SystemInitialstateconfigurationform (Figura 4.7) é uma classe de interface gráfica com o usuário. Ela é responsável por fornecer ao engenheiro de aplicação uma interface gráfica que lhe permite realizar a configuração do estado inicial do sistema. Ou seja, após uma aplicação ser instanciada o engenheiro de aplicação poderá, por mcio dessa interface gráfica, solicitar a execução de uma operação que automaticamente cria o papel Administrador, o usuário Administrador do Sistema, todos os objetos a serem protegidos dessa aplicação e atribui ao papel Administrador direitos de acesso a todos os objctos protegidos da aplicação. Essa interface gráfica é apresentada na Figura E. 1 do ApêndiceE.

Todas as classes de interface gráfica com o usuário do SS são apresentadas na Tabela 4.1 e, como pode ser observado, apenas as classes Accesscontrolmainwindow, Roleform c UserForm são ligadas às classes da camada de interface gráfica com o usuário do framework GREN. 


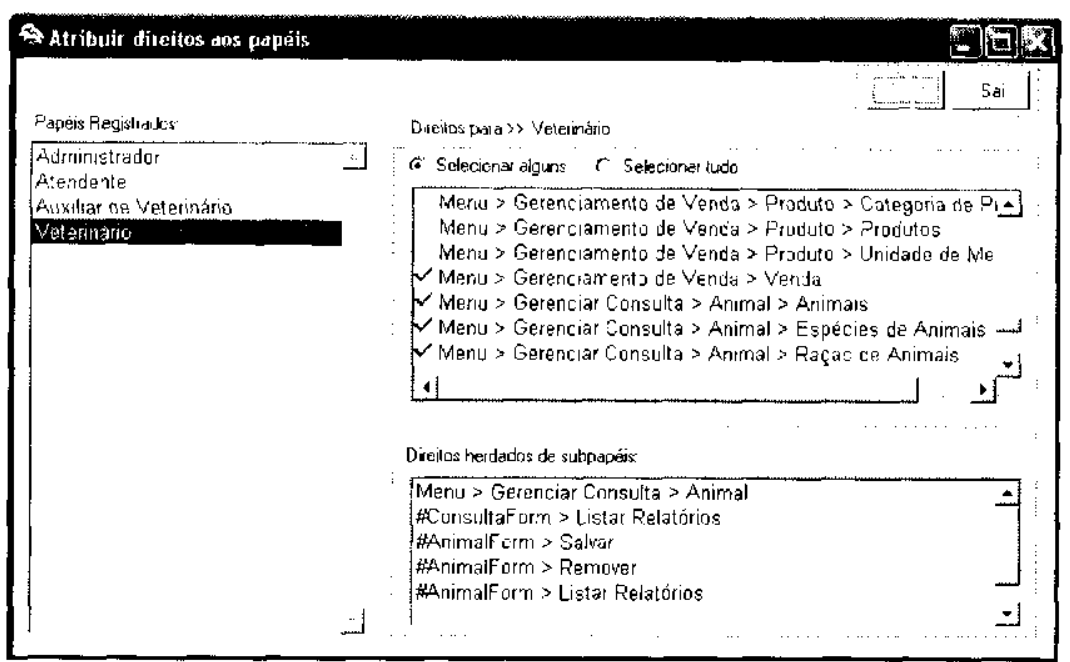

Figura 4.9: Interface gráfica do SS para gerenciamento de permissões.

Tabela 4.1: Classes GUI do sistema de segurança e respectivas superclasses.

\begin{tabular}{|l|l|}
\hline \multicolumn{1}{|c|}{ Camada de Interface Gráfica com o Usuário- $\Lambda$ CSForms } \\
\hline \multicolumn{1}{|c|}{ Classe } & \multicolumn{1}{|c|}{ Superclasse } \\
\hline \hline AccessControlMainWindow & GREN.GRENApplicationMainForm \\
\hline AlterPasswordForm & UI.SimpleDialog \\
\hline Loginform & UI.SimpleDialog \\
\hline RightsForm & UI.ApplicationModel \\
\hline RoleForm & GREN.StaticobjectForm \\
\hline SystemInitialstateConfigurationForm & UI.SimpleDialog \\
\hline UserForm & GREN.StaticobjectForm \\
\hline
\end{tabular}

Cada um dos subinteresses identificados dentro do interesse de segurança e projetados como aspecto (Figura 4.6) foi implementado como classes aspecto em Smalltalk a partir do pacote de classes AspectS.

A classe aspecto AsAuthentication trata da implementação do sub-interesse de autenticação dos usuários da aplicação. Essa classe possui duas sugestões que foram implementadas pelos métodos adviceUserAuthentication1() e adviceUserAuthentication2(). 0 método adviceUserAuthentication1() é a implementação da sugestão do tipo after e o scu código é apresentado na Figura 4.10. Conforme mostra a linha de código oito da Figura 4.10, essa sugestão simplesmente invoca o método $\operatorname{login()~implementado~na~classe~que~}$ é interceptada pelo aspecto AsAuthentication. Esse método login tem a função de atribuir um valor booleano a uma variável da aplicação que indica que um determinado usuário está conectado ou não no sistema. Conforme mostra a definição dos pontos de junção nas linhas de código quatro a seis da Figura 4.10, essa sugestão será executada sempre após a execução do método postopenwith (), implementado na classe cujo nome deve ser retornado pelo método mainApplicationName. 


\subsection{PROJETO, IMPLEMENTAÇÃO E TESTES DO SUBSISTEMA DE SEGURANÇA 59}

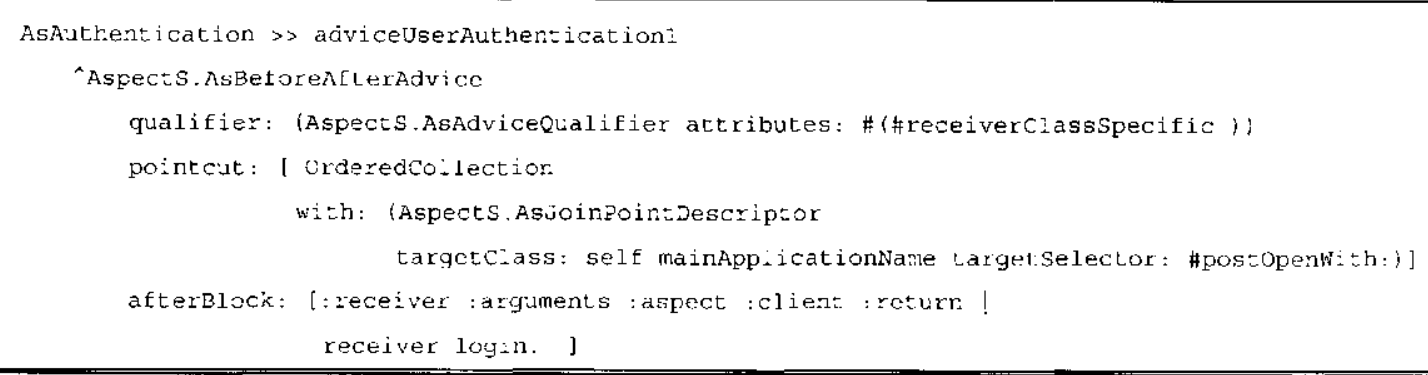

Figura 4.10: Código da sugestão advi ceUserAuthentication1

O método adviceUserAuthentication2() é a implementação da sugestão do tipo before cujo código é apresentado na Figura 4.11. Conforme mostra o bloco de código representado pelas linhas sete a nove da Figura 4.11, essa sugestão manipula um objeto do tipo Login para realizar a autenticação de usuários. Assim, por meio da linha de código oito é aberta a janela de autenticação de usuários, onde o usuário deverá informar a sua identificação. Assim, se o usuário foi autenticado e reconhecido pelo sistema, na linha de código nove, é atribuído à variável aLoggeduser o objeto que representa o usuário autenticado. Caso contrário, ou seja, se o sistema não reconheceu o usuário, a variável aLoggedUser, pertencente à classe interceptada, receberá o valor nil. Conforme mostra a definição dos pontos de junção nas linhas de código quatro a seis, essa sugestão scrá executada sempre antes da cxecução do método log in () implementado na classe cujo nome deve ser retornado pelo método ma inApplicationName.

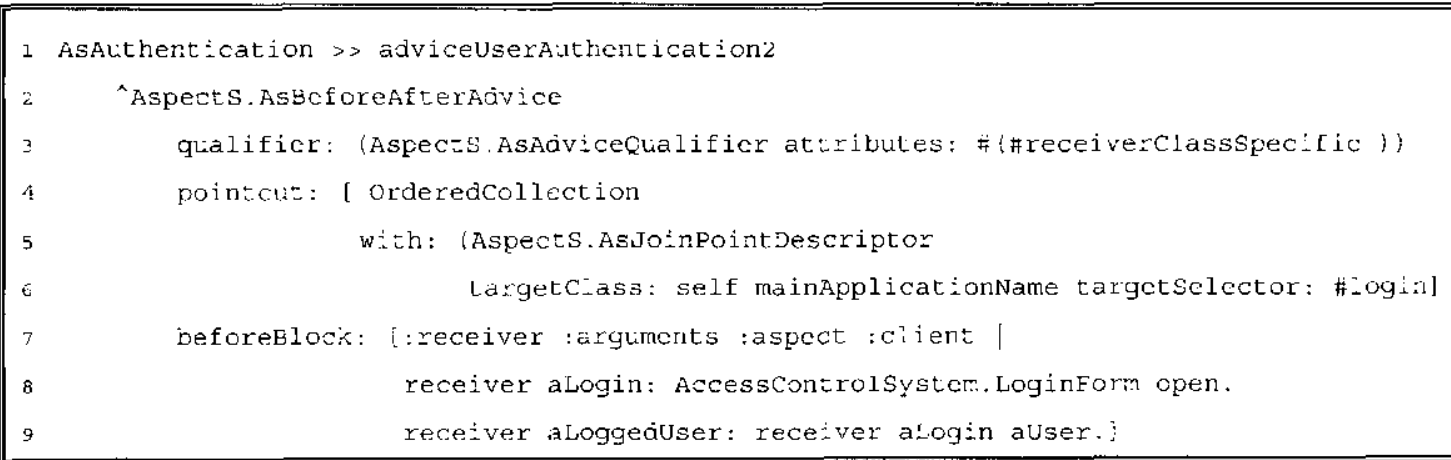

Figura 4.11: Código da sugestão adviceUserAuthentication2

A classe aspecto AsAccessLog trata da implementação do sub-interesse de registro de acesso dos usuários da aplicação. Essa classe possui duas sugestões do tipo after que são implementadas respectivamente pelos métodos adviceLoginRegister (), que trata do registro do acesso do usuário quando este solicita entrar no sistcma c adviceLogoutRegister (), que trata do registro da saída do usuário da aplicação. Essas informações de acesso são armazenadas na base de dados da aplicação. 
O código do método adviceLoginRegister() é apresentado na Figura 4.12. O método que é invocado dentro do bloco de código afterBlock: [ ], na linha de código sete, implementa o comportamento básico da sugestão, que é registrar na base de dados da aplicação o nome do usuário, a data e a hora em que ele solicitou entrar no sistema. De acordo com os pontos de junção identificados por meio das linhas de código quatro e cinco, esse comportamento é executado sempre após a execução do método login (), implementado na classe cujo nome deve ser retornado pelo método mainApplicationName.

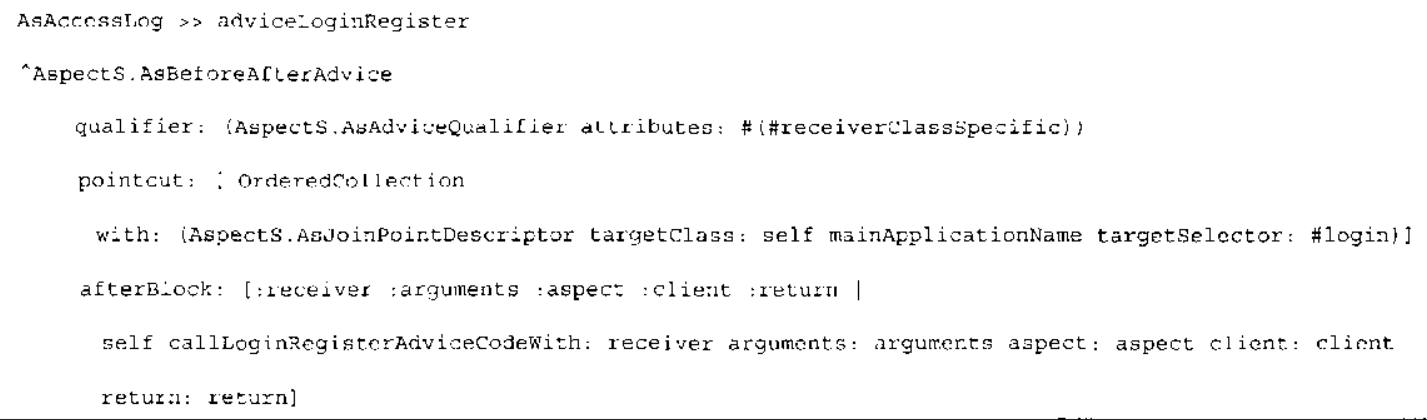

Figura 4.12: Código da sugestão advi.ceLoginRegister

A sugestão adviceLogoutRegister é apresentada na Figura 4.13. O comportamento da sugestão, que é registrar na base de dados da aplicação o nome do usuário, a data c a hora em que ele solicitou sair do sistema, é implementado pelo método invocado dentro do bloco de código afterBlock: [], na linha de código sete. Conforme os pontos de junção dcfinidos pelas linhas de código quatro e cinco, esse comportamento deve ser executado sempre após a execução do método logout (), implementado na classe cujo nome deve ser retornado pelo método mainApplicationName.

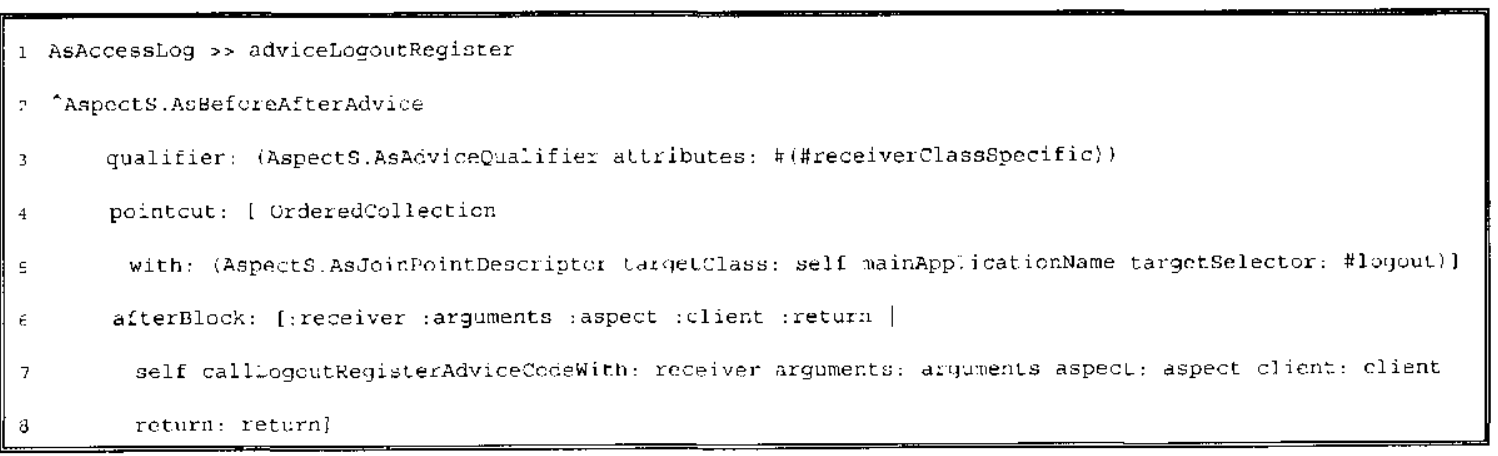

Figura 4.13: Código da sugestão advi iceLogoutRegister

A classe aspecto AsAccessControl é responsável pela implementação do sub-interesse de controle de accsso dos usuários da aplicação. O controle de acesso restringe-se às opera- 


\subsection{PROJETO, IMPLEMENTAÇÃO E TESTES DO SUBSISTEMA DE SEGURANÇA 61}

ções do sistema. O acesso às operações do sistema é controlado ocultando/exibindo e habilitando/desabilitando as opções do menu da aplicação e checando os direitos de acesso de um determinado usuário quando este tenta exccutar uma operação por meio da interface gráfica da aplicação. A classe aspecto AsAccesscontrol possui uma sugestão do tipo before implcmentada pelo método advicemenuControlopen(), duas sugestões do tipo after implementadas pelos métodos adviceMenuControlIn () c adviceMenuControlout () e uma sugestão do tipo around que é implementada pelo método adviceoperationControl (). As sugestões implementadas pelos métodos adviceMenuControlopen(), adviceMenucontrolIn() e advicemenuControlout () têm a responsabilidade de construir o menu da aplicação ocultando/exibindo e habilitando/desabilitando as opçōes do menu.

A sugestão implementada pelo método advi ceMenuControlopen () é executada sempre antes da execução do método pos topenwi th (), que é implementado na classe cujo nome deve ser retornado pelo método mainApplicationName. Ou seja, ela deve ser executada sempre antes da aplicação ser aberta. Assim, ela constrói o menu da aplicação e oculta todas as opções do menu, exceto as opções do menu Arquivo que são apenas habilitadas ou desabilitadas. $O$ menu Arquivo possui três opções: Entrar, que permite um usuário se conectar ao sistema; Sair, que possibilita o usuário se desconectar do sistema; c Fechar, que permite fechar o sistema. Com a execução dessa sugestão as opções Entrar e Fechar são habilitadas e Sair é desabilitada.

A sugestão implementada pelo método adviceMenuControlin () é executada sempre após a execução dos métodos beLogon (), implementado na classe interceptada e cujo nome deve ser retornado pelo método ma inApplicationName. Assim, caso o usuário consiga se conectar ao sistema, cssa sugestão constrói o menu da aplicação exibindo as opções do menu de acordo com os direitos de acesso do usuário conectado. Com relação ao menu Arquivo, as opções Entrar e Fechar são desabilitadas e a opção Sair é habilitada.

A sugestão implementada pelo método adviceMenuControlout () é executada sempre após a execução dos métodos logout (), implementado na classe interceptada e cujo nome deve ser retornado pelo método mainApplicationName. Assim, após o usuário se desconectar do sistema, essa sugestão constrói o menu da aplicação e oculta as opções do menu. Com relação ao menu Arquivo, as opções Entrar e Fechar são habilitadas e a opção sair é desabilitada.

A sugestão implementada pelo método adviceoperationControl () controla a execução de todas as operações da aplicação disponíveis aos usuários por meio da interface gráfica da aplicação. Portanto, quando um usuário tenta executar alguma operação como, por exemplo, excluir uma entrada da aplicação, essa sugestão checa os direitos de acesso do usuário sobre a operação requisitada. Por ser uma sugestão do tipo around, essa sugestão toma o controle sobre a execução do método (operação) que foi interceptado. Assim, permite que o método seja executado somente se o usuário tiver direito de acesso sobre tal operação. Caso contrário, a sugestão retorna uma mensagem ao usuário informando 
que ele não possui o direito de executar a operação solicitada. Os pontos de junção dessa sugestão dependem da aplicação instanciada e não foram especificados estaticamente como ocorreu na implementação das demais sugestões, ao invés disso, eles foram especificados usando a natureza reflexiva da linguagem Smalltalk. Para apoiar cssa especificação foram alteradas três classes do GREN: StaticobjectForm, BasicBusinessTransactionForm e BasicQuotationform. Fssas classes são classes de interface do GREN e implementam as principais operaçōes relacionadas aos recursos de negócio. Em cada uma delas foi criado um método (protectedoperations (1) que retorna uma lista contendo as principais operaçõcs implementadas pela classe, e esse método é usado na especificação dos pontos de junção da sugestão adviceoperationcontrol(). Por meio da natureza reflexiva do Smalltalk é possível descobrir quais classes da aplicação instanciada devem ser interceptadas, que são exatamente aquelas que herdam de uma das classes staticobjectForm, BasicBusinessTransactionForm ou BasicQuotationForm. Essas classes da aplicação instanciada devem ser interceptadas durante a recepção de uma mensagem (operação/método), contida na lista de operações retornada pelo método protectedoperations () de sua superclasse.

O código relativo ao método advi ceoperationControl () é apresentado na Figura 4.14. O método pointcuts() invocado na linha de código quatro da Figura 4.14 é responsável por retornar uma lista com todos os pontos de junção nos quais a sugestão around deve scr executada.

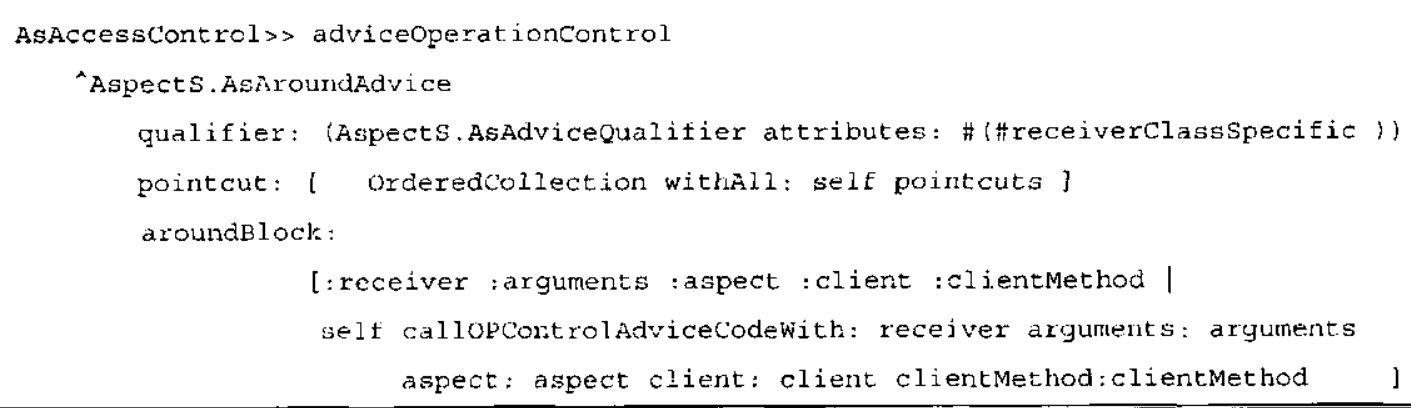

Figura 4.14: Código da sugestão adviccoperationControl

\subsubsection{Testes do Subsistema de Segurança}

Testes funcionais foram realizados durante a implementação do sistema de scgurança para garantir que os requisitos do sistema estavam scndo implementados corretamente. Estes testes foram realizados simulando-se instanciações do GREN na modalidade Caixa-Branca e englobaram testes unitários e testes intra e inter-classes (Harrold ct al., 1992). 
Para testar a integridade das classes aspecto, o SS foi inicialmente aplicado a um sistema para clínica veterinária, cujo documento de requisitos encontra-se no Apêndice C. A instanciação do sistema para clínica veterinária foi realizada pela autora, durante o cumprimento de uma disciplina de mestrado, e ocorrcu de acordo com o Manual de Instanciação (cookbook) do GREN (Braga, 2002a). Assim, o código do sistema de clínica veterinária foi reaproveitado, preocupando-sc apenas $\mathrm{cm}$ acrescentar as classes e métodos necessários para o funcionamento dessa aplicação em conjunto com o SS. Com isso, foi possível testar que os aspectos do SS interceptavam as classes da aplicação corretamente. Também foi feita a instanciação de um sistema de locadora de vídeo scguindo o cookbook do GREN. Durante essa instanciação foram anotados os pontos no cookbook nos quais deveriam ser feitas as alterações referentes à inclusão de novos passos necessários para a instanciação da nova versão do GREN (com o SS).

\subsection{Atualização da documentação do framework GREN}

No passo 6 do processo de evolução, Figura 2.1, foram feitas as atualizações da documentação do GREN e do manual do GREN-Wizard. Além dessa documentação ser útil para a instanciação, também é necessária para futuras manutenções do GREN e do GREN-Wizard. A documentação do GREN consiste basicamente de seu manual de instanciação, no qual foi atualizada a hierarquia de classes e foram adicionadas novas tabelas referentes às classes a serem instanciadas do SS, bem como um passo adicional para que o engenheiro de aplicaçoes configure o estado inicial do sistema. Foram também incluídos os passos necessários para a instalação do SS e do pacote de classes AspectS. No Apêndice E são apresentas algumas informações que constam na atualização da documentação do GREN.

\subsubsection{Considerações sobre o processo de instanciação caixa-branca para a nova versão do GREN}

Com as instanciações realizadas, conclui-se que o processo para instanciar um framework caixa-branca definido por Braga (2002b) atende à nova versão do GREN. O processo de instanciação de Braga (2002b) é composto por quatro passos: análise do sistema, mapeamento entre o modelo de análise e o framework, implementação das classes específicas e testes do sistema resultante. Todavia, a particularização desse processo para a nova versão do GREN, descrita no cookbook do GREN (Braga, 2002a) sofreu algumas alterações. Embora os passos do processo não tenham sido alterados, foram inseridas, em cada passo, novas tarefas a screm realizadas caso a instanciação inclua o SS. A seguir são descritas as particularidades a serem consideradas, em cada um dos passos do processo, em uma instanciação do GREN incluindo o SS 
Análise do sistema - O primeiro passo para se instanciar um framework caixa-branca do processo de Braga (2002b) é a análise do sistema com base na linguagem de padrões GRN (Braga et al., 1999). Esse passo pode ser realizado normalmente conforme é descrito no processo original. Com relação a inclusão do SS, o instanciador da aplicação deve apenas estudar a documentação relativa a esse subsistema e decidir se deve usá-lo ou não caso a aplicação a ser instanciada necessite do requisito de segurança. Entretanto, o instanciador também poderá, caso descje, utilizar o modelo de análise do SS como base para modelar o seu próprio sistema de scgurança ou estender o próprio modclo do SS. Porém, na documentação do SS não são ciladas diretrizes para a a cxtensão de seu modelo e nem de sua implementação, o que poderá ser realizado $\mathrm{cm}$ um trabalho futuro. O resultado desse passo é uma lista de padrões e variantes utilizados, uma lista de tomada de decisões quando a linguagem de padrões não atende a todos os requisitos do sistema e a decisão de incluir ou não o SS na instanciação.

Mapeamento entre o modelo de análise e o framework - De posse do modelo de análise e do histórico dos padrões e variantes utilizados, neste segundo passo produz-se o mapeamento entre o modelo de análise $\mathrm{e}$ as classes do framework. O resultado é uma lista das classes e métodos a serem implementados. Ncstc passo devem ser seguidas as diretrizes definidas por (Braga ct al., 1999) para realizar esse mapeamento. Caso a aplicação inclua o SS, a documentação atualizada do GREN fornece informações sobre quais classes do SS devem ser especializadas e os seus respectivos métodos que devem ser sobrepostos. Para tal, quatro tabelas são fornecidas:

- A Tabela E.1 e a Tabcla E.2 apresentadas no Apêndice E contêm informação para a criação das classes concretas. Nessas tabelas são apresentados os nomes das classes do SS a screm especializadas e uma sugestão para o nome das classes concretas a serem criadas.

- Também apresentadas no Apêndice E, a Tabela E.3 mostra quais métodos das classes aspecto do SS devem ser sobrepostos e a Tabela E.4 os métodos da camada GUI do SS.

Implementação do sistema específico - Esse passo pode ser realizado normalmente como definido no cookbook do GREN. Todavia, com relação a criação do menu principal da aplicação, deve-se seguir as instruções apresentadas na seção E.2.3 do Apêndice E. A elaboraçã̃o do script SQL para gerar a base de dados da aplicação resultante deve incluir as tabelas referentes ao SS contidas no script apresentado na seção E.2.4 do Apêndice E. Por fim, antes da compilação da aplicação, deve-se realizar a configuração do estado inicial do sistema conforme, instruções apresentadas na seção E.2.5 do Apêndice E.

Testes do sistema resultante - Esse passo deve ser rcalizado como definido no processo original de Braga (2002b). Contudo, o instanciador deve claborar casos de testes também para 
testar o SS embutido na aplicação resultante para garantir que a instanciação foi realizada corretamente.

\subsection{Teste da nova versão do framework GREN}

Os testes realizados anteriormente (seção 4.3.3) tiveram dois propósitos. O primeiro foi testar o SS inserido em uma aplicação completa, testando todos os passos do processo de instanciação do framework GREN. O segundo objetivo foi identificar os pontos no processo que deveriam ser modificados para incluir o SS na instanciação, o que foi descrito na seção 4.4.

Com a documentação atualizada faz-se necessário outro teste realizado por pessoa (ou pessoas) diferente daquelas que fizeram a evolução do sistema e a atualização da documentação. Este é equivalente a um teste Beta. Ncste caso, foi escolhida a Prof ${ }^{a}$. Rosana Braga, criadora da primeira versão do GREN, que realizou o teste instanciando um sistema para loja de brinquedos. A nova versão do GREN foi instalada no microcomputador da Prof ${ }^{2}$. Braga c a instanciação foi feita baseada apenas na documentação atualizada.

O resultado foi bastante bom, pois a instanciação foi feita sem problemas e sem necessidade de ajuda, tendo sido instanciada corretamente a aplicação. Esse teste mostrou que a documentação de instanciação, com as modificações introduzidas com a inscrção do Subsistema de Segurança, está apta a ser usada por outros engenheiros de software.

\subsection{Evolução do GREN-Wizard}

Após a implementação do SS e dos testes da nova versão do GREN resultante da manutenção apresentada anteriormente, foi realizada a evolução do GREN-Wizard (Braga \& Masiero, 2002a), que é uma ferramenta para auxiliar a instanciação automática do framework GREN, permitindo, assim, que as novas instanciações realizadas a partir dessa ferramenta incluam também as funcionalidades do Subsistema de Segurança.

Para a evolução do GREN-Wizard, inicialmente foi realizado um estudo de sua hierarquia de classes, para compreensão de sua atual implementação e identificação dos pontos a serem alterados em decorrência dessa evolução. A evolução realizada não implicou em alteração na estrutura de classes do GREN-Wizard, já que foram apenas acrescentados novos métodos relativos à instanciação das funcionalidades do SS. Nas Tabelas D.I e D.3 do Apêndice D, constam as classes alteradas, variávcis de instância adicionadas, métodos adicionados, alterados e corrigidos, respectivamente, do GREN c do GREN-Wizard decorrente do processo de evolução do GREN-Wizard. A Tabela D.2 apresentada também no Apêndice D, mostra as modificaçōes feitas na base de dados do GREN-Wizard.

A evolução realizada ć visível ao instanciador de aplicações em apenas dois passos do processo de instanciação: 
1. Foi necessário incluir uma opção na interface gráfica para permitir a instanciação de aplicações com ou sem o SS. Essa alteração na interface do GREN-Wizard é apresentada na Figura 4.15 e destacada por uma área pontilhada e apontada por uma seta. Ela é visível ao instanciador logo no primeiro passo de instanciação, quando é solicitada a operação para criar uma nova aplicação.

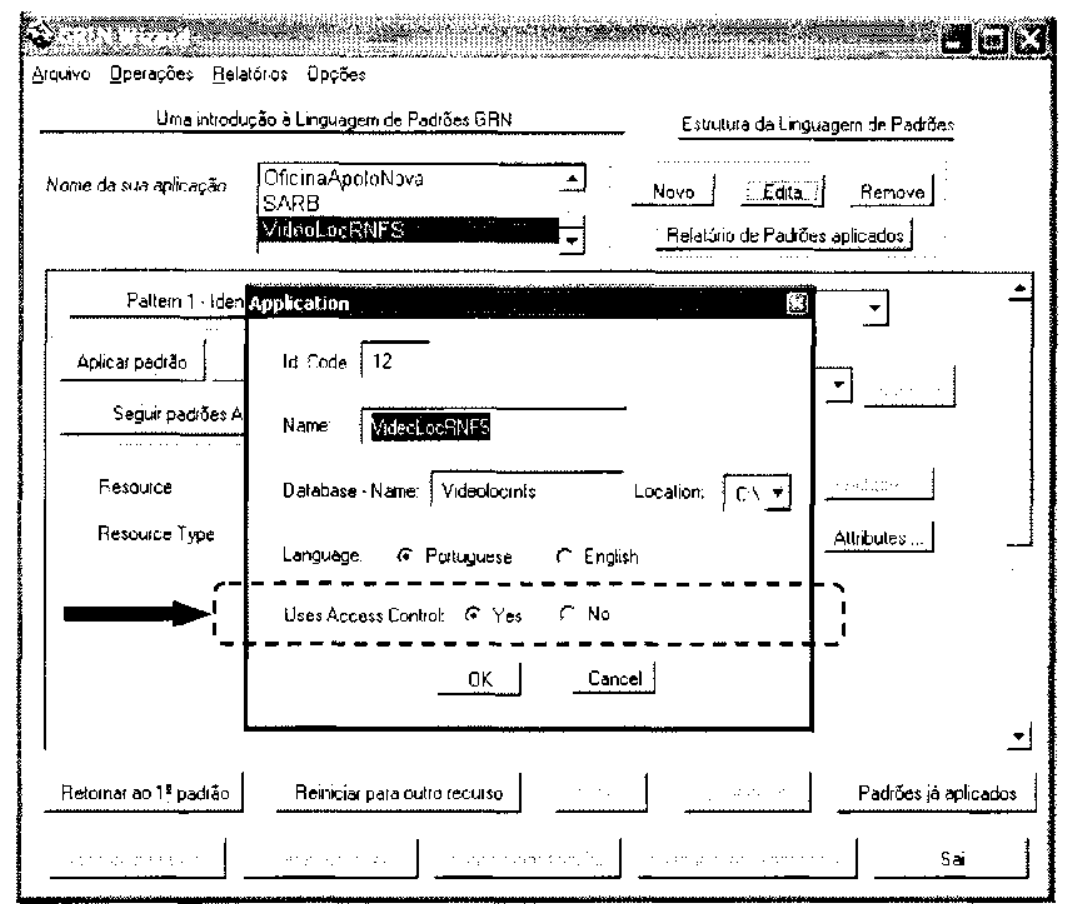

Figura 4.15: Interface GREN-Wizard (Criação de uma nova aplicação).

2. O segundo ponto visível ao instanciador ć a interface para configuração do estado inicial da aplicação instanciada, apresentada na Figura 4.16. Essa interface aparece automaticamente no final do processo de instanciação, após o instanciador executar a operação para criar as tabelas da base de dados da aplicação instanciada. Com essa interface, o instanciador deve somente solicitar a execução da operação por meio do botão configurar e a configuração é realizada automaticamente.

Após a evolução do GREN-Wizard, realizaram-se novos testes para verificar o seu funcionamento, gerando automaticamente vários sistemas. Neste caso, da mesma forma que o processo de instanciação caixa-branca, não houve modificaçôes nos passos de instanciação, apenas foi acrescentada uma opção para permitir que o instanciador escolha ou não incluir o SS, bem como um último passo, que é a tarefa de configurar o estado inicial da aplicação. O sistema faz a configuração do estado inicial da aplicação automaticamente, o instanciador necessita apenas selecionar essa operação na interface da ferramenta de instanciação. Os resultados dos testes foram satisfatórios, tendo atendido os requisitos do SS inicialmente propostos $\mathrm{c}$ também serviram para a correção de alguns erros encontrados na implementação original da ferramenta. 


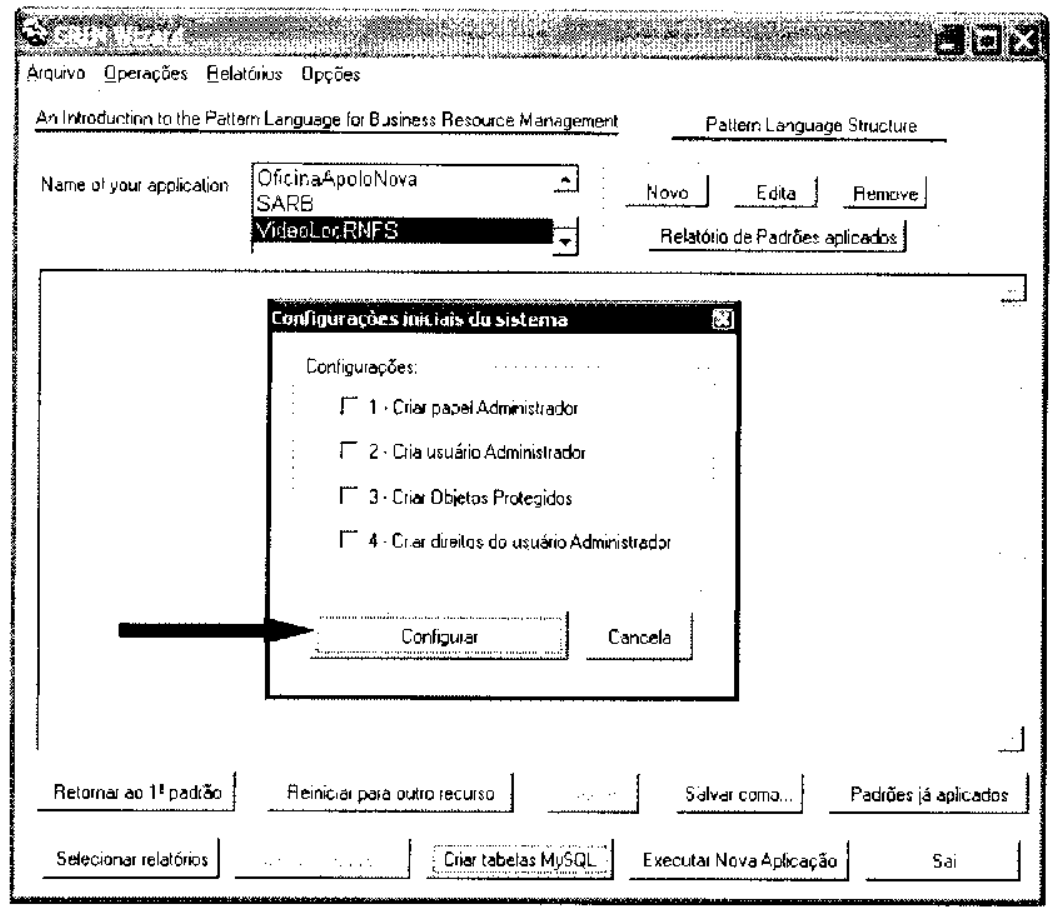

Figura 4.16: Interace GREN-Wizard (Configuração do estado inicial da aplicação)

\subsection{Gerenciamento de Controle de Versão}

A primeira versão do GREN (1.0) e do GREN-Wizard foi liberada como parte do trabalho de doutorado de Braga (2002b). Essa versão passou a ser usada por alunos do Grupo de Engenharia de software do ICMC para testes do framework e várias aplicações foram instanciadas de forma caixa-branca e/ou usando o GREN-Wizard. Vários erros encontrados durante essas instanciações e também requisitos que não puderam ser implementados deram origem a várias manutenções no GREN, uma das quais permitiu o desenvolvimento deste trabalho de mestrado. Partindo-se desse fato foi estabelecido o gerenciamento de controle de versão do GREN, que é representado, de forma visual, na Figura 4.17. As primeiras manutenções geraram uma segunda versão do GREN e do GREN-Wizard (1.1). A implementação do SS, apresentada neste capítulo, deu origem à versão 1.2 do GREN e do GREN-Wizard. A versão 1.2 é a primeira versão com parte orientada a aspectos do GREN.

Também vem sendo desenvolvida em paralelo uma nova versão do GREN para o ambiente Java contendo todas as funcionalidades da versão 1.1 mas, embora previsto, não há planos concretos para o desenvolvimento do GREN-Wizard para essa nova versão. 


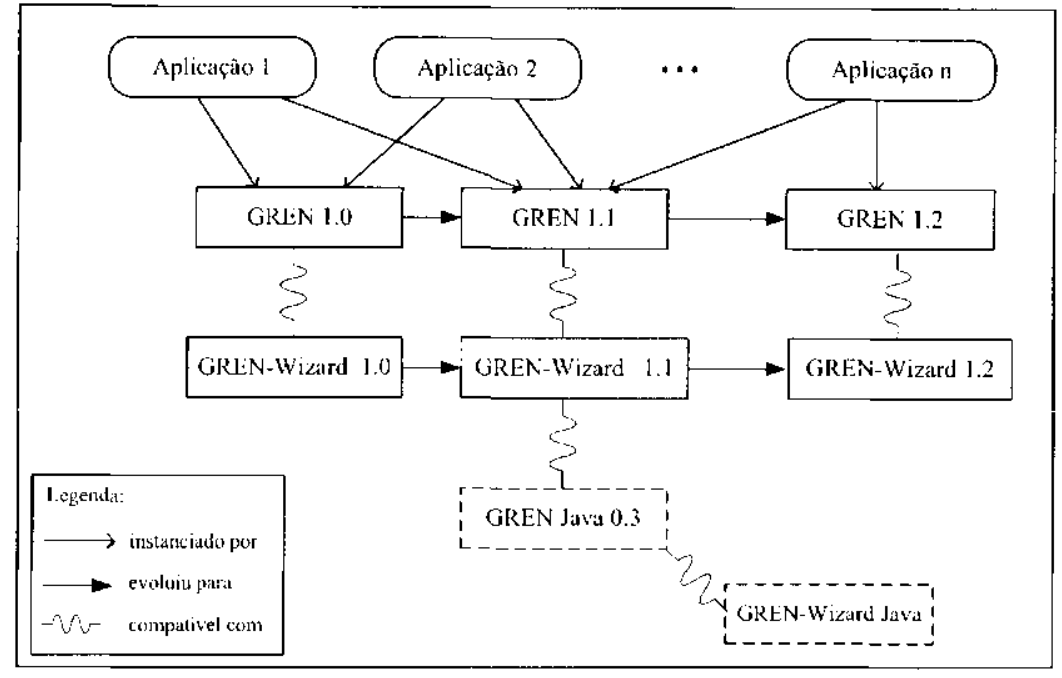

Figura 4.17: Planejamento de controle de configuração do GREN.

\subsection{Considerações Finais}

Neste capítulo foi apresentada a evolução do framework GREN, na qual foi realizada a implementação do Subsistema de Segurança de acordo com a abordagem POA. Em decorrência dessa evolução também foi feita cvolução da ferramenta para instanciação automática do GREN, a GREN-Wizard. Na evolução do GREN foram criadas dezessete novas classes e implementados quatrocentos e oito novos métodos referentes ao SS e também foram modificadas três classes do GREN: StaticobjectForm, BasicBusinessTransactionform e BasicQuotationForm. A evolução do GREN-Wizard não acarretou a criação de nenbuma classe nova, mas dezesseis novos métodos foram criados, quatorze métodos foram alterados e três métodos foram corrigidos. A evolução do GREN-Wizard também provocou modificações em sua base de dados e a alteração de um método do GREN. Embora o SS tenha sido implementado com aspectos, essa característica não tem impacto sobre o trabalho do instanciador de aplicações, pois o SS foi implementado como um componente fechado e scu pontos de instanciação (mesmo das classes aspecto) são métodos normais. Dessa forma, o instanciador de aplicações não necessita ter conhecimento dos conceitos da POA e tampouco sobre como esses conceitos são implementados pelo pacote de classes AspectS. 


\section{Exemplo - Instanciação da nova versão do GREN para Sistema de Clínica \\ Veterinária}

\subsection{Considerações Iniciais}

Neste Capítulo mostra-se, passo a passo, a instanciação da nova versão do GREN, incluindo o SS, para o sistema de Clínica Veterinária. Primeiramente, é mostrada a instanciação realizada manualmente de forma caixa-branca e, em segundo, é apresentada a instanciação realizada por meio do GREN-Wizard

\subsection{Instanciação do GREN de forma caixa-branca.}

Esta instanciação seguiu os passos do manual de instanciação do GREN atualizado.

\subsubsection{Análise do Sistema}

O primeiro passo da instanciação é a análise do sistema com base na linguagem de padrões GRN (Braga et al., 1999). O resultado dessa análise é o modelo de classes mostrado na Figura 5.1 e o histórico de padrões e variantes que foram aplicados, os quais são apresentados na Tabela 5.1 c, para cstc caso, a decisão de incluir o SS nessa instanciação. Como pode ser 
obscrvado na Tabela 5.1, a GRN foi aplicada duas vezes, uma vez para o recurso Produto e outra para o recurso Animal, e o histórico de padrões e variantes é apresentado na ordem de aplicação da GRN. Os novos atributos inseridos em cada classe durante a fase de análise aparecem sublinhados na Figura 5.1 e os papéis desempenhados por cada classe no padrão aplicado aparecem representados nos balões.

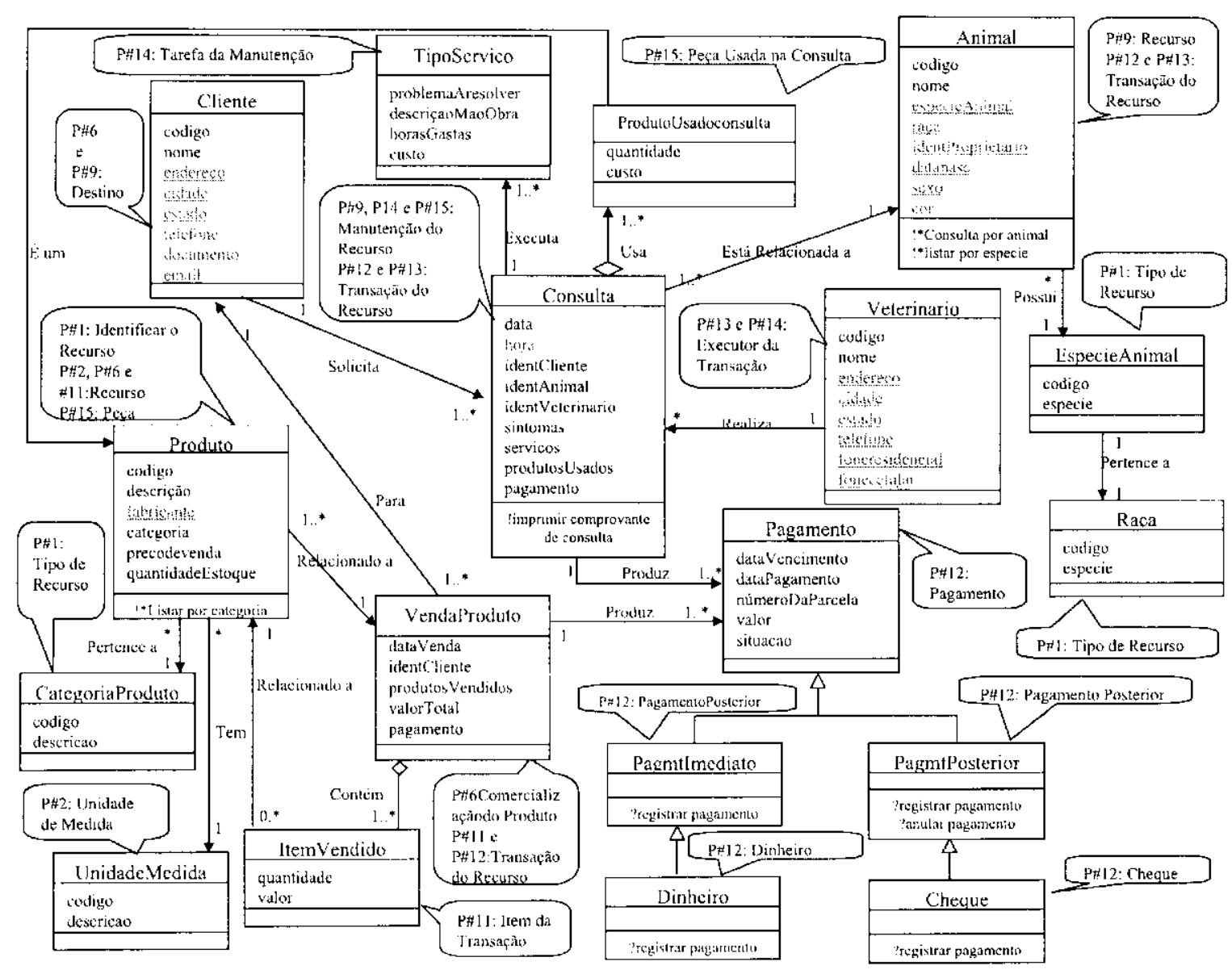

Figura 5.1: Modelo de análise do sistema para Clínica Veterinária com os padrões aplicados.

\subsubsection{Mapeamento do modelo de análise para o GREN}

O segundo passo consiste em fazer o mapeamento do modelo conceitual do sistema de Clínica Veterinária para o framework GREN, utilizando a documentação do GREN e os resultados obtidos no primeiro passo. A documentação do GREN é composta por diversas tabelas que mostram, para cada padrão da GRN, as classes correspondentes do GREN a serem especializadas e os métodos a serem sobrepostos durante a instanciação e, também, pelas tabelas que mostram as classes a serem especializadas e os respectivos métodos a serem sobrepostos referentes ao Subsistema de Segurança. O resultado deste passo é a criação de tabelas de mapeamento contendo a lista de classes e métodos correspondentes a screm implementados. As classes de 
Tabela 5.1: Padrões e variantes aplicados na fase de análise

\begin{tabular}{|c|c|c|}
\hline Padrão & Variante ou Sub-padrão & Papéis Desempentados $=$. Vome da Classe \\
\hline PI - Identificar o Recurso & Default & $\begin{array}{l}\text { Recurso = Produto } \\
\text { Tipo de Recurso = CalcgoriaProduto }\end{array}$ \\
\hline P2 - Quantificar o Recurso & Recurso Mensurável & $\begin{array}{l}\text { Recurso = Produto } \\
\text { Unicliade de Medida = Unidade.Medida }\end{array}$ \\
\hline P6 - Comercializar u Recurso & Sem origem - Vendia & $\begin{array}{l}\text { Recurso = Produto } \\
\text { Conercializaçâo do Recurso = VendaProduto } \\
\text { Destino = Clicntc }\end{array}$ \\
\hline PII - ltemizar Transaçũo do Recurso & Default & $\begin{array}{l}\text { Recurso = Produtu } \\
\text { Transaçāo do Recurso = VendaProdutuo } \\
\text { Item da Transą̧̧âo = ltemVendido }\end{array}$ \\
\hline P12 - Pagar pela Tratusação do Recurso & Default & 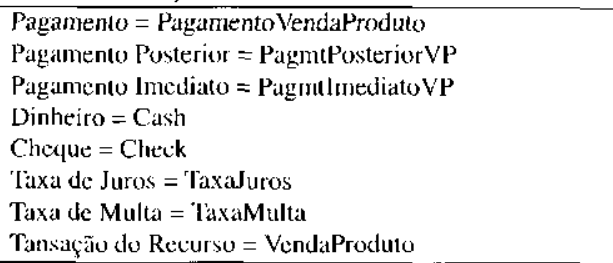 \\
\hline$\overline{\mathrm{Pl}}$ - Identificar o Recurso & Múltiplos Tipos de Recurso & $\begin{array}{l}\text { Recurso = Animal } \\
\text { Tipo de Recurso = Fspecie } \\
\text { Tipo de Recurso = Raca }\end{array}$ \\
\hline P9- Manter o Recurso & Sem origem & $\begin{array}{l}\text { Recurso = Animal } \\
\text { Manutençäo do Recurso = Consulta } \\
\text { Destino= Cliente }\end{array}$ \\
\hline P12 - Piggar pela Transiçāo do Recurso & Default & 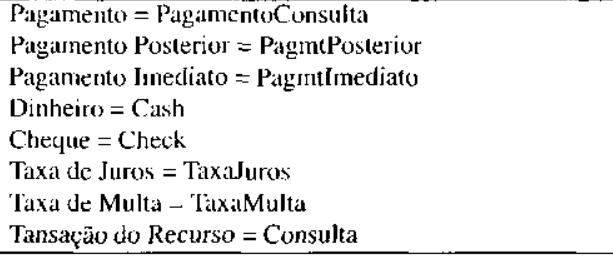 \\
\hline P13-Identificar o Executor da Transaçẫo & Sem comissä́o & $\begin{array}{l}\text { Executor da Transaçäo = Velerinário } \\
\text { Tratasaçăo do Recurso = Consulta }\end{array}$ \\
\hline P14 - ldentificar as Tarefas da Manulençăo & Default & $\begin{array}{l}\text { Tarefa de Manutenção = TipoServico } \\
\text { Manutenção do Recurso = Consulta } \\
\text { Exccutor da Manutençăo = Veterinario }\end{array}$ \\
\hline P15 - Identificar Pef̧as da Manutenção & Default & 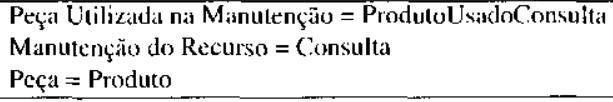 \\
\hline
\end{tabular}

negócio a serem implementadas foram mapeadas na Tabela 5.2 e as classes de interface gráfica com o usuário na Tabela 5.3. As tabelas contendo as classes e métodos referentes ao SS, a serem implementadas, já estão prontas e devem apenas ser consultadas na fase de implementação. As tabelas referentes à instanciação do SS são apresentadas no Apêndice E desta dissertação.

\subsubsection{Implementação do sistema para Clínica Veterinária}

O terceiro passo na instanciação do GREN para o sistema da Clínica Veterinária foi implementar as classes e métodos seguindo as tabelas de mapeamento obtidas no passo anterior. A documentação do GREN também fornece algoritmos que auxiliam na criação de novas classes, adaptação da interface gráfica com o usuário para a inserção de novos atributos e programação dos menus do sistema. A Figura 5.2 mostra parte da hicrarquia de classes do GREN e de classes derivadas no sistema para Clínica Veterinária. Ela apresenta o relacionamento de herança entre as classes da aplicação específica, as classes do GREN e as classes do Subsistema de Segurança. Além disso, essa figura também ilustra o relacionamento de interceptação entre 
Tabela 5.2: Mapeamento APP para Clínica Veterinária.

\begin{tabular}{|c|c|c|c|}
\hline $\begin{array}{l}\text { Classe da aplicação a ser } \\
\text { criada }\end{array}$ & Supcrclasse do GREN & Atributos adicionais & Métodos adicionais \\
\hline Consulta & ResourceMainlenance & horat & (set e get para os novos atributos) \\
\hline Cliente & DestinationParty & $\begin{array}{l}\text { cndereco, cidade, estado, telefone, } \\
\text { documento, cmail }\end{array}$ & (set e get para os novos auributos) \\
\hline Animal & Resource & $\begin{array}{l}\text { identProprietario, dattatlasc, sexo, } \\
\text { cor }\end{array}$ & (set e get para us novos atributos) \\
\hline EspecieAnimal & SimpleType & - & 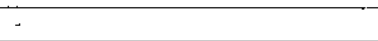 \\
\hline Raca & SimpleType & - & - \\
\hline Produto & StockResource & fabricante & (sct c gec para os novos atributos) \\
\hline CategoriaProduto & Simple'lype & - & - \\
\hline UnidadeMedida & Measurel/nity & - & - \\
\hline VendaProduto & Basicsale & - & - \\
\hline ItemVendido & Transactionltem & - & - \\
\hline Veterinario & TransactionExccutor & $\begin{array}{l}\text { endereco,cidade,eslado. foneresi- } \\
\text { dencial, fonccelular }\end{array}$ & (set e get paral os novos atributos? \\
\hline ProdutoUsadoConsultá & ManteinancePart & - & - \\
\hline Tiposervico & Mitinlenniance Task & & - \\
\hline PagamentovendaProduto & Payment & - & - \\
\hline PagmtImediato & Nada a Fazer & - & - \\
\hline PagmtPosterior & Nada a Fazer & - & - \\
\hline Cash & Cash & - & - \\
\hline Check & Check & - & - \\
\hline TaxaMulta & FineRate & - & - \\
\hline TaxaJuras & InterestRate & - & - \\
\hline PagamentoConsulta & Payment & - & - \\
\hline
\end{tabular}

Tabela 5.3: Mapeamento GUI para Clínica Veterinária.

\begin{tabular}{|c|c|c|c|}
\hline Classe da interface a ser criada & Superclasse do GREN & Nome do Spec no GREN & Spec a ser criado \\
\hline Consultaform & OncResourceMaintWPTWForm & oneResBasicMaintWTWPSpec & consultispec \\
\hline ClienteForns & DestimationPartyForm & windowSpec & clienteSpec \\
\hline AnimalForm & SingleResourceForm & singleResSpec & animulspec \\
\hline EspecicAnimalForm & StaticObjectForm & windowSpec & - \\
\hline Ralcaform & S1aticObjectForm & windowSpec & - \\
\hline ProdutoForml & MesasurableResourceForm & measResSpec & produtoSpec \\
\hline CategorialProdutotiorm & StaticObjectForin & windowSpec & 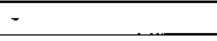 \\
\hline LinidadeMedida & MeasureUnityliorm & windowSpec & - \\
\hline VendiaProduroform & MultiResource'Tradeform & multiResTradeSpec & - \\
\hline ItemVendidoForm & Transactionltenform & meas'TransitemSpec & \\
\hline Veterinariof:orm & TransactionExccutorForm & transExecutorSpec & veterinarioSpec \\
\hline ProdutoUsadoConsuttaForm & ManteinancePartForm & windowSpec & -1 \\
\hline TipuServicoform & Maintennance'laskform & windowSpec & - \\
\hline PagamentoVendaProdutoForm & Paymeniform & windowSpec & 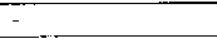 \\
\hline TaxaMultaForm & FineRalteform & windowSpec & - \\
\hline TaxaJurosliorm & InteresiRateForm & windowSpec & \\
\hline PagamentoConsultaForm & PilymentForm & windowspec & \\
\hline
\end{tabular}

as classes aspecto e as classes da aplicação específica ${ }^{1}$. Como pode-se observar, as classes aspecto $A s \Lambda u t h e n t i c a t i o n A p p$ e AsAccessLogApp interccptam apenas a classe principal da aplicação ClinicaVeterinariaMainwindow, já a classe aspecto AsAccesscontrolApp intercepta, além da classe principal da aplicação, várias outras classes da aplicação, uma vez que controla a execução das operações implementadas nessas classes.

'Para simplificaçăo, a Figura 5.2 apresenta apenas algumas classes da aplicação da Clínica Vetcrinária. 


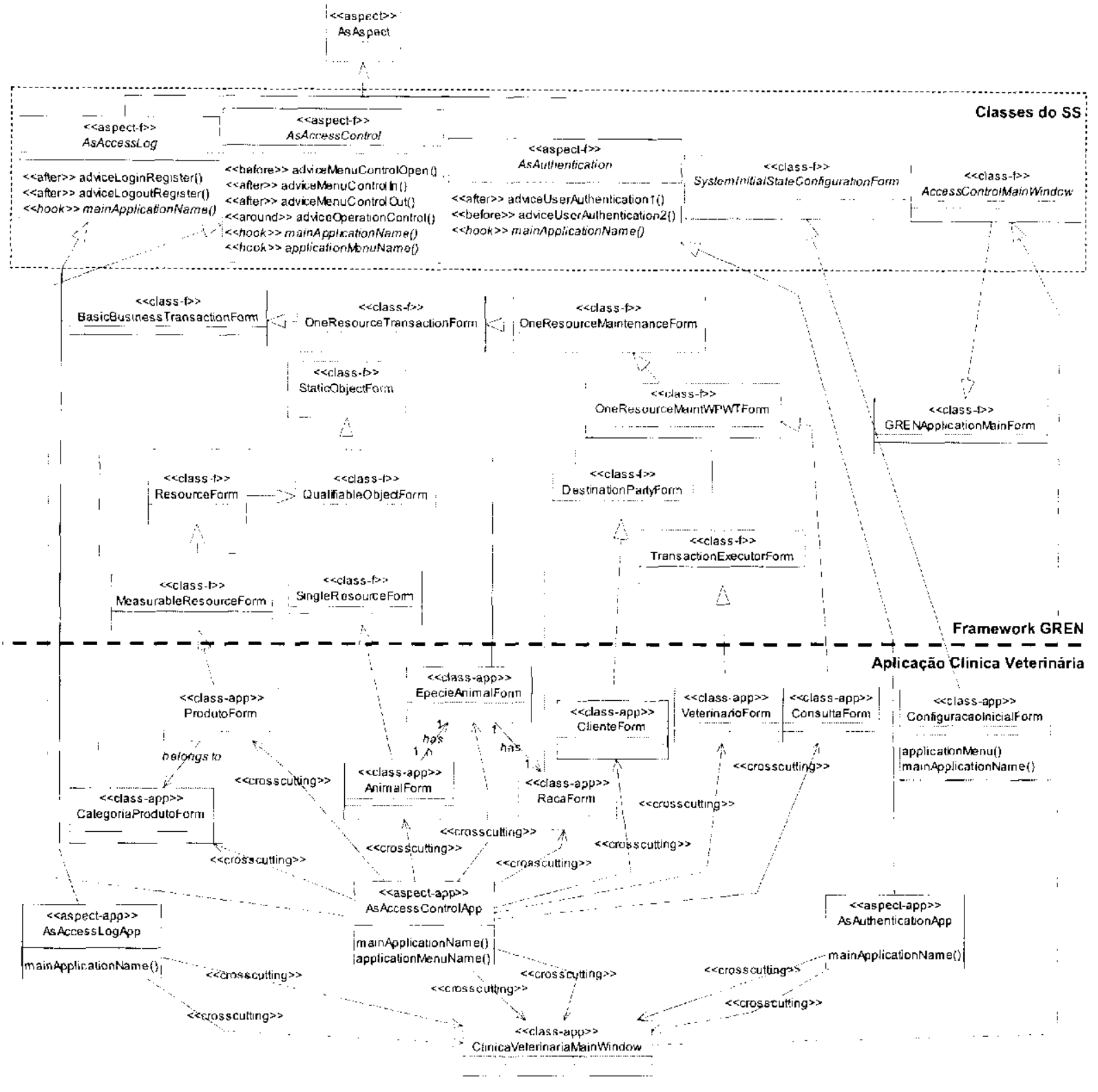

Figura 5.2: Parte da hierarquia de classes do GREN e de classes do sistema para Clínica Veterinária.

\subsubsection{Criação da base de dados para o sistema de Clínica Veterinária}

Após a implementação das classes e métodos do sistema para a Clínica Veterinária, o próximo passo é a criação de um script para gerar a base de dados da aplicação instanciada. A documentação do GREN apresenta um modelo de script default e um algoritmo, que usa essc modelo de script para especificar quais tabclas devem ser criadas conforme os padrões e variantes da GRN aplicados na análise do sistema. Além disso, apresenta também as tabelas que devem ser criadas caso a instanciação esteja considerando o Subsistema de Segurança. Dessa forma, o script para gerar a base de dados para o sistema da Clínica Veterinária contém, além 
das tabelas correspondentes aos padrões da GRN aplicado ao sistema, as tabclas correspondentes ao Subsistema de Segurança ${ }^{2}$.

\subsubsection{Configuração do estado inicial do sistema}

Após a criação da base de dados da aplicação, como o sistema para Clínica Veterinária inclui o SS, deve-se inicialmente configurar o estado inicial do sistema antes de sua compilação. Para tal foi executada a linha de comando abaixo no Workspace do ambiente VisualWorks.

Clinicaveterinaria.Conf iguracaoInicial.Form openwithspec: \#configspec

Essa linha de comando faz abrir a janela que permite ao instanciador solicitar a configuração automática do estado inicial da aplicação e pode ser visualizada na Figura E.I do Apêndice E.

\subsubsection{Teste do sistema para Clínica Veterinária}

Para testar o sistema de Clínica Veterinária foram elaborados casos de testes para todas as funcionalidades da aplicação, bem como do SS. Para tal, foram exercitadas toda as opções do menu. A Figura 5.3 mostra os menus e a janela principal do sistema de Clínica Veterinária. Algumas das opções dos menus selecionados nessa figura dizem respeito ao SS e são visualizadas apenas pelo usuário Administrador do Sistema. No menu Relatórios, somente o Administrador possui o direito de visualizar os dois últimos relatórios. No menu Manutenção, com exceção da primeira opção Alterar Senha, todas as demais opções são restritas ao Administrador do Sistema.

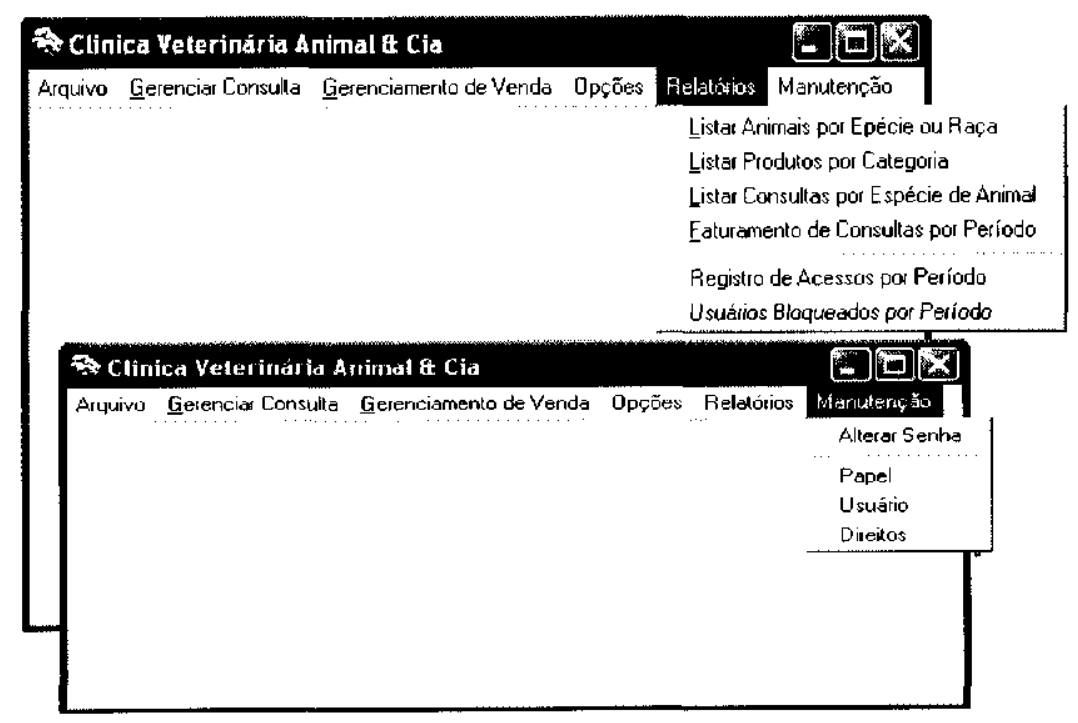

Figura 5.3: Menus e janela principal do sistema para Clínica Veterinária.

${ }^{2}$ Essas tabelas podem scr visualizadas no script contido no Apêndice E. 
Assim que a aplicação é compilada e a janela principal é aberta, o aspecto responsável pela autenticação apresenta a janela para que o usuário possa se conectar ao sistema, que pode ser observada na figura Figura 5.4. Na primeira execução do aplicação existe um único usuário, o Administrador do Sistema, que deve registrar os papéis da aplicação por meio da interface apresentada na Figura 5.5, atribuir direitos (permissões) a csses papéis por meio da interfacc mostrada na Figura 5.6 e registrar os demais usuários e atribuir-lhes papéis por meio da interface apresentada na Figura 5.7 .

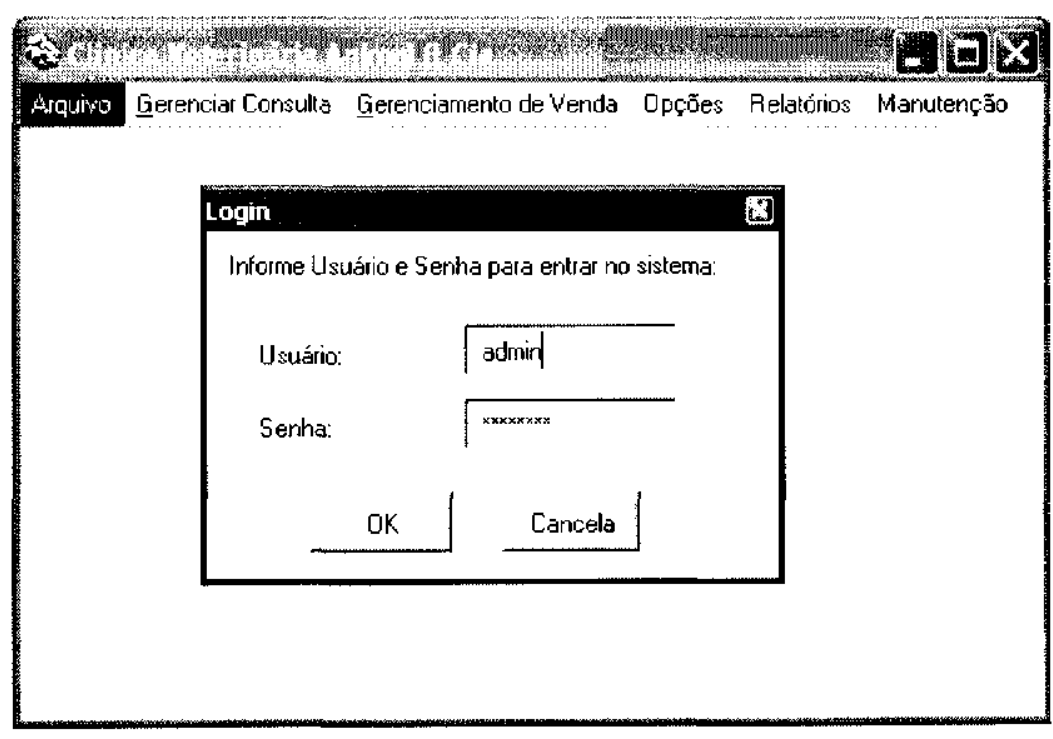

Figura 5.4: Janela para autenticação de usuários.

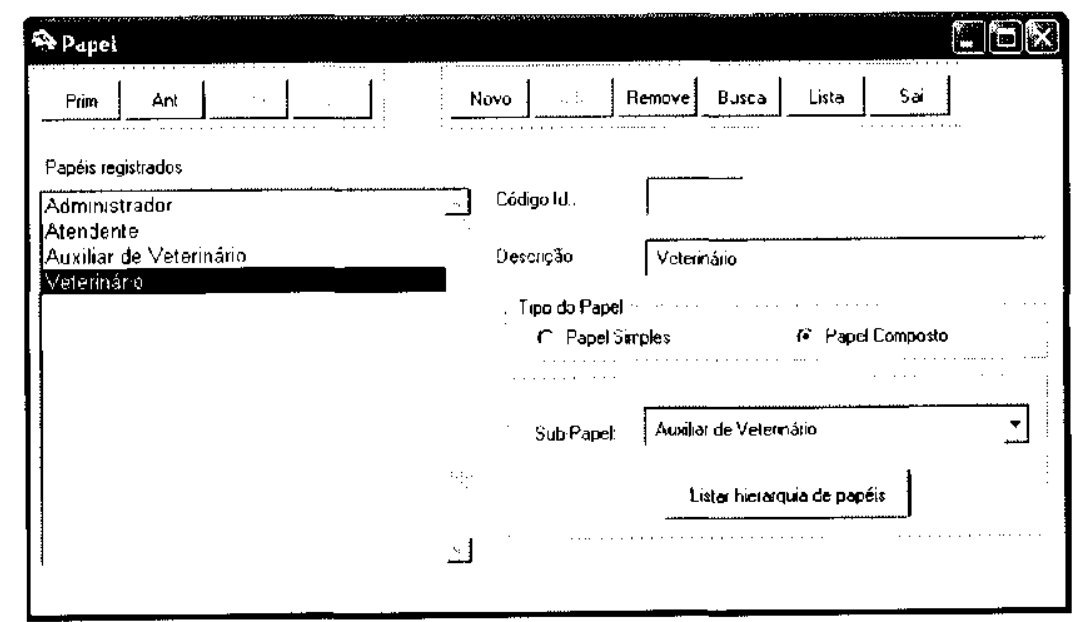

Figura 5.5: Janela para manutenção de papéis da aplicação . 


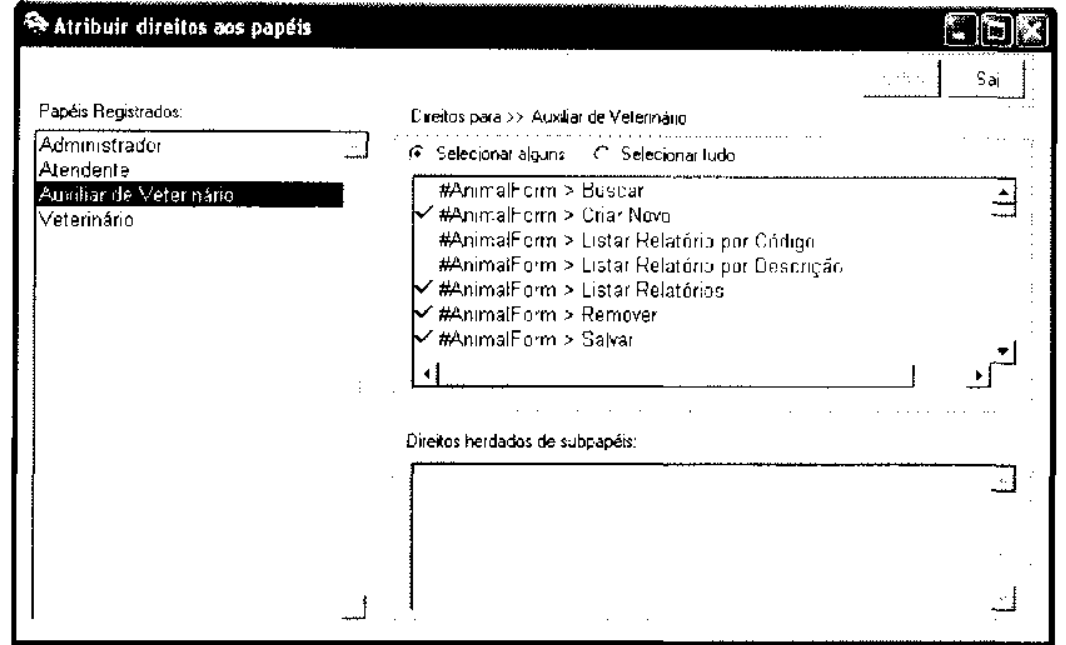

Figura 5.6: Jancla para atribuição de direitos aos papéis da aplicação.

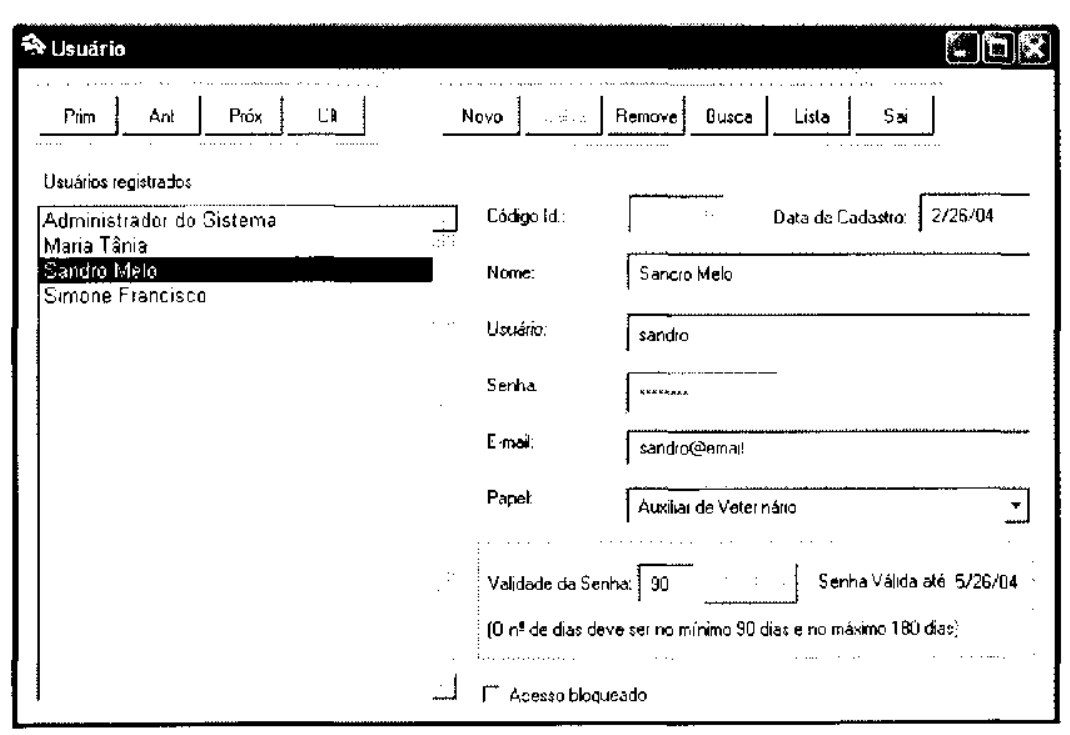

Figura 5.7: Janela para manutenção de usuários da aplicação.

A Figura 5.8 mostra um exemplo de um dos relatórios destinados ao Administrador do Sistema. O relatório de acessos $\mathrm{cm}$ um período é elaborado a partir de informações, que são armazenadas na base de dados por meio das interceptações do aspecto responsável por registrar a entrada e saída dos usuários do sistema. Esse relatório informa o usuário que tentou se conectar ao sistema, o status do acesso desse usuário e a data e hora de entrada e saída do sistema. 


\begin{tabular}{|c|c|c|c|}
\hline \multicolumn{4}{|c|}{ GREN Report } \\
\hline \multicolumn{4}{|c|}{$\begin{array}{l}\text { GREN-REPORTS - CLINICA VETERINÁRIA ANIMAL \& CIA } \\
\text { Registro de Acessos - Periado; 23/5/2004 a 26/5/2004 } \\
\text { Data: } 26 \text { de Haio de } 2004\end{array}$} \\
\hline Dsuririo & Stertus & Dita-Hara de Estrada & 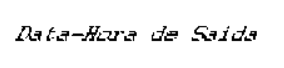 \\
\hline sandro & Acesso Permitido & $23 / 5 / 2004-3: 43: 11 \mathrm{pm}$ & $23 / 5 / 2004-4 \cdot 04: 42 \mathrm{pm}$ \\
\hline & $\begin{array}{l}\text { Acesso Permitido } \\
\text { Acesso Pexmitido }\end{array}$ & $\begin{array}{l}23 / 5 / 2004-3: 25: 31 \mathrm{pm} \\
25 / 5 / 2004-7: 45: 15 \mathrm{pm}\end{array}$ & $\begin{array}{l}23 / 5 / 2004-3: 32: 00 \mathrm{pm} \\
25 / 5 / 2004-8: 59: 41 \mathrm{pm}\end{array}$ \\
\hline Barbosa & $\begin{array}{l}\text { Acesso namo ido } \\
\text { Usuario naso existe. }\end{array}$ & $26 / 5 / 2004-9: 12: 12 \mathrm{pm}$ & - \\
\hline $\operatorname{admin}$ & Ácesso Permitido & $26 / 5 / 2004-9: 12: 41$ pn & - \\
\hline
\end{tabular}

Figura 5.8: Exemplo do relatório de registro de acessos $\mathrm{cm}$ um período.

A Figura 5.9 mostra uma interceptação do aspecto responsável por realizar o controle de acesso às operações do sistema. Essa figura ilustra uma tentativa de um usuário remover uma consulta. A execução dessa operação é interceptada pelo aspecto de controle de accsso e é checado o dircito de acesso do usuário corrente sobre a operação requisitada. Como o aspecto checou que o usuário não tem direito de acesso para executar tal operação, o aspecto executou o envio de uma mensagem de informação ao usuário, ao invés de permitir a execução da operação requisitada.

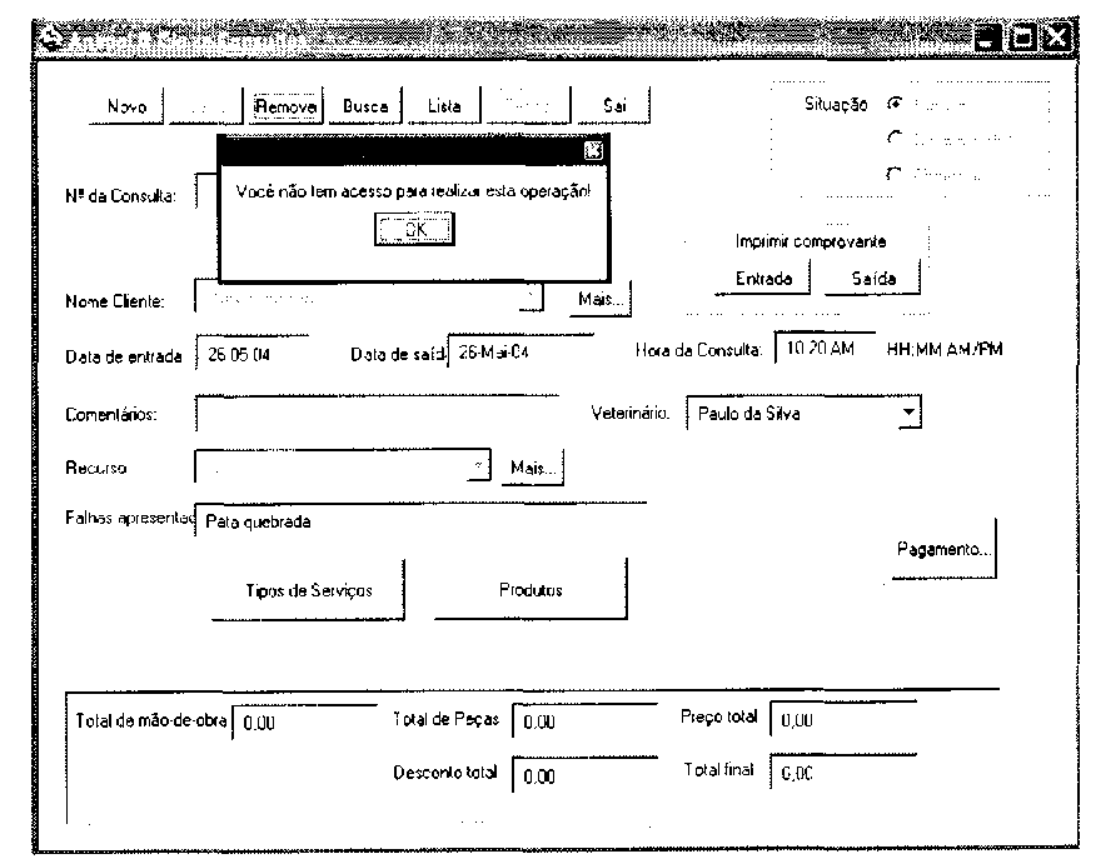

Figura 5.9: Excmplo da interceptação do aspecto que realiza o controle de acesso. 


\subsection{Instanciação do GREN usando a ferramenta GREN- Wizard}

O processo de utilizaçãao de um wizard definido por Braga (2002b) possui quatro passos: análise do sistema, uso do Wizard para a geração das classes da aplicação, implementação de funcionalidades não cobcrtas pelo framework e testes do sistema resultantc. Esses passos foram seguidos para a instanciação do sistema para Clínica Veterinária por meio do GREN-Wizard.

\subsubsection{Análise do Sistema}

Essa fase é idêntica à fase de análise para a instanciação dc forma caixa-branca, descrita anteriormente na seção 5.2.1. Nela produz-se o modelo de análise apresentado na Figura 5.1 e o histórico de padrões e variantes que foram aplicados, mostrados na Tabela 5.1.

\subsubsection{Uso do GREN-Wizard para a geração das classes da aplica- ção}

Para a utilização do GREN-Wizard na instanciação de uma aplicação deve-se seguir os seguintes passos (Braga et al., 2004):

Definição do Modelo . Neste passos são informados ao GREN-Wizard os padrões aplicados durante a fase de análise. Entretanto, antes de se informar os padrões aplicados devese criar uma nova aplicação. Ao solicitar essa operação é apresentada uma janela, na qual deve ser informado o nome da nova aplicação, Figura 5.10a, e em seguida seguida o GREN-Wizard apresenta uma outra janela na qual devem ser informadas as particularidades da nova aplicação, Figura 5.10b. Como essa aplicação deve incluir o Subsistema de Segurança essa opção foi selecionada e aparece destacada na Figura 5.10b por um retângulo tracejado. Em seguida devem ser informados os padrōes aplicados durante a fase de análise. A Figura 5.11 ilustra a aplicação do Padrão 14 - Identificar as tarefas da Manutenção.

Escolha dos relatórios . A Figura 5.12 mostra a interface fornecida pelo GREN-Wizard para a seleção dos relatórios da aplicação instanciada. Os relatórios disponíveis são relacionados aos padrões informados ao GREN-Wizard no passo de definição do modelo.

Geração das Classes . Neste passo, após terem sido informados todos os padrões e escolhidos os relatórios necessários, a operação Gerar Aplicação é solicitada. O GREN-Wizard gerará todas as classes da aplicação e também as classes pertinentes ao SS, bem como realizará a sobreposição e inserção, respectivamente, dos métodos e dos atributos necessários. 

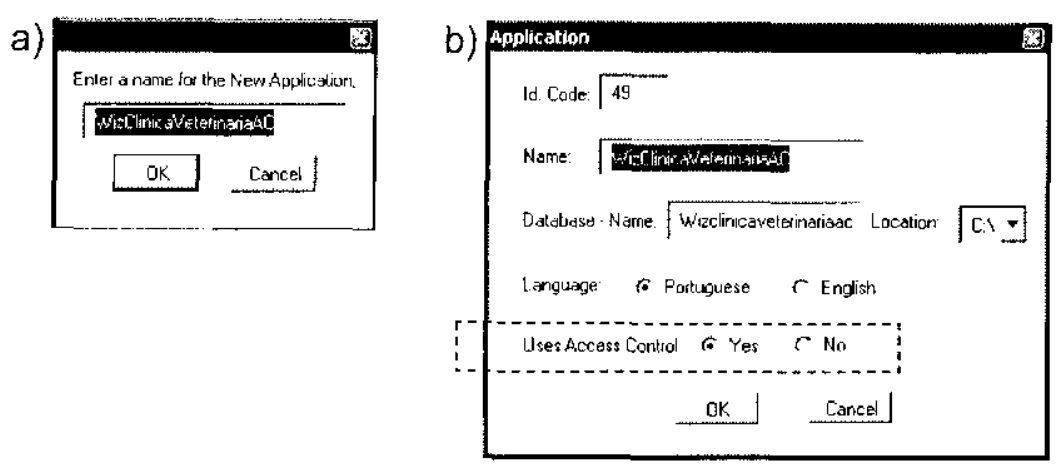

Figura 5.10: Janelas para a criação de uma nova aplicação.

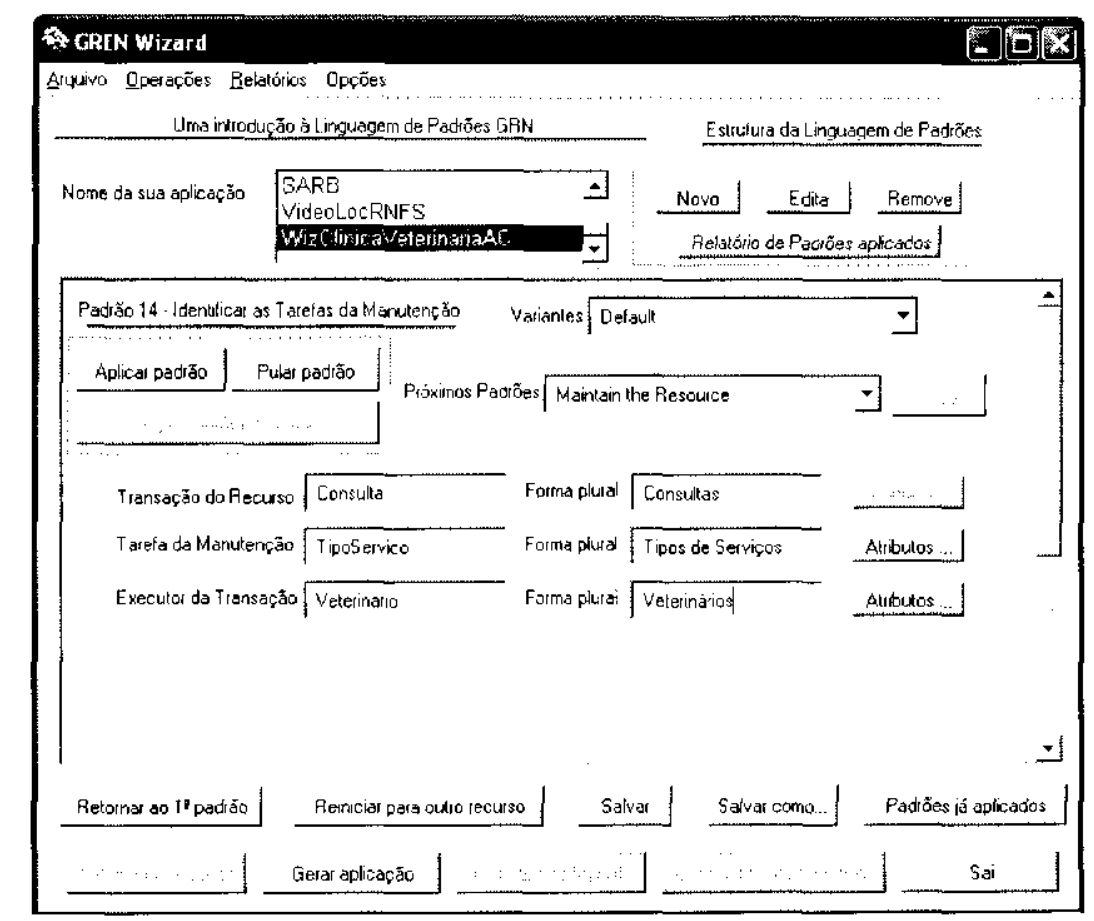

Figura 5.11: Exemplo da aplicação de um padrão.

Geração da base de dados . Neste passo, ao solicitar a operação para criar a base de dados, o GREN-Wizard criará todas as tabelas da aplicação e como essa instanciação incluiu o SS, as tabelas pertinentes a ele também serão criadas. Após criar a base de dados, o GRENWizard apresentará uma interface para que seja configurado o estado inicial da aplicação, mostrada na Figura 5.13.

Adaptação da interface gráfica com o usuário . Como são inseridos novos atributos em alguma classes, pode ser necessário ajustar o tamanho de algumas das interfaces da aplicação e também a posição dos atributos inseridos. 


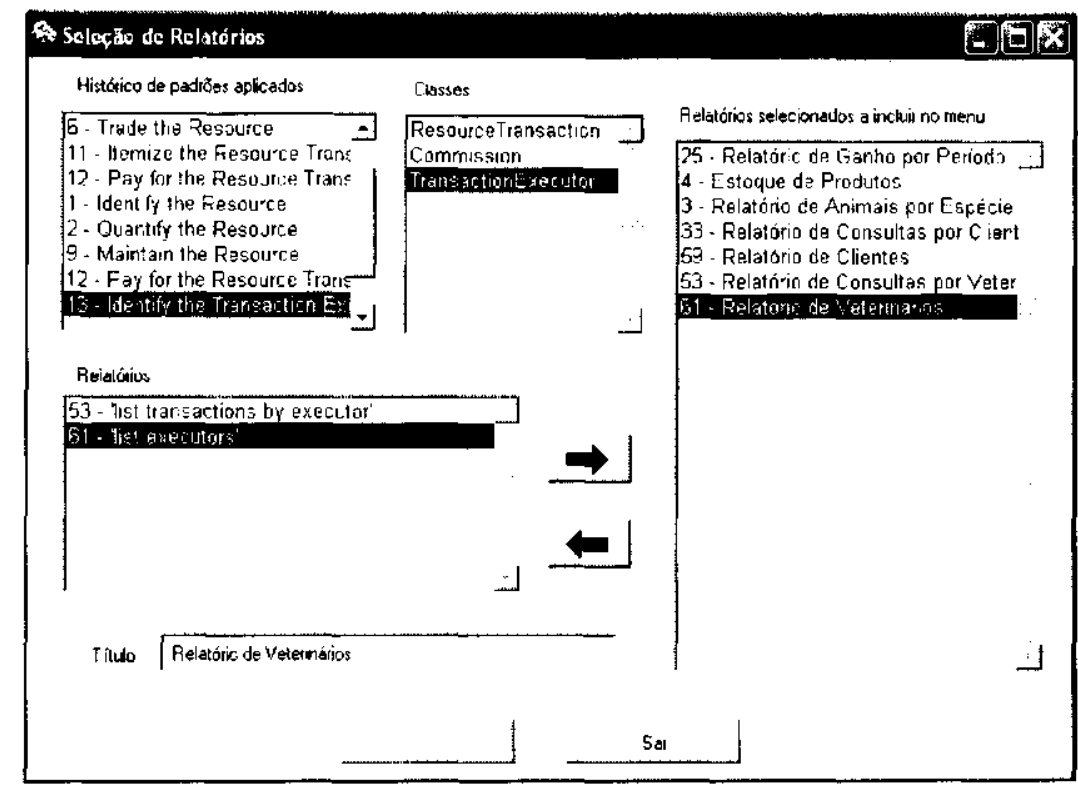

Figura 5.12: Jancla para seleção dos relatórios da aplicação.

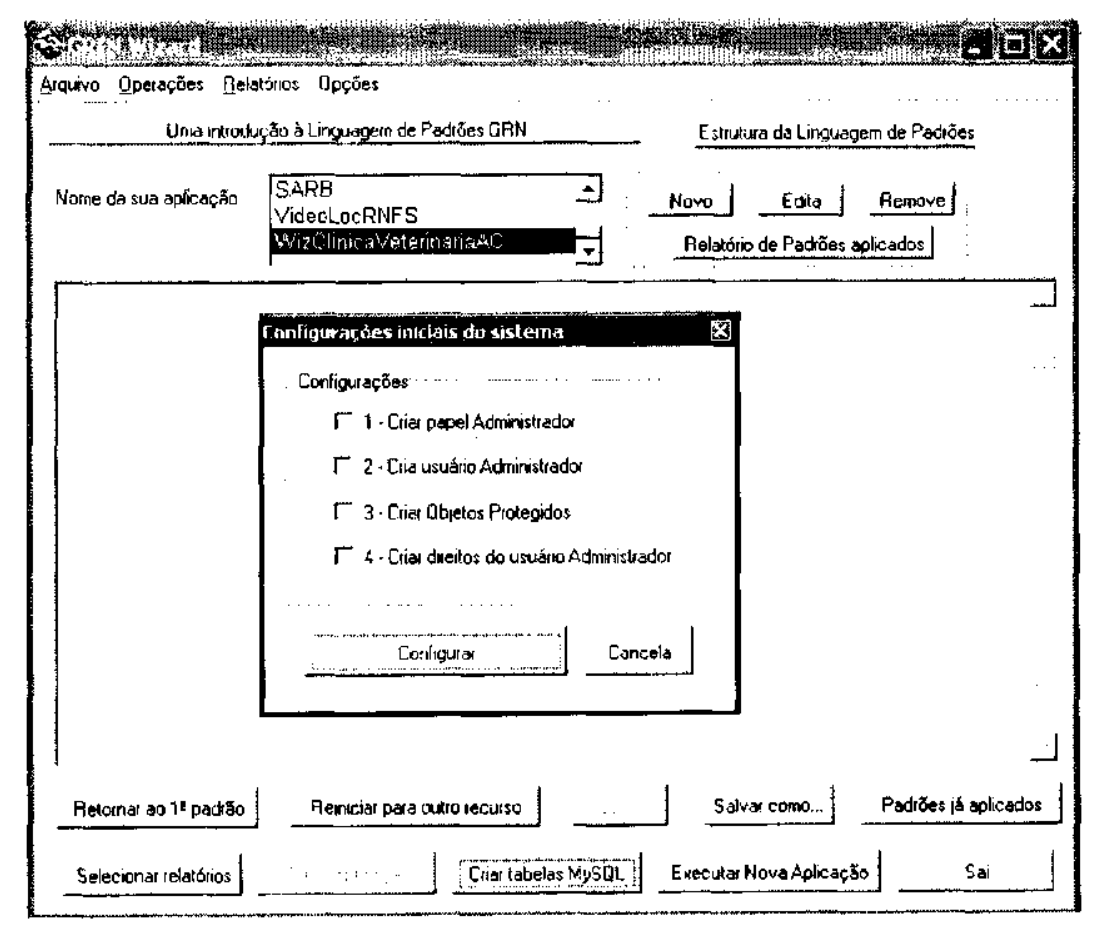

Figura 5.13: Contiguração do estado inicial do sistema para Clínica Veterinária.

\subsubsection{Implementação de funcionalidades não cobertas pelo fra- mework}

Todas as funcionalidades da sistema para Clínica Vetcrinária foram cobertas pelo GREN, dessa forma este passo não foi executado. 


\subsubsection{Testes do sistema resultante}

Esse passo é idêntico ao passo descrito na seção 5.2 .4 e, assim, foram elaborados casos de testes para testar o funcionamento da aplicação da Clínica Veterinária, assim como do Subsistema de Segurança. Exemplos de telas da aplicação gerada não são mostradas nesta seção porque são idênticas àquelas apresentadas na seção 5.2.4.

\subsection{Considerações finais}

Este Capítulo apresentou um exemplo de instanciação do framework GREN, incluindo o Subsistema de Segurança, primeiramente manualmente e de forma caixa-branca e em seguida usando o GREN-Wizard. Na instanciação manual foram gastas aproximadamente vinte e uma horas para obter o código final do sistema para Clínica Veterinária (cinco horas de análise, quatro horas para o mapeamento, oito horas para implementação e qualro para tesles). Infere-se que o tempo gasto na instanciação é menor do que o tempo que scria gasto se a mesma aplicação fosse programada sem o uso do framework, uma vez que exigiria um número de linhas de código muito maior. Na instanciação realizada as linhas de código adicionadas consistem de código de métodos para lidar com os novos atributos que não faziam parte dos padrões aplicados, e alguns métodos que devem ser concretizados referentes ao Subsistema de Segurança. Na instanciação realizada com o GREN-Wizard foram gastos duas horas e quarenta minutos para a obtenção do código final da aplicação (quarenta minutos no uso do GREN-Wizard para a geração da aplicação c duas horas na rcalização dos testes da aplicação). Como a fase de análise já havia sido realizada na instanciação manual, ela foi reutilzada na instanciação com o Wizard e por isso foi desconsiderado o tempo gasto com essa atividade. O tempo gasto com os testes foi menor cm relação ao tempo usado na instanciação manual, simplesmente, porque, neste caso, foi realizado um número menor de testes. 


\subsection{Considerações Iniciais}

Este trabalho constituiu da cvolução do framework GREN, na qual foi implementado um Subsistema de Segurança orientado a aspectos (SS). A evolução realizada seguiu o processo de evolução de frameworks proposto por Cagnin et al. (2004). O SS foi implementado por meio de classes normais e classes aspecto. As classes aspecto foram implementadas a partir do pacote de classes AspectS. Após a evolução do GREN também foi rcalizada a cvolução da ferramenta GREN-Wizard para torná-la compatível com a nova versão do GREN criada.

\subsection{Avaliação}

$O$ uso de aspectos facilitou a manutenção realizada, em especial o projeto e a programação, porque toda a lógica da aplicação de segurança foi desenvolvida em separado, como se fosse um componente. Toda a interação entre o SS e as demais classes do framework GREN ć realizada por meio das classes aspecto do SS. Com isso, não foram inseridos erros no framework durante a implementação, crros que provavelmente poderiam ser inseridos ao fazer a manutenção tradicional, na qual o código do SS estaria espalhado e entrelaçado nas classes do framework. Pode-se concluir deste experimento, que manutenções aperfeiçoativas, nas quais um requisito não funcional ć completamente implementado, beneficiam-se grandemente da implementação orientada a aspectos. Requisitos funcionais que podem ser implementados como aspectos também podem se beneficiar, mas eles ocorrem em número muito menor. Outros tipos de manutenção, que apenas modificam funcionalidades existentes ou fazem adaptações ao 
ambiente operacional parecem não se beneficiar dessa tecnologia, mas esse não foi o foco destc trabalho.

O SS foi implementado como um componente fechado, no sentido de que se o engenheiro de aplicações optar por incluí-lo, deverá utilizar todas as funcionalidades por ele oferecidas. Entretanto, a implementação permite, com pouco esforço, tornar algumas funcionalidades opcionais como, por cxemplo, o registro de acesso, que poderia ser uma funcionalidade não implementada em uma aplicação específica. Para tal, o SS deveria ser instanciado de maneira caixa-branca. Neste caso, a classe encarregada da instalação do aspecto que trata do registro de acesso deveria ser especializada e o método responsável por essa tarefa ser sobreposto. Assim, o SS pode ser visto também como um framework que pode ter suas classes especializadas, permitindo a alteração das regras implementadas. Poderia também ser usado em conjunto com outras aplicações (implementadas cm linguagem Smalltalk) não instanciadas a partir do GREN. Entretanto, neste caso, seria necessário um estudo mais elaborado com relação à funcionalidade que executa automaticamente a configuração inicial dos objetos protegidos dessa aplicação, uma vez que, na implementação atual do SS, essa funcionalidade está fortemente ligada a algumas classes do framework GREN. Seria neccssário também a redefinição dos pontos de junção do aspecto que trata do controle de acesso da aplicação. Uma outra característica interessante do SS é o fato de que seus pontos de instanciação são métodos normais e, dessa forma, o instanciador da aplicação não necessita ter conhecimento sobre programação orientada a aspectos.

Com relação à implementação das classes aspecto do SS, foram, inicialmente, encontradas algumas dificuldades na utilização do pacote de classes AspectS. Por ser um pacote ainda em experimentação, havia poucos exemplos de uso e a documentação ainda não estava concluída na época de implementação do SS. Entretanto, após o estudo e execução dos exemplos disponíveis, concluiu-se que o pacote de classes AspectS atenderia à implementação do SS

$O$ fato de permitir a fácil habilitação ou não do SS em aplicações instanciadas a partir do framework GREN abre a possibilidade de uma utilidade importante da abordagem orientada a aspectos: pontos variáveis do framework que têm características de opcionalidade como, por excmplo, habilitar ou desabilitar uma certa funcionalidade, são candidatos a serem implementados utilizando aspectos.

Para a instanciação caixa-branca da nova versão do GREN foi usado o processo genérico de instanciação de frameworks proposto por Braga (2002b). A particularização desse processo para a instanciação da nova versão do GREN não altcrou os passos do processo seguido, apenas novas tarefas a serem realizadas com relação à instanciação do SS foram adicionadas $\mathrm{cm}$ pontos específicos dos passos do processo.

Manutençōes preventivas, nas quais é feito um refatoramento de funcionalidades já existen tes, também podem ser realizadas usando a abordagem de programação orientada a aspectos Entretanto, percebe-se que esse tipo de manutenção exige um esforço adicional, pois além do esforço necessário para a implementação de tal funcionalidade seguindo a abordagem de POA e identificação dos pontos de junção no código existente, é necessário também, um esforço para 
reestruturar o código existente, pois é preciso remover o código que se encontra espalhado e entrelaçado pelas diversas classes do framework. Este fato aumenta a complexidade da manutenção, uma vez que pode acarretar em alterações na estrutura das classes do framework e conseqüentemente provocar manutenção em blocos de código que não estejam diretamente ligados ao interesse tratado e, sendo assim, é mais suscetível à introdução de erros nas funcionalidades do framework. Processos de engenharia reversa de sistemas $O O$ visando à reorganização do código base em OA (Aspectualização) têm sido publicados recentemente (Ramos, 2004).

\subsection{Contribuições}

A realização deste trabalho contribuiu para mostrar que a arquitetura geral dos frameworks orientados a objetos pode ser estendida por meio de aspectos, criando módulos (componentes e aspectos) independentes que facilitam o reuso e a manutenção. Esta possibilidade ocorre principalmente para a implementação de requisitos não funcionais. O reuso é favorecido, pois além de ser o principal objetivo dos frameworks, com a adição da abordagem de programação orientada a aspectos, um aspecto pode ser reusado simplesmente incluindo-o ou não nas instanciações do framework. Já a manutenção é favorecida principalmente pela independência obtida entre componentes $\mathrm{c}$ aspectos, possibilitando a introdução de uma nova funcionalidade sem a inserção de erros no código existente.

Este trabalho contribuiu também para a melhoria do framework GREN, para o qual foi criada uma nova versão que inclui um novo requisito inicialmente não implementado em suas primeiras versões. Dois trabalhos de doutorado, em andamento, ambos do Grupo de Engenharia de Software do ICMC-USP também foram beneficiados, pois este trabalho serviu para aperfeiçoar o processo de evolução de frameworks proposto por Cagnin et al. (2004) em seu trabalho de doutorado (Cagnin, 2002) e para validar e checar a generalidades dos perfis UML-AOD (Camargo \& Masiero, 2004b) e UML-AOF (Camargo \& Masicro, 2004a) propostos durante o desenvolvimento do trabalho de doutorado de Camargo (2003).

\subsection{Sugestões de Trabalhos Futuros}

Como resultado da análise realizada no framework GREN há dois requisitos não funcionais que poderiam ser implementados seguindo a abordagem de POA: o requisito de persistência e o controle dos componentes relativos à interface gráfica com o usuário (GUI). O código relativo ao controle dos componentes da GUI do GREN encontra-se totalmente espalhado nas classes responsáveis pela interface gráfica do GREN. O requisito de persistência foi implementado no GREN conforme o padrão PersistentLayer (Yoder et al., 1998) por meio da classe Persistenteobject. A conexão com a base de dados é tratada por meio da classe ConnectionManager $\mathrm{c}$ a classe OIDManager trata da geração do código dos objetos persis 
tentes. Embora essa implementação tenha se preocupado cm separar o interesse de persistência atribuindo as responsabilidades de persistência dos dados à classe Pers istenteobject, ainda assim, a implementação desse requisito cncontra-se espalhada por outras classes do framework, pois existem métodos abstratos que devem ser concretizados durante a fase de instanciação do framework nas classes que representam objetos persistentes e que devem ser especializadas a partir de classes do GREN que herdam direta ou indiretamente da classe Persistentobject. Além disso, existem métodos relativos ao requisito de persistência implementados en algumas classes do GREN.

Uma outra sugestão de trabalho futuro é a extensão do SS para aperfeiçoar suas funcionalidades. Por exemplo, o aspecto responsável pelo registro de acessos poderia ser estendido para armazenar na base de dados todas ou as operações mais críticas (como exclusão de informações, registro de pagamentos, ctc) realizadas pelo usuário na aplicação. Na implementação atual esse aspecto registra apenas a entrada e saída do usuário na aplicação.

O SS também poderia ser usado com outras aplicaçōes implementadas em linguagem Smalltalk não derivadas de instanciações a partir do framework GREN realizando-se, assim, um experimento para avaliar a dificuldade desse tipo de reuso e que mudanças deveriam ser feitas na arquitetura do SS para facilitar essc tipo de reuso.

Também poderiam ser feitos experimentos, usando a abordagem de POA, para o tratamento de requisitos funcionais como, por exemplo a implementação de partes variáveis do framework, que poderiam ser implementadas como aspectos e que scriam ativadas durante o processo de instanciação ou execução dinâmica do framework. 


\section{Referências Bibliográficas}

AKsit, M.; TEKINERDOGAN, B. Solving the modeling problems of object-oriented languages by composing multiple aspects using composition filters. In: Proceedings of the Workshop on Aspect Oriented Programming (ECOOP 1998), Brussels - Belgium: Springer-Verlag, 1998.

ALwis, B. S. Aspects of Incremental Programming. Dissertação de Mestrado, University of Britsh Columbia, Vancouver, Canada, 2002.

AOSD Aspect-oriented software delop homepage. 2004. Disponível $\mathrm{cm}:<\mathrm{http}: / /$ www. aosd. net >. Acesso em: 12/03/2004.

ASPECTS AspectS homepage. 2004. Disponívcl cm: <http://www-ia. tu-ilmenau.de/ hirsch/Projects/Squeak/AspectS/\#aspects>. Acesso em: $12 / 03 / 2004$

Becker, U, D ${ }^{2} \mathrm{AL}$ : A design-based aspect language for distribution control. In: Proceedings of the International Workshop on Aspect-Oriented Programming at ECOOP, Brussels - Belgium: Springer-Verlag, 1998.

BRAGA, R. T. V. Manual de instanciação do GREN. ICMC - USP, São Carlos SP, documento de trabalho, 96 p., versão 1.1, 2002a

BRAGA, R. T. V. Um processo para construção e instanciação de frameworks baseados em uma linguagem de padrões para um domínio especifico. Tese de Doutoramento, ICMC/USP, São Carlos - São Paulo, 2002b.

Braga, R. T. V.; Germano, F. S. R.; Masiero, P. C. A pattern language for bussiness resource management. In: Proccedings 6th Annual conference on Pattern Languages of Programs (PLP'99), Monticello, Illinois, EUA, 1999, p. 1 - 33. 
Braga, R. T. V.; Germano, F. S. R.; Masiliro, P. C. System development using a pattern language-based tool. In: In: 6th International Conference on Enterprise Information Systems, Porto - Portugal, 2004, p. 155 - 162.

Braga, R. T. V.; MASiero, P. C. Gren-wizard: a tool to instantiate the GREN framework. In: Caderno de Ferramentas do $16^{\circ}$ Simpósio Brasileiro de Engenharia de Software (SBES), Gramado-RS, 2002a, p. $408-413$.

Braga, R. T. V.; MASIERO, P. C. A process for framework construction based on a pattern language. In: Proccedings of the 26th Annual International Computer Software and Applications Conference (COMPSAC 2002), Oxford, Inglaterra: IEEE, 2002b, p. 615 - 620.

BraGA, R. T. V.; MASIERO, P. C. The role of pattern languages in the instantiation of object-oriented frameworks. In: Proccedings of the Workshop on Reuse in Object-Oriented Informations Systems Design, 8th International Conference on Object-Oriented Information Systems (OOIS'02), Montpellier, France: Springer-Verlag, lecture Notes On Computer Science, 2002 c, p. $122-131$.

Brant, J. Methodwrappers homepage. 2004. Disponível em: <http://st-www. cs.uiuc.edu/ brant/Applications/MethodWrappers.html>. Acesso em: $12 / 03 / 2004$

CAGNIN, M. I. Investigação e definição de um processo de reengenharia orientada a objetos visando ao apoio por computador, Monogralia de Qualificação de doutorado apresentada ao ICMC - USP, 2002.

Cagnin, M. I.; Mal.donado, J. C.; Glrmano, F. R.; Masiero, P. C.; Braga, R. T. V.; SILVA, M. T. F.; PENTEADO, R. D. A comprehensive evolution process for application frameworks, submitted paper, 2004.

Cagnin, M. I.; Maldonado, J. C.; Pinteado, R. D.; Germano, F. R. Parfait: Towards a frameworks-based agile reengineering process. In: Agile Development Conference, Salt Lake City, Utha, EUA, 2003, p. $22-31$.

CAmargo, V. V. Desenvolvimento de frameworks no contexto da separação de interesses, Monografia de Qualificação de doutorado apresentada ao ICMC - USP, 2003.

Camargo, V. V.; Masifro, P. C. Aspect-based persistence framework. Relatório Técnico, ICMC - USP, São Carlos - SP, 2003.

CAMARgo, V. V.; MASIERO, P. C. Um perfil UML para o projeto de framewoks orientados a aspectos. Relatório Técnico, ICMC - USP, São Carlos - SP, 2004a.

CAMARGO, V. V.; MASIERO, P. C. Um perfil UML para projeto de sistemas orientados a aspectos. Relatório Técnico, ICMC - USP, São Carlos - SP, 2004b. 
Camargo, V. V.; Ramos, R. A.; Penteado, R.; Masiero, P. C. Projeto baseado em aspectos do padrão da camada de persistência. In: Simpósio Brasileiro de Engenharia de Software (SBES), Manaus - Brasil, 2003.

Chavez, C.; Lucena, C. P. Desing suport for aspect-oriented software development. In: In: Doctoral Symposium at OOPSLA'2001 and Poster Session at OOPSLA'2001, Tampa Bay, Florida, USA, 2001.

CINCOM VisualWorks 5i.4 non-commercial. 2004. Disponível em: <http://www. cincom. com>. Acesso em: 17/02/2004.

Constantinides, C.; Bader, A.; Elrad, T.; Fayad, M.; Netinant, P. Designing an aspect oriented framework in a object oriented environment. In ACM Computing Surveys Symposium on Applications Frameworks, v. 32, n. 1, 2000

Elrad, T;; Aksit, M.; KicZales, G.; Lieberherr, K.; Ossher, H. Discussing aspects of AOP. Communications of the ACM, v. 44, n. 10, p. $33-38,2001$ a

EI.RAD, T.; FII.MAN, R. E.; BADFR, A. Apect-oriented programming: Introduction. Communications of the ACM, v. 44, n. 10, p. $29-32,2001 \mathrm{~b}$.

FAYAD, M. E.; SCHMIDT, D. C. Object-oriented application frameworks. Communications of the $A C M$, v. 40, n. 10 , p. $32-38,1997$.

FAYAd, M. E.; SChmidt, D. C.; Jonilson, R. E. Application frameworks. In: "Mohamed E. Fayad, Douglas C. Schmidt and Ralph E. Johnson Building Application Frameworks: Object-Oriented Fundations of Framework Design, John Wiley and Sons, p. 3- 27 ”, 1999.

FERnANDez, E. B.; PAN, R. A pattern language for security models. In: Proceedings of the 8th Conference o Pattern Languages of Progrms (PLOP'O1), Monticello, Illinois, EUA, 2001 .

FILTERS Aspect-oriented research on composition filters homepage. 2004. Disponível em: <http://tres.cs.utwente.nl/composition_filters >. Acesso em: $12 / 03 / 2004$.

Fontoura, M.; Pree, W.; Rumpe, B. The UML profile for framework architectures. Addison Wesley, 2002.

Gamma, E.; HELM, R.; JOHNSON, R.; VLISSIDES, J. Desing patterns-elements of reusable object-oriented software. Addison-Wesley Computing Series, 1995.

Garcia, A.; Silva, V.; Chavf.7, C.; LlCena, C. Engineering multi-agent systems with aspects and patterns. Journal of the Brazilian Computer Society, v. 8, n. 1, p. $57-72,2002$. 
Gimenes, I. M. S.; Travassos, G. H. O enfoque de desenvolvimento de linha de produto para desenvolvimeto de software. $21^{\circ}$ Jornada de Atualização em Informática, evento Integrante do $22^{\circ}$ Congresso da SBC, 2002.

GRADECKI, J. D.; LESIECK1, N. Mastering aspectJ-aspect oriented programming in java. $1^{\circ} \mathrm{ed}$. Wiley Publishing, 2003.

VAN GuRP, J.; BosCh, J. Design, implementation and evolution of object oriented frameworks: concepts and guidelines. Software - Practice and Experience (SPE), v. 31, n. 3, p. $277-300,2001$

HARRISON, W.; OSSHER, H. Subject-oriented programming (a critique of pure objects). In: Proccedings of the Conference on Object-Oriented Programming: Systems, Languages and Applications (OOPSLA'93), Washington: ACM, 1993, p. $411-428$.

Harrold, M. J.; MCGregor, J. D.; FitzPatrick, K. J. Incremental testing of objectoriented class structures. In: Proceeding of the 14th International Conference on Software Engineering, Melbourne, Australia: ACM Press, 1992, p. 68-80.

HirschFet.D, R. AspectS - Aspect-Oriented Programming with Squeak. In: Revised Papers from the International Conference NetObjectDays on Objects, Components, Architectures, Services, and Applications for a Networked World, v. 2591 de Lecture Notes in Computer Science, Springer-Verlag, 2002, p. 216-232 (Lecture Notes in Computer Science, v.2591).

HYPER/J, I. H. Hyper/J ${ }^{T M}:$ Multi-dimensional separation of concerns for java ${ }^{T M} .2004$. Disponível em: <http://www.research.ibm.com/hyperspace/HyperJ/ HyperJ . htm >. Acesso em: 12/(03/2004.

Kiczales, G.; Hilsdale, E.; Hugunin, J.; Kersten, M.; Palm, J.; Griswoi.d, W. G. An Overview of AspectJ. Lecture Notes in Computer Science, v. 2072, p. 327-355, $2001 \mathrm{a}$.

Kiczales, G.; Hilsdale, E.; Hugunin, J.; Kersten, M.; Pal.m, J.; Griswold, W. G. Getting Started with AspectJ. Communications of the ACM, v. 44, n. 10, p. 59-65, $2001 \mathrm{~b}$.

Kiczales, G.; Lamping, J.; Menidihekar, A.; Maeda, C.; Lopes, C.; Loingtier, J.M.; IRWIN, J. Aspect-oriented programming. In: Proceedings of the European Conference on Object-Oriented Programming, Springer-Verlag, 1997, p. 220-242.

KiSElEV, I. Aspect oriented programming with aspectj. $1^{\circ} \mathrm{ed}$. Sams Publishing, 2003.

LARMAN, G. Utilizando UML e padrões: Uma introduçăo à análise e ao projeto orientados a objetos. Bookman, 2000 .

LAy, A.; MurPhy, G.; WALKer, R. J. Separating concerns with hyper/J ${ }^{T M}$. In: Workshop on Multidimensional Separation of Concerns, ICSE, 2000. 
LOPES, C. V. D: A Language Framework for Distributed Programming. Tese de Doutoramento, College of Computer Science - Northeastern University, 1997.

MatTsson, M.; Bosch, J. Frameworks as components: A classification of framework evolution. In: Proccedings of Nordic Workshop on Programming Environment Research, Ronneby, Sweden, 1998, p. $163-174$.

Netinant, P.; Constantinides, C.; Elrad, T.; Fayad, M. Aspect-oriented frameworks: The design of adaptable operating systems. In: Addendum to the 2000 Proceedings of the Conference on Object-Oriented Programming, Systems, Languages, and Applications, Minncapolis, Minnesota, United States: ACM Press, poster Scssion, 2000, p. 61 - 62.

PACE, J. A. D.; CAMPO, M. R. Analyzing the role of aspects in software design. Communications of the ACM, v. 44, n. 10, p. $67-73,2001$.

Pawlak, R.; Duchien, L.; Florin, G.; AbD Lionel Seinturier, F. L.-A.; Martelli, L. A UML notation for aspect-oriented software design. In: Proceedings of Workshop of Aspect Oriented Modeling with UML of Proceedings of Aspect Oriented Software Development Conference (AOSD), 2002.

PREE, W. Desing patterns for object-oriented software development. Addison-Wesley, 1995

Pressman, R. S. Software engineering: A practitioner's approach. $5^{\circ} \mathrm{ed}$. McGraw-Hill, 2001.

Ramos, R. A. Aspecting: Abordagem para migração de sistemas oo para sistemas oa. Dissertação de Mestrado, Universidade Federal de São Carlos, São Carlos - SP, dissertação de Mestrado apresentada ao Programa de Pós Graduação em Ciência da Computação, 2004.

RASSHID, A.; ChITCHyAn, R. Persistence as an aspect. In: Proccedings of $2^{n}$ d International Conference on Aspect Oriented Software Development - AOSD, Boston - USA, 2003.

ROBERTS, D.; JOHNSON, R. Evolving frameworks: A pattern language for developing object oriented frameworks. In: "R. C Martin and D. Riehle and F. Buchmann Pattern Languages of Program Design 3, Addison - Weslcy, p. 471 - 486”, 1998.

Ross, D. T. Structured analysis: A language for communicating ideas. IEEE Transactions on Software Engineering, v. 3, n. 1, p. 16-34, 1977.

SCIIMIDT, D. C. An architectural ovcrvicw of the ace framework: A case-study of successful cross-platform systems software reuse. USENIX login magazine, tools special issue, 1998.

SQuEAK Squeak homepage. 2004. Disponível em: <http://www. squeak.org>. Acesso em: 12/03/2004. 
Stein, D.; HanenberG, S.; Unland, R. Designing aspect-oriented crosscutting in UML. In: Proceedings of Workshop of Aspect Oriented Modeling with UML (AOSD), Enschede, 2002 .

SuzUKi, J.; Yамамото, Y. Extending UML with Aspects: Aspect Support in the Design Phase. In: Proceedings of the Workshop on Object-Oriented Technology, Lisbon - Portugal: Springer-Verlag, 1999, p. 299-300.

TYRUBA Tyrubahomepage. 2004. Disponível em: <http://tyruba. sourceforge. net $/>$. Acesso em: 12/03/2004.

UML Unified modelling language specification 1.5. 2004. Disponível em: $<\mathrm{http}: / /$ www . omg . org/technology/documents / formal / uml . htm>. Acesso em: 29/03/04.

VOLDER, K. D. Type-oriented logic mete programming. Tese de Doutoramento, Vrije Universiteit Brussel, programming Technology Laboratory, 1998.

Volder, K. D.; D’Hondt, T. Aspect-oriented logic meta programming. In: Proceedings of Meta-Level Architectures and Reflection, Second International Conference, Reflection'99, Springer-Verlag, 1999, p. $250-272$.

WEINAND, A.; GAMma, E.; MARTy, R. Et++ - an object-oriented application framework in $\mathrm{c}++$. In: Proccedings of the Conference on Object-Oriented Programming: Systems, Languages and Applications (OOPSLA'88), San Diego, California, EUA: ACM Press, special Issue of SIGPLAN Notices, 1988, p. $46-57$.

WEISS, D. M.; LAI, C. T. R. Software product-line engineering - a family-based software development process. Addison-Wesley, 1999.

YODER, J. W.; JOHNSON, R. E.; WILSON, Q. D. Connecting business objects to relational databases. In: Conference on the Pattern Languages of Programs 5 (PLOP), Monticello-IL, EUA, 1998. 


\section{Subsistema de Segurança proposto para o framework GREN (SS).}

Documento de Requisitos

Abril de 2004

\section{A.1 Visão Geral do Sistema}

O Subsistema de Segurança proposto para o framework GREN tem por objetivo controlar o acesso a transaçōes das aplicaçōes instanciadas. Ele faz o gerenciamento de usuários, de papéis e das transações a serem protegidas $\mathrm{cm}$ uma aplicação específica. O controle do acesso de cada usuário sobre as transações da aplicação é feito por meio de papéis. Dessa forma, o SS permite criar papéis aos quais são atribuídos direitos sobre as transações da aplicação e esses papéis são atribuídos aos usuários da aplicação. Além disso, um papel pode ser composto de um sub-papel que, por sua vez, também pode incluir um outro sub-papel. Isso possibilita que um usuário herde direitos dos sub-papéis do papel que lhe foi atribuído. As transações a serem protegidas em uma aplicação específica são as opções de seu menu principal e a execução de operações como, por exemplo: salvar, excluir, visualizar relatórios. O SS deve autenticar os usuários quando estes solicitam entrar no sistema (aplicação específica), registrar a sua entrada e saída do sistema, bem como as tentativas de entrar no sistema realizadas por usuários inválidos. O SS deve, ainda, bloquear o acesso de usuários ao sistema de acordo com determinadas especificações. O gerenciamento do SS deve ser feito por um usuário que possui o papel Administrador. Com 
este propósito, o SS deve gerar alguns relatórios para permitir a gestão adequada do mesmo pelo usuário Administrador, como o relatórios de usuários bloqueados e relatório de registro de acesso à aplicação.

\section{A.2 Requisitos}

1. A aplicação deve possuir um administrador, com respectiva senha de acesso, que tem o poder de gerenciar todas as entradas c saídas do SS, bem como manipular todas as entradas e saídas da aplicação específica na qual os SS está embutido.

2. O SS deve permitir pelo menos três níveis de acesso para os demais usuários do sistema: nível 1 - restrito: acesso apenas a alguns tipos de saída (por exemplo, consulta a catálogos, etc.); nível 2 - intermediário: acesso apenas a operações de entrada e alguns tipos de saída; e nível 3 - total: acesso a todas as operaçōes entradas e saídas). Opcionalmente, esses níveis podem ser especificados como papćis de atores que interagem com a aplicação especifica.

3. O SS deve permitir a inclusão, altcração e exclusão de usuários da aplicação. Essas opções só podem ser executadas pelo administrador da aplicação. Os dados do usuário são: nome completo, nome abreviado, data de cadastro, tipo de acesso, e-mail, senha e data de validade da senha (renovável por 3 meses).

4. O administrador da aplicação deve ter acesso total a todas as informações geradas a partir do SS exceto às senhas dos demais usuários.

5. O SS deve permitir a verificação diária de usuários com senha expirada, bloqueando seu acesso a aplicação.

6. O SS deve bloquear o acesso do usuário quando este tentar entrar no sistema com senha errada, ( 3 tentativas consecutivas com senha incorreta bloqueia o acesso do usuário ao sistema por 1 dia; após 3 bloqueios consecutivos somente o administrador poderá desbloquear o acesso de um eventual usuário bloqueado).

7. O tempo de validade da senha deve ser de no mínimo 90 dias e de no máximo 180 dias. Esses limites podem ser mudados pelo administrador do sistema.

8. O SS deve permitir ao administrador desbloquear um usuário que tenha sido bloqueado por senha expirada, ou por tentativa de acesso ilegal.

9. O SS deve permitir ao usuário trocar sua senha a qualquer momento. Para tal, o usuário deverá informar a sua senha atual e a nova senha confirmando-a pelo menos mais uma vez. 
10. Uma senha válida para o sistema deve conter doze caracteres sendo, quatro desses, caracteres numéricos.

11. O SS deve permitir que as operações de entrada e saída sejam executadas apenas por usuários com o nível de acesso adequado. A cada operação deve ser designado um nível e tal operação somente poderá ser executada por usuários de nível maior ou igual a ele.

12. O SS deve solicitar nome e senha do usuário apenas no momento de entrada no sistema O usuário fica responsável por encerrar a conexão quando não for mais utilizar o sistema.

13. O SS deve permitir consultar o registro dos acessos efetuados pelos usuários do sistema e saber o ID, data e hora do acesso e o status do acesso (ok, senha ilegal, ID inexistente etc).

14. O SS deve fornecer ao administrador um relatório, relatando os usuários bloqueados dentro de um certo período. O relatório deve informar pelo menos os seguintes dados: ID do usuário e senha bloqueada. 


\section{Casos de uso elaborados para o SS proposto para o framework GREN}

Os casos de uso são apresentados como uma sequiência típica de eventos (Larman, 2000). Caso algum evento, mostrado nas tabelas, apresente outras alternativas para a sua realização, elas são apresentadas logo abaixo da tabela como uma sequiência alternativa de eventos.

Com o objetivo de tornar visível, nos casos de uso elaborados, os eventos candidatos a se tornarem aspectos na fase de implementação foram adicionadas algumas marcações nesses caso de uso:

1. Para proporcionar a separação de eventos relacionados a requisitos funcionais do SS dos eventos relacionados a requisitos não funcionais, estes últimos aparecem delimitados (ou marcados) por colchetes "[]". Os eventos relacionados a requisitos não funcionais são candidatos a serem implementados futuramente como funcionalidades (sugestões) dos aspectos.

2. Após a identificação e marcação dos eventos relacionados aos requisitos não funcionais, eles foram analisados e classificados em três interesses: Autenticação, Registro de acesso e Controle de acesso. Esses interesses são candidatos a serem implementados como aspectos em uma fase posterior do processo de desenvolvimento do sistema. Essa classificação pode ser visualizada em cada caso de uso por meio de um letra sobrescrita após o fecha colchete ']'. Dessa forma, [evento] ${ }^{A}$ - indica que o evento descrito entre colchetes pertence ao interesse de Autenticação. [evento] ${ }^{B}$ - indica que o evento descrito entre colchetes pertence ao interesse de Registro de acesso e [eventol $]^{C}$ - indica que o evento descrito entre colchetes pertence ao interesse de Controle de acesso. 
Tabela B.1: Caso de uso Entrar no Sistema.

\begin{tabular}{|c|c|}
\hline \multicolumn{2}{|c|}{ Caso de uso 1: Fntrar no Sistema (Login) } \\
\hline Usuário & Sistema \\
\hline $\begin{array}{l}\text { 1. Solicita operação Entrar no sis- } \\
\text { tema }\end{array}$ & 2. Recebe a solicitação e [apresenta a janela de $\left.\log { }^{A}\right]^{A}$. \\
\hline $\begin{array}{l}\text { 3. Informa o nome de usuário e se- } \\
\text { nha de acesso ao sistema. }\end{array}$ & $\begin{array}{l}\text { 4. Checa a existência do usuário na tabela de usuários e checa a integri- } \\
\text { dade da senha. }\end{array}$ \\
\hline & $\begin{array}{l}5 \text { Se o usuário cxiste e a senha confere, o sistema checa a data de vali- } \\
\text { dade da senha }\end{array}$ \\
\hline & $\begin{array}{l}\text { 5. } 1 \text { se a senha já estiver expirada o sistema bloqueia o logon do usuá- } \\
\text { rio, informa que a sua senha expirou c [rcgistra o nome do usuá- } \\
\text { rio que tentou se conectar ao sistema, a data e hora da tentativat } \\
\text { e o status 'Usuário bloqueado'] }{ }^{B} \text {. }\end{array}$ \\
\hline & $\begin{array}{l}5.2 \text { se a senha ainda não expirou, o sistema permite acesso ao } \\
\text { usuário, [desabilita as transaçôes que não são acessíveis àquelc } \\
\text { usuário] }{ }^{C} \text {. }\end{array}$ \\
\hline & $\begin{array}{l}\text { [Registra o nome do usuário que tentou se conectar ao sistema, } \\
\text { a data e hora da tentativa c o status 'Acesso permitido' }]^{3} \text {. Se a } \\
\text { senha estiver para expirar a } 10,5 \text { ou } 1 \text { dia, o sistema informa o } \\
\text { usuário sobre este fato. }\end{array}$ \\
\hline & $\begin{array}{l}\text { 6. Após três tentativas de entrar no sistema com senha incorreta, o sis- } \\
\text { tema bloqueará o acesso do usuário por um período de } 24 \text { horas, após } \\
\text { esse periodo o acesso será desbloqueado automaticamente. Após o blo- } \\
\text { queio o sistema enviarí um aviso ao usuário informando-o sobre o blo- } \\
\text { queio e que ele deve contatar o administrador se quiser desbloquear antes } \\
\text { das } 24 \text { horas. }\end{array}$ \\
\hline & $\begin{array}{l}\text { 7. O sistema informará o usuário se ele for bloqueado no sistema por três } \\
\text { vezcs consecutivas c pede que cntre em contato com o administrador do } \\
\text { sistema para desbloquear o seu acesso. }\end{array}$ \\
\hline
\end{tabular}

Seqüência Alternativa de Eventos:

Linha 5: Se o usuário não existe, o sistema informa "usuário não existe", [registra o nome do usuário que tentou se conectar ao sistema, a data e a hora da tentativa e o status 'Usuário não existe' $]^{B}$ e [apresenta novamente a janela de $\left.\log i n\right|^{A}$.

Linha 5: Se o usuário existe e a senha não confere, o sistema informa "senha incorreta", [registra o nome do usuário que tentou se conectar ao sistema, a data e a hora da tentativa e o status 'Senha incorreta' ${ }^{B}$ e [apresenta a janela de login novamente] ${ }^{A}$. Após a segunda tentativa com senha incorreta, o sistema informa que bloqueará o acesso do usuário se este informar sua senha incorreta novamente. 
Tabela B.2: Caso de uso Sair do Sistema

\begin{tabular}{|c|c|}
\hline \multicolumn{2}{|c|}{ Caso de uso 2: Sair do Sistema (Logout) } \\
\hline Usuário & Sistema \\
\hline 1. Solicita a operação de Sair do sistena. & $\begin{array}{l}\text { 2. Reccbe a solicitação e [registra a data c a hora em } \\
\text { que o usuário desconectou do sistema. }{ }^{B} \text {. } \\
\text { [Reconstrói o menu da aplicação, deixando disponível } \\
\text { apenas as opçōes para Entrar e Fechar a aplicaçāo e } \\
\text { ocultando todos as demais opções do menu] }{ }^{C \text {. }}\end{array}$ \\
\hline
\end{tabular}

Tabela B.3: Caso de uso Manutenção de Usuários (Criar novo)

\begin{tabular}{|c|c|}
\hline \multicolumn{2}{|c|}{ Caso de uso 3: Manutenção de Usuários (Criar novo) } \\
\hline Usuário & Sistema \\
\hline $\begin{array}{l}\text { 1. O usuário administrador seleciona a opção dc } \overline{M a} \text { - } \\
\text { nutenção } \Rightarrow \text { Usuário. }\end{array}$ & $\begin{array}{l}\text { 2. O sistema apresenta uma janela onde será possí- } \\
\text { vel realizar a manutenção de usuários, a qual permitc } \\
\text { fazer Inserção, Remoçâo ou Ateração de usuários do } \\
\text { sistema. }\end{array}$ \\
\hline $\begin{array}{l}\text { 3. Caso a manutenção seja inserção - o usuário solicita } \\
\text { a operação Criar novo objcto (usuário). }\end{array}$ & $\begin{array}{l}\text { 4. [O sistema verifica se o usuário tem permissão para } \\
\text { exccutar a operação requisitada }]^{C} \text {. } \\
\text { 4. } 1 \text { se o usuário possui permissão para executar a } \\
\text { operação requisitada o sistema hiabilita a in- } \\
\text { terface para que o usuário possa entrar com as } \\
\text { informações. }\end{array}$ \\
\hline $\begin{array}{l}\text { 5. O usuário informa os dados do novo objeto (usuá- } \\
\text { rio) a ser persistido e scleciona a operação salvar. }\end{array}$ & $\begin{array}{l}\text { 6. O sistema trata da persistência dos dados do novo } \\
\text { objeto criado. }\end{array}$ \\
\hline
\end{tabular}

Sequência Alternativa de Eventos:

Linha 4.1: Se o usuário não possui permissão para executar a operação requisitada [o sistema deve informá-lo sobre este fato $]^{C}$.

Tabela B.4: Caso de uso Manutenção de Usuários (Remover)

\begin{tabular}{|c|c|}
\hline \multicolumn{2}{|c|}{ Caso de uso 3: Manulenção de Usuários (Remover) } \\
\hline Usuátio & Sistema \\
\hline $\begin{array}{l}\text { 1. O usuário administrador seleciona a opção de } \mathrm{Ma} \text { - } \\
\text { nutenção }=>\text { Usuário. }\end{array}$ & $\begin{array}{l}\text { 2. O sistema apresenta uma janela onde será possí- } \\
\text { vel realizar a manutenção de usuários, a qual permite } \\
\text { fazcr Inserção, Remoção ou Alteração de usuários do } \\
\text { sistema. }\end{array}$ \\
\hline $\begin{array}{l}\text { 3. Caso a manutenção seja remoção - o usuário es- } \\
\text { colhe o objeto a ser removido e seleciona a operação } \\
\text { remover. }\end{array}$ & $\begin{array}{l}4 \text { [O sistema verifica se o usuário tem permissão para } \\
\text { exccutar a operaçăa requisitada }]^{C} \text {. } \\
4.1 \text { se o usuário possui permissão para executar a } \\
\text { operação requisitada o sistema remove o ob- } \\
\text { jeto a ser apagado da base de dados. }\end{array}$ \\
\hline
\end{tabular}


Sequiência Alternativa de Eventos:

Linha 4.1: Se o usuário não possui permissão para executar a opcração requisitada [o sistema deve informá-lo sobre este fato] ${ }^{C}$.

Tabela B.5: Caso de uso Manutenção de Usuários (Alterar)

\begin{tabular}{|c|c|}
\hline \multicolumn{2}{|c|}{ Caso de uso 3: Manutenção de Usuários (Alterar) } \\
\hline Lsuário & Sistema \\
\hline $\begin{array}{l}\text { 1. O usuário administrador scleciona a opção de } M a- \\
\text { nutenção } \rightarrow \text { Usuário. }\end{array}$ & $\begin{array}{l}\text { 2. O sistema apresenta uma jancla onde será possí } \\
\text { vel realizar a manutenção de usuários, a qual permite } \\
\text { fazer Inserção. Remoção ou Alteração de usuários do } \\
\text { sistema. }\end{array}$ \\
\hline $\begin{array}{l}\text { 3. Caso a manutenção seja alteração - o usuário se- } \\
\text { leciona o objeto a ser alterado, rectliza as alterações e } \\
\text { seleciona a operação salvar. }\end{array}$ & $\begin{array}{l}4 \text { [O sistema verifica se o usuário tem permissão para } \\
\text { executar a operação requisitada] } \\
\text { 4. } 1 \text { se o usuário possui permissão para exccutar a } \\
\text { operação requisitada o sistema trata da persis- } \\
\text { tência dos dados referentes ao objeto modif- } \\
\text { cado. }\end{array}$ \\
\hline
\end{tabular}

Sequiência Alternativa de Eventos:

Linha 4.1: Se o usuário não possui permissão para executar a operação requisitada [o sistema deve informá-lo sobre este fato] $]^{C}$.

Tabela B.6: Caso de uso Manutenção de Papéis (Criar novo)

\begin{tabular}{|c|c|}
\hline \multicolumn{2}{|c|}{ Caso de uso 4: Manutenção de Papéis (Criar novo) } \\
\hline Usuário & Sistcma \\
\hline $\begin{array}{l}\text { 1. O usuário administrador seleciona a opção de } M a \text { - } \\
\text { nutenção }=>\text { Papéis. }\end{array}$ & $\begin{array}{l}\text { 2. O sistema apresenta uma janela onde será possivel } \\
\text { realizar a manutenção de papéis, a qual permite fazer } \\
\text { Inserçâo, Remoçâo ou Altera̧̧ão de papéis do sistema. }\end{array}$ \\
\hline $\begin{array}{l}\text { 3. Caso a manutenção seja inserção - o usuário solicita } \\
\text { a operação Criar novo objeto (papel). }\end{array}$ & $\begin{array}{l}4 \text { [O sistema verifica se o usuário tem permissão para } \\
\text { executar a operação requisitada }]^{C} \text {. } \\
4.1 \text { se o usuário possui permissão para executar a } \\
\text { operação requisitada o sistema habilita a in- } \\
\text { terface para que o usuário possa entrar com as } \\
\text { informaçōes. }\end{array}$ \\
\hline $\begin{array}{l}\text { 5. O usuário informa os dados do novo objeto (papel) } \\
\text { a ser persistido e seleciona a operação salvar. }\end{array}$ & $\begin{array}{l}\text { 6. O sistema trata da persistência dos dados do novo } \\
\text { objeto criado. }\end{array}$ \\
\hline
\end{tabular}


Sequêencia Alternativa de Eventos:

Linha 4.1: Se o usuário não possui permissão para executar a operação requisitada [o sistema deve informá-lo sobre este fato] ${ }^{C}$.

Tabela B.7: Caso de uso Manutenção de Papéis (Remover)

\begin{tabular}{|c|c|}
\hline \multicolumn{2}{|c|}{ Caso de uso 4: Manutenção de Papéis (Remover) } \\
\hline Usuário & Sistema \\
\hline $\begin{array}{l}\text { 1. O usuário administrador seleciona a opção de } M a- \\
\text { nutençấo }=>\text { Papéis. }\end{array}$ & $\begin{array}{l}\text { 2. O sistema apresenta uma janela onde será possivel } \\
\text { realizar a manutenção de papéis, a qual permite fazer } \\
\text { Inserçâo, Remoção ou Alteração de papéis do sistema. }\end{array}$ \\
\hline $\begin{array}{l}\text { 3. Caso a manutenção seja remoção - o usuário es- } \\
\text { colhe o objeto a ser removido e seleciona a operação } \\
\text { remover. }\end{array}$ & $\begin{array}{l}4 \text { [O sistema verifica se o usuário tem permissão para } \\
\text { executar a operação requisitada] }{ }^{C} \text {. } \\
\text { 4. } 1 \text { se o usuário possui permissão para executar a } \\
\text { operação requisitada o sistema remove o ob- } \\
\text { jeto a ser apagado da base de dados. }\end{array}$ \\
\hline
\end{tabular}

Sequiência Altermativa de Eventos:

Linha 4.1: Se o usuário não possui permissão para executar a operação requisitada fo sistema deve informá-lo sobre este fato] ${ }^{C}$.

Tabela B.8: Caso de uso Manutenção de Papéis (Alterar)

\begin{tabular}{|l|c|}
\hline \multicolumn{2}{|c|}{ Caso de uso 4: Manutençầo de Papéis (Alterar) } \\
\hline \hline $\begin{array}{l}\text { 1. O usuário administrador seleciona a opção de Ma- } \\
\text { nutenção } \Rightarrow \text { Papéis. }\end{array}$ & $\begin{array}{l}\text { 2. O sistema apresenta uma jancla onde será possível } \\
\text { realizar a manutenção de papéis, a qual permite fazer } \\
\text { lnserç̧ão, Remoção ou Alteração de papéis do sistema. }\end{array}$ \\
\hline $\begin{array}{l}\text { 3. Caso a manutenção seja alteração - o usuário se- } \\
\text { leciona o objeto a ser alterado, realiza as alterações e } \\
\text { seleciona a operação salvar. }\end{array}$ & $\begin{array}{l}4 \text { [O sistema verifica se o usuário tem permissão para } \\
\text { executar a operação requisitada }{ }^{C} .\end{array}$ \\
& $\begin{array}{l}\text { 4. 1 se o usuário possui permissão para executar a } \\
\text { operação reçuisitada o sistema trata da persis- } \\
\text { tência dos dados referentes ao objeto modifi- } \\
\text { cado. }\end{array}$ \\
\hline
\end{tabular}

Seqüência Alternativa de Eventos:

Linha 4.1: Se o usuário não possui permissão para executar a operação requisitada [o sistema deve informá-lo sobre este fatol ${ }^{C}$. 
Tabela B.9: Caso de uso Manutenção de Direitos (Atribuir direitos a um papel)

\begin{tabular}{|l|l|}
\hline \multicolumn{2}{|c|}{ Caso de uso 5: Manutenção de Direitos (Atribuir direitos a um papel) } \\
\hline $\begin{array}{l}\text { Usuário } \\
\text { 1. O usuário administrador seleciona a opção de } M a-\end{array}$ & $\begin{array}{l}\text { 2. O sistema apresenta uma janela onde será possí- } \\
\text { vel realizar a manutenção de direitos, a qual permite } \\
\text { o usuário Administrador Atribuir e Remover direitos } \\
\text { aos papéis registrados no sistema. }\end{array}$ \\
\hline $\begin{array}{l}\text { 3. Caso at manutenção seja atribuir direitos a um papel } \\
\text { - o usuário seleciona o papel desejado e em seguidain- } \\
\text { forma todos os privilégios que deseja atribuir ao papel } \\
\text { escolhido anteriormente e seleciona a operação salvar. }\end{array}$ & $\begin{array}{l}\text { a umatenção realizada seja atribuir direitos } \\
\text { do novo objeto criado. }\end{array}$ \\
\hline
\end{tabular}

Tabela B.10: Caso de uso Manutenção de Direitos (Remover direitos de um papel)

\begin{tabular}{|c|c|}
\hline \multicolumn{2}{|c|}{ Caso de uso 5: Manutenção de Direitos (Remover direitos de um papcl) } \\
\hline Usuário & Sistema \\
\hline $\begin{array}{l}\text { 1. O usuário administrador seleciona a opção de } M a- \\
\text { nutenção } \rightarrow \text { Direitos. }\end{array}$ & $\begin{array}{l}\text { 2. O sistema apresenta uma jancla onde será possí- } \\
\text { vel realizar a manutenção de direitos, a qual permite } \\
\text { o usuário Administrador Atribuir c Remover direitos } \\
\text { aos papéis registrados no sistema. }\end{array}$ \\
\hline $\begin{array}{l}\text { 3. Caso a manutenção seja remover direitos de um } \\
\text { papel - o usuário seleciona o papel desejado em se- } \\
\text { guida seleciona todos os privilégios que deseja remo- } \\
\text { ver deste papel e seleciona a opcração remover. }\end{array}$ & $\begin{array}{l}4 \text { caso a manutenção realizada seja remover direitos } \\
\text { de um papel, o sistema remove o objeto a ser apagado } \\
\text { da base de dados. }\end{array}$ \\
\hline
\end{tabular}

Tabela B.11: Caso de uso Alterar Senha

\begin{tabular}{|c|c|}
\hline \multicolumn{2}{|c|}{ Caso de uso 6: Alterar Senha (usuário comum e administrador do sistema) } \\
\hline Usuário & Sistema \\
\hline $\begin{array}{l}\text { 1. Seleciona a opção de Manutenção }=>\text { Alterar Se- } \\
\text { nha }\end{array}$ & $\begin{array}{l}\text { 2. Exibe janela para troca de senha. Solicita que o } \\
\text { usuário informe a senha atual, a nova senha c uma } \\
\text { confirmação da nova senha. }\end{array}$ \\
\hline $\begin{array}{l}\text { 3. Usuário informa senha atual, nova senha e confir- } \\
\text { mação da nova senha. }\end{array}$ & \\
\hline $\begin{array}{l}\text { 4. Ĺsuário seleciona opção para confirmar a nova se- } \\
\text { nha } O K\end{array}$ & $\begin{array}{l}\text { 5. Sistema confere se a noval senha é valida. Regra: } \\
\text { para ser válida a senha deve ser diferente da senha } \\
\text { atual e deve possuir sendo, quatro desses, caracteres } \\
\text { numéricos. }\end{array}$ \\
\hline & $\begin{array}{l}5.1 \text { se a senha for diferente da atual e válida grava a } \\
\text { nova senha do usuário. }\end{array}$ \\
\hline
\end{tabular}

Sequência Alternativa de Eventos:

Linha 5: Se a senha for igual à senha atual, o sistema informará ao usuário "Senha inválida. Entre com uma nova senha." 
Tabela B.12: Caso de uso Desbloquear Usuário

\begin{tabular}{|l|l|}
\hline \multicolumn{2}{|c|}{ Caso de uso 7: Desbloqucar Usuário } \\
\hline \hline Usuário & \multicolumn{1}{|c|}{ Sistema } \\
\hline 3. Busca o usuário que deseja desbloquear a senha. & $\begin{array}{l}\text { 2. Sistema apresenta a janela na qual será realizado } \\
\text { este tipo de manutenção. }\end{array}$ \\
\hline 5. Efetua o desbloqueio. & $\begin{array}{l}\text { 4. Devolve o usuário pesquisado. } \\
\text { usuário desblovaueado. }\end{array}$ \\
\hline
\end{tabular}

Baseando-se nos casos de uso elaborados, a seguir é apresentada uma lista de variabilidades previstas para o subsistema de controle de acesso:

1. Implementar o item 6 do caso de uso 1 Entrar no Sistema.

2. Tempo de validade da senha:

(a) Poderá ser instanciado com um valor default fixo de 3 meses;

(b) Poderá ser instanciado alterando o valor default;

(c) Permitir diferentes tempos para diferentes usuários

3. Implementar uma regra para senha ou ter uma como default. 


\section{Documento de Requisitos do Sistema para Clínica Veterinária}

Documento de Requisitos

Setembro de 2002

\section{C.1 VISÃO GERAL DO SISTEMA}

O sistema para a Clínica Veterinária Animal \& Cia trata do gerenciamento das consultas realizadas em animais domésticos (por exemplo, cães e gatos). A consulta pode ser de rotina, mas pode implicar em diagnósticos que cnvolvam outros serviços a serem prestados pelo veterinário, como injeções, vacinação, cirurgias, ctc. Além disso, o animal pode precisar de medicamentos, que podem ser adquiridos na própria clínica. A clínica possui também diversos produtos para venda, como rações, brinquedos, casas de madeira, shampoos, escovas, bebedouros, etc. Esses produtos podem ser vendidos separadamente, ou integrados a uma consulta. Diversos relatórios devem ser gerados pelo sistema para permitir a gestão adequada da clínica, como o relatório de estoque de medicamentos e produtos, consultas feitas $\mathrm{cm}$ um determinado animal, relatório de vendas de produtos, etc 


\section{C.2 REQUISITOS FUNCIONAIS}

\section{C.2.1 Lançamentos diversos}

1. O sistema deve permitir a inclusão, alteração e remoção de animais, com os seguintes atributos: código do animal, nome do animal (opcional), identificação de seu proprietário (que é um cliente), data de nascimento (opcional), espécie do animal, raça, sexo e cor.

2. O sistema deve permitir a inclusão, alteração e remoção de clientes, com os seguintes atributos: código, nome, endereço, cidade, estado, telefone, documento, email.

3. O sistema deve permitir a inclusão, alteração e remoção de espécie de animais, com os seguintes atributos: código de identificação e espécie do animal.

4. O sistema deve permitir a inclusão, alteração e remoção de raças, com os seguintes atributos: código de identificação e descriçăo da raça.

5. O sistema deve permitir a inclusão, alteração e remoção dos diversos produtos vendidos na clínica veterinária, com os seguintes atributos: código do produto, descrição do produto, fabricante, categoria (se é alimento, acessórios, medicamento, etc.), preço de venda e quantidade em estoque.

6. O sistema deve permitir a inclusão, alteração e remoção das diversas categorias de produtos, com os seguintes atributos: código e descrição da categoria.

7. O sistema deve permitir a inclusão, alteração e remoção de veterinários da Animal \& Cia, com os seguintes atributos: nome, endereço, cidade, estado, telefone residencial e telefone celular

8. O sistema deve permitir a inclusão, alteração e remoção de tipos de serviços prestados durante a consulta, com os seguintes atributos: código de identificação, descrição do tipo de serviço e preço cobrado por hora.

9. O sistema deve permitir o processamento da consulta de um animal, com os seguintes atributos: data e hora da consulta, identificação do cliente/animal (previamente cadastrado), identificação do veterinário que efetuou a consulta, descrição dos sintomas do animal, identificação dos serviços executados como parte da consulta, relação de medicamentos e produtos usados na consulta e forma de pagamento.

10. O sistema deve permitir o processamento de venda de produto, com os seguintes atributos: data da venda, identificação do cliente (previamente cadastrado), relação de produtos adquiridos, valor total e forma de pagamento. 
11. O sistema deve permitir as seguintes opções de pagamento da consulta: 1) à vista (em dinheiro ou cheque); 2 ) em 1 ou mais cheques pré-datados.

\section{C.2.2 Impressão de diversos tipos de relatórios e consultas}

1. O sistema deve permitir a impressão de uma listagem dos produtos/medicamentos em estoque, agrupados por categorias, contendo a descrição do produto, fabricante, preço, c quantidade em estoque.

2. O sistema deve permitir a impressão de um comprovante de consulta, contendo o nome do cliente, data c horário da consulta, nome do veterinário responsável, serviços prestados, produtos adquiridos e valores totais. Nesse mesmo comprovante deve ser mostrada a forma de pagamento escolhida e deve ser reservado um espaço para assinatura do cliente.

3. O sistema deve permitir a impressão de um relatório de animais, classificados por espécie, contendo: raça, nome do animal, nome do proprietário, data de nascimento, sexo e cor.

4. 15. O sistema deve permitir a impressão de uma consulta online mostrando todas as consultas realizadas em um determinado animal, agrupadas por espécie, contendo o nome do animal, raça, nome do proprietário, data da consulta, veterinário responsável, serviços realizados e valor total.

5. O sistema deve permitir a impressão de um relatório resumindo do faturamento da Animal \& Cia. no período (por exemplo, semanal ou quinzenal), contendo, para cada dia do período, um resumo das consultas e vendas nesse dia.

6. O sistema deve permitir a impressão de um relatório contendo os cheques pré-datados a serem depositados no dia contendo o nome do cliente, a data do cheque e valor.

\section{C.3 REQUISITOS NÃO FUNCIONAIS}

\section{C.3.1 Confiabilidade}

1. O sistema deve ter capacidade para recuperar os dados perdidos da última operação que realizou em caso de falha.

2. O sistema deve fornecer facilidades para a realização de backups dos arquivos do sistema.

3. O sistema deve possuir senhas de acesso e identificação para diferentes tipos de usuários: administrador do sistema, veterinários c clientes que têm acesso ao sistema da clínica veterinária (em quiosques especiais). 


\section{C.3.2 Eficiência}

1. O sistema deve responder a consultas on-line $\mathrm{cm}$ menos de 5 segundos.

2. O sistema deve iniciar a impressão de relatórios solicitados dentro de no máximo 20 segundos após sua requisição.

\section{C.3.3 Portabilidade}

1. O sistema deve ser executado em computadores Pentium $200 \mathrm{mHz}$ ou superior, com sistema operacional Windows 98 ou acima.

2. O sistema deve ser capaz de armazenar os dados em base de dados Oracle ou Sybase.

\section{C.3.4 Glossário}

\begin{tabular}{|c|c|}
\hline Termo & Descrição \\
\hline Animal & $\begin{array}{l}\text { Animal que é consultado na clínica, podendo ser de diversas espécies e } \\
\text { raças }\end{array}$ \\
\hline Backcup & Cópia de segurança ou cópia de salvaguarda \\
\hline Categoria de Produto & $\begin{array}{l}\text { Diversas classificaçôes nas quais os produtos vendidos pela clínica podem } \\
\text { ser agrupados, por exemplo: medicamentos, alimentos, acessórios, etc. }\end{array}$ \\
\hline Cliente & Proprietário de um ou mais animais que podem ser consultados na clínica. \\
\hline Consulta & $\begin{array}{l}\text { Evento no qual um animal comparece à clínica para ser feito um ou } \\
\text { mais serviços como consulta para diagnóstico de doença, vacinação, etc., } \\
\text { podendo-se também, durante a consulta, vender medicamentos ou outros } \\
\text { produtos para animais. }\end{array}$ \\
\hline Espécie do animal & Espécie na qual os animais são classificados, por exemplo, cães, gatos, etc. \\
\hline Pagamento da Consulta & $\begin{array}{l}\text { Pagamento que o proprietário do animal deve fazer referente aos serviços } \\
\text { prestados pela clínica e produtos adquiridos durante a consulta. }\end{array}$ \\
\hline Produto & $\begin{array}{l}\text { Diversos bens vendidos pela clínica ao proprietário do animal, como por } \\
\text { exemplo vacinas, remédios anti-piolhos, ração, bebedouro, shampoos, etc. }\end{array}$ \\
\hline Raça & $\begin{array}{l}\text { Raça específica de uma espécie de animal, por exemplo, um cão pode ser } \\
\text { Labrador, Pastor alcmão, Coker, Poodlc, ctc. }\end{array}$ \\
\hline Tipo de Serviço & $\begin{array}{l}\text { Serviço of crecido pela clínica ao animal, como por exemplo, vacinação, } \\
\text { aplicação de injeções, banho, tosa, cirurgias, ctc. }\end{array}$ \\
\hline Veterinário & $\begin{array}{l}\text { Profissional contratado pela clínica para efetuar consulta em animais que } \\
\text { comparecem à clínica. }\end{array}$ \\
\hline
\end{tabular}




\section{Alterações resultantes da evolução GREN-Wizard}

A evolução realizada no GREN-Wizard não implicou em alteração na sua estrutura de classes, apenas foram acrescentados novos métodos, em algumas classes, rclativos à instanciação das funcionalidades do SS. Na Tabela D.3 são apresentadas para cada classe do GREN-Wizard alterada, as respectivas variáveis de instância ou de classe adicionadas e os métodos criados, alterados e corrigidos nessas classes. Essa evolução também provocou impacto na base de dados do GREN-Wizard e em uma das classes do framework GREN. Na Tabela D. 1 é apresentada a classe do GREN alterada e na Tabela D.2 é apresentada a alteração realizada na base de dados do GREN-Wizard.

Tabela D.1: Classes alteradas do framework GREN.

\begin{tabular}{|l|l|l|l|l|}
\hline Classes & $\begin{array}{l}\text { Variáveis Cria- } \\
\text { das (I)instância } \\
\text { (C)elasse }\end{array}$ & $\begin{array}{l}\text { Métodos Criados Altera- } \\
\text { dos } \\
\text { gidos }\end{array}$ \\
\hline \hline GiREN $\Lambda$ pplicationMainForm & & & mainMenu & \\
\hline
\end{tabular}

Tabela 10.2: Tabelas pertencente à base de dados do GREN-wizard alteradas

\begin{tabular}{|l|l|l|}
\hline Tabelas & Colunas Adicionadas & Colunas Removidas \\
\hline \hline Grenapplication & useAccesscontrol & \\
\hline
\end{tabular}


Tabela D.3: Classes alteradas do GREN-Wizard.

\begin{tabular}{|c|c|c|c|c|}
\hline Classes & $\begin{array}{l}\text { Variáveis Criadas } \\
\text { (I)instância (C)classe }\end{array}$ & Métodos Criados & Métodos Alterados & Métodos Corrigidos \\
\hline GRENApplication & uscAccessControl (I) & $\begin{array}{l}\text { useAccessControl } \\
\text { useAccessControl: } \\
\text { useAccessControlAsString } \\
\text { appUsesAccessControl }\end{array}$ & $\begin{array}{l}\text { initialize } \\
\text { initialize:index: } \\
\text { initializeWith: } \\
\text { insertionFieldClause } \\
\text { insertionValueClause } \\
\text { updateSetClause }\end{array}$ & updateWhereClause \\
\hline GRENApplicationForm & useAccessControl (I) & uscAccessControl & $\begin{array}{l}\text { initializeWithApp } \\
\text { openInterface:with: } \\
\text { closeAccept } \\
\text { appSpec }\end{array}$ & \\
\hline Gren WizardCodeGenerato & & $\begin{array}{l}\text { createAspectClasses } \\
\text { initializeSystemlnitialConfiguration } \\
\text { aspectClassMethods } \\
\text { interfaceClassMethods } \\
\text { mainClassMethods } \\
\text { createAccessControlSystemMethods } \\
\text { addNewSubMenultens: } \\
\text { createAppMenu } \\
\text { createMcnuItcm: } \\
\text { createSubMcnultens: } \\
\text { createAccessControlSystcmOn: }\end{array}$ & $\begin{array}{l}\text { creatcSpecAndResourceMethods } \\
\text { overrideMainWindowHookMethods } \\
\text { createSQITables:path: }\end{array}$ & \\
\hline GrenWizardGLI & & & generateApp & $\begin{array}{l}\text { editBi } \\
\text { changedApp }\end{array}$ \\
\hline
\end{tabular}




\section{Documentação adicional do SS}

\section{E.1 Instalação do Subsistema de Segurança e do pa- cote de classes AspectS}

1- Copiar os arquivos (extensões .pcl e .pst) para o diretório C: $\backslash$ Vw5i4nc \parcels: Aspects-041-5i4. * e Accesscontrol1.0. *.

2- Criar os namespaces: AspectS e AccessControlsystem. Siga as opções do menu Browse $\gg$ All Namespaces, clique sobre Smalltalk, para quc os novos namespaces fiquem abaixo dele e, novamente, vá ao menu Namespace $\gg$ Add $\gg$ Namespace. Aparecerá um template como mostrado abaixo. NameofPool deve ser substituído pelo nome do novo namespace. O namespace Aspects deve importar apenas private Smalltalk. *, e o namespace Accesscontrolsystem, GREN . * e private Smalltalk. *. Clique o botão direito e Accept para gravar cada namespace.

Smalitalk defincNamcSpace: \#NameofPool
private: falsc
imports: 'OtherNameSpace. *
private Smalltalk. '
category: 'As yet unclassified'

3- Executar Tools $\gg$ Load Parcel Named. Digite * <enter $>$ e selecione o pacote Aspects-041-5i $4 .{ }^{*}$. Clique OK.

4- Copiar os arquivos da pasta Message para $C: \backslash V w 5 i .4 n c \backslash$ messages. 
5- Executar, no workspace do VisualWorks, os seguintes comandos (selecione cada comando e exccutc do it com o botão direito do mouse)

\section{E.2 Considerações sobre a instanciação}

\section{E.2.1 Classes concretas}

Para dispor de todas as funcionalidades do SS é necessário criar apenas cinco classes concretas, sendo três classes de aplicação, as quais dizem respcito às classes implementadas segundo a proposta de POA e duas classe de interface. Uma das classes de interface representa a janela principal da aplicação e a outra a classe responsável pelo estabelecimento da configuração inicial da aplicação instanciada.

A Tabela E.1 e a Tabela E.2 contêm informação para a criação das classes concretas. Nas tabelas são apresentados os nomes das classes do SS a serem especializadas e uma sugestão para o nome das classes concretas a serem criadas. Outras classes que pertencem à implementação do SS, mas que não precisam ter classes correspondentes na aplicação concreta, não são mencionadas nessas tabelas.

Tabela E.1: Classes aspecto do SS X Classes aspecto da aplicação específica a serem criadas.

\begin{tabular}{|l|l|}
\hline Superclasse do Ss & Sugestão de nome da classe concreta \\
\hline \hline AccessControlSystem. AsAccessControl & AsAccessControlApp \\
\hline AccessControlsystem. AsAccessLog & AsAccessLogApp \\
\hline AccessControlSystem. AsAuthentication & AsAuthenticationApp \\
\hline
\end{tabular}

Tabela E.2: Classes de interface do SS X Classes de interface da aplicação específica a serem criadas.

\begin{tabular}{|c|c|}
\hline Superclasse do ss & Sugestão de nome da classe concreta \\
\hline Accessconcrolsystem. Accesscontrolmainwindow & NomeAplicacãoEpeíficaprincipalwindow \\
\hline Accesscontro: System. SystemInitialstatecoretgurat ionform & SystemlnitialstateCorfigurationnppForm \\
\hline
\end{tabular}

\section{E.2.2 Métodos sobrepostos}

A Tabcla E.3 mostra quais métodos das classes aspecto do SS devem ser sobrepostos e a Tabela E.4 os métodos da camada GUI do SS. 
Tabela E.3: Classes aspecto do SS X métodos a serem sobrepostos.

\begin{tabular}{|c|c|c|c|c|}
\hline Nome da Superclasse & $\begin{array}{l}\text { Protocolo } \\
\end{array}$ & Nome do método a sobrepor & C/I & Corpo do método \\
\hline $\begin{array}{l}\text { AsAccessLog, AsAccessControl c } \\
\text { AsAuthentication }\end{array}$ & abstractMethods & mainApplication Name & I & $\begin{array}{l}\text { Retorna o nome da classe prin- } \\
\text { cipal da aplicação que contém o } \\
\text { menu da aplicação. Exemplo: 'Vi- } \\
\text { deolocadoraMainWWindow }\end{array}$ \\
\hline AsAicessControl & abstractMethods & ipplicuationMentuNariste & I & $\begin{array}{l}\text { Returna ô nome do método res- } \\
\text { ponsável por construir o menu da } \\
\text { aplicaçâio. Exemplo: ^\#videoloci- } \\
\text { doraMenu }\end{array}$ \\
\hline
\end{tabular}

Tabela E.4: Classes de interface do SS X métodos a serem sobrepostos.

\begin{tabular}{|c|c|c|c|c|}
\hline Nome da Superclasse & Protocolo & Nome do método a sobrepor & $\mathrm{C} / \mathbf{l}$ & Corpo do método \\
\hline \multirow[t]{2}{*}{ SystemInitialStateConfiguration Form } & \multirow[t]{2}{*}{ abstractMethods } & mainApplicationName & c. & $\begin{array}{l}\text { Retrina o nome da classe principal } \\
\text { da aplicaçâuo que contérn o menu di } \\
\text { aplicação. Exemplo: 'Videolocado- } \\
\text { raMainWindow }\end{array}$ \\
\hline & & applicationMenu & $\mathrm{C}$ & 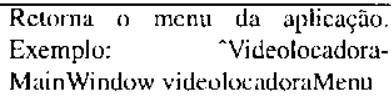 \\
\hline \multirow[t]{3}{*}{ Acces Control MainWindow } & \multirow[t]{3}{*}{ classReferences } & accessControl $\hat{\Lambda}$ spectName & I & $\begin{array}{l}\text { Retorna o nome da classe especia- } \\
\text { lizada a partir da classe de aspecto } \\
\text { As AccessControl. Exemplo: -Vi- } \\
\text { deolocidora. As } A \text { ccessConirol } A p p\end{array}$ \\
\hline & & accessLog AspectName & $T$ & $\begin{array}{l}\text { Retorna o nome da classe especiat } \\
\text { lizada a partir da classe de aspecto } \\
\text { AsAccessLog. Exemplo: "Videolo- } \\
\text { cadora.AsAcccssl ogApp }\end{array}$ \\
\hline & & authentication AspectName & 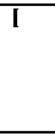 & $\begin{array}{l}\text { Rctorna o nome da classc especia- } \\
\text { lizada a partir da classe de aspecto } \\
\text { AsAuthentication. Exemplo: "Vi- } \\
\text { deolocidora. AsAuthenticationApp }\end{array}$ \\
\hline
\end{tabular}

\section{E.2.3 Janela Principal/Menus}

i ) A jancla principal deve ser criada a partir da ferramenta CANVAS do VisualWorks. Para tal, crie um novo canvas e instale-o na classe principal da aplicaçāo específica. A classe principal da aplicação, criada conforme informações da Tabela, E.2 deve herdar da classe AccessControlmainwindow do SS.

ii) O menu da aplicação deve ser criado tomando-se como base o menu "accesscontrolmenu" oferecido pela implementação do Sistema de Segurança. Para tal use a ferramenta MenuEditor do VisualWorks, por meio da opção Load localize a classe AccessControlMainwindow na catcgoria "Accesscontrolsystem", selecione o menu e personalize-o da forma descjada. As opções do menu nas quais a cláusula String esteja marcada com (RNFS) não devem ser removidas ou sobrepostas, pois estão diretamente relacionadas à execução das funcionalidades do SS.

\section{E.2.4 Persistência}

i ) Criar nova base de dados para armazenar as tabelas conforme instruções do manual de instanciação do GREN. O nome da base de dados deve ser o mesmo nome dado ao namespace da aplicação específica. 
ii ) Montar um script SQL para criação das tabelas que irão armazenar os objetos persistentes da aplicação específica de acordo com as instruções do manual de instanciação do GREN

iii ) O SS também apresenta objetos persistentes, os quais devem ser armazcnados em tabelas na base de dados criada para a aplicação específica. O script para criação das tabelas referentes ao SS é mostrado abaixo, as tabelas deste script devem ser incluídas no script da aplicação específica obtido no item ii.

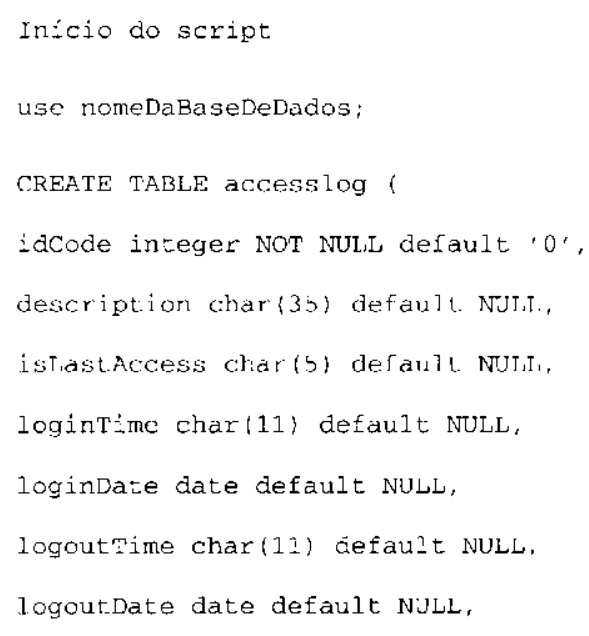


description char(35) defauit NJLI

Type char(1) derault NULL);

CREATE TABEE User

idCode integer NOT NULI default ' 0 ',

cescription char(35) default NULL

userName char $\{20\}$ default NULL,

registerDate date default NJLI,

email char(30) default NULi

password char(12) default NULL,

passwordDatevigour date de[au]t NUr..,

RoleType integer default NUII,

passoaysval inl(3) defauit ' 90 ',

blockadecounter integer default $\cdot 0$.

blockadestate int(1) YOT NULL default ' 0 ',

blockDate date default '1900-01-01',

blocktime time default 00:00:00');

quit

Fim do script

iv ) Executar o script final obtido pelos passos ii e iii conforme instruções do manual de instanciação do GREN.

\section{E.2.5 Configuração do estado inicial da aplicação}

Após complctar a instanciação da aplicação específica é preciso configurar o seu estado inicial, ou seja, criar o papel Administrador, o usuário Administrador do Sistema, criar todos os objetos protegidos do sistema (menu/operações) c criar os direitos do papel Administrador sobre todas as operações e menus do sistema c armazenar todas cssas informações na base de dados da aplicação específica. A implementação do SS oferece uma interface visual, apresentada na Figura E.1, que automatiza esta tarefa, dessa forma, para exccutá-la, o instanciador de aplicação deve apenas executar no Workspace do VisualWorks o comando descrito abaixo: 


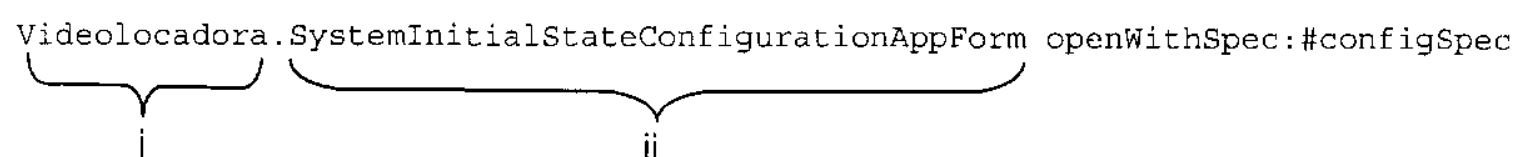

i - Nome do Namespace da aplicação específica instanciada.

ii - Nome da classe especializada a partir da classe SystemInitialstateconfigurationForm, responsável pela iniciação da configuração, o nome dessa classe foi sugerido na Tabela E.2.

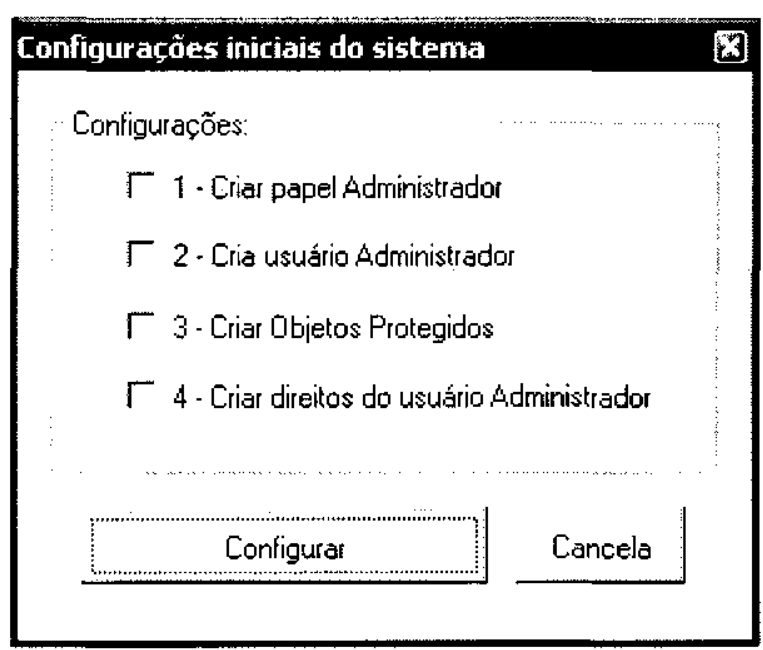

Figura E.1: Interface para configuração do estado inicial da aplicação instanciada

Os valores iniciais do nome de usuário e senha criados para o usuário Administrador do Sistema são, respectivamente, admin e admin123. Estas informações serão requisitas pelo sistema de autenticação de usuários ao ser executada a aplicação específica e deverão ser modificados pelo usuário Administrador após o primciro acesso ao sistema. 


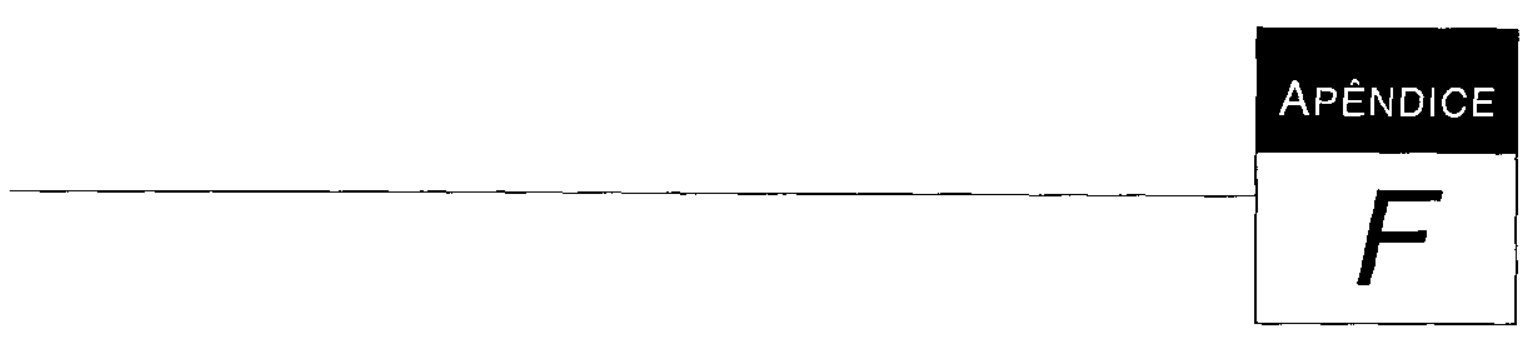

\section{Hierarquia de Classes das novas versões do GREN e da GREN-wizard}

\section{F.1 Hierarquia de Classes do GREN}

As classes da linguagem Smalltalk aparecem em itálico. As demais são classes do GREN.

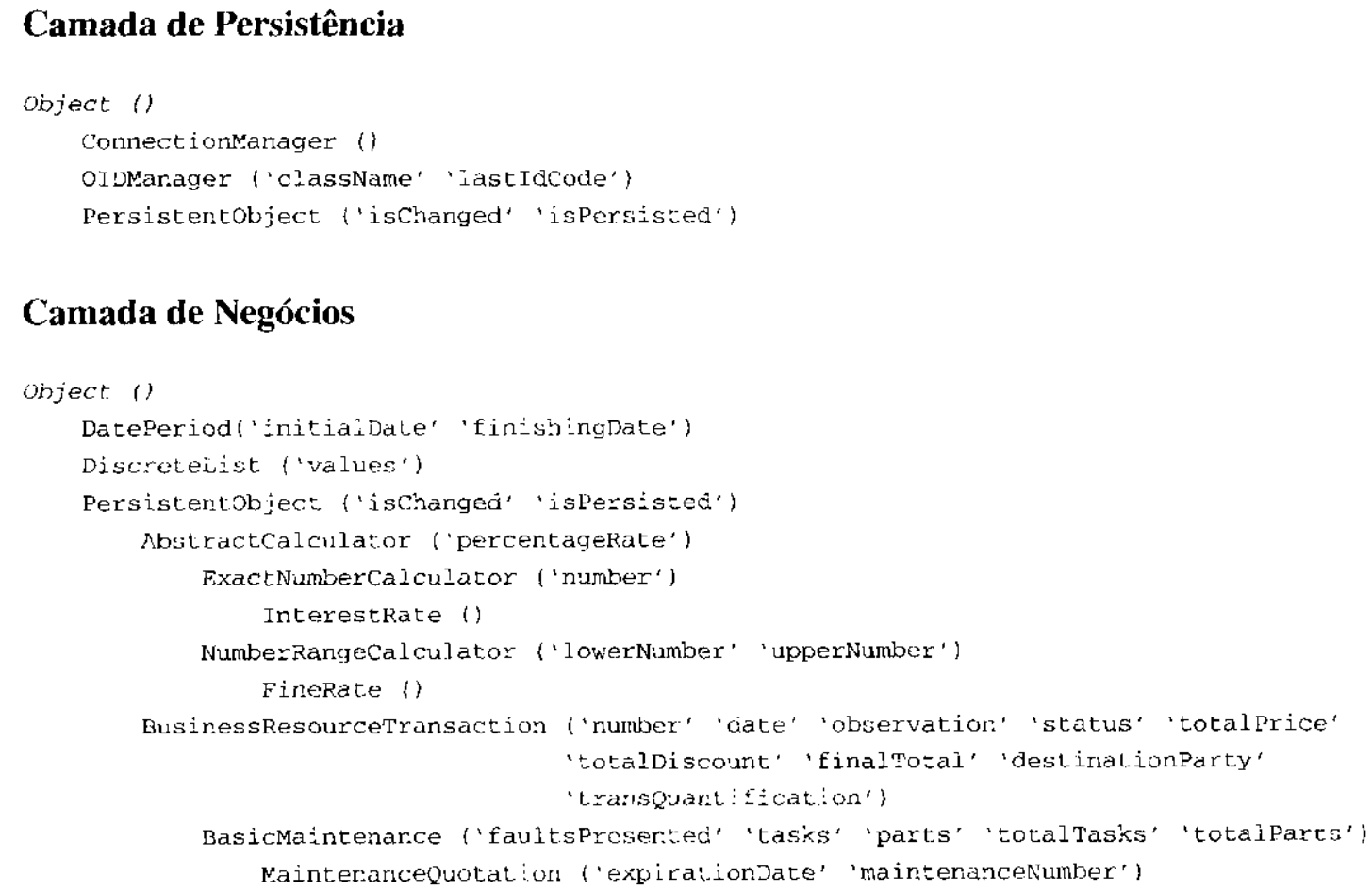




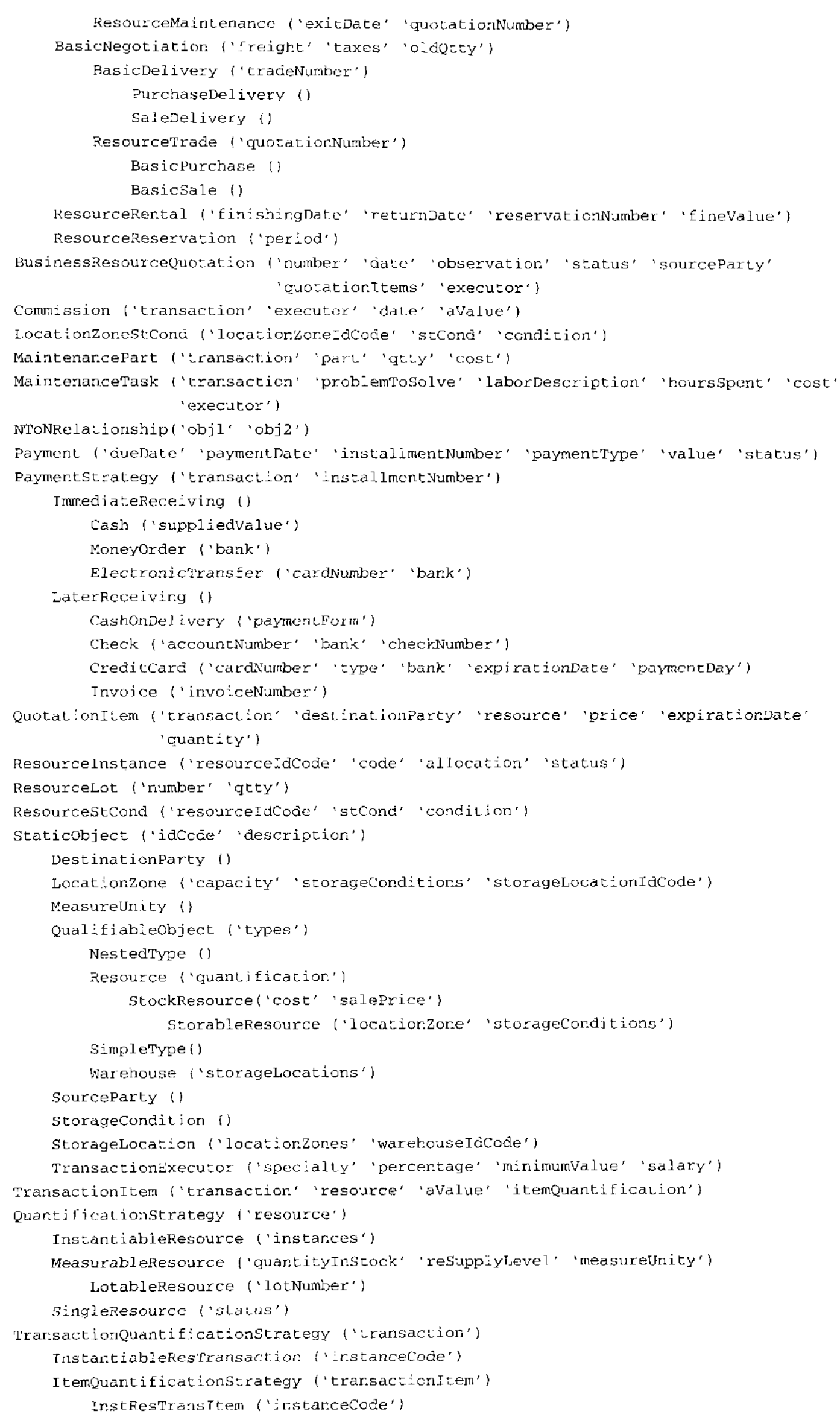




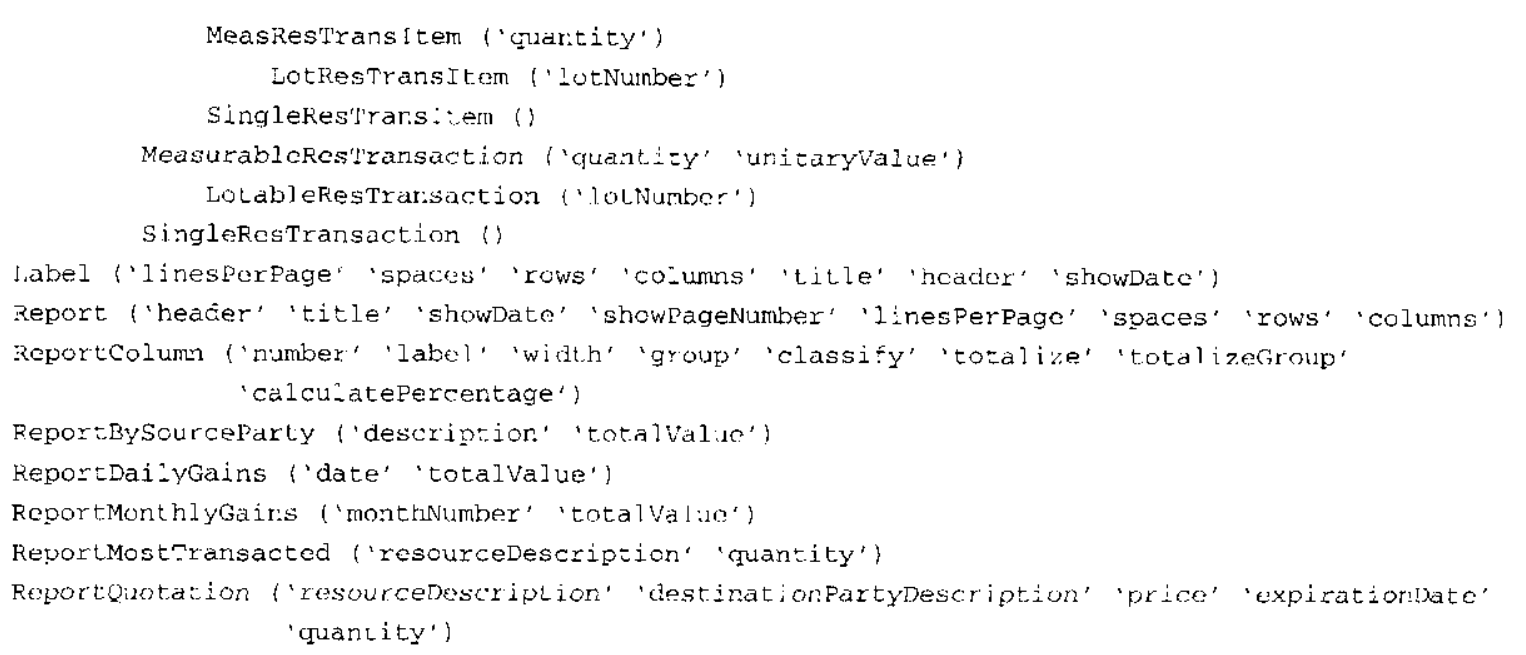

\section{Camada de Interface com o Usuário}

object ()

Model ("dependents') ApplicationModel ('builder' 'uisession')

BdsicBusinessTrarsactionform ('number' 'aTransaction' 'date' 'observation' 'status' 'totalprice' 'totaldiscounl' 'adestinationparty' 'allDestinationParties' 'asourcepar'ty' 'al Sourcopartics' 'aExccutor' 'ailexecutors' 'editing 'inserting' 'fina'Tctal' 'basicBtnsCanvas' 'totalscanvas' 'tot.a'scanvasspec')

MultiResourceTransactionForm ('itcmsSubtorm' 'itemsSpec')

Muili ResourceRentalForn ('finishingDate' 'returnDate' 'reservat onNumber'

'returning' 'finevaiue'

Mult iResourceNegoliationform ('Iroight' 'taxes', MultiResourceDel ivery Form ('LradeNumber') MultiResourceTradeForm ('quotationNumber')

Mu] tiResourceReservationform ('beginDate' 'enavate')

OncResourcetransactionform ('akesource' 'ailkesources' 'instancecode' 'quantity' 'unitaryvalue' 'lotNunber.'

OneResourcekeservationForn ('beginDate' 'endDate'? InstantiableResReservalionform (1)

OneResourceMaintenanceForm ('fau'tspresented' 'exitDate' 'closing') Onleresour ceMa int.NPNTForm ('lasks' 'part.s') OneResourceMaintwFWTForm ('tasks' 'parts')

OnekesourceMaintQuntForm ('fuul isfresented' 'expirationDate' 'effected') OneResourceMaintQuotalior.NPNTForm ('tasks' 'parts') OneResourceMainlQuctalioniwitForm ('lasks' 'parts')

OreResourcekentäForm ('finishingDate' 'returnDate' 'reservationNurber' 'zeiurrirg' 'firevalue')

InstantiableResourceRentalform (1 MeasurableResurcekental Form ()

OneResouxcelegotiationForn ('Lreight' 'Laxes') OneResourcedel i verytorm ('tradeNumber'

OnekesourceTradeform (1)

Inst:antiablokesourcel'raderorm

MeasurabiekesourceTrudoForn (1)

BasicQuotationform ''number' 'al' rar:saction' 'date' 'observation' 'status 'choscnDestination'artiestist' 'chosenResurcestisit

'allDestinazionzarties' 'aResource' 'allizesources'

'aso:rrce"arty' 'al'Sourcceparties' 'aExecutor' 'allexecutors' 'editing' 'inserting' 'basicbtnsCanvas'

ExactivulerCalculatortorm ('afirckute' 'porcentagekate' 'number', 
InterestRateForm (1)

GRFNApplicationMainform ()

GRFNApplicationModel ('parentApplication')

BasicButtonsForm ()

Bas: icReturnButtonsForm ()

BasicNvgButtonsForm ()

BasicTutalsForm ('totaiPrice' 'totaldiscoun', 'firaltotal')

BasicMaintenanceTotalsForm ('totalpars' 'totalTask')

BasicRertal'Totalsform ('rineValue' 'salevalue')

BasicTradeTotalsform ('freight' 'taxes')

CreateI, istForm('rlamcList' 'vaiueslist' 'ischanged')

Discretel.:stForm()

Tab] eI: $\operatorname{st} \operatorname{Form}()$

MaintenancePartForm ('partDescription' 'qtty' 'cost' 'total' 'subcotal

'gartsusedList' 'eciting' 'inserting' 'apartused'

'allparts' "ischanged')

Mainterance'Taskform ('laborDescription' 'hoursSpent' 'problemToSolve' 'Lotal'

'cost' 'taskstist' 'editing. 'inserting' 'aTask' 'aExccutor'

'ailexecutors' 'ischanged')

NToNRelationshipForm ('selectedtist' 'completedist' 'ischanged')

paymentForm ' 'apayment' 'allinstal ments' 'issaved' 'dueDate' 'paymentDate'

'Erstallmcitnamber' 'tocaivalue' 'status' 'interest' 'fine'

'tolal Installmencs' 'suppliedvalue' 'changeva-ue' 'cardNumber'

'type' 'bānk' 'accountNumber' 'checkNumber' 'invoicenumber'

'expirationDate' 'paymentDay' 'paymentForm')

Qualificationformo ()

Quaificalionform1 ('resourcerype1' 'ailResourceTypes1'

Qualificationi'orm2 ('resource'rype2' 'aliResourcerypes2') Qualificationform3 ('resourcel'ype3' 'allzesource'"ypes3.' Qualizicaticr.forma ('rosourceTYpe4' 'allResourceTypes4'

rransactionttemspatasetForm ('resource' 'avalue' 'quantity' 'instancecode' 'LotNumber' 'rowsList' 'itemsList' 'selectedttem')

NumberRangeCaicuiatorForm ('azineRate' 'allFineRates' 'percentageRate' 'lowerNumber 'upperNumber')

FineRaveForm

Stat:cobjectForm ('astaticobject' 'alıstaticobjects' 'w_idcode' 'w_description' 'navigationbtrs' 'basicBtnscanvas')

Destinationpartyrorm (1)

LocationzoneForm ('storageCondilions' 'capacity' 'storageLccationDescr'

$$
\text { 'warehouschescr' 'allstorageConditions') }
$$

MeasureUnityForm (1)

QualifiableobjectForm 'typescanvas's' 'typescanvasspec'

ResourceForm (1)

InstantiableResourceForm ('instancesi,ist' 'selectedInstarce' 'se-ectcdRow')

MeasurableResuurccForn ('Guantityinstock' 'resupplyżeve' 'measureUnity' 'a12Measureunitics'

Sirgieresourcelorm ('status')

Warehouserorm ('storageLocations')

Sourcepartytiorm ()

Storagecondit ionerorm ()

Storage'ocationform ('locationzones' 'warehouseDescr')

'TransactionExecutorform ('speciaizy' 'percentage' 'minimumvalue' 'salary'

Simplebialog 1...

DatePer:ocform ('aDatePericd' 'initialDate' 'firishingDate'

LanguageMoci i ficationform ('Zanguage')

Quotationitenform ('quantily' 'expirationDate' 'price' 'quotationform' 'aQuocationItem' 'dest.PartList' 'resourcelist'

ResourceInstanceForm ('akesource Instance' 'code' 'allocation' 'status')

storageform ('aResource' 'ZocatlonzoneDescr' 'storageConditions' 
'allLocationzones' 'allstorageConditions')
TransactionltemForm ('anIten' 'transacticnNumber' 'resourcedescription' 'avalue'
'resourcestist' 'quantity' 'instanceCode' 'lotNumber' 'editing') RentalitemForm ()

\section{Camada do Subsistema de Segurança}

$\mathrm{Na}$ hierarquia de classes apresentada a seguit, as classes em itálico pertencem à linguagem Smalltalk, as classes em itálico e precedidas de um sinal de asterisco $\left(^{*}\right)$ já faziam parte da hierarquia de classes do GREN e são citadas para indicar de quais classes do GREN as classes do Subsistemas de Segurança foram especializadas. A Classe AsAspect pertence ao pacote de classes AspectS, a partir do qual as classes aspecto do SS foram especializadas.

Object ()

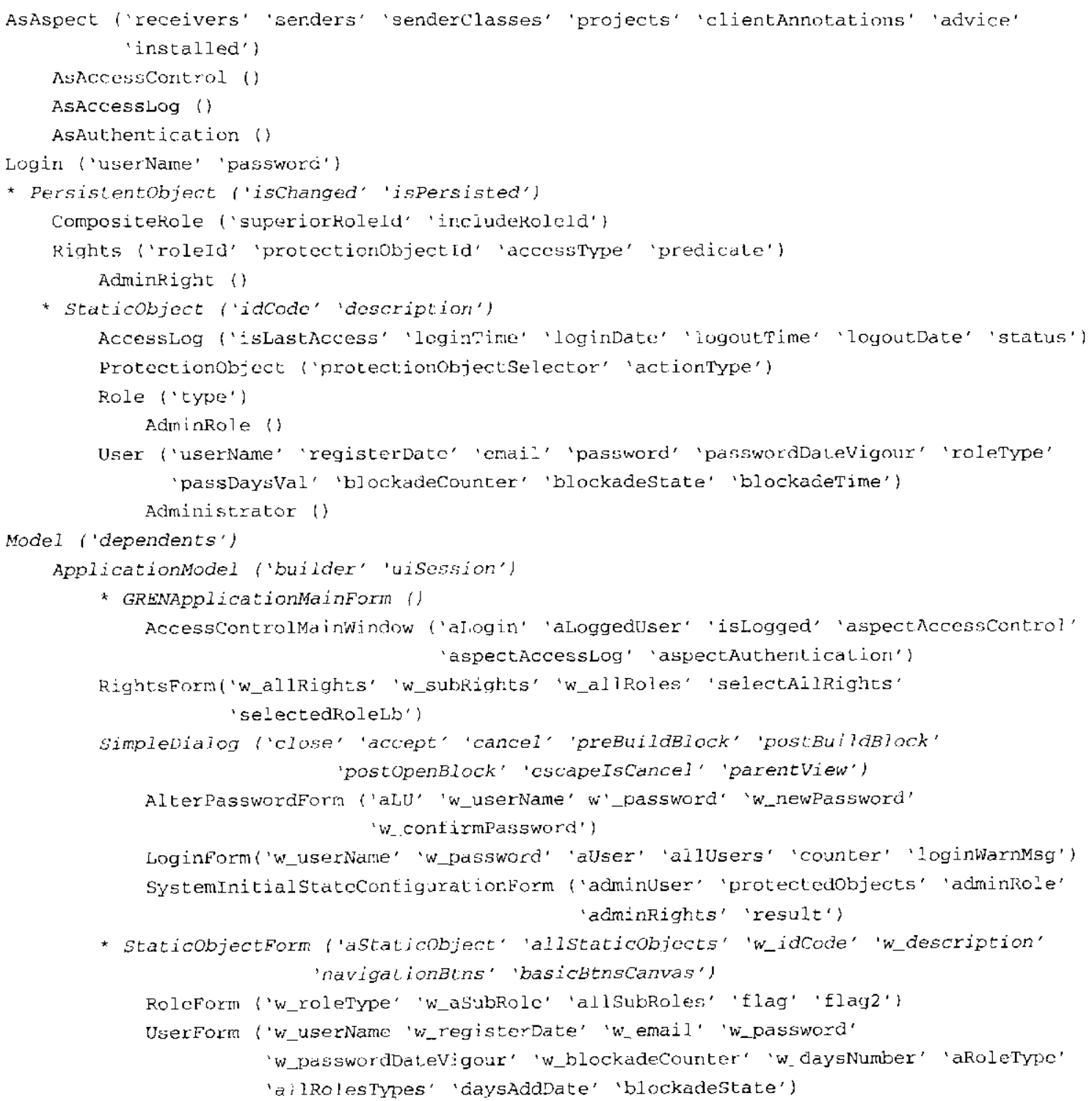




\section{F.2 Hierarquia de Classes da Ferramenta GREN-Wizard}

Como pode ser observado na hierarquia de classes apresentada nesta seção, a evolução da ferramenta GREN-Wizard não implicou na criação de novas classes. As modificações foram as seguintes: inserção de um novo atributo (useAccessControl) nas classes GRENApplication e GRENAppl icationf'orm, precedidas por dois sinais de asterisco (**), e criação e modificação de alguns métodos que podem ser visualizado no Apêndice D.

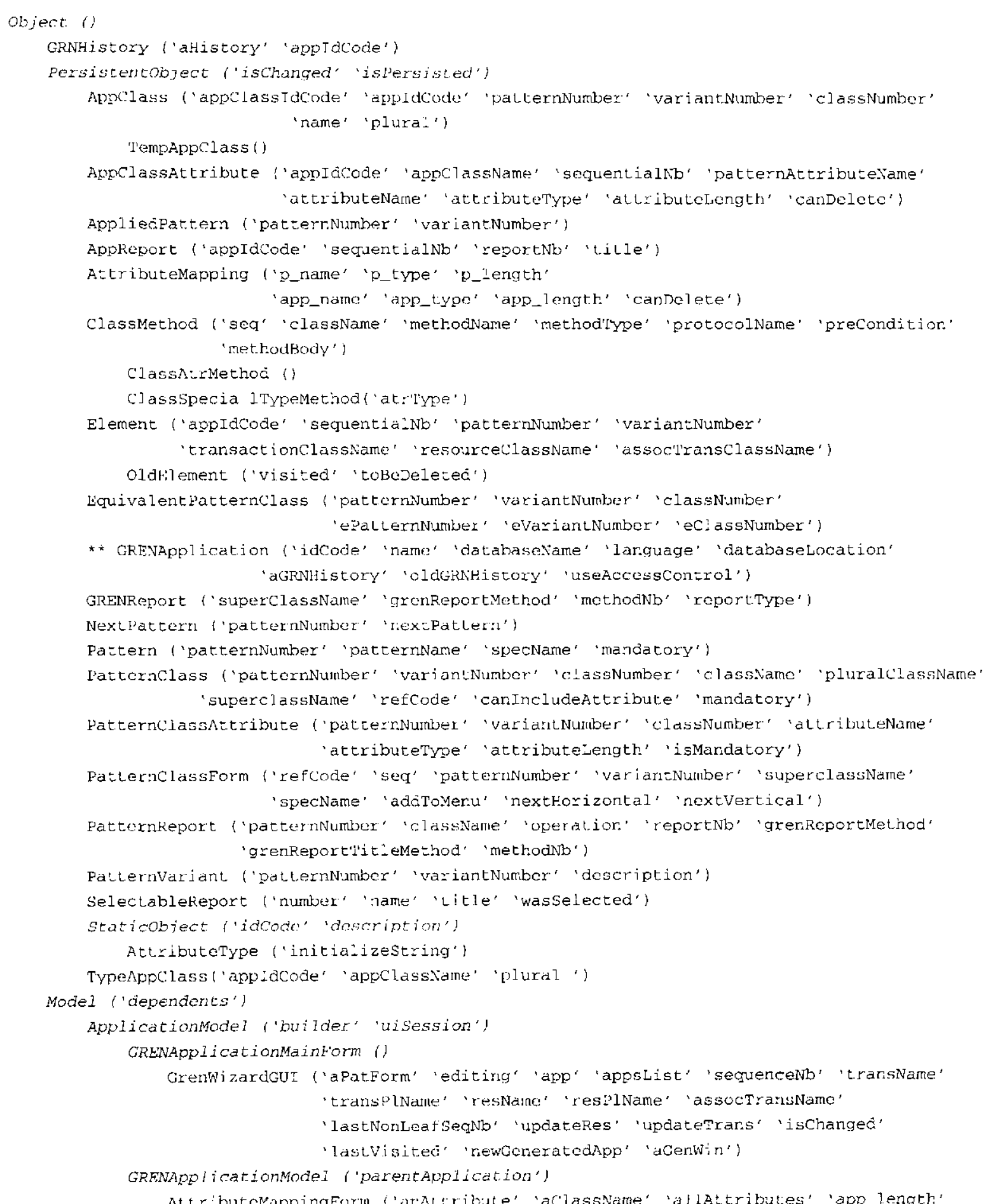


'p_type' 'app_type' 'app_name' 'p_name' 'sequentialmb'

'p lengtin' 'ischanged' 'rolcplayed'

Attributes Importation ('classessplayingRo'e' 'listofaddedAttributes'

'asuperciassName')

Generacionwindow ('consistency' 'application' 'attributes' 'interface' 'mer:as' 'methods's

GrenwizardCodeGenerator ('app' 'appNamespace' 'meruclass' 'aconcreteciassName' 'ariacidedat tribule' 'aClassmethod'

PatternForm ('wasAppliea' 'wasskipped' 'patternNumber' 'varjantApplied'

'allvariants' 'variartChosen' 'rextPattern' 'nextPatternchosen'

'allXextpatcorns' 'Currentelement' 'adding' 'unlyRevisiting'

'class1Name' 'class2Name' 'class3Name' 'class4Name' 'classiname'

'classoname' 'class7Name' 'class8Name' 'class9Name' 'Classioname'

'ciass11Name' 'class12Name' 'plclassinarne' 'plclass2name'

'pJ.class3natre. 'plC-isss4name' 'plclassbName' 'plclass6name'

'plCass7Name' 'p]Class8Nane' 'plClass9Name' 'plClass:OName'

'plCIass: 1Natue' 'plClass12Natie'l

ReportsSejection ('atitle' 'history' 'appliedpatterns' 'selectedReports'

'listofkepozts' 'IistoEclasses' 'ischanged')

Htm? Forms ('introduction'text")

AttributeListForm ('IistApp cype' 'list_tables' 'list_attributes' 'ischarged'\}

AttributeDiscretel,istyorm(

AttributeTable:istForm!)

CreateListForm('nameList' 'valuesList' 'ischanged')

Discretelistrorm( )

(TablelistForm!)

PatternLanguageDatabase (1)

Simpledialog ('close' 'accepl' 'Cancel' 'prebuildBlock' 'postbuildBlock' 'postopenBIock' 'escapelscancel' 'parentView')

** GRENApplicationForm ('anApplication' 'IdCode' 'name' 'databaseName' 'language' 'databaselocation' 'useAccesscontrol'? 